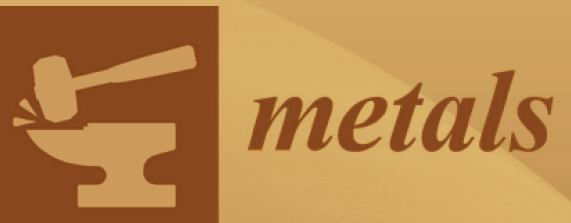

Advances in

Selective Flotation

and Leaching

Process in

Metallurgy

Ilhwan Park

Printed Edition of the Special Issue Published in Metals 


\section{Advances in Selective Flotation and Leaching Process in Metallurgy}





\section{Advances in Selective Flotation and Leaching Process in Metallurgy}

Editor

Ilhwan Park 
Editor

Ilhwan Park

Hokkaido University

Japan

\section{Editorial Office}

MDPI

St. Alban-Anlage 66

4052 Basel, Switzerland

This is a reprint of articles from the Special Issue published online in the open access journal Metals (ISSN 2075-4701) (available at: https://www.mdpi.com/journal/metals/special_issues/flotation_ leaching_metallurgy).

For citation purposes, cite each article independently as indicated on the article page online and as indicated below:

LastName, A.A.; LastName, B.B.; LastName, C.C. Article Title. Journal Name Year, Volume Number, Page Range.

ISBN 978-3-0365-2980-6 (Hbk)

ISBN 978-3-0365-2981-3 (PDF)

(C) 2022 by the authors. Articles in this book are Open Access and distributed under the Creative Commons Attribution (CC BY) license, which allows users to download, copy and build upon published articles, as long as the author and publisher are properly credited, which ensures maximum dissemination and a wider impact of our publications.

The book as a whole is distributed by MDPI under the terms and conditions of the Creative Commons license CC BY-NC-ND. 


\section{Contents}

About the Editor $\ldots \ldots \ldots \ldots \ldots \ldots \ldots \ldots \ldots \ldots \ldots \ldots \ldots$

Ilhwan Park

Advances in Selective Flotation and Leaching Process in Metallurgy

Reprinted from: Metals 2022, 12, 144, doi:10.3390/met12010144 _ . . . . . . . . . . 1

Ilhwan Park, Seunggwan Hong, Sanghee Jeon, Mayumi Ito and Naoki Hiroyoshi

A Review of Recent Advances in Depression Techniques for Flotation Separation of $\mathrm{Cu}-\mathrm{Mo}$

Sulfides in Porphyry Copper Deposits

Reprinted from: Metals 2020, 10, 1269, doi:10.3390/met10091269 _ . . . . . . . . . . . 5

Ilhwan Park, Seunggwan Hong, Sanghee Jeon, Mayumi Ito and Naoki Hiroyoshi

Flotation Separation of Chalcopyrite and Molybdenite Assisted by Microencapsulation Using Ferrous and Phosphate Ions: Part I. Selective Coating Formation

Reprinted from: Metals 2020, 10, 1667, doi:10.3390/met10121667 . . . . . . . . . . . . . . 31

Ilhwan Park, Seunggwan Hong, Sanghee Jeon, Mayumi Ito and Naoki Hiroyoshi

Flotation Separation of Chalcopyrite and Molybdenite Assisted by Microencapsulation Using Ferrous and Phosphate Ions: Part II. Flotation

Reprinted from: Metals 2021, 11, 439, doi:10.3390/met11030439 _ . . . . . . . . . . 4

Vothy Hornn, Mayumi Ito, Hiromasa Shimada, Carlito Baltazar Tabelin, Sanghee Jeon, Ilhwan Park and Naoki Hiroyoshi

Agglomeration-Flotation of Finely Ground Chalcopyrite Using Emulsified Oil Stabilized by Emulsifiers: Implications for Porphyry Copper Ore Flotation

Reprinted from: Metals 2020, 10, 912, doi:10.3390/met10070912

Kosei Aikawa, Mayumi Ito, Atsuhiro Kusano, Ilhwan Park, Tatsuya Oki, Tatsuru Takahashi, Hisatoshi Furuya and Naoki Hiroyoshi

Flotation of Seafloor Massive Sulfide Ores: Combination of Surface Cleaning and Deactivation of Lead-Activated Sphalerite to Improve the Separation Efficiency of Chalcopyrite and Sphalerite

Reprinted from: Metals 2021, 11, 253, doi:10.3390/met11020253

Pengyu Zhang, Saizhen Jin, Leming Ou, Wencai Zhang and Yuteng Zhu

Fine Bauxite Recovery Using a Plate-Packed Flotation Column

Reprinted from: Metals 2020, 10, 1184, doi:10.3390/met10091184

Guiqing Liu, Bangsheng Zhang, Zhonglin Dong, Fan Zhang, Fang Wang, Tao Jiang and Bin Xu

Flotation Performance, Structure-Activity Relationship and Adsorption Mechanism of O-Isopropyl-N-Ethyl Thionocarbamate Collector for Elemental Sulfur in a High-Sulfur Residue Reprinted from: Metals 2021, 11, 727, doi:10.3390/met11050727 . . . . . . . . . . . . 91

Sujin Chae, Kyoungkeun Yoo, Carlito Baltazar Tabelin and Richard Diaz Alorro

Hydrochloric Acid Leaching Behaviors of Copper and Antimony in Speiss Obtained from Top Submerged Lance Furnace

Reprinted from: Metals 2020, 10, 1393, doi:10.3390/met10101393 . . . . . . . . . . . . . . 111 
Labone L. Godirilwe, Kazutoshi Haga, Batnasan Altansukh, Yasushi Takasaki, Daizo Ishiyama, Vanja Trifunovic, Ljiljana Avramovic, Radojka Jonovic,

Zoran Stevanovic and Atsushi Shibayama

Copper Recovery and Reduction of Environmental Loading from Mine Tailings by High-Pressure Leaching and SX-EW Process

Reprinted from: Metals 2021, 11, 1335, doi:10.3390/met11091335 . . . . . . . . . . . . . . . . 119

Sanghee Jeon, Sharrydon Bright, Ilhwan Park, Carlito Baltazar Tabelin, Mayumi Ito and Naoki Hiroyoshi

The Effects of Coexisting Copper, Iron, Cobalt, Nickel, and Zinc Ions on Gold Recovery by Enhanced Cementation via Galvanic Interactions between Zero-Valent Aluminum and Activated Carbon in Ammonium Thiosulfate Systems

Reprinted from: Metals 2021, 11, 1352, doi:10.3390/met11091352 . . . . . . . . . . . . . 133

Pankaj Kumar Choubey, Nityanand Singh, Rekha Panda, Rajesh Kumar Jyothi,

Kyoungkeun Yoo, Ilhwan Park and Manis Kumar Jha

Development of Hydrometallurgical Process for Recovery of Rare Earth Metals (Nd, Pr, and

Dy) from Nd-Fe-B Magnets

Reprinted from: Metals 2021, 11, 1987, doi:10.3390/met11121987 . . . . . . . . . . . . . . . 147 


\begin{abstract}
About the Editor
Ilhwan Park received his Ph.D. from Hokkaido University in 2019, and afterward, he was appointed assistant professor at the Division of Sustainable Resources Engineering, Faculty of Engineering, Hokkaido University, Japan. The subjects of his research are the recovery of critical metals/minerals from primary and secondary resources by mineral processing (e.g., flotation, magnetic separation, gravity separation, etc.) and hydrometallurgy (e.g., leaching, solvent extraction, cementation, etc.). In addition, Dr. Park has been engaged in the development of sustainable techniques for the prevention/control of acid mine/rock drainage (AMD/ARD) and the remediation of contaminated soils and water. From his work, he has published papers in leading international journals in the fields of mineral processing, extractive metallurgy, and environmental science.
\end{abstract}





\title{
Editorial \\ Advances in Selective Flotation and Leaching Process in Metallurgy
}

\author{
Ilhwan Park
}

Citation: Park, I. Advances in Selective Flotation and Leaching Process in Metallurgy. Metals 2022, 12, 144. https://doi.org/10.3390/ met12010144

Received: 11 January 2022

Accepted: 11 January 2022

Published: 12 January 2022

Publisher's Note: MDPI stays neutral with regard to jurisdictional claims in published maps and institutional affiliations.

Copyright: (C) 2022 by the author Licensee MDPI, Basel, Switzerland. This article is an open access article distributed under the terms and conditions of the Creative Commons Attribution (CC BY) license (https:// creativecommons.org/licenses/by/ $4.0 /)$.
Division of Sustainable Resources Engineering, Faculty of Engineering, Hokkaido University, Sapporo 060-8628, Japan; i-park@eng.hokudai.ac.jp; Tel.: +81-11-706-6315

\section{Introduction and Scope}

Metals are a finite resource that are necessary to maintain living standards in modern society, due to their countless applications, such as transportation vehicles, building and construction, household appliances, electronic devices, etc. In addition, the world is rapidly transitioning to "low-carbon technologies" using renewable energy sources (e.g., solar, wind, etc.) to combat climate change, and these technologies require vast amounts of metals per unit generation compared to that of conventional fossil generation; for example, 11-40 times more copper $(\mathrm{Cu})$ for solar photovoltaic $(\mathrm{PV})$ systems and 6-14 times more iron (Fe) for wind power stations [1].

Unfortunately, easily exploitable ore deposits are hard to find, which makes it unavoidable that mining industries must develop complicated ore deposits with low-grade and fine grain-size. The complexity of these ore bodies requires fine grinding to achieve the appropriate liberation of valuable minerals. Typically, there are two scenarios to extract metals from finely-ground ores; that is, (1) concentration of valuable minerals via "flotation" followed by smelting process and (2) direct extraction of metals from finely-ground ores by "leaching" followed by purification and recovery processes (e.g., solvent extraction and electrowinning (SX-EW)). Therefore, flotation and leaching, both of which are the first stage of each scenario, of finely-ground ores are of crucial importance to assure the continued supply of metals. Thus, this Special Issue introduces the latest scientific advances in selective flotation and leaching processes essential for the production of metals in a sustainable manner.

\section{Contributions}

Eleven articles have been published in the present Special Issue of Metals, encompassing the fields of flotation and hydrometallurgy. The papers are all of highly scientific value and will be of great interest to readers of Metals. The contents of the published papers will be briefly summarized as follows.

\subsection{Flotation}

Copper has been widely used in various applications, due to its excellent electri$\mathrm{cal} /$ thermal conductivity, high corrosion resistance, etc. [2], approximately $60 \%$ of which is produced from porphyry copper deposits (PCDs) [3]. The beneficiation of porphyry copper ores is mostly achieved by a two-step flotation process; that is, (i) bulk flotation to recover $\mathrm{Cu}$ and molybdenum (Mo) minerals from gangue minerals and (ii) selective flotation of Mo minerals from $\mathrm{Cu}-\mathrm{Mo}$ bulk concentrates using sodium hydrosulfide (NaHS) as a $\mathrm{Cu}$ depressant. Although this process is efficient and well established, the use of NaHS for $\mathrm{Cu} /$ Mo separation has several drawbacks. A review paper by Park et al. [3] introduced recent depression techniques, including alternative inorganic/organic depressants as well as oxidation treatments involving the use of ozone $\left(\mathrm{O}_{3}\right)$, plasma, hydrogen peroxide $\left(\mathrm{H}_{2} \mathrm{O}_{2}\right)$, and electrolysis. Moreover, Park et al. [4,5] developed a new depression technique (i.e., 
microencapsulation using ferrous and phosphate ions), which preferentially coated chalcopyrite $\left(\mathrm{CuFeS}_{2}\right)$ with ferric phosphate $\left(\mathrm{FePO}_{4}\right)$ layers rather than molybdenite $\left(\mathrm{MoS}_{2}\right)$. As a result, the floatability of chalcopyrite was selectively reduced, while molybdenite floated well by the addition of kerosene (Mo collector).

As high-grade and easily exploitable copper ores have been getting depleted, the development of flotation techniques for copper ores with low-grade and small grain size, as well as unconventional resources such as seafloor massive sulfide (SMS) ores, is becoming an important issue [6-8]. Hornn et al. [7] investigated the application of agglomeration using surfactant-stabilized oil emulsion to improve flotation recovery of finely-ground chalcopyrite. The recovery of fine particles $\left(D_{50}<5 \mu \mathrm{m}\right)$ by flotation is well known to be difficult due to the low collision probability between air bubbles and mineral particles [9-12]. A study by Hornn et al. [7] revealed that agglomeration using surfactant-stabilized oil emulsion was effective in increasing the apparent particle size of fine chalcopyrite particles from $3.5 \mu \mathrm{m}$ to $\sim 10 \mu \mathrm{m}$, thereby improving $\mathrm{Cu}$ recovery from $68 \%$ to $>97 \%$. Meanwhile, Aikawa et al. [8] proposed a novel flotation procedure to recover chalcopyrite selectively from SMS ores. The major target minerals of SMS ores are chalcopyrite and sphalerite $(\mathrm{ZnS})$, so they should be recovered sequentially via a two-step flotation process whereby chalcopyrite is first recovered, followed by floating sphalerite. In the first stage of flotation, however, both chalcopyrite and sphalerite were recovered together even with zinc sulfate $\left(\mathrm{ZnSO}_{4}\right.$; sphalerite depressant) because of the presence of anglesite $\left(\mathrm{PbSO}_{4}\right)$ that releases $\mathrm{Pb}^{2+}$ and activates sphalerite. To address this problem, Aikawa et al. [8] employed EDTA washing before flotation, which was effective in removing anglesite, and thus chalcopyrite could be recovered selectively by flotation with $\mathrm{ZnSO}_{4}$.

Apart from studies on the flotation of copper minerals, in this Special Issue, there are two papers on the recovery of fine bauxite [13] and elemental sulfur [14] by flotation. Zhang et al. [13] utilized a plate-packed flotation column (PFC) for fine bauxite, and the $\mathrm{Al}_{2} \mathrm{O}_{3}$ recovery and grade increased by $2.11 \%$ and $1.85 \%$, respectively, compared to the result obtained with unpacked flotation column (UFC). Additionally, they clarified the mechanism of how fine bauxite recovery was improved in a PFC by population balance model (PBM) incorporated with computational fluid dynamics (CFD) techniques; that is, installing the packing-plates significantly reduces the turbulent kinetic energy, which contributed to the formation of small-sized bubbles in the flotation column. A study by Liu et al. [14] demonstrated the recovery of elemental sulfur from the pressure acid leaching residue of ZnS concentrate. The recovery of elemental sulfur from high-sulfur residue can not only add economic value, as it is an important chemical material used for many applications, but also protect the environment. They compared three collectors (e.g., O-Isopropyl-N-Ethyl thionocarbamate (IPETC), ammonium dibutyl dithiophosphate (ADDTP), and sodium ethyl xanthate (SEX)), and among them, IPETC exhibited a superior collecting ability and selectivity to the elemental sulfur, which was further proved by density functional theory (DFT) calculation [14].

\subsection{Hydrometallurgy}

In this Special Issue, four articles deal with hydrometallurgical processing for $\mathrm{Cu}$, gold (Au), and rare earth metals (REMs) [15-18]. Chae et al. [15] studied hydrochloric acid ( $\mathrm{HCl})$ leaching behaviors of $\mathrm{Cu}$ and antimony $(\mathrm{Sb})$ in speiss obtained from top submerged lance (TSL) furnace. In general, the speiss containing $\mathrm{Cu}, \mathrm{Sb}$, and precious metals (e.g., Au, silver $(\mathrm{Ag})$, etc.) is first processed by sulfuric acid $\left(\mathrm{H}_{2} \mathrm{SO}_{4}\right)$ leaching to extract $\mathrm{Cu}$. However, it is reported that the leaching efficiency of $\mathrm{Cu}$ from the speiss in $\mathrm{H}_{2} \mathrm{SO}_{4}$ media is decreased due to the increased amount of $\mathrm{Sb}$ in the speiss caused by the co-treatment of various secondary resources during the TSL process. The solubility of $\mathrm{Sb}$ in $\mathrm{H}_{2} \mathrm{SO}_{4}$ is low, which hinders the leaching of $\mathrm{Cu}$. In other words, $\mathrm{Sb}$ should be dissolved to improve the leaching efficiency of $\mathrm{Cu}$, so $\mathrm{HCl}$ leaching experiments under various conditions were conducted by Chae et al. [15]. As a result, they found the optimum condition of $\mathrm{HCl}$ leaching where more than $99 \%$ of $\mathrm{Cu}$ could be dissolved. 
As high-grade ores are depleted, the reprocessing of mine tailings to extract residual valuable metals/minerals is now getting increased attention. Godirilwe et al. [16] studied $\mathrm{Cu}$ recovery from mine tailings via flotation, high pressure oxidation leaching (HPOL), and SX-EW process. After flotation of mine tailings, the grade of $\mathrm{Cu}$ was upgraded from $0.24 \%$ to $0.65 \%$, and the HPOL process of the concentrate yielded a high $\mathrm{Cu}$ leaching rate of 94.4\%. Afterward, the pregnant leach solution (PLS) containing $2.9 \mathrm{~g} / \mathrm{L} \mathrm{Cu}$ and $102.9 \mathrm{~g} / \mathrm{L}$ Fe was purified by solvent extraction using LIX-84I, which produced the stripped solution comprising of $44.8 \mathrm{~g} / \mathrm{L} \mathrm{Cu}$ and $1.4 \mathrm{~g} / \mathrm{L}$ Fe where $\mathrm{Cu}$ could be electrowon with a current efficiency of about $95 \%$.

The Cu-catalyzed ammonium thiosulfate leaching is one of the most promising alternatives to cyanidation for extracting gold from ores [17]. A major problem of thiosulfate leaching is its difficulty in recovering gold from the PLS; that is, the conventional Au recovery techniques (e.g., activated carbon (AC) adsorption and cementation using base metals) are inefficient. To address this problem, Jeon et al. [19,20] developed a novel recovery technique called enhanced cementation using AC and zero-valent aluminum (ZVAl), which yielded Au recovery of $>99 \%$. However, the previous studies on enhanced cementation using AC and ZVAl were conducted with relatively pure gold thiosulfate solutions [19,20], which significantly differs from the actual PLS where a variety of metal ions coexist. Thus, Jeon et al. [17] investigated the effects of coexisting metal ions (e.g., cobalt (Co), $\mathrm{Cu}, \mathrm{Fe}$, nickel (Ni), and zinc $(\mathrm{Zn})$ ) on Au recovery via enhanced cementation, and they found that the presence of $\mathrm{Fe}^{2+}, \mathrm{Co}^{2+}, \mathrm{Ni}^{2+}$, and $\mathrm{Zn}^{2+}$ showed the detrimental effects on Au recovery. However, $\mathrm{Cu}^{2+}$ acted as a catalyst that minimized the negative effects of these metal ions on Au cementation, yielding $85-90 \%$ of Au recovery.

Rare earth metals are essential to achieve a carbon-neutral society because significant quantities of REMs are utilized for manufacturing strong permanent magnets, a critical component used in generators for wind turbines and traction motors for electric vehicles (EVs) [21,22]. There are, however, only a few countries with exploitable rare earth deposits, so the production of REMs through the recycling of wastes is of topical importance. Choubey et al. [18] developed the hydrometallurgical process to extract REMs from NdFeB permanent magnets of waste hard disks. The demagnetized magnet was completely dissolved in $2 \mathrm{M} \mathrm{H}_{2} \mathrm{SO}_{4}$ at $75^{\circ} \mathrm{C}$ in $60 \mathrm{~min}$, and then dissolved REMs and Fe were selectively precipitated from the leach liquor at pH 1.75 and 3.5-4.0, respectively. Finally, the precipitated REM hydroxides were converted to their oxides by heating at $120{ }^{\circ} \mathrm{C}$ for $2 \mathrm{~h}$.

\section{Conclusions and Outlook}

A variety of topics have been covered in this Special Issue, presenting recent developments of flotation and leaching. Furthermore, the published articles effectively demonstrate the diversity of the recent research and development in the field. Nevertheless, there are still many challenges to overcome in this research field, so we hope that this Special Issue will serve as a springboard for future discussions and scientific debates on challenging topics related to flotation and leaching.

Having served as a Guest Editor, I am delighted by how well the contributions met the high standards of quality and originality that contributed to the success of this Special Issue. I would like to warmly thank all the authors for their contributions as well as the reviewers for their efforts to ensure a high-quality publication. In addition, I wish to extend my gratitude to the Editors of Metals for their continuous support and the Metals Editorial Assistants for their valuable and inexhaustible engagement and support during the preparation of this volume. My special thanks go to Mr. Toliver Guo for his support and assistance.

Funding: This research received no external funding.

Conflicts of Interest: The author declares no conflict of interest. 


\section{References}

1. Hertwich, E.G.; Gibon, T.; Bouman, E.A.; Arvesen, A.; Suh, S.; Heath, G.A.; Bergesen, J.D.; Ramirez, A.; Vega, M.I.; Shi, L. Integrated Life-Cycle Assessment of Electricity-Supply Scenarios Confirms Global Environmental Benefit of Low-Carbon Technologies. Proc. Natl. Acad. Sci. USA 2015, 112, 6277-6282. [CrossRef]

2. Schlesinger, M.E.; King, M.J.; Sole, K.C.; Davenport, W.G. Extractive Metallurgy of Copper, 5th ed.; Elsevier: London, UK, 2011.

3. Park, I.; Hong, S.; Jeon, S.; Ito, M.; Hiroyoshi, N. A Review of Recent Advances in Depression Techniques for Flotation Separation of Cu-Mo Sulfides in Porphyry Copper Deposits. Metals 2020, 10, 1269. [CrossRef]

4. Park, I.; Hong, S.; Jeon, S.; Ito, M.; Hiroyoshi, N. Flotation Separation of Chalcopyrite and Molybdenite Assisted by Microencapsulation Using Ferrous and Phosphate Ions: Part I. Selective Coating Formation. Metals 2020, 10, 1667. [CrossRef]

5. Park, I.; Hong, S.; Jeon, S.; Ito, M.; Hiroyoshi, N. Flotation Separation of Chalcopyrite and Molybdenite Assisted by Microencapsulation Using Ferrous and Phosphate Ions: Part II. Flotation. Metals 2021, 11, 439. [CrossRef]

6. Hornn, V.; Park, I.; Ito, M.; Shimada, H.; Suto, T.; Tabelin, C.B.; Jeon, S.; Hiroyoshi, N. Agglomeration-Flotation of Finely Ground Chalcopyrite Using Surfactant-Stabilized Oil Emulsions: Effects of Co-Existing Minerals and Ions. Miner. Eng. 2021, $171,107076$. [CrossRef]

7. Hornn, V.; Ito, M.; Shimada, H.; Tabelin, C.B.; Jeon, S.; Park, I.; Hiroyoshi, N. Agglomeration-Flotation of Finely Ground Chalcopyrite Using Emulsified Oil Stabilized by Emulsifiers: Implications for Porphyry Copper Ore Flotation. Metals 2020, 10, 912. [CrossRef]

8. Aikawa, K.; Ito, M.; Kusano, A.; Park, I.; Oki, T.; Takahashi, T.; Furuya, H.; Hiroyoshi, N. Flotation of Seafloor Massive Sulfide Ores: Combination of Surface Cleaning and Deactivation of Lead-Activated Sphalerite to Improve the Separation Efficiency of Chalcopyrite and Sphalerite. Metals 2021, 11, 253. [CrossRef]

9. Trahar, W.J. A Rational Interpretation of the Role of Particle Size in Flotation. Int. J. Miner. Process. 1981, 8, 289-327. [CrossRef]

10. Hornn, V.; Ito, M.; Shimada, H.; Tabelin, C.B.; Jeon, S.; Park, I.; Hiroyoshi, N. Agglomeration-Flotation of Finely Ground Chalcopyrite and Quartz: Effects of Agitation Strength during Agglomeration Using Emulsified Oil on Chalcopyrite. Minerals 2020, 10, 380. [CrossRef]

11. Hornn, V.; Ito, M.; Yamazawa, R.; Shimada, H.; Tabelin, C.B.; Jeon, S.; Park, I.; Hiroyoshi, N. Kinetic Analysis for AgglomerationFlotation of Finely Ground Chalcopyrite: Comparison of First Order Kinetic Model and Experimental Results. Mater. Trans. 2020, 61, 1940-1948. [CrossRef]

12. Bilal, M.; Ito, M.; Koike, K.; Hornn, V.; Ul Hassan, F.; Jeon, S.; Park, I.; Hiroyoshi, N. Effects of Coarse Chalcopyrite on Flotation Behavior of Fine Chalcopyrite. Miner. Eng. 2021, 163, 106776. [CrossRef]

13. Zhang, P.; Jin, S.; Ou, L.; Zhang, W.; Zhu, Y. Fine Bauxite Recovery Using a Plate-Packed Flotation Column. Metals 2020, 10, 1184. [CrossRef]

14. Liu, G.; Zhang, B.; Dong, Z.; Zhang, F.; Wang, F.; Jiang, T.; Xu, B. Flotation Performance, Structure-Activity Relationship and Adsorption Mechanism of O-Isopropyl-N-Ethyl Thionocarbamate Collector for Elemental Sulfur in a High-Sulfur Residue. Metals 2021, 11, 727. [CrossRef]

15. Chae, S.; Yoo, K.; Tabelin, C.B.; Alorro, R.D. Hydrochloric Acid Leaching Behaviors of Copper and Antimony in Speiss Obtained from Top Submerged Lance Furnace. Metals 2020, 10, 1393. [CrossRef]

16. Godirilwe, L.L.; Haga, K.; Altansukh, B.; Takasaki, Y.; Ishiyama, D.; Trifunovic, V.; Avramovic, L.; Jonovic, R.; Stevanovic, Z.; Shibayama, A. Copper Recovery and Reduction of Environmental Loading from Mine Tailings by High-Pressure Leaching and SX-EW Process. Metals 2021, 11, 1335. [CrossRef]

17. Jeon, S.; Bright, S.; Park, I.; Tabelin, C.B.; Ito, M.; Hiroyoshi, N. The Effects of Coexisting Copper, Iron, Cobalt, Nickel, and Zinc Ions on Gold Recovery by Enhanced Cementation via Galvanic Interactions between Zero-Valent Aluminum and Activated Carbon in Ammonium Thiosulfate Systems. Metals 2021, 11, 1352. [CrossRef]

18. Choubey, P.K.; Singh, N.; Panda, R.; Jyothi, R.K.; Yoo, K.; Park, I.; Jha, M.K. Development of Hydrometallurgical Process for Recovery of Rare Earth Metals (Nd, Pr, and Dy) from Nd-Fe-B Magnets. Metals 2021, 11, 1987. [CrossRef]

19. Jeon, S.; Tabelin, C.B.; Takahashi, H.; Park, I.; Ito, M.; Hiroyoshi, N. Enhanced Cementation of Gold via Galvanic Interactions Using Activated Carbon and Zero-Valent Aluminum: A Novel Approach to Recover Gold Ions from Ammonium Thiosulfate Medium. Hydrometallurgy 2020, 191, 105165. [CrossRef]

20. Jeon, S.; Bright, S.; Park, I.; Tabelin, C.B.; Ito, M.; Hiroyoshi, N. A Simple and Efficient Recovery Technique for Gold Ions from Ammonium Thiosulfate Medium by Galvanic Interactions of Zero-Valent Aluminum and Activated Carbon: A Parametric and Mechanistic Study of Cementation. Hydrometallurgy 2021, 208, 105815. [CrossRef]

21. Park, I.; Kanazawa, Y.; Sato, N.; Galtchandmani, P.; Jha, M.K.; Tabelin, C.B.; Jeon, S.; Ito, M.; Hiroyoshi, N. Beneficiation of Low-Grade Rare Earth Ore from Khalzan Buregtei Deposit (Mongolia) by Magnetic Separation. Minerals 2021, 11, 1432. [CrossRef]

22. Jha, M.K.; Choubey, P.K.; Dinkar, O.S.; Panda, R.; Jyothi, R.K.; Yoo, K.; Park, I. Recovery of Rare Earth Metals (REMs) from Nickel Metal Hydride Batteries of Electric Vehicles. Minerals 2022, 12, 34. [CrossRef] 
Review

\title{
A Review of Recent Advances in Depression Techniques for Flotation Separation of $\mathrm{Cu}-\mathrm{Mo}$ Sulfides in Porphyry Copper Deposits
}

\author{
Ilhwan Park ${ }^{1, *}$, Seunggwan Hong ${ }^{2}$, Sanghee Jeon ${ }^{1}$, Mayumi Ito ${ }^{1}$ and Naoki Hiroyoshi ${ }^{1}$ \\ 1 Division of Sustainable Resources Engineering, Faculty of Engineering, Hokkaido University, \\ Sapporo 060-8628, Japan; shjun1121@eng.hokudai.ac.jp (S.J.); itomayu@eng.hokudai.ac.jp (M.I.); \\ hiroyosi@eng.hokudai.ac.jp (N.H.) \\ 2 Division of Sustainable Resources Engineering, Graduate School of Engineering, Hokkaido University, \\ Sapporo 060-8628, Japan; chanitroi@gmail.com \\ * Correspondence: i-park@eng.hokudai.ac.jp; Tel.: +81-11-706-6315
}

Received: 29 August 2020; Accepted: 16 September 2020; Published: 21 September 2020

\begin{abstract}
Porphyry copper deposits (PCDs) are some of the most important sources of copper $(\mathrm{Cu})$ and molybdenum (Mo). Typically, the separation and recovery of chalcopyrite $\left(\mathrm{CuFeS}_{2}\right)$ and molybdenite $\left(\mathrm{MoS}_{2}\right)$, the major $\mathrm{Cu}$ and Mo minerals, respectively, in PCDs are achieved by two-step flotation involving (1) bulk flotation to separate $\mathrm{Cu}-\mathrm{Mo}$ concentrates and tailings (e.g., pyrite, silicate, and aluminosilicate minerals) and (2) Cu-Mo flotation to separate chalcopyrite and molybdenite. In $\mathrm{Cu}-\mathrm{Mo}$ flotation, chalcopyrite is depressed using $\mathrm{Cu}$ depressants, such as $\mathrm{NaHS}, \mathrm{Na}_{2} \mathrm{~S}$, Nokes reagent $\left(\mathrm{P}_{2} \mathrm{~S}_{5}+\mathrm{NaOH}\right)$, and $\mathrm{NaCN}$, meaning that it is recovered as tailings, while molybdenite is floated and recovered as froth product. Although conventionally used depressants are effective in the separation of $\mathrm{Cu}$ and $\mathrm{Mo}$, they have the potential to emit toxic and deadly gases such as $\mathrm{H}_{2} \mathrm{~S}$ and $\mathrm{HCN}$ when operating conditions are not properly controlled. To address these problems caused by the use of conventional depressants, many studies aimed to develop alternative methods of depressing either chalcopyrite or molybdenite. In this review, recent advances in chalcopyrite and molybdenite depressions for $\mathrm{Cu}-\mathrm{Mo}$ flotation separation are reviewed, including alternative organic and inorganic depressants for $\mathrm{Cu}$ or Mo, as well as oxidation-treatment technologies, such as ozone $\left(\mathrm{O}_{3}\right)$, plasma, hydrogen peroxide $\left(\mathrm{H}_{2} \mathrm{O}_{2}\right)$, and electrolysis, which create hydrophilic coatings on the mineral surface.
\end{abstract}

Keywords: porphyry copper deposits; chalcopyrite; molybdenite; flotation; conventional and alternative depression techniques

\section{Introduction}

Porphyry copper deposits (PCDs) are the world's most important sources of copper (Cu) because they account for more than $60 \%$ of global annual copper production [1,2]. Although these deposits are widespread, they seem to be localized in time and space within the overall evolutionary pattern of magmatic arcs along plate convergent margins; that is, they are predominantly associated with (i) Mesozoic to Cenozoic orogenic belts in western North and South America, (ii) Tethyan orogenic belts in eastern Europe and southern Asia, and (iii) Paleozoic orogens in Central Asia and eastern North America (Figure 1) [1,3-5]. PCDs are low-grade (around $0.3-2.0 \% \mathrm{Cu}$; average $0.44 \%$ copper in 2008); however, they have significant economic value due to their large size (typically greater than 100 million tons), long mine lives (spanning several decades), and high production rates (i.e., millions of tons of copper per year) [1]. These deposits are also important sources of molybdenum (Mo), gold $(\mathrm{Au})$, and silver $(\mathrm{Ag})[1,5]$. PCDs greatly contribute to the world's supply of Mo, accounting for more than $50 \%$ of the total supply [6]. In addition, elevated concentrations of rhenium (Re), 
tellurium (Te), and platinum-group elements (PGEs) are incorporated in PCDs, which are recovered as byproducts; that is, Re, Te, and PGEs are mostly recovered from processes related to molybdenite $\left(\mathrm{MoS}_{2}\right)$, anode slimes generated from the electrorefining of copper anodes, and the smelting of copper ores, respectively [1].

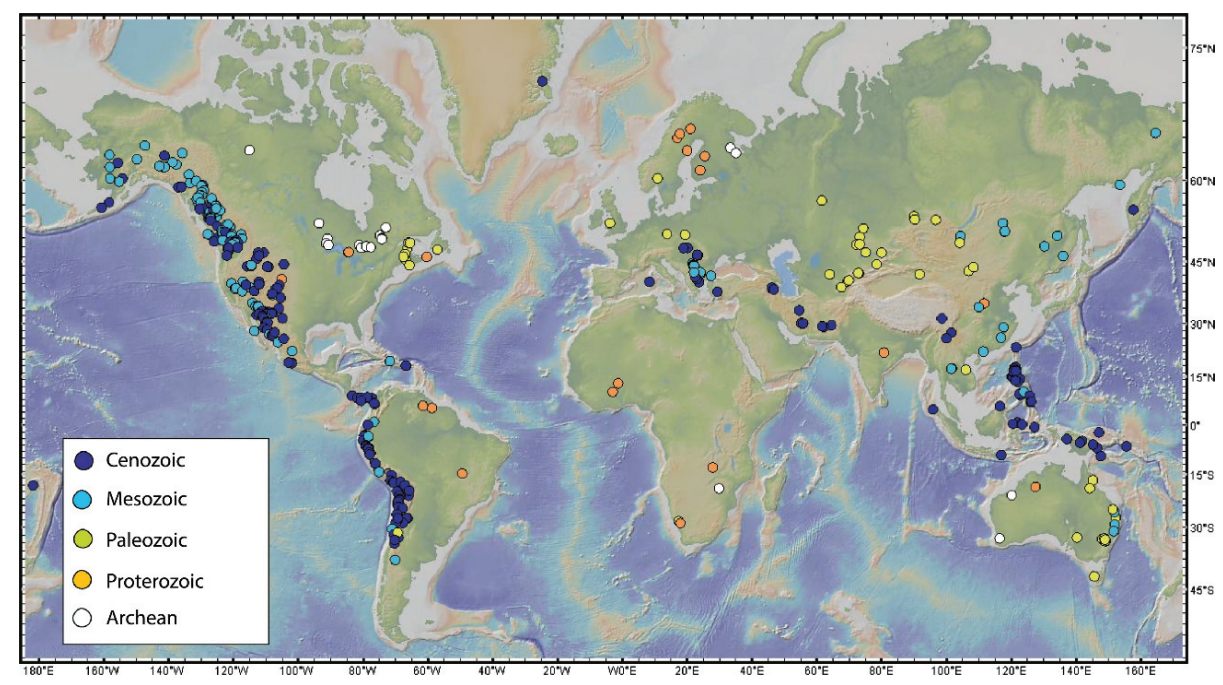

Figure 1. Occurrence of porphyry copper deposits through time (reprinted with permission from Lee and Tang [3], copyright (2020) Elsevier).

Typically, the recovery of copper sulfides (mostly chalcopyrite) and molybdenite from PCDs is conducted via a series of processes; that is, open-pit mining of PCDs to excavate the ores, closed-circuit comminution to liberate valuable and nonvaluable minerals, and multistep flotation of ground ores to separate $\mathrm{Cu}$-Mo concentrates and tailings (e.g., pyrite and silicate minerals), followed by the separation of $\mathrm{Cu}$ and $\mathrm{Mo}$ minerals from $\mathrm{Cu}-\mathrm{Mo}$ concentrates by flotation using $\mathrm{Cu}$ depressants (e.g., $\mathrm{NaHS}, \mathrm{Na}_{2} \mathrm{~S}$, Nokes reagent $\left(\mathrm{P}_{2} \mathrm{~S}_{5}+\mathrm{NaOH}\right)$, and $\left.\mathrm{NaCN}\right)$ - the detailed processes for PCDs are discussed in the following section. Afterwards, $\mathrm{Cu}$ concentrates are treated by a pyrometallurgical process to produce $\mathrm{Cu}$ metal, while Mo concentrates are treated by leaching using $\mathrm{HCl}-\mathrm{FeCl}_{3}$ to produce the high-grade $\mathrm{MoS}_{2}$ used for lubricants, or by roasting and acid pressure-oxidation processes to produce technical Mo oxide $\left(\mathrm{MoO}_{3}\right)[7]$.

During $\mathrm{Cu}-\mathrm{Mo}$ flotation separation, $\mathrm{Cu}$ depressants work effectively to separate $\mathrm{Cu}$ and $\mathrm{Mo}$ minerals, but there are serious drawbacks, such as (i) the potential to release toxic and deadly gases (e.g., $\mathrm{H}_{2} \mathrm{~S}$ and $\mathrm{HCN}$ ) when pulp $\mathrm{pH}$ is not properly maintained; (ii) the corrosive nature of $\mathrm{Cu}$ depressants, which destroy pipelines; (iii) the imperfect recovery of molybdenite; and (iv) considerable losses of precious metals such as gold and silver when cyanide is used [8-10]. In order to replace conventionally used $\mathrm{Cu}$ depressants, which have the above limitations, many studies have been conducted to develop alternative methods, including the use of environmentally friendly organic and inorganic depressants to reduce the floatability of either chalcopyrite or molybdenite, and oxidation treatments involving the use of ozone $\left(\mathrm{O}_{3}\right)$, plasma, hydrogen peroxide $\left(\mathrm{H}_{2} \mathrm{O}_{2}\right)$, and electrolysis to create hydrophilic coatings on the surfaces of the chalcopyrite. Despite the existence of extensive studies, there is no review that summarizes all findings on this important topic. In this review, therefore, newly developed techniques for $\mathrm{Cu}-\mathrm{Mo}$ flotation separation are reviewed. Specifically, we discuss mechanisms involved in selective depression for either chalcopyrite or molybdenite, and the advantages and disadvantages of each technique. 


\section{Typical Process of $\mathrm{Cu}-\mathrm{Mo}$ Sulfide Ores}

Figure 2 shows the typical flow sheet for the beneficiation of $\mathrm{Cu}-\mathrm{Mo}$ sulfide ores, consisting of three steps: (1) comminution to liberate target minerals, (2) bulk flotation to recover $\mathrm{Cu}-\mathrm{Mo}$ minerals from gangue minerals, and (3) selective flotation of Mo minerals (mostly molybdenite) from Cu-Mo bulk concentrates [10]. The ores are first crushed by a primary crusher, such as a jaw or gyratory crusher, and then ground with a semi-autogenous (SAG) and/or ball mill where conditioning agents such as a $\mathrm{Cu}-\mathrm{Mo}$ collector (e.g., xanthate- and/or oil-based collector(s)) and $\mathrm{pH}$ adjuster (e.g., lime $(\mathrm{CaO})$ ) are introduced to improve the separation of $\mathrm{Cu}-\mathrm{Mo}$ and gangue minerals during bulk flotation. The purpose of adding lime is to make the pulp $\mathrm{pH}$ alkaline, at which pyrite, one of the representative gangue minerals, could be effectively depressed. This depression of pyrite under alkaline conditions could be explained by the competitive adsorption of $\mathrm{OH}^{-}$and the xanthate-based collector. There are critical $\mathrm{pH}$ values for sulfide minerals, below which xanthate ion can be adsorbed, while above which its adsorption is inhibited due to the competitive adsorption of $\mathrm{OH}^{-}$[11]. For instance, critical pH values for pyrite and chalcopyrite in the solution containing $25 \mathrm{mg} / \mathrm{L}$ potassium ethyl xanthate at room temperature are 10.5 and 11.8 , respectively, so the selective flotation of chalcopyrite could be achieved when pulp pH is adjusted to be between 10.5 and 11.8 [11]. There are two additional mechanisms of pyrite depression under alkaline conditions: (i) dixanthogen, an adsorbed form of xanthate-based collector on pyrite surface, becomes thermodynamically unstable; and (ii) pyrite surface is covered with ferric hydroxide having a hydrophilic nature [12]. After bulk flotation, tailings are disposed of into the tailings storage facility (TSF), while concentrates are transferred to the conditioning process, followed by flotation for the separation of $\mathrm{Cu}$ and Mo minerals. As shown in Figure 2, the conditioning process is aimed at depressing $\mathrm{Cu}$ minerals by using $\mathrm{Cu}$ depressants such as NaHS. This depressant is readily dissociated in the aqueous solution, and produces $\mathrm{NaOH}$ and $\mathrm{H}_{2} \mathrm{~S}$ (Equation (1)). At pH 9-10, $\mathrm{H}_{2} \mathrm{~S}$ is transformed into $\mathrm{HS}^{-}$(Equation (2)), which reacts with xanthate-adsorbed Cu minerals; thereby, the surfaces of $\mathrm{Cu}$ minerals are modified from hydrophobic to hydrophilic due to the desorption of xanthate adsorbed on them (Equation (3), where $\mathrm{CuX}$ denotes the surface of xanthate-adsorbed $\mathrm{Cu}$ minerals). After pretreating $\mathrm{Cu}-\mathrm{Mo}$ bulk concentrates with NaHS, Mo minerals are recovered as froth products, while $\mathrm{Cu}$ minerals are recovered as tailings. According to Hirajima et al. [13], the pretreatment of $\mathrm{Cu}-\mathrm{Mo}$ bulk concentrates using NaHS significantly decreased $\mathrm{Cu}$ recovery from 85 to $10 \%$, while Mo recovery was increased from 85 to $99 \%$ (Figure 3), indicating that NaHS was effective in selectively depressing $\mathrm{Cu}$ minerals. As a result of a single stage of $\mathrm{Cu}-\mathrm{Mo}$ flotation using NaHS, the froth product contains around $10 \% \mathrm{Cu}$, which is most likely caused by entrainment. In industry, thus, froth products are further processed via multiple cleaning stages to meet the requirement of saleable Mo concentrates.

$$
\begin{gathered}
\mathrm{NaHS}+\mathrm{H}_{2} \mathrm{O} \leftrightarrow \mathrm{NaOH}+\mathrm{H}_{2} \mathrm{~S} \\
\mathrm{H}_{2} \mathrm{~S} \leftrightarrow \mathrm{H}^{+}+\mathrm{HS}^{-} \\
2 \mathrm{CuX}+\mathrm{HS}^{-} \leftrightarrow \mathrm{Cu}_{2} \mathrm{~S}+2 \mathrm{X}^{-}+\mathrm{H}^{+}
\end{gathered}
$$

Similarly, the Nokes reagent $\left(\mathrm{P}_{2} \mathrm{~S}_{5}+\mathrm{NaOH}\right), \mathrm{Na}_{2} \mathrm{~S}$, and $\mathrm{NaCN}$ were also adopted as $\mathrm{Cu}$ depressants $[7,10,14,15]$. The function of the Nokes reagent and $\mathrm{Na}_{2} \mathrm{~S}$ is the same as that of $\mathrm{NaHS}$ for producing $\mathrm{HS}^{-}$, which desorbs the adsorbed xanthate on $\mathrm{Cu}$ minerals (Equations (2)-(6)).

$$
\begin{gathered}
\mathrm{P}_{2} \mathrm{~S}_{5}+6 \mathrm{NaOH} \leftrightarrow 2 \mathrm{Na}_{3} \mathrm{PO}_{2} \mathrm{~S}_{2}+\mathrm{H}_{2} \mathrm{~S}+2 \mathrm{H}_{2} \mathrm{O} \\
\mathrm{P}_{2} \mathrm{~S}_{5}+10 \mathrm{NaOH} \leftrightarrow \mathrm{Na}_{3} \mathrm{PO}_{2} \mathrm{~S}_{2}+\mathrm{Na}_{3} \mathrm{PO}_{3} \mathrm{~S}+2 \mathrm{Na}_{2} \mathrm{~S}+5 \mathrm{H}_{2} \mathrm{O} \\
\mathrm{Na}_{2} \mathrm{~S}+2 \mathrm{H}_{2} \mathrm{O} \leftrightarrow \mathrm{H}_{2} \mathrm{~S}+2 \mathrm{NaOH}
\end{gathered}
$$




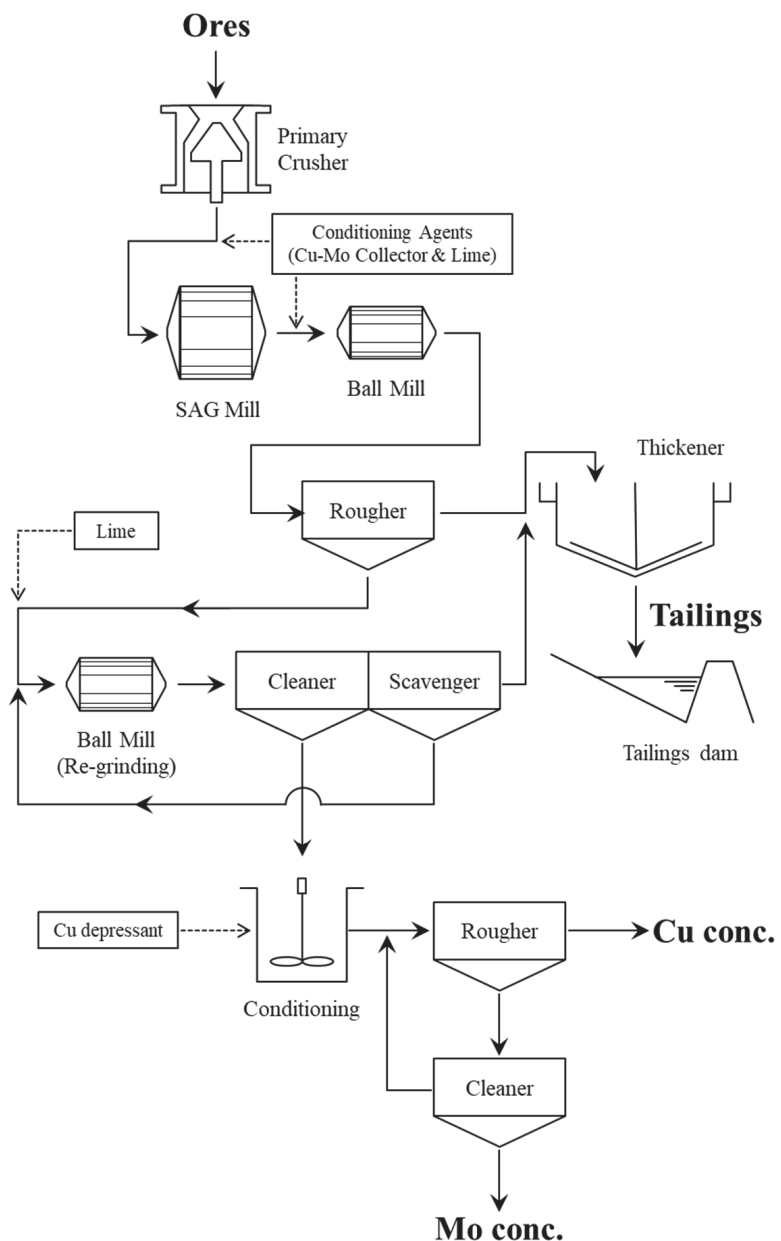

Figure 2. Beneficiation flowsheet of $\mathrm{Cu}-\mathrm{Mo}$ sulfide ores [7].
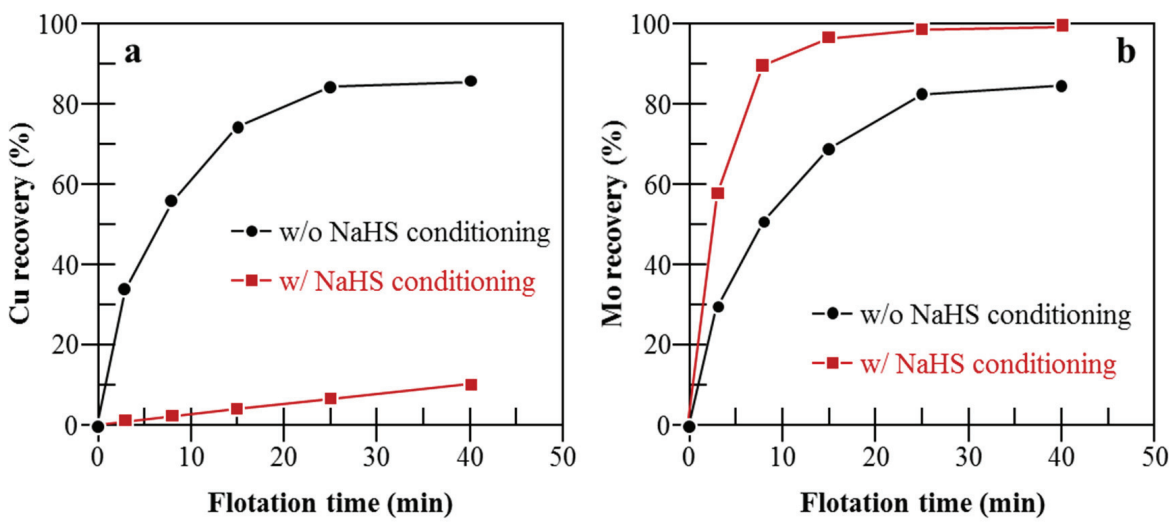

Figure 3. Effects of NaHS on recovery of (a) chalcopyrite and (b) molybdenite (reprinted with permission from Hirajima et al. [13], copyright (2017) Elsevier). 
In the case of $\mathrm{NaCN}$, its depressive mechanism is different, as $\mathrm{NaCN}$ is hydrolyzed in aqueous solution to form $\mathrm{NaOH}$ and $\mathrm{HCN}$ (Equation (7)). Then, the latter dissociates to $\mathrm{CN}^{-}$under alkaline conditions (Equation (8)). The action of $\mathrm{CN}^{-}$as a $\mathrm{Cu}$ depressant lies in its strong ability to form a copper-cyanide complex (Equation (9)) [14].

$$
\begin{gathered}
\mathrm{NaCN}+\mathrm{H}_{2} \mathrm{O} \leftrightarrow \mathrm{NaOH}+\mathrm{HCN} \\
\mathrm{HCN} \leftrightarrow \mathrm{H}^{+}+\mathrm{CN}^{-} \\
2 \mathrm{Cu}^{2+}+6 \mathrm{CN}^{-} \leftrightarrow 2\left[\mathrm{Cu}(\mathrm{CN})_{2}\right]^{-}+\mathrm{C}_{2} \mathrm{~N}_{2}
\end{gathered}
$$

By increasing the concentration of $\mathrm{CN}^{-}$, it creates additional species of the copper-cyanide complex such as $\left[\mathrm{Cu}(\mathrm{CN})_{3}\right]^{2-}$ and $\left[\mathrm{Cu}(\mathrm{CN})_{4}\right]^{3-}[16]$. Cyanide reacts with not only $\mathrm{Cu}^{2+}$, but also copper-xanthate formed on the surfaces of $\mathrm{Cu}$ minerals, resulting in a decrease in their hydrophobicity due to the replacement of xanthate with cyanide. In addition, cyanide can directly react with the surface of $\mathrm{Cu}$ minerals where $\mathrm{CN}^{-}$is adsorbed, thereby making it impossible to adsorb xanthate [16], and it is a reducing agent that reduces pulp potential in which chalcopyrite does not float.

Although effective, these depressants typically used for $\mathrm{Cu}-\mathrm{Mo}$ separation have the potential to generate toxic and lethal gases if used haphazardly. As shown in Figure 4, the protonated forms of $\mathrm{H}_{2} \mathrm{~S}$ and $\mathrm{HCN}$ start forming at a $\mathrm{pH}$ below 10 and 12, respectively. Once they exist in aqueous solution, their vaporizations are readily progressed even under ambient conditions due to their relatively high vapor pressure (i.e., $\mathrm{P}_{\mathrm{H} 2 \mathrm{~S}}=20.03 \mathrm{~atm}$ at $25^{\circ} \mathrm{C} ; \mathrm{P}_{\mathrm{HCN}}=0.98 \mathrm{~atm}$ at $25^{\circ} \mathrm{C}$ ) $[17,18]$. The problem of the formation of vaporized $\mathrm{H}_{2} \mathrm{~S}$ and $\mathrm{HCN}$ lies in its serious toxicity to human beings, the toxic actions of which occur via the inhibition of cytochrome oxidase that prevents the cellular utilization of oxygen, followed by the inhibition of the terminal step of electron transport in brain cells, resulting in loss of consciousness, respiratory arrest, and ultimately death $[19,20]$. Another problem of using $\mathrm{NaCN}$ in flotation is the significant losses of precious metals such as gold and silver incorporated in PCDs because cyanide is known to dissolve them by forming stable complexes [10]. Because of these problems, mineral-processing plants in which conventional depressants are used should either consist of covered flotation cells with an active ventilation system or always maintain pulp $\mathrm{pH}$ at above around 9.5 [21].
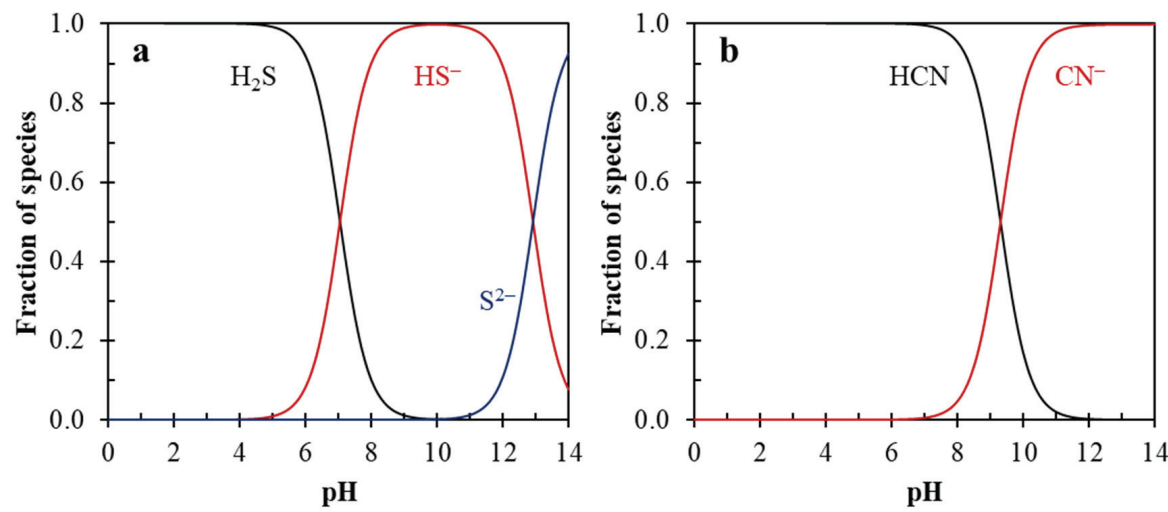

Figure 4. $\mathrm{pH}$-dependent speciation of $(\mathbf{a})$ sulfide $\left(\mathrm{p} K_{\mathrm{a} 1}=7.1\right.$ and $\left.\mathrm{p} K_{\mathrm{a} 2}=12.9 ;[\mathrm{S}]_{\mathrm{tot}}=1 \mathrm{M}\right)$ and (b) cyanide $\left(\mathrm{pK} K_{\mathrm{a}}=9.3 ;[\mathrm{CN}]_{\text {tot }}=1 \mathrm{M}\right)$. 


\section{Alternative Options for Selective Flotation of $\mathrm{Cu}-\mathrm{Mo}$ Bulk Concentrates}

\subsection{Molybdenite Depression}

To replace the use of potentially toxic depressants such as $\mathrm{NaHS}$ and $\mathrm{NaCN}$, there have been significant efforts to find suitable alternative depressants for molybdenite, for example, dextrin, lignosulfonate, carboxymethyl-based organic compounds, and humic acid. The summary of this section is present in Table 1.

Table 1. Summary of molybdenite depression.

\begin{tabular}{|c|c|c|c|c|c|}
\hline Mo Depressant & Feed & & Results & & Features \\
\hline Dextrin [22-26] & $\begin{array}{l}\text { Natural } \mathrm{MoS}_{2}[24], \mathrm{Cu} \\
\text { ore }(0.7-3.03 \% \mathrm{Cu}, \\
0.011-0.14 \% \mathrm{Mo})[26] .\end{array}$ & $\checkmark$ & $\begin{array}{l}\text { Mo recovery }\left(\mathrm{R}_{\mathrm{Mo}}\right) \\
\text { decreased from } 92 \% \text { to } \\
1.5 \% \text { with } 100 \mathrm{mg} / \mathrm{L} \\
\text { dextrin }[24] . \\
\text { Recovery of } \mathrm{Cu}\left(\mathrm{R}_{\mathrm{Cu}}\right) \\
\text { and Mo }\left(\mathrm{R}_{\mathrm{Mo}}\right) \text { was } \\
88.2 \% \text { and } 18.5 \% \text {, } \\
\text { respectively, with } 200 \\
\text { g/t dextrin [26]. }\end{array}$ & $\checkmark$ & $\begin{array}{l}\text { In the presence of } \\
\text { organic compound (e.g., } \\
\text { iso-octane), the } \\
\text { depressing efficiency of } \\
\text { dextrin decreased [24]. } \\
\text { Dextrin is effective in } \\
\text { depressing MoS }, \text { but } \\
\text { increases water recovery, } \\
\text { causing the recovery of } \\
\text { unwanted minerals [26]. }\end{array}$ \\
\hline Lignosulfonate [27-31] & $\begin{array}{l}\text { Natural } \mathrm{CuFeS}_{2} \text { and } \\
\mathrm{MoS}_{2}[28] .\end{array}$ & $\checkmark$ & $\begin{array}{l}\text { Single } \\
\text { mineral-flotation tests } \\
\text { showed that } \\
\text { sodium-based } \\
\text { lignosulfonates were } \\
\text { effective in selectively } \\
\text { depressing } \mathrm{MoS}_{2} \text { [28]. }\end{array}$ & $\checkmark$ & $\begin{array}{l}\text { Presence of } \mathrm{Ca}^{2+} \\
\text { introduced by } \\
\text { calcium-based } \\
\text { lignosulfonates and/or } \\
\text { lime (pH adjuster) to the } \\
\text { flotation system } \\
\text { depressed not only } \mathrm{MoS}_{2} \\
\text { but also } \mathrm{CuFeS}_{2}[28] .\end{array}$ \\
\hline $\begin{array}{l}\text { O-carboxymethyl } \\
\text { chitosan } \\
(\mathrm{O}-\mathrm{CMC})[32,33]\end{array}$ & $\begin{array}{l}\text { Natural CuFeS } 2 \text { and } \\
\mathrm{MoS}_{2}[32] .\end{array}$ & $\checkmark$ & $\begin{array}{l}\text { Selective depression of } \\
\mathrm{MoS}_{2}\left(\mathrm{R}_{\mathrm{Mo}}<12 \% ; \mathrm{R}_{\mathrm{Cu}}\right. \\
>90 \%) \text { was achieved } \\
\text { using } 150 \mathrm{ppm} \text { O-CMC } \\
\text { with } 20 \mathrm{ppm} \\
\text { potassium isobutyl } \\
\text { xanthate (KIBX) and } 20 \\
\text { ppm methyl isobutyl } \\
\text { carbinol (MIBC) at pH } \\
5-9[32] .\end{array}$ & $\checkmark$ & $\begin{array}{l}\text { O-CMC could be } \\
\text { adsorbed on both } \\
\text { minerals but via } \\
\text { different mechanisms; } \\
\text { O-CMC was adsorbed } \\
\text { on CuFeS } 2 \text { via weak } \\
\text { physical interactions, } \\
\text { while its adsorption on } \\
\text { MoS }_{2} \text { occurred via } \\
\text { hydrophobic } \\
\text { interactions [32,33]. }\end{array}$ \\
\hline Humic acid (HA) [34] & $\begin{array}{l}\text { Natural } \mathrm{CuFeS}_{2} \text { and } \\
\mathrm{MoS}_{2}[34] .\end{array}$ & $\checkmark$ & $\begin{array}{l}\text { Mixed-mineral } \\
\text { flotation with } 20 \text { ppm } \\
\text { HA resulted in }>80 \% \\
R_{\mathrm{Cu}} \text { and } \mathrm{R}_{\mathrm{Mo}} \approx 20 \% \text { at } \\
\text { pH 5-9 [34]. }\end{array}$ & $\checkmark$ & $\begin{array}{l}\text { Similar to O-CMC, the } \\
\text { adsorption mechanisms } \\
\text { of } \mathrm{HA} / \mathrm{CuFeS}_{2} \text { and } \\
\mathrm{HA} / \mathrm{MoS}_{2} \text { were defined } \\
\text { as electrostatic and } \\
\text { hydrophobic } \\
\text { interactions, } \\
\text { respectively [34]. }\end{array}$ \\
\hline $\begin{array}{l}\text { Carboxymethylcellulose } \\
\text { (CMC) [35-37] }\end{array}$ & Natural $\mathrm{MoS}_{2}[35]$. & $\checkmark$ & $\begin{array}{l}\text { Two CMC polymers } \\
\text { (i.e., HSHB and LSLB) } \\
\text { were tested, and both } \\
\text { were effective in } \\
\text { depressing } \mathrm{MoS}_{2} ; \text { in } \\
\text { SPW, RMo was } 8 \% \text { with } \\
5 \text { ppm HSHB and } 2 \% \\
\text { with } 5 \text { ppm LSLB [35]. }\end{array}$ & $\checkmark$ & $\begin{array}{l}\text { CMCs act as both a Mo } \\
\text { and a Cu } \\
\text { depressant }[36,37] \text {. } \\
\text { Depending on the type } \\
\text { of ore, two approaches } \\
\text { (i.e., (1) depressing } \mathrm{MoS}_{2} \\
\text { with floating } \mathrm{CuFeS}_{2} \text { and } \\
\text { (2) depressing } \mathrm{CuFeS}_{2} \\
\text { with floating } \mathrm{MoS}_{2} \text { ) can } \\
\text { be applicable }[35-37] \text {. }\end{array}$ \\
\hline
\end{tabular}

\subsubsection{Dextrin}

Hernlund [22], for example, used dextrin as a Mo depressant. Dextrin is a water-soluble polysaccharide having the general formula of $\left(\mathrm{C}_{6} \mathrm{H}_{10} \mathrm{O}_{5}\right)_{n}$, produced by the enzymatic hydrolysis 
of starch $[23,24]$. The adsorption mechanism of dextrin molecules on the surface of molybdenite was proposed to occur via hydrophobic interaction [24,25]. As a result, the molybdenite surface is rendered hydrophilic, so its recovery decreased significantly from $92 \%$ to $1.5 \%$ when $100 \mathrm{mg} / \mathrm{L}$ dextrin was added [24]. A similar result was obtained by Jorjani et al. [26], who investigated the flotation behavior of porphyry copper ores containing Cu minerals (e.g., chalcopyrite and chalcocite), molybdenite, and aluminosilicates (e.g., albite, illite, kaolinite, muscovite, orthoclase, and vermiculite). This depressant could work well to decrease molybdenite recovery from around $50 \%$ to $15 \%$; however, at a certain amount of added dextrin (i.e., $200 \mathrm{~g} / \mathrm{ton}$ ), it causes an increase in water content in froth products, resulting in the recovery of unwanted gangue minerals such as aluminosilicates by entrainment. In other words, it is recommended for froth products to be washed to obtain better products with low contents of undesired minerals [26]. Moreover, dextrin could not act as a Mo depressant in the presence of oily collectors, e.g., iso-octane (2,2,4-trimethylpentane, $\left.\left(\mathrm{CH}_{3}\right)_{3} \mathrm{CCH}_{2} \mathrm{CH}\left(\mathrm{CH}_{3}\right)_{2}\right)$, which is another disadvantage of the use of dextrin for $\mathrm{Cu}-\mathrm{Mo}$ flotation [24].

\subsubsection{Lignosulfonates}

Lignosulfonates, a group of water-soluble and strong anionic polyelectrolytes typically obtained as a byproduct of wood processing for the extraction of cellulose [27,28], were first used for the separation of molybdenite and talc, both of which are hydrophobic in nature [29-31]. For molybdenite/talc separation, the reverse flotation of talc was proposed, where talc-bearing molybdenite ores are conditioned by lignosulfonate, with lime used as $\mathrm{pH}$ adjuster to increase the $\mathrm{pH}$ to around 11.5, resulting in the selective depression of molybdenite while talc is floated. In the case of chalcopyrite/molybdenite separation, however, the combination of lignosulfonate and lime depressed not only molybdenite but also chalcopyrite at $\mathrm{pH} \sim 11$, making their separation impossible [28]. The floatability of chalcopyrite at the same $\mathrm{pH}$ but adjusted using $\mathrm{KOH}$ was unaffected by the presence of lignosulfonates. From these results, it can be concluded that $\mathrm{Ca}^{2+}$ has a strong effect on chalcopyrite depression, especially under alkaline conditions most likely due to the formation of $\mathrm{Ca}(\mathrm{OH})_{2}$ on its surface. There are two possible mechanisms of how the formation of $\mathrm{Ca}(\mathrm{OH})_{2}$ depresses the floatability of chalcopyrite: (1) $\mathrm{Ca}(\mathrm{OH})_{2}$ is a hydrophilic compound, so it directly prevents the bubble attachment; and (2) the formation of $\mathrm{Ca}(\mathrm{OH})_{2}$ changes the surface charge of chalcopyrite from negative to positive, making lignosulfonates (i.e., strong anionic polyelectrolytes) favorable to be adsorbed $[27,28]$. On the other hand, the floatability of molybdenite was strongly depressed by lignosulfonate in a wide $\mathrm{pH}$ range of 5-11, regardless of used $\mathrm{pH}$ adjusters (e.g., $\mathrm{CaO}, \mathrm{Na}_{2} \mathrm{CO}_{3}$, and $\mathrm{KOH}$ ). These results suggest that chalcopyrite/molybdenite separation could be achieved by using (not calcium-based) sodium sulfonates in the absence of $\mathrm{Ca}^{2+}$. This means that lime, the most commonly used $\mathrm{pH}$ adjuster for depressing pyrite in bulk $\mathrm{Cu} / \mathrm{Mo}$ flotation, is required to be replaced with other basic materials to eliminate the presence of $\mathrm{Ca}^{2+}$ in the pulp. Similar to the case of dextrin, lignosulfonates also lose their ability to depress molybdenite when the mineral surface is rendered hydrophobic by an oily collector such as dodecane $\left(\mathrm{CH}_{3}\left(\mathrm{CH}_{2}\right)_{10} \mathrm{CH}_{3}\right)$ prior to depressant adsorption [28].

\subsubsection{Carboxymethyl-Based Organic Compounds and Humic Acid}

O-carboxymethyl chitosan ( $\mathrm{O}-\mathrm{CMC})$, a derivative of the second most abundant natural polysaccharide (i.e., chitosan), is nontoxic, biodegradable, cost-effective, and has better solubility in water compared to that of chitosan, which make it suitable for uses in a wide range of technologies. Yuan and coworkers $[32,33]$ utilized O-CMC for the depression of molybdenite during $\mathrm{Cu}-\mathrm{Mo}$ flotation. As shown in Figure 5a, the result of single-mineral flotation with $20 \mathrm{ppm}$ potassium isobutyl xanthate (KIBX) showed that both minerals were highly recoverable ( 97\%) in the absence of O-CMC; however,

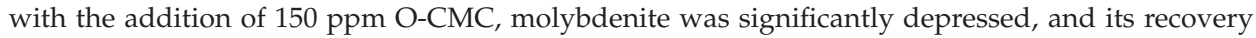
decreased to around $11 \%$, whereas the floatability of chalcopyrite was not affected by O-CMC [32]. This selective depression of molybdenite was also achieved during the flotation of a $\mathrm{Cu}-\mathrm{Mo}$ mixture in the presence of $150 \mathrm{ppm} \mathrm{O}-\mathrm{CMC}$ (Figure 5b). The topographic atomic-force-microscopy (AFM) images 
of chalcopyrite and molybdenite before and after treatment with O-CMC are illustrated in Figure $5 c-f$, showing that O-CMC created aggregates (100-200 $\mathrm{nm}$ diameter with $\sim 2 \mathrm{~nm}$ height) that were only present on the surface of molybdenite. This result implies that $\mathrm{O}-\mathrm{CMC}$ cannot be adsorbed on the chalcopyrite surface, but it is indeed possible according to their follow-up study [33]. Electrokinetic studies showed that the zeta potential of chalcopyrite treated with O-CMC notably decreased and was close to that of O-CMC macromolecules. In addition, X-ray photoelectron-spectroscopy (XPS) measurements of $\mathrm{O}-\mathrm{CMC}$-treated chalcopyrite indicated that apparent signatures of O-CMC were detected in the spectra of $\mathrm{C} 1 \mathrm{~s}, \mathrm{~N} 1 \mathrm{~s}$, and $\mathrm{O}$ 1s. Although $\mathrm{O}-\mathrm{CMC}$ could be adsorbed on the chalcopyrite surface, its adsorption is reversible due to the weak physical interactions (e.g., electrostatic interactions), which means that it could be mechanically desorbed. After washing O-CMC-treated chalcopyrite with Milli-Q water, in fact, the signals of adsorbed O-CMC disappeared in AFM and time-of-flight secondary ion-mass spectrometry (ToF-SIMS) imaging and diffused-reflectance infrared Fourier transform (DRIFT) spectroscopy [33]. However, $\mathrm{O}-\mathrm{CMC}$ is adsorbed on the molybdenite basal planes via hydrophobic interactions that are more irreversible than those between O-CMC and chalcopyrite. Due to the different adsorption characteristics of $\mathrm{O}-\mathrm{CMC}$ on chalcopyrite/molybdenite, selective depression of molybdenite could be achieved during $\mathrm{Cu}-\mathrm{Mo}$ flotation. Yuan and coworkers [34] investigated the selective depression of humic acid (HA), a major organic constituent of soil and one of the most abundant naturally occurring organic macromolecules, for $\mathrm{Cu}-\mathrm{Mo}$ flotation, and their results indicated that HA could selectively depress molybdenite by a similar adsorption mechanism as that of O-CMC; that is, the adsorption of HA on chalcopyrite and molybdenite takes place via electrostatic and hydrophobic interactions, respectively.

In the case of polymer adsorption on the mineral surface, electrolyte concentration and composition had considerable impact on adsorbed layer properties (e.g., thickness, coverage, and roughness) [35]. For example, Kor et al. [35] investigated the effects of electrolyte concentration and composition on the adsorption of two carboxymethylcellulose (CMC) polymers (high substitution, high blockiness (HSHB); low substitution, low blockiness (LSLB)) onto the molybdenite surface, and confirmed that higher ionic strength $\left(2.76 \times 10^{-2} \mathrm{M} \mathrm{KCl}\right)$ contributes to thicker layers with higher coverage compared to those observed in $10^{-2} \mathrm{M} \mathrm{KCl}$ (Table 2). Moreover, simulated process water (SPW), a complex electrolyte containing multivalent metal ions, further increases the thickness of adsorbed layers. As shown in Figure $6 \mathrm{a}$, the flotation recovery of bare molybdenite in $10^{-2} \mathrm{M} \mathrm{KCl}$ electrolyte is around $92 \%$, but the addition of $5 \mathrm{mg} / \mathrm{L}$ HSHB decreased Mo recovery to $30 \%$ in $10^{-2} \mathrm{M} \mathrm{KCl}, 14 \%$ in $2.76 \times 10^{-2} \mathrm{M} \mathrm{KCl}$, and $8 \%$ in SPW. Compared with HSHB, the depressing effect of LSLB for molybdenite is stronger, that is, the recovery of LSLB-treated molybdenite was $5 \%$ in in $10^{-2} \mathrm{M} \mathrm{KCl}, 4 \%$ in $2.76 \times 10^{-2} \mathrm{M} \mathrm{KCl}$, and $2 \%$ in SPW (Figure $6 \mathrm{~b}$ ), indicating that a thicker layer with higher coverage results in the better suppression of molybdenite floatability.

However, the floatability of chalcopyrite is also affected by HSHB and LSLB. In the absence of CMCs, the maximal recovery $\left(R_{\max }\right)$ of chalcopyrite is $91 \% \pm 5 \%$, whereas $R_{\max }$ is decreased to $66 \% \pm 4 \%$ with $25 \mathrm{mg} / \mathrm{L} \mathrm{HSHB}$ and $38 \% \pm 2 \%$ with $25 \mathrm{mg} / \mathrm{L}$ LSLB [36]. According to Qui et al. [37], CMCs can be used for depressing chalcopyrite in $\mathrm{Cu}-\mathrm{Mo}$ flotation separation. This means that the depressing ability of CMCs is not limited to molybdenite, that is, CMCs can play roles in depressing chalcopyrite and/or molybdenite, which is strongly dependent on operating conditions and ore compositions. Similarly, the problems with the use of organic polymers (e.g., starches and dextrins), widely used as a $\mathrm{Pb}$ depressant for $\mathrm{Cu}-\mathrm{Pb}$ separation and as a pyrite depressant, are associated with the nonspecific depression of all sulfides when an excessive dosage is introduced [38]; thus, the flotation circuits using organic depressants need constant attention to avoid failure in sulfide separation. 

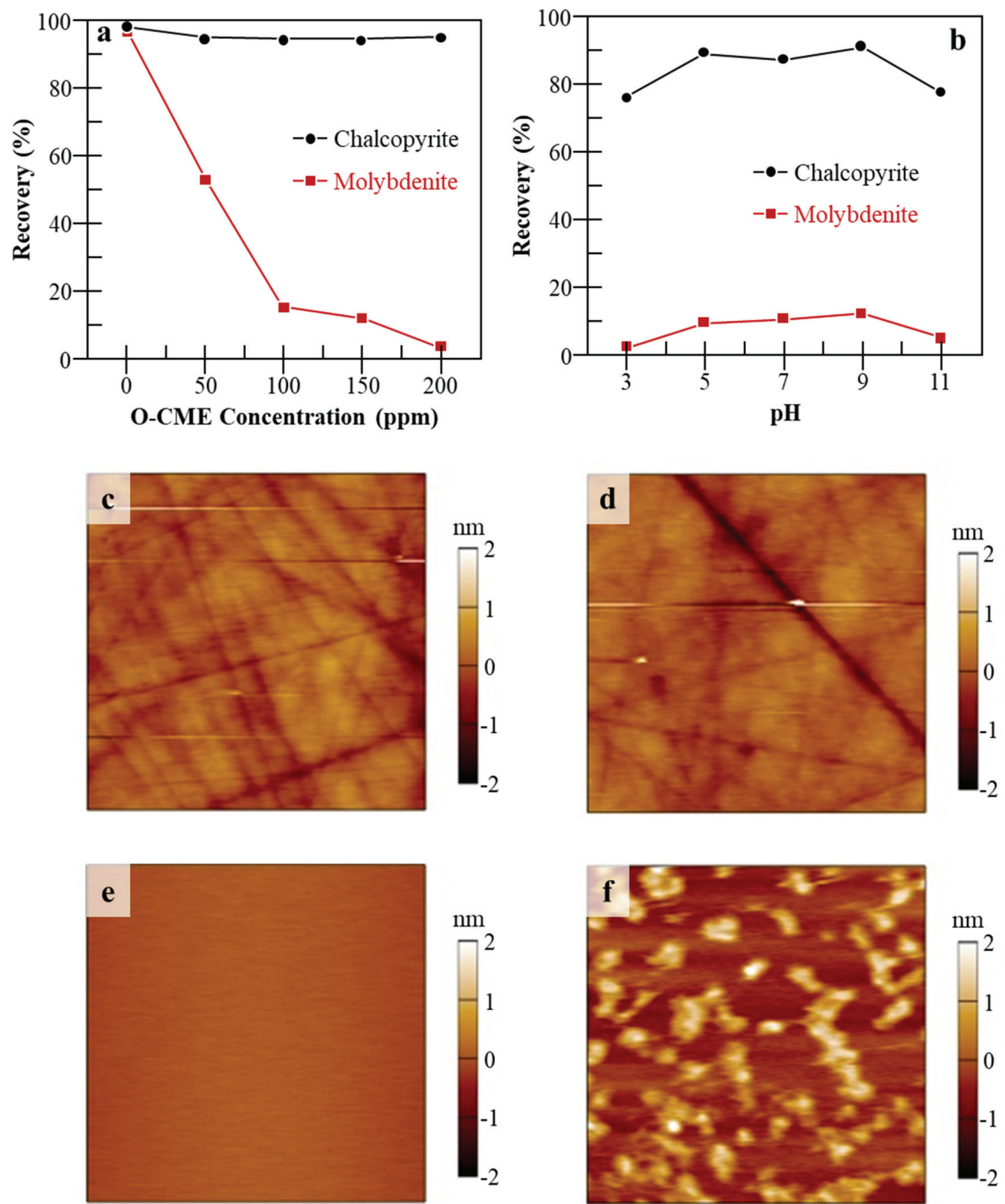

Figure 5. Effect of $\mathrm{O}-\mathrm{CMC}$ on selective depression of molybdenite: (a) single-mineral flotation in $1 \mathrm{mM}$ $\mathrm{KCl}$ solution with $20 \mathrm{ppm} \mathrm{KIBX}$ at $\mathrm{pH} 9$ under various concentrations of O-CMC; (b) flotation of artificially mixed minerals (chalycopyrite:molybdenite $=1: 1$ by weight) in $1 \mathrm{mM} \mathrm{KCl}$ solution with 20 ppm KIBX and150 ppm O-CMC as function of pH, and atomic-force-microscopy (AFM) height profiles of (c) bare chalcopyrite, (d) chalcopyrite treated with 150 ppm O-CMC, (e) bare molybdenite, and (f) molybdenite treated with 150 ppm O-CMC (reprinted with permission from Yuan et al. [32], copyright (2019) Elsevier). 
Table 2. Thickness and surface coverage $(\Gamma)$ of adsorbed CMC $(5 \mathrm{mg} / \mathrm{L})$ at $\mathrm{pH} 9$ on molybdenite (reprinted with permission from Kor et al. [35], copyright (2014) American Chemical Society). HSHB, high substitution, high blockiness; LSLB, low substitution, low blockiness; SPW, simulated process water.

\begin{tabular}{ccccc}
\hline \multirow{2}{*}{ Electrolyte } & \multicolumn{2}{c}{ HSHB } & \multicolumn{2}{c}{ LSLB } \\
\cline { 2 - 5 } & Thickness (nm) & $\Gamma(\%)$ & Thickness (nm) & $\Gamma(\%)$ \\
\hline $10^{-2} \mathrm{M} \mathrm{KCl}$ & $1.1 \pm 0.2$ & 23 & $2.6 \pm 0.2$ & 100 \\
$2.76 \times 10^{-2} \mathrm{M} \mathrm{KCl}$ & $1.6 \pm 0.6$ & 95 & $4.0 \pm 0.4$ & 100 \\
$\mathrm{SPW}^{*}$ & $2.7 \pm 0.5$ & 100 & $6.3 \pm 0.4$ & 100 \\
\hline
\end{tabular}

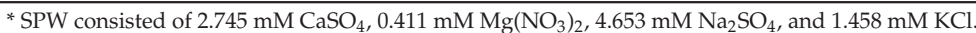
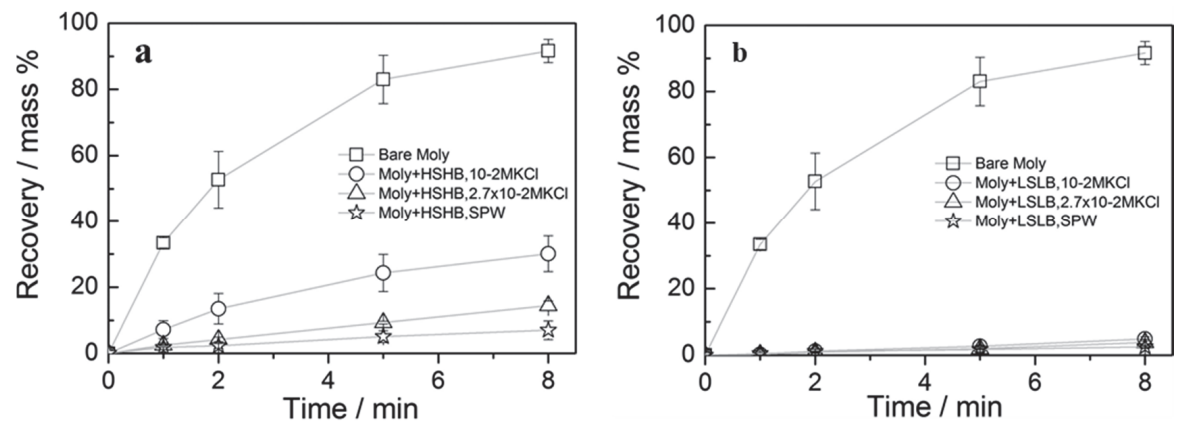

Figure 6. Single-mineral flotation of bare molybdenite and in presence of $5 \mathrm{mg} / \mathrm{L} \mathrm{CMC} \mathrm{((a)} \mathrm{HSHB}$ and (b) LSLB) at three studied electrolyte conditions: $10^{-2} \mathrm{M} \mathrm{KCl}, 2.76 \times 10^{-2} \mathrm{M} \mathrm{KCl}$, and SPW, all at pH 9 (reprinted with permission from Kor et al. [35], copyright (2014) American Chemical Society).

\subsection{Depression of $\mathrm{Cu}$ Minerals}

As discussed in an earlier section, many molybdenite depressants could effectively improve the separation between Mo and $\mathrm{Cu}$ minerals. In the case of PCDs, however, the strategy of depressing chalcopyrite has been more commonly adopted than depressing molybdenite has, primarily due to mass-balance considerations [28], that is, the amount of molybdenite in PCDs is typically lower than that of $\mathrm{Cu}$ minerals, which makes the flotation process that recovers molybdenite by depressing chalcopyrite attractive. If the separation is done by the depression of molybdenite and the simultaneous flotation of chalcopyrite, it may cause the mechanical entrainment of molybdenite within a large volume of chalcopyrite concentrate [28], which lowers the grade of $\mathrm{Cu}$ concentrate, and leads to appreciable loss of molybdenite. Alternative depression techniques for chalcopyrite, including inorganic/organic depressants and oxidation treatments, are reviewed and summarized in Table 3. 
Table 3. Summary of chalcopyrite depression.

\begin{tabular}{|c|c|c|c|}
\hline Cu Depressant & Feed & Results & Features \\
\hline $\mathrm{Na}_{2} \mathrm{SO}_{3}[39-45]$ & $\begin{array}{l}\text { Natural } \mathrm{CuFeS}_{2} \text { and } \\
\mathrm{MoS}_{2}[44] .\end{array}$ & $\begin{array}{l}\text { With the addition of } 0.1 \\
\mathrm{M} \mathrm{Na}_{2} \mathrm{SO}_{3}, \mathrm{CuFeS}_{2} \\
\text { floatability dramatically } \\
\text { decreased to } \approx 0 \% \text {, while } \\
>95 \% \mathrm{MoS}_{2} \text { floated [44]. }\end{array}$ & $\begin{array}{l}\mathrm{Na}_{2} \mathrm{SO}_{3} \text { can also act as } \\
\text { an activator for } \mathrm{CuFeS}_{2} \text {, } \\
\text { of which the surface is } \\
\text { covered with ferric } \\
\text { oxyhydroxide [45]. }\end{array}$ \\
\hline Seawater [46-58] & $\begin{array}{l}\text { Natural } \mathrm{CuFeS}_{2} \text { and } \\
\mathrm{MoS}_{2}[49] .\end{array}$ & $\begin{array}{l}\text { Mixed-mineral flotation } \\
\text { using artificial seawater } \\
\text { at pH } 10 \text { resulted in } \\
\text { lower recovery of both } \\
\text { minerals (around } \\
\text { 10-15\%), but separation } \\
\text { efficiency was greatly } \\
\text { improved by using } 416 \\
\text { mg/L emulsified } \\
\text { kerosene }\left(\mathrm{R}_{\mathrm{Cu}}>70 \%,\right. \\
\left.\mathrm{R}_{\mathrm{Mo}} \approx 20 \%\right)[49] .\end{array}$ & $\begin{array}{l}\text { The adsorption of } \\
\text { seawater precipitates } \\
\left(\text { e.g., } \mathrm{Mg}(\mathrm{OH})_{2} \text { and }\right. \\
\left.\mathrm{CaCO}_{3}\right) \text { is the primary } \\
\text { cause of both minerals' } \\
\text { depression; however, } \\
\text { emulsified oil limits its } \\
\text { adsorption on } \mathrm{MoS}_{2} \text { [49]. }\end{array}$ \\
\hline $\begin{array}{l}\text { Organic depressants } \\
\text { (e.g., PGA [59], } \\
\text { DMSA [60], DBT [61], } \\
\text { chitosan [62-65], } \\
\text { ATDT [66], and } \\
\text { AHS [67]) }\end{array}$ & $\begin{array}{l}\text { Bulk Cu-Mo conc. [59], } \\
\text { Cu-Mo ore [60], Cu-Mo } \\
\text { rough conc. [61], natural } \\
\mathrm{CuFeS}_{2} \text { and } \mathrm{MoS}_{2}[62], \\
\mathrm{CuFeS}_{2} \text { and } \mathrm{MoS}_{2} \\
\text { purified by } \\
\text { flotation [66,67]. }\end{array}$ & $\begin{array}{l}\text { All reviewed organic } \\
\text { depressants were } \\
\text { effective in depressing } \\
\mathrm{CuFeS}_{2} \text {, while they were } \\
\text { negligible for } \mathrm{MoS}_{2} \\
\text { floatability }[59-62,66,67] \text {. }\end{array}$ & $\begin{array}{l}\checkmark \mathrm{S} \text { and/or } \mathrm{N} \text { atoms in } \\
\text { organic compounds have } \\
\text { strong affinity with } \mathrm{Cu} \\
\text { atoms in } \mathrm{CuFeS} \text {, } \\
\text { making these organic } \\
\text { depressants highly } \\
\text { selective for } \\
\mathrm{CuFeS}_{2}[59-62,66,67] .\end{array}$ \\
\hline $\begin{array}{l}\text { Oxidation treatments } \\
\text { (e.g., ozone }\left(\mathrm{O}_{3}\right)[68-73] \text {, } \\
\text { plasma [74], } \\
\mathrm{H}_{2} \mathrm{O}_{2}[13,75-77] \text {, and } \\
\text { electrolysis [78]). }\end{array}$ & $\begin{array}{l}\text { Bulk Cu-Mo conc. [69], } \\
\text { natural } \mathrm{CuFeS}_{2} \text { and } \\
\mathrm{MoS}_{2}[13,74,75], \text { mineral } \\
\text { electrodes }[78] .\end{array}$ & $\begin{array}{l}\text { After oxidation } \\
\text { treatments, chalcopyrite } \\
\text { is aggressively oxidized, } \\
\text { resulting in a decrease in } \\
\mathrm{CuFeS}_{2} \text { floatability due } \\
\text { to the formation of } \\
\text { hydrophilic oxidation } \\
\text { products on its } \\
\text { surface }[13,69,74,75,78] \text {. }\end{array}$ & $\begin{array}{l}\mathrm{MoS}_{2} \text { was also oxidized, } \\
\text { and on its surface, } \\
\text { oxidation products (e.g., } \\
\mathrm{MoO}_{3} \text { ) were formed; } \\
\text { however, } \mathrm{MoO}_{3} \text { is highly } \\
\text { soluble under alkaline } \\
\text { conditions, so its effect } \\
\text { on MoS floatability } \\
\text { becomes negligible } \\
\text { under typical Cu-Mo } \\
\text { flotation conditions } \\
\text { (pH > 9) [13,74,75,78]. }\end{array}$ \\
\hline
\end{tabular}

\subsubsection{Inorganic Depressants}

The xanthate-induced flotation of sulfide minerals is significantly influenced by pulp potential [39-42]. For example, the flotation of chalcopyrite using butyl xanthate shows that its recovery was lowered with decreasing Eh (Figure 7). At the Eh of $-0.4 \mathrm{~V}$, the addition of a collector had a negligible effect on the recovery of chalcopyrite, but was effective in the Eh range from -0.1 to $0.2 \mathrm{~V}$ due to the formation of a $\mathrm{Cu}(\mathrm{I})$-xanthate complex (-0.1 to $0.0 \mathrm{~V}$; Equation (10)) as well as dixanthogen (0.0 to $0.1 \mathrm{~V}$; Equation (11)) [42].

$$
\begin{gathered}
\mathrm{CuX}+\mathrm{FeS}_{2}+\mathrm{e}^{-} \rightarrow \mathrm{CuFeS}_{2}+\mathrm{X}^{-}, \mathrm{E}^{0}=-0.096 \mathrm{~V} \\
\mathrm{X}_{2}+2 \mathrm{e}^{-} \rightarrow 2 \mathrm{X}^{-}, \mathrm{E}^{0}=-0.009 \mathrm{~V}
\end{gathered}
$$




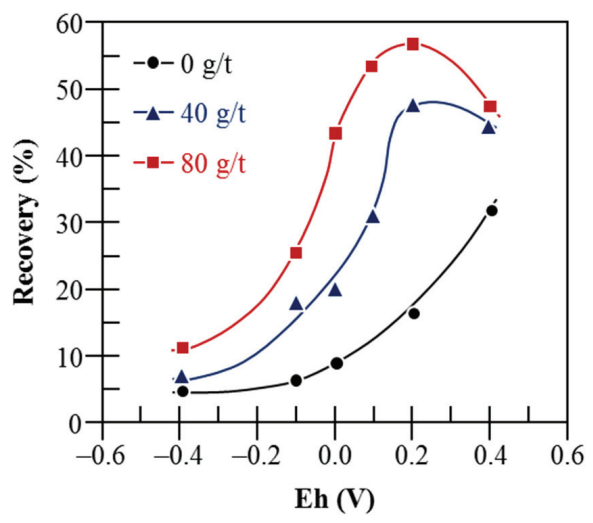

Figure 7. Recovery of chalcopyrite as function of Eh and butyl xanthate addition at pH 8.1 (reprinted with permission from Grano et al. [39], copyright (1990) Elsevier).

At an Eh greater than $0.2 \mathrm{~V}$, however, the recovery of chalcopyrite started decreasing because of the decomposition of the $\mathrm{Cu}(\mathrm{I})$-xanthate complex (Equation (12)), making the mineral surface less hydrophobic [43].

$$
2 \mathrm{HCuO}_{2}^{-}+\mathrm{X}_{2}+6 \mathrm{H}^{+}+4 \mathrm{e}^{-} \rightarrow 2 \mathrm{CuX}+4 \mathrm{H}_{2} \mathrm{O}, \mathrm{E}^{0}=-1.402 \mathrm{~V}
$$

On the basis of Eh dependence on chalcopyrite flotation, Miki et al. [44] used $\mathrm{Na}_{2} \mathrm{SO}_{3}$ as a depressant that provided the reducing conditions where the floatability of chalcopyrite decreased. The flotation results using a TMD solution (mixture of TX15216 (alkyl mercaptan), MX-7017 (modified thionocarbamate), and diesel oil), and methyl isobutyl carbinol (MIBC) as collector and frother, respectively, indicated that molybdenite was recovered by more than $95 \%$, while the recovery of chalcopyrite was almost $0 \%$ when conditioned with $0.1 \mathrm{M} \mathrm{Na}_{2} \mathrm{SO}_{3}$ at $\mathrm{pH} 10.8$ for $1 \mathrm{~h}$ (Figure 8a). XPS spectra of chalcopyrite treated with $\mathrm{Na}_{2} \mathrm{SO}_{3}$ showed that various hydrophilic species (i.e., $\mathrm{CuO}$, $\mathrm{Cu}(\mathrm{OH})_{2}, \mathrm{FeOOH}$, and $\left.\mathrm{Fe}_{2}\left(\mathrm{SO}_{4}\right)_{3}\right)$ were formed on its surface. Miki and coworkers [44] proposed the mechanism on the formation of hydrophilic compounds that occurs via a series of reactions; that is, reductive dissolution of chalcopyrite by $\mathrm{Na}_{2} \mathrm{SO}_{3}$ (Equation (13)), oxidative dissolution of $\mathrm{Cu}_{2} \mathrm{~S}$ (Equation (14)), and hydrolysis/precipitation of $\mathrm{Cu}^{2+}$ and $\mathrm{Fe}^{3+}$ (Equations (15)-(18)).

$$
\begin{gathered}
2 \mathrm{CuFeS}_{2}+6 \mathrm{Cu}^{2+}+3 \mathrm{SO}_{3}{ }^{2-}+6 \mathrm{OH}^{-} \rightarrow 4 \mathrm{Cu}_{2} \mathrm{~S}+2 \mathrm{Fe}^{3+}+3 \mathrm{SO}_{4}{ }^{2-}+3 \mathrm{H}_{2} \mathrm{O} \\
\mathrm{Cu}_{2} \mathrm{~S} \rightarrow 2 \mathrm{Cu}^{2+}+\mathrm{S}+4 \mathrm{e}^{-} \\
\mathrm{Cu}^{2+}+\mathrm{H}_{2} \mathrm{O} \rightarrow \mathrm{CuO}+2 \mathrm{H}^{+} \\
\mathrm{Cu}^{2+}+2 \mathrm{H}_{2} \mathrm{O} \rightarrow \mathrm{Cu}(\mathrm{OH})_{2}+2 \mathrm{H}^{+} \\
\mathrm{Fe}^{3+}+2 \mathrm{H}_{2} \mathrm{O} \rightarrow \mathrm{FeOOH}+3 \mathrm{H}^{+} \\
2 \mathrm{Fe}^{3+}+3 \mathrm{SO}_{4}{ }^{2-} \rightarrow \mathrm{Fe}_{2}\left(\mathrm{SO}_{4}\right)_{3}
\end{gathered}
$$



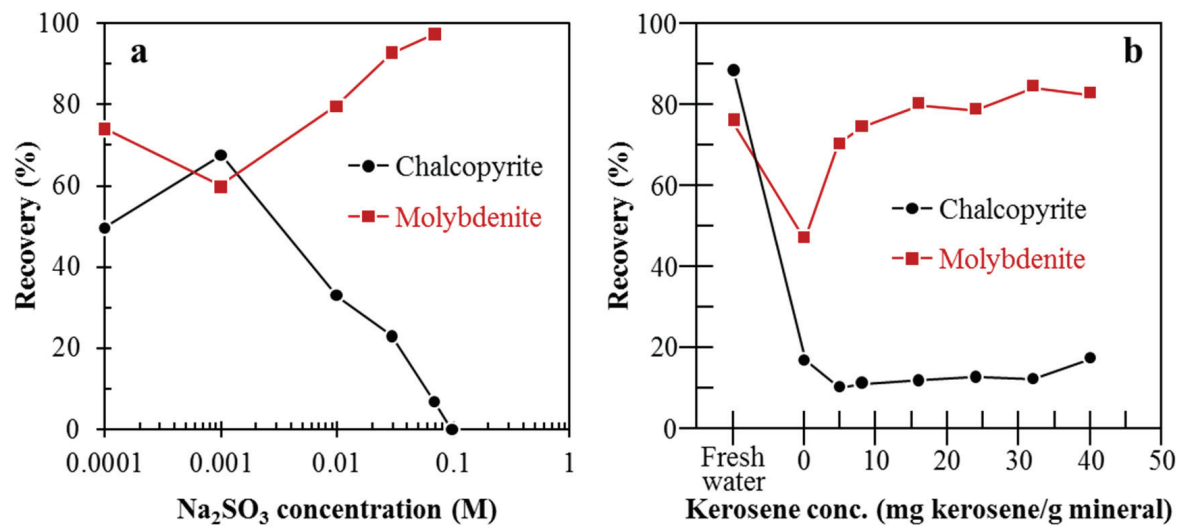

Figure 8. Recovery of chalcopyrite and molybdenite with varying concentrations of (a) $\mathrm{Na}_{2} \mathrm{SO}_{3}$ in TMD solution (mixture of TX15216 (alkyl mercaptan), MX-7017 (modified thionocarbamate), and diesel oil) [43] and (b) kerosene in $\mathrm{MgCl}_{2}$ solution (reprinted with permission from Hirajima et al. [54], copyright (2016) Elsevier).

Meanwhile, the change in molybdenite surface after $\mathrm{Na}_{2} \mathrm{SO}_{3}$ treatment was almost negligible, indicating that the molybdenite surface remained hydrophobic. These results support the potential of $\mathrm{Na}_{2} \mathrm{SO}_{3}$ as a $\mathrm{Cu}$ depressant for $\mathrm{Cu}-\mathrm{Mo}$ flotation separation. However, $\mathrm{Na}_{2} \mathrm{SO}_{3}$ does not always depress the floatability of chalcopyrite, but it can act as an activator depending on the state of the chalcopyrite surface. In the case of chalcopyrite, of which the surface is significantly covered with ferric oxyhydroxide, for example, the floatability of chalcopyrite is depressed to entrainment level (i.e., $<10 \%$ ) due to the presence of the hydrophilic nature of ferric oxyhydroxide on its surface. Meanwhile, the depressing effect of adsorbed ferric species is diminished when $\mathrm{Na}_{2} \mathrm{SO}_{3}$ is introduced because ferric species are reductively dissolved by $\mathrm{SO}_{3}{ }^{2-}$ (Equations (19) and (20)), resulting in the exposure of iron-deficient chalcopyrite [45]. Therefore, the use of $\mathrm{Na}_{2} \mathrm{SO}_{3}$ as a $\mathrm{Cu}$ depressant should be carefully designed to avoid the failure of $\mathrm{Cu}-\mathrm{Mo}$ separation.

$$
\begin{gathered}
\mathrm{SO}_{4}{ }^{2-}+\mathrm{H}_{2} \mathrm{O}+2 \mathrm{e}^{-} \rightarrow \mathrm{SO}_{3}{ }^{2-}+2 \mathrm{OH}^{-}, \mathrm{E}^{0}=-0.93 \mathrm{~V} \\
\mathrm{Fe}(\mathrm{OH})_{3}+\mathrm{e}^{-} \rightarrow \mathrm{Fe}(\mathrm{OH})_{2}+\mathrm{OH}^{-}, \mathrm{E}^{0}=-0.56 \mathrm{~V}
\end{gathered}
$$

In arid and semiarid regions where the supply of fresh water is limited, the use of seawater in mineral-processing plants is a sustainable option. However, seawater, a concentrated solution of $\mathrm{NaCl}$ (around $0.6 \mathrm{M}$ ) with various secondary ions (e.g., $0.41 \mathrm{~g} / \mathrm{L} \mathrm{Ca}^{2+}, 1.28 \mathrm{~g} / \mathrm{L} \mathrm{Mg}^{2+}, 2.71 \mathrm{~g} / \mathrm{L} \mathrm{SO}_{4}{ }^{2-}$, and $0.11 \mathrm{~g} / \mathrm{L} \mathrm{HCO}_{3}{ }^{-}$), significantly changes the flotation behavior of molybdenite [46-49]. For example, the floatability of chalcopyrite is not affected by types of water sources (i.e., fresh and sea water) in the $\mathrm{pH}$ range of $7.5-11.5$, but molybdenite is dramatically depressed in seawater when $\mathrm{pH}$ is higher than 9.5-10.0 [47,50-52]. This indicates that a significant amount of molybdenite is lost during rougher and cleaner flotation if the pulp $\mathrm{pH}$ is adjusted to $10-12$ by using lime for depressing pyrite [47]. The primary detrimental effect on molybdenite floatability is due to the adsorption of magnesium hydroxy complexes $\left(\mathrm{Mg}(\mathrm{OH})^{+}{ }_{(\mathrm{aq})}\right)$ and magnesium hydroxide precipitates $\left(\mathrm{Mg}(\mathrm{OH})_{2(\mathrm{~s})}\right)$, which start forming at a pH above around 9.5 [50]. Qui et al. [53] analyzed the surface of molybdenite conditioned in seawater at $\mathrm{pH} 11$ by using scanning electron microscopy (SEM), auger electron spectroscopy (AES), XPS, and ToF-SIMS, and confirmed that colloidal $\mathrm{Mg}(\mathrm{OH})_{2}$ and crystallized $\mathrm{CaCO}_{3}$ were deposited on the molybdenite surface. Meanwhile, Hirajima et al. [54] reported that $\mathrm{Mg}(\mathrm{OH})_{2}$ depressed not only molybdenite but also chalcopyrite at $\mathrm{pH}>9$. Similarly, Nagaraj and Farinato [55] also reported that both molybdenite and chalcopyrite floatability was decreased in $\mathrm{Mg}^{2+}$-containing solution at 
$\mathrm{pH}>9.5$ although the former was more strongly affected than the latter was. These indicate that seawater does not always show identical impact on $\mathrm{Cu}$ recovery, which changes depending on the type of used reagents and ore compositions [49]. In the case that both $\mathrm{Cu}$ and Mo were depressed by $\mathrm{Mg}(\mathrm{OH})_{2}$, Hirajima and coworkers [54] proposed the utilization of kerosene emulsion for the flotation separation of chalcopyrite and molybdenite in a $0.01 \mathrm{M} \mathrm{MgCl}_{2}$ solution (equivalent to about $243 \mathrm{mg} / \mathrm{L} \mathrm{Mg}^{2+}$ ). As shown in Figure 8b, the recoveries of chalcopyrite and molybdenite in $0.01 \mathrm{M}$ $\mathrm{MgCl}_{2}$ solution at $\mathrm{pH} 11$ decreased from $90 \%$ to $18 \%$ and from $75 \%$ to $50 \%$, respectively; however, molybdenite recovery was selectively improved with the addition of kerosene emulsion. Comparing the dynamic-force-microscopy (DFM) images of molybdenite surfaces conditioned in $0.01 \mathrm{M} \mathrm{MgCl}_{2}$ at $\mathrm{pH} 11$ with and without emulsified kerosene, the coverage of precipitate on molybdenite surface was apparently lower when kerosene was conditioned together. This is most likely because kerosene is a nonpolar oily collector that has strong affinity with molybdenite; thus, it is preferably adsorbed on the molybdenite surface, which limits the attachment of $\mathrm{Mg}(\mathrm{OH})_{2}$. The study of Suyantara et al. [49], a follow-up study of Hirajima et al. [54], reported that kerosene emulsion could also be used for improving $\mathrm{Cu}-\mathrm{Mo}$ flotation separation in artificial seawater. In the case that only molybdenite is depressed in seawater under alkaline conditions (i.e., $\mathrm{pH}$ 10-12), three options can be proposed: (1) the use of dispersants (e.g., sodium hexametaphosphate (SHMP)) to disperse seawater precipitates adsorbed on molybdenite surface [56,57]; (2) the removal of problematic ions (e.g., $\mathrm{Ca}^{2+}$ and $\mathrm{Mg}^{2+}$ ) using $\mathrm{Na}_{2} \mathrm{CO}_{3}$ and $\mathrm{CaO}$ prior to rougher/cleaner flotation [58]; and (3) the operation of rougher/cleaner flotation at a $\mathrm{pH}$ lower than 9.5 , where $\mathrm{Ca}^{2+} / \mathrm{Mg}^{2+}$ precipitations are limited, with alternative pyrite depressants that can act at $\mathrm{pH}<9.5$ [47].

\subsubsection{Organic Depressants}

Along with the investigation on inorganic depressants, there have been many studies on organic depressants; for example, pseudo-glycolythiourea acid (PGA) [59], 2,3-disulfanylbutanedioic acid (DMSA) [60], disodium bis (carboxymethyl) trithiocarbonate (DBT) [61], chitosan [62], 4-amino-3-thioxo-3,4-dihydro-1,2,4-triazin-5(2H)-one (ATDT) [66], and acetic acid-[(hydrazinylthioxomethyl)thio]-sodium (AHS) [67]. Chen and coworkers [59] used PGA (Figure 9a) and investigated its effect on $\mathrm{Cu}-\mathrm{Mo}$ separation. Under the optimized conditions, Mo recovery reached around $90 \%$ with a grade of $26 \%$ (original grade in feed $=0.4 \%$ ) via one rougher $\left(375 \mathrm{~g} / \mathrm{t} \mathrm{Na} \mathrm{NiO}_{3}\right.$, $4000 \mathrm{~g} / \mathrm{t} \mathrm{PGA}$, and $200 \mathrm{~g} / \mathrm{t}$ kerosene), one scavenger (500 g/t PGA and $200 \mathrm{~g} / \mathrm{t}$ kerosene), and two cleaners (62 g/t Na $\mathrm{SiO}_{3}, 1000 \mathrm{~g} / \mathrm{t}$, and $66 \mathrm{~g} / \mathrm{t}$ kerosene), where $\mathrm{Na}_{2} \mathrm{SiO}_{3}, \mathrm{PGA}$, and kerosene were used as a dispersant, $\mathrm{Cu}$ depressant, and Mo collector, respectively. Meanwhile, the recovery of $\mathrm{Cu}$ was around $0.7 \%$, and its grade decreased from $18 \%$ (Cu grade in feed) to $10 \%$ (Cu grade in concentrate), indicating that PGA could be used as a $\mathrm{Cu}$ depressant in $\mathrm{Cu}-\mathrm{Mo}$ flotation. To understand the mechanism of how PGA selectively depresses chalcopyrite, Chen et al. [59] conducted PGA adsorption tests with single minerals of chalcopyrite and molybdenite, and the results suggested that PGA was adsorbed on both minerals' surfaces, but the adsorption capacity of chalcopyrite was much larger compared to that of molybdenite. Infrared (IR) analyses of minerals after PGA adsorption tests indicated that the IR spectrum of PGA-adsorbed chalcopyrite was significantly changed with the appearance of new peaks (e.g., - $\mathrm{COOH}$ and - $\mathrm{CS}$ - of PGA), the disappearance of chalcopyrite peaks, and the great shift of $\mathrm{SO}_{4}{ }^{2-}$ peaks. These changes in IR signatures were most likely caused by the chemisorption between $\mathrm{S}$ atoms in PGA, the most reactive site based on its largest electron density of highest occupied molecular orbital (HOMO), and $\mathrm{Cu}$ atoms on the chalcopyrite surface. On the other hand, the IR spectrum of molybdenite showed only small shifts of absorption peaks less than $3 \mathrm{~cm}^{-1}$, which indicated that PGA is physically adsorbed on the surface of molybdenite. Even in the presence of butyl xanthate (BX), the most common collector for sulfide flotation, PGA could be adsorbed on chalcopyrite and molybdenite surfaces. The adsorption capacity of BX on both minerals' surfaces decreased as PGA concentration increased, which means that BX adsorption was limited due to the competitive adsorption between PGA and BX on chalcopyrite and molybdenite surfaces. Moreover, PGA has strong 
reducibility that can reduce dixanthogen molecules formed on chalcopyrite and molybdenite surfaces via the electrochemical reaction of $\mathrm{BX}$. Fermi energies $\left(E_{\mathrm{F}}\right)$ of PGA, molybdenite, and chalcopyrite are $-3.936,-4.138$, and $-5.433 \mathrm{eV}$, respectively. The direction of electron transition is always from a highto a low-energy level; thus, PGA preferably gave the electrons to chalcopyrite than to molybdenite when the two minerals coexisted.

(a)<smiles>N=C(N)SCC(=O)O</smiles>

(c)<smiles>O=C(O[Na])SC(=S)SC(=O)O[Na]</smiles>

(e)<smiles>Nn1c(=O)cn[nH]c1=S</smiles>

ATDT (b)<smiles>O=C(O)C(S)C(S)C(=O)O</smiles>

(d)

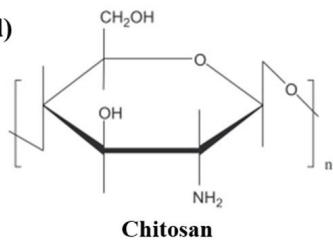

(f)<smiles>NNC(=S)SCC(=O)O</smiles>

AHS

Figure 9. Molecular structure of organic depressants: (a) pseudo-glycolythiourea acid (PGA), (b) 2,3-disulfanylbutanedioic acid (DMSA), (c) disodium bis (carboxymethyl) trithiocarbonate (DBT), (d) chitosan (reprinted with permission from Crini and Badot [65], copyright (2008) Elsevier), (e) 4-amino-3-thioxo-3,4-dihydro-1,2,4-triazin-5(2H)-one (ATDT), and (f) acetic acid-[(hydrazinylthioxomethyl)thio]-sodium (AHS).

A novel and selective depressant named DMSA was first used in the flotation of Cu-Mo sulfides by Li and coworkers [60]. As illustrated in Figure 9b, DMSA contains two carboxyl and two sulfhydryl groups. Adsorption tests showed that DMSA can be adsorbed more intensively on chalcopyrite than molybdenite can; that is, the adsorption capacities of DMSA on chalcopyrite and molybdenite were 0.29 and $0.05 \mathrm{mg} / \mathrm{g}$, respectively. According to the calculation based on frontier-molecular-orbital (FMO) theory, the largest electron density of HOMO is located on two $\mathrm{S}$ atoms, both of which actively interact with minerals. Additionally, it is interesting to note that the Fermi energies of DMSA, molybdenite, and chalcopyrite are $-5.573,-4.353$, and $-6.110 \mathrm{eV}$, respectively, which indicate that the electron transfer between DMSA and chalcopyrite, an essential process for the adsorption of organic with a strong reducibility, occurs more easily than that between DMSA and molybdenite, consistent with the adsorption results. A similar result was obtained from the study of Yin et al. [61] who used DBT as a depressant (Figure 9c). The IR spectrum of molybdenite after DBT treatment showed that the characteristic bands of DBT were not observed; however, the IR spectrum of DBT-treated chalcopyrite showed the appearance of new peaks of $\mathrm{C}=\mathrm{S}$ stretching, $\mathrm{C}-\mathrm{O}$ stretching, $\mathrm{CH}_{2}$ wagging, $\mathrm{CH}_{2}$ scissoring, and $\mathrm{C}-\mathrm{C}$ stretching, not observed in the IR spectrum of chalcopyrite without DBT treatment, indicating that DBT was notably adsorbed on the chalcopyrite surface. The DBT-treated chalcopyrite was further analyzed by XPS, and the C 1s and S 2p spectra also proved the presence of DBT on its surface. The $S$ $2 p_{3 / 2}$ peaks of DBT adsorbed on the chalcopyrite surface were shifted to higher binding energies than those of DBT, while the binding energies of $\mathrm{Cu} 2 \mathrm{p}_{3 / 2}$ and $\mathrm{Cu} 2 \mathrm{p}_{1 / 2}$ were shifted to lower positions after DBT was adsorbed. From these results, Yin and coworkers [61] concluded that $\mathrm{S}$ atoms in DBT 
(i.e., the electron donor) might interact with the $\mathrm{Cu}$ atoms in chalcopyrite (i.e., the electron acceptor). Due to the selective and strong affinity of DMSA and DBT with chalcopyrite, those organic compounds could be successfully used as a $\mathrm{Cu}$ depressant in $\mathrm{Cu}-\mathrm{Mo}$ flotation.

As such, organic depressants that contain $\mathrm{S}$ atom(s) as a constituent in their molecules, such as PGA, DMSA, and DBT, have the strong ability to selectively depress chalcopyrite in $\mathrm{Cu}-\mathrm{Mo}$ concentrates. Another attempt of using chitosan (Figure 9d) has also been made for the same purpose [62-64]. Chitosan, a natural biodegradable and nontoxic polyaminosaccharide, contains an amino functional group $\left(-\mathrm{NH}_{2}\right)$ known to have strong affinity with $\mathrm{Cu}^{2+}$, which implies that it can specifically interact with $\mathrm{Cu}$-bearing minerals. $\mathrm{Li}$ and coworkers [62] used chitosan as a $\mathrm{Cu}$ depressant in $\mathrm{Cu}-\mathrm{Mo}$ flotation. According to the result of single-mineral flotation, chitosan depressed both chalcopyrite and molybdenite, but it was effective in selectively depressing chalcopyrite when both minerals existed together in the pulp. This result could be explained by the competitive adsorption of chitosan between the two minerals, proved by adsorption isotherm tests, which showed that the adsorption density of chitosan on chalcopyrite was greater than that on molybdenite. As a result, chitosan could succeed in the selective flotation of molybdenite from $\mathrm{Cu}-\mathrm{Mo}$ concentrates, that is, the recoveries of molybdenite and chalcopyrite in the froth product were around $70 \%$ and $24 \%$, respectively. Furthermore, organic compounds that contained both amine- and thione-functional groups, such as ATDT (Figure 9e) and AHS (Figure 9f), were reported to be effective in depressing chalcopyrite due to bidentate coordination to $\mathrm{Cu}^{\mathrm{I} / \mathrm{II}}$ via $\mathrm{S}$ and $\mathrm{N}$ atoms to form a stable five-membered chelating ring (Figure 10) [66,67]. The selectivity index (SI) of $\mathrm{Mo} / \mathrm{Cu}$ in the absence of a depressant was around 1.44, but considerably improved to 2.98 with ATDT and to 5.77 with AHS.

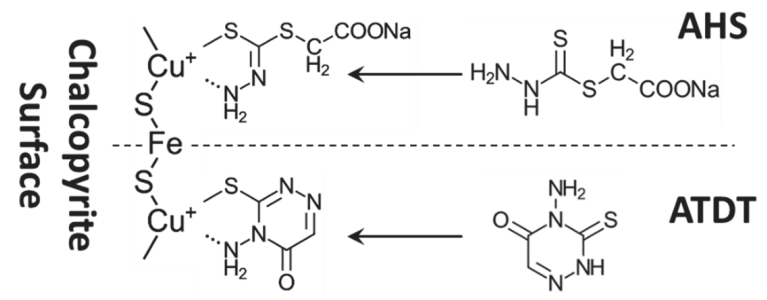

Figure 10. Proposed adsorption models of AHS and ATDT on chalcopyrite surface.

\subsection{Oxidation Treatments for Depressing Cu Minerals}

\subsubsection{Ozone Oxidation}

In the early 1990s, the application of ozone $\left(\mathrm{O}_{3}\right)$ for the depression of $\mathrm{Cu}$ minerals (e.g., chalcopyrite and chalcocite) and the selective recovery of molybdenite from $\mathrm{Cu}-\mathrm{Mo}$ bulk concentrates was studied $[68,69]$. Ozone, a strong oxidant, as illustrated in Equations (21) and (22), is widely used for water treatment due to its exceptional ability to oxidize organic compounds and to disinfect bacteria $[70,71]$.

$$
\begin{gathered}
\mathrm{O}_{3}+6 \mathrm{H}^{+}+6 \mathrm{e}^{-} \rightarrow 3 \mathrm{H}_{2} \mathrm{O}, \mathrm{E}^{0}=1.51 \mathrm{~V} \\
\mathrm{O}_{3}+2 \mathrm{H}^{+}+2 \mathrm{e}^{-} \rightarrow \mathrm{O}_{2}+\mathrm{H}_{2} \mathrm{O}, \mathrm{E}^{0}=2.07 \mathrm{~V}
\end{gathered}
$$

Moreover, the decomposition of ozone in water produces hydroxyl radicals (HO•) (Equation (23)), which are among the most reactive free radicals and among the strongest oxidants (Equation (24)) [71,72].

$$
\begin{gathered}
\mathrm{O}_{3}+\mathrm{H}_{2} \mathrm{O} \rightarrow 2 \mathrm{HO}^{\bullet}+\mathrm{O}_{2} \\
\mathrm{HO}^{\bullet}+\mathrm{H}^{+}+\mathrm{e}^{-} \rightarrow \mathrm{H}_{2} \mathrm{O}, \mathrm{E}^{0}=2.33 \mathrm{~V}
\end{gathered}
$$


In the typical flotation process of $\mathrm{Cu}-\mathrm{Mo}$ ores (Figure 2), the flotation separation of $\mathrm{Cu}$ and $\mathrm{Mo}$ from $\mathrm{Cu}-\mathrm{Mo}$ bulk concentrates is achieved by using $\mathrm{NaHS}$, which desorbs the adsorbed xanthate on the chalcopyrite surface, that is, chalcopyrite becomes unrecoverable as a froth product while molybdenite is selectively floated and recovered. Although xanthates are known as weak collectors of molybdenite, it can also be adsorbed on the surface of molybdenite [73]. However, the molybdenite surface is naturally hydrophobic, so even in the absence of xanthate on its surface, molybdenite is still floatable with nonpolar oily collectors (e.g., diesel oil and kerosene), which makes the desorption of xanthate by NaHS strongly affect the floatability of chalcopyrite rather than that of molybdenite. Similar to $\mathrm{NaHS}$, the utilization of ozone, having strong potential to oxidize organic compounds, can improve $\mathrm{Cu}-\mathrm{Mo}$ flotation separation by destroying xanthate adsorbed onto the mineral surface. Ye et al. [69] utilized ozone as a conditioning process for $\mathrm{Cu}-\mathrm{Mo}$ separation, and reported that ozone conditioning oxidized all tested minerals (e.g., chalcocite, chalcopyrite, and molybdenite), leading to their floatability lowering. However, $\mathrm{Cu}$ minerals are more sensitive to ozone compared to molybdenite, so the selective depression of $\mathrm{Cu}$ minerals is possible by employing ozone-based oxidation treatment. For example, a flotation circuit that consists of a rougher flotation with ozone conditioning for $2 \mathrm{~min}$, followed by a cleaner flotation after $3 \mathrm{~min}$ of ozone treatment of low-grade $\mathrm{Cu}-\mathrm{Mo}$ concentrate $(0.25 \% \mathrm{Mo})$, can produce a Mo concentrate of which grade and recovery are $26 \%$ and $82.5 \%$, respectively [69]. After rougher flotation, $10.5 \%$ of molybdenite still remained in rougher tailing, which was further conditioned with ozone for $1 \mathrm{~min}$, followed by scavenger flotation. The distributions of Mo in scavenger concentrate and cleaner tailings are $9.4 \%$ and $7.0 \%$, respectively, indicating that overall Mo recovery would be expected to reach $98.9 \%$ when they were reintroduced to the process (denoted as dotted lines in Figure 11).

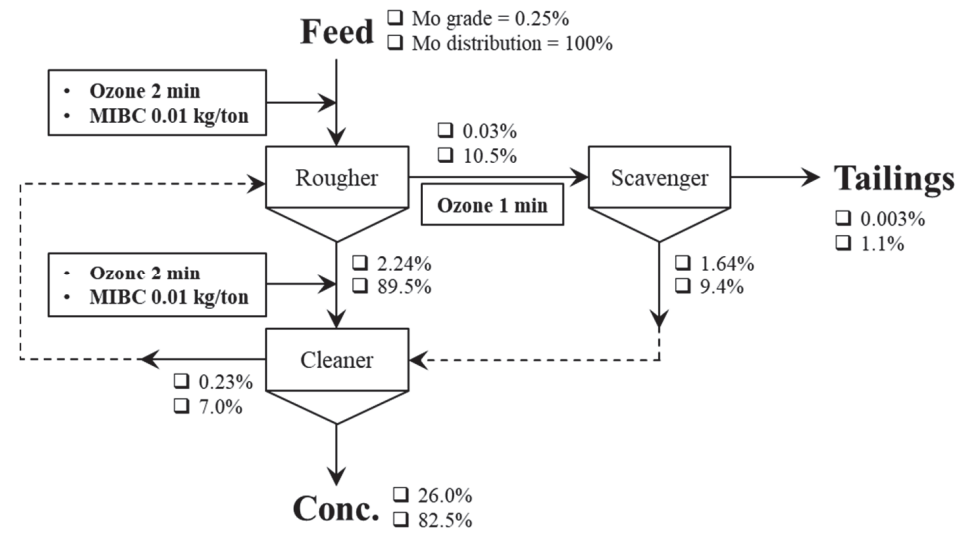

Figure 11. Flowsheet for selective flotation of molybdenite from $\mathrm{Cu}-\mathrm{Mo}$ concentrates using three-stage ozone conditioning. Dotted lines represent possible recycle streams (reprinted with permission from Ye et al. [69], copyright (1990) Springer Nature).

\subsubsection{Plasma Oxidation}

Similarly, Hirajima et al. [74] examined oxidation treatment using plasma as a conditioning process for the selective flotation of chalcopyrite and molybdenite. After $10 \mathrm{~min}$ treatment of chalcopyrite with plasma at $10 \mathrm{~W}$, AFM images showed that the chalcopyrite surface became rough $(3.979 \mathrm{~nm})$ compared to the one without plasma treatment $(1.280 \mathrm{~nm})$, and there was no significant effect of washing on the change in surface roughness (Figure 12). In the case of molybdenite, its surface roughness increased from 3.797 to $5.176 \mathrm{~nm}$ after plasma treatment $(10 \mathrm{~W})$ for $10 \mathrm{~min}$, but it became smooth when washing followed; that is, the washing of plasma-treated molybdenite for 30, 60, and $120 \mathrm{~min}$ decreased its surface roughness to $4.263,3.484$, and $3.289 \mathrm{~nm}$, respectively. The presence of reaction products on the 
surfaces of chalcopyrite and molybdenite after plasma treatment significantly affected their floatability. As shown in Figure 13a, the recovery of untreated chalcopyrite and molybdenite was around 90\%, but dramatically decreased to $10-30 \%$ after plasma treatment. Washing following could improve the floatability of molybdenite treated with plasma, whereas chalcopyrite recovery was kept constant regardless of washing. To clarify the flotation behaviors of chalcopyrite and molybdenite with plasma treatment followed by washing, Hirajima et al. [74] conducted XPS analysis of plasma-treated minerals with various washing times. The result of XPS analysis of plasma-treated molybdenite showed that it was covered with molybdenum(VI) oxide $\left(\mathrm{MoO}_{3}\right)$; however, the peaks of $\mathrm{MoO}_{3}$ in $\mathrm{Mo} 3 \mathrm{~d}$ and $\mathrm{O}$ $1 \mathrm{~s}$ spectra were lowered after washing. In the case of plasma-treated chalcopyrite, its surface was covered with goethite $(\mathrm{FeOOH})$ and iron(III) sulfate $\left(\mathrm{Fe}_{2}\left(\mathrm{SO}_{4}\right)_{3}\right)$, both of which are oxidation products of chalcopyrite having hydrophilic properties. After washing, the peaks of iron(III) sulfate disappeared, while goethite still remained on the surface of chalcopyrite. This is the reason why the floatability of plasma-treated chalcopyrite did not increase even after washing for $120 \mathrm{~min}$. Washing cannot improve molybdenite floatability when both minerals are treated together by plasma. This might be due to iron ions (e.g., $\mathrm{Fe}^{2+}$ and/or $\mathrm{Fe}^{3+}$ ) being released from chalcopyrite that are precipitated on the surface of not only chalcopyrite but also molybdenite, reducing the hydrophobicity of both minerals. To overcome this limited recovery of molybdenite, Hirajima and coworkers [74] investigated the addition of kerosene, a commonly used reagent for Mo flotation. As a result of the addition of $25 \mu \mathrm{L}$ emulsified kerosene, molybdenite recovery increased from around $40 \%$ to $80 \%$, while it had a negligible effect on chalcopyrite recovery, increasing from $20 \%$ to $30 \%$.

(a)

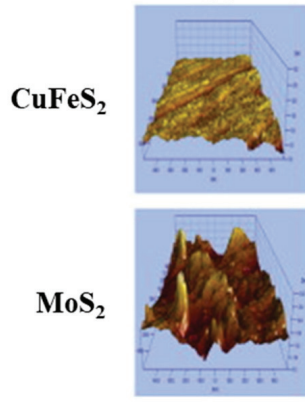

Fresh (b)
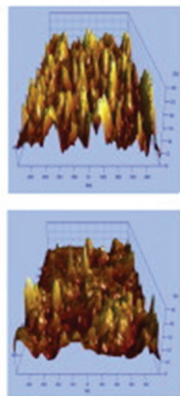

0 (c)
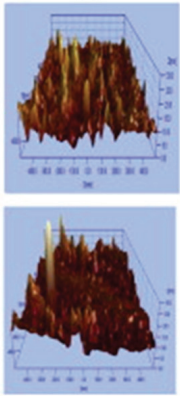

30 (d)
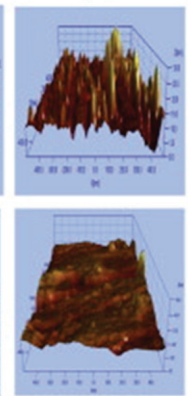

60 (e)

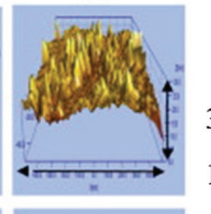

$30 \mathrm{~nm}$

$1000 \mathrm{~nm}$

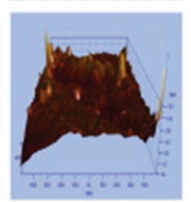

120

Washing time after plasma treatment (min)

Figure 12. AFM images of chalcopyrite and molybdenite: (a) untreated samples and one treated with plasma at $10 \mathrm{~W}$ for $10 \mathrm{~min}$ followed by washing by pH 9 solution for (b) 0, (c) 30, (d) 60, and (e) $120 \mathrm{~min}$ (reprinted with permission from Hirajima et al. [74], copyright (2014) Elsevier). 


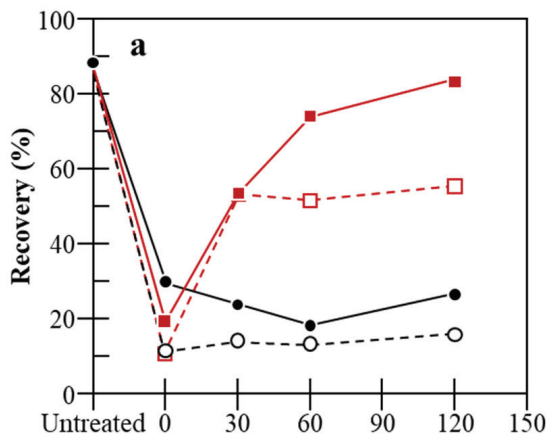

Washing time after plasma treatment (min)

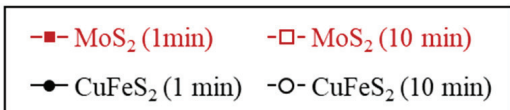

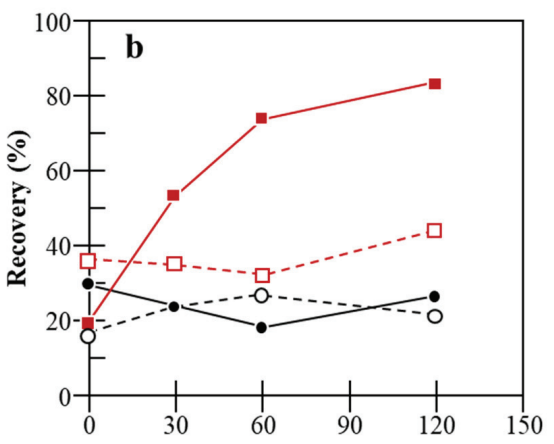

Washing time after plasma treatment (min)

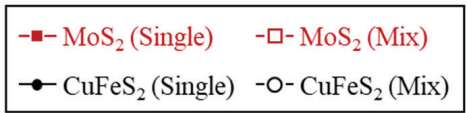

Figure 13. Flotation recovery of chalcopyrite and molybdenite treated (a) with and without $10 \mathrm{~W}$ plasma for 1 or $10 \mathrm{~min}$ followed by washing (single system), and (b) with $10 \mathrm{~W}$ plasma for $1 \mathrm{~min}$ followed by washing (single and mixed system) (reprinted with permission from Hirajima et al. [74], copyright (2014) Elsevier).

\subsection{3. $\mathrm{H}_{2} \mathrm{O}_{2}$ Oxidation}

Although plasma treatment for $\mathrm{Cu}-\mathrm{Mo}$ ores prior to flotation was effective in improving the separation of chalcopyrite and molybdenite, its application on an industrial scale remains difficult to realize [75]. Because of this limitation, Hirajima and coworkers [13] examined another oxidation process using hydrogen peroxide $\left(\mathrm{H}_{2} \mathrm{O}_{2}\right)$, which acts as an oxidant under acidic conditions (Equation (25)), but behaves as a reductant under alkaline conditions (Equation (26)).

$$
\begin{gathered}
\mathrm{H}_{2} \mathrm{O}_{2}+2 \mathrm{H}^{+}+2 \mathrm{e}^{-} \rightarrow 2 \mathrm{H}_{2} \mathrm{O}, \mathrm{E}^{0}=1.78 \mathrm{~V} \\
\mathrm{H}_{2} \mathrm{O}_{2} \rightarrow 2 \mathrm{H}^{+}+\mathrm{O}_{2}+2 \mathrm{e}^{-}, \mathrm{E}^{0}=-0.68 \mathrm{~V}
\end{gathered}
$$

Moreover, $\mathrm{H}_{2} \mathrm{O}_{2}$ can produce hydroxyl and hydroperoxyl radicals $\left(\mathrm{HO}^{\bullet}\right.$ and $\mathrm{HOO}^{\bullet}$, respectively) acting as powerful oxidizing agents in the presence of iron ions (e.g., $\mathrm{Fe}^{2+}$ and $\mathrm{Fe}^{3+}$ ) via Fenton $\left(\mathrm{Fe}^{2+} / \mathrm{H}_{2} \mathrm{O}_{2}\right)$ and Fenton-like $\left(\mathrm{Fe}^{3+} / \mathrm{H}_{2} \mathrm{O}_{2}\right)$ reactions, as shown in the following equations:

$$
\begin{aligned}
& \mathrm{Fe}^{2+}+\mathrm{H}_{2} \mathrm{O}_{2} \rightarrow \mathrm{Fe}^{3+}+\mathrm{HO}^{\bullet}+\mathrm{OH}^{-}, \\
& \mathrm{Fe}^{3+}+\mathrm{H}_{2} \mathrm{O}_{2} \rightarrow \mathrm{Fe}^{2+}+\mathrm{HOO}^{\bullet}+\mathrm{H}^{+} .
\end{aligned}
$$

After 10 min treatment of chalcopyrite using $0.1 \% \mathrm{H}_{2} \mathrm{O}_{2}$, the floatability of chalcopyrite decreased from $85 \%$ to $19 \%$, most likely due to the formation of hydrophilic oxidation products (e.g., $\mathrm{CuO}, \mathrm{Cu}(\mathrm{OH})_{2}$, $\mathrm{FeOOH}$, and $\left.\mathrm{Fe}_{2}\left(\mathrm{SO}_{4}\right)_{3}\right)$ on the chalcopyrite surface. Meanwhile, the floatability of molybdenite was not affected by $\mathrm{H}_{2} \mathrm{O}_{2}$ treatment (the recoveries of untreated and $\mathrm{H}_{2} \mathrm{O}_{2}$-treated molybdenite were $73 \%$ and $79 \%$, respectively) because the oxidation products of molybdenite (e.g., $\mathrm{MoO}_{2}$ and $\mathrm{MoO}_{3}$ ) are soluble under alkaline conditions. Hirajima et al. [13] also compared the effectiveness of oxidation treatments using ozone and $\mathrm{H}_{2} \mathrm{O}_{2}$ on $\mathrm{Cu}-\mathrm{Mo}$ flotation separation, and it was confirmed that $\mathrm{H}_{2} \mathrm{O}_{2}$ treatment showed better separation efficiency compared to that of ozone treatment because ozone reduced the recovery of not only chalcopyrite (from $85 \%$ to $28 \%$ ), but also molybdenite (from $73 \%$ to $53 \%$ ). Although effective, the application of $\mathrm{H}_{2} \mathrm{O}_{2}$ treatment to $\mathrm{Cu}-\mathrm{Mo}$ bulk concentrates with high pulp density (around 50\%) has some drawbacks compared to the NaHS method: (1) molybdenite 
recovery by $\mathrm{H}_{2} \mathrm{O}_{2}$-based flotation is lower than that of conventional flotation process using NaHS; (2) it requires a prolonged treatment of around $4.5 \mathrm{~h}$ to effectively depress the floatability of chalcopyrite, while 10 min is enough for the NaHS method; and (3) it uses a high concentration of $\mathrm{H}_{2} \mathrm{O}_{2}$ (i.e., $2 \%$ ), which makes $\mathrm{H}_{2} \mathrm{O}_{2}$-based flotation costly [75]. To overcome these limitations of $\mathrm{H}_{2} \mathrm{O}_{2}$ oxidation treatment, Suyantara and coworkers [75] investigated the simultaneous use of $\mathrm{H}_{2} \mathrm{O}_{2}$ and FeSO 4 , which can stimulate a Fenton-like reaction. In an alkaline solution, $\mathrm{FeSO}_{4}$ releases $\mathrm{Fe}^{2+}$, which is then transformed into iron oxyhydroxide (goethite, $\alpha$-FeOOH; lepidocrocite, $\gamma$-FeOOH) and/or ferrihydrite, where a Fenton-like reaction occurs in the presence of $\mathrm{H}_{2} \mathrm{O}_{2}$ as shown in the following equations [76]:

$$
\begin{gathered}
\equiv \mathrm{Fe}^{\mathrm{III}}-\mathrm{OH}+\mathrm{H}_{2} \mathrm{O}_{2} \rightarrow\left(\mathrm{H}_{2} \mathrm{O}_{2}\right)_{\mathrm{s}} \\
\left(\mathrm{H}_{2} \mathrm{O}_{2}\right)_{\mathrm{s}} \rightarrow \equiv \mathrm{Fe}^{\mathrm{II}}+\mathrm{H}_{2} \mathrm{O}+\mathrm{HOO}^{\bullet} \\
\equiv \mathrm{Fe}^{\mathrm{II}}+\mathrm{H}_{2} \mathrm{O}_{2} \rightarrow \equiv \mathrm{Fe}^{\mathrm{III}}-\mathrm{OH}+\mathrm{HO}^{\bullet} \\
\mathrm{HOO}^{\bullet} \rightarrow \mathrm{H}^{+}+\mathrm{O}_{2}^{\bullet-} \\
\equiv \mathrm{Fe} \mathrm{III}_{-} \mathrm{OH}+\mathrm{HOO}^{\bullet} / \mathrm{O}_{2}^{\bullet-} \rightarrow \equiv \mathrm{Fe}^{\mathrm{II}}+\mathrm{H}_{2} \mathrm{O} / \mathrm{OH}^{-}+\mathrm{O}_{2} .
\end{gathered}
$$

According to $\mathrm{Li}$ et al. [77], who evaluated the decomposition rate of $\mathrm{H}_{2} \mathrm{O}_{2}$ in the absence and presence of $\mathrm{FeOOH}$, it was confirmed that the addition of $\mathrm{FeOOH}$ significantly enhanced $\mathrm{H}_{2} \mathrm{O}_{2}$ decomposition compared to the one without $\mathrm{FeOOH}$. Suyantara et al. [75], who used $\mathrm{H}_{2} \mathrm{O}_{2}$ with $\mathrm{FeSO}_{4}$ for the oxidation treatment of $\mathrm{Cu}-\mathrm{Mo}$ bulk concentrates prior to flotation, confirmed that the addition of $\mathrm{FeSO}_{4}$ could reduce the amount of added $\mathrm{H}_{2} \mathrm{O}_{2}$ from $2.0 \%$ to $0.5 \%$ and treatment time from $4.5 \mathrm{~h}$ to $5 \mathrm{~min}$. Due to these positive effects of $\mathrm{FeSO}_{4}$ addition to $\mathrm{H}_{2} \mathrm{O}_{2}$ oxidation treatment, the process of using $\mathrm{H}_{2} \mathrm{O}_{2}$ and $\mathrm{FeSO}_{4}$ is predicted to reduce operating costs, that is, the costs for $\mathrm{NaHS}_{2} \mathrm{H}_{2} \mathrm{O}_{2}$, and $\mathrm{H}_{2} \mathrm{O}_{2} / \mathrm{FeSO}_{4}$ methods were calculated to approximately 20,100, and $15 \mathrm{USD} / \mathrm{t}$, respectively [75].

\subsubsection{Electrolysis Oxidation}

The electrical resistivities of chalcopyrite and molybdenite are $234 \Omega$ and $1.2-1.5 \mathrm{M} \Omega$, respectively, which means that chalcopyrite is more electrochemically active than molybdenite is [78]. From the difference in the minerals' electrical resistivity, Miki et al. [78] attempted to apply electrolysis, a technique that applies a fixed potential in which mineral undergoes oxidation process(es) to selectively render the chalcopyrite surface hydrophilic. Anodic polarization results at an applied potential of $1.2 \mathrm{~V}$ showed that a high current density of chalcopyrite electrodes (around $0.4 \mathrm{~mA} / \mathrm{m}^{2}$ ) was observed, indicating that the oxidation of chalcopyrite was actively progressed, as shown in the following equation:

$$
\mathrm{CuFeS}_{2}+8 \mathrm{H}_{2} \mathrm{O} \rightarrow \mathrm{Cu}^{2+}+\mathrm{Fe}^{2+}+2 \mathrm{SO}_{4}{ }^{2-}+16 \mathrm{H}^{+}+16 \mathrm{e}^{-}
$$

On the other hand, the current density of molybdenite electrodes was around $0.05-0.15 \mathrm{~mA} / \mathrm{m}^{2}$, substantially lower compared to that of chalcopyrite. This most likely resulted from the high resistivity of molybdenite, which makes it difficult to be oxidized. After treating chalcopyrite and molybdenite electrodes by electrolysis oxidation at $1.2 \mathrm{~V}$ for $800 \mathrm{~s}$, the contact angle of chalcopyrite changed from $71.7^{\circ}$ to $42.4^{\circ}$, whereas there was almost no effect on the contact angle of molybdenite, changing from $68.6^{\circ}$ to $67.0^{\circ}$. The contact-angle results indicate that electrolysis treatment could selectively convert the wettability of chalcopyrite from hydrophobic to hydrophilic. Although flotation tests of electrolysis-treated chalcopyrite/molybdenite were not conducted, electrolysis oxidation is in a promising state as pretreatment for improving the selective flotation of molybdenite from $\mathrm{Cu}-\mathrm{Mo}$ concentrates.

\subsection{Microencapsulation Techniques for Depressing Cu Minerals}

As discussed in Section 3.3.4, chalcopyrite and molybdenite have different electrical resistivities, which means that the depression techniques involved in electrochemical processes have the potential to 
be applied to $\mathrm{Cu}-\mathrm{Mo}$ flotation separation. For example, the authors studied carrier microencapsulation (CME), a technique that creates metal-oxyhydroxide coatings on the surfaces of semiconducting minerals such as pyrite and arsenopyrite (FeAsS) [79-84]. In CME, metal ions (e.g., $\mathrm{Al}^{3+}, \mathrm{Fe}^{3+}, \mathrm{Si}^{4+}$, and $\mathrm{Ti}^{4+}$ ) and the organic carrier (e.g., catechol, 1,2-dihydroxybenzene, and $\left.\mathrm{C}_{6} \mathrm{H}_{4}(\mathrm{OH})_{2}\right)$ are used, and they produce various forms of metal-catecholate complexes (e.g., $\left[\mathrm{Al}(\mathrm{cat})_{n}\right]^{3-2 \mathrm{n}},\left[\mathrm{Fe}(\mathrm{cat})_{n}\right]^{3-2 n}$, $\left[\mathrm{Si}(\mathrm{cat})_{3}\right]^{2-}$ and $\left[\mathrm{Ti}(\mathrm{cat})_{3}\right]^{2-}$, where $\mathrm{n}$ is $\left.1-3\right)$. These complexes undergo oxidative decomposition only on the surface of semiconducting minerals such as pyrite and arsenopyrite (FeAsS), and metal ions released from the complexes are then precipitated as metal oxyhydroxides (Figure 14). Similar to CME, other microencapsulation techniques involved in electrochemical process(es) are most likely able to selectively form hydrophilic coatings on the surface of chalcopyrite having relatively low electrical resistivity, while the molybdenite surface is not covered with the coatings because it is hard for electrochemical reactions to occur on its surface. Although there is no study on this topic, it is of importance to develop environmentally friendly processes for $\mathrm{Cu}-\mathrm{Mo}$ flotation separation.

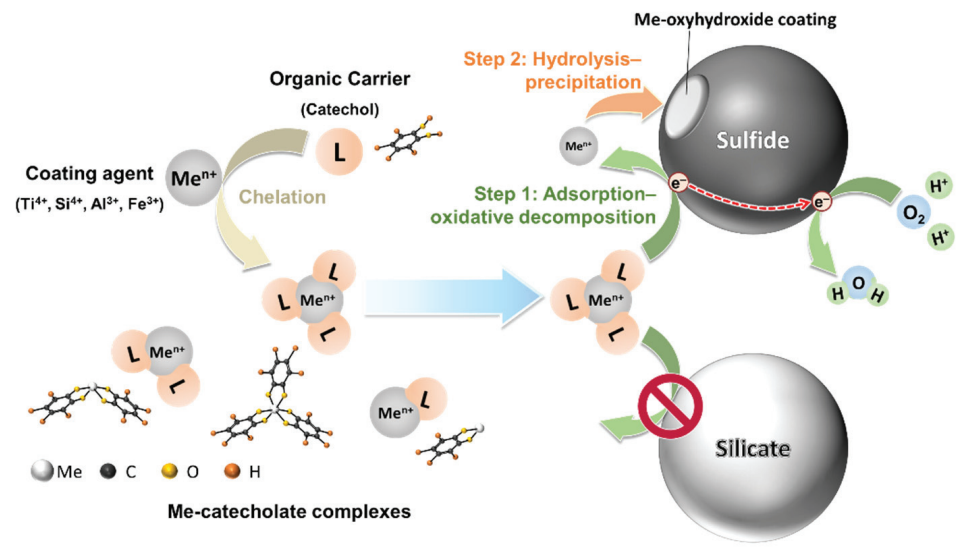

Figure 14. Schematic diagram of carrier microencapsulation (reprinted with permission from Park et al. [83], copyright (2019) Elsevier).

\section{Summary}

Porphyry copper deposits are one of the most important sources of copper and molybdenum. The separation/recovery of copper and molybdenum from these deposits is typically processed by a flotation series, that is, bulk flotation to remove gangue minerals and produce $\mathrm{Cu}-\mathrm{Mo}$ concentrates that are then processed by $\mathrm{Cu}-\mathrm{Mo}$ flotation to separate them. In $\mathrm{Cu}-\mathrm{Mo}$ flotation, various types of $\mathrm{Cu}$ depressants (e.g., $\mathrm{NaHS}, \mathrm{Na}_{2} \mathrm{~S}$, Nokes reagent, and $\mathrm{NaCN}$ ) have been adopted for selective depression of $\mathrm{Cu}$ minerals. However, these reagents are potentially dangerous due to the possibility of emitting toxic and deadly gases, such as $\mathrm{H}_{2} \mathrm{~S}$ and $\mathrm{HCN}$, when operating conditions are not properly controlled. To avoid accidents caused by the use of conventional $\mathrm{Cu}$ depressants, there are many studies on the utilization of environmentally friendly depressants for molybdenite or chalcopyrite, and oxidation treatments for chalcopyrite.

For the depression of molybdenite, various organic compounds, such as dextrin, lignosulfonate, O-carboxymethyl chitosan, carboxymethyl cellulose, and humic acid, were adopted. Molybdenite is well-known to have strong hydrophobicity, so those organic compounds are favorably and selectively adsorbed on the molybdenite surface via hydrophobic interactions. The utilization of Mo depressants is effective for the separation of $\mathrm{Cu}$ and Mo minerals, but there is a serious drawback, lowering the purity of froth products. This is because the content of molybdenite in PCDs is substantially lower than that of chalcopyrite, so the strategy of recovering chalcopyrite with the depression of molybdenite can cause the mechanical entrainment of molybdenite within a large volume of $\mathrm{Cu}$ concentrate, which 
lowers the grade of $\mathrm{Cu}$ concentrate and leads to appreciable loss of molybdenite. Another option for $\mathrm{Cu}-\mathrm{Mo}$ flotation separation is to depress $\mathrm{Cu}$ minerals while recovering molybdenite. For this, alternative organic/inorganic depressants were extensively examined. Moreover, oxidation treatments using ozone, plasma, $\mathrm{H}_{2} \mathrm{O}_{2}$, and electrolysis to destroy adsorbed xanthate and/or to create hydrophilic coatings on the surface of chalcopyrite were studied. The obtained results are promising for $\mathrm{Cu}-\mathrm{Mo}$ separation; however, there still remain important topics on the optimization and scaling-up of the process that are necessary for the application of newly developed depression techniques to actual $\mathrm{Cu}-\mathrm{Mo}$ flotation separation.

Author Contributions: Conceptualization, I.P., S.H., S.J., M.I., and N.H.; writing-original-draft preparation, I.P.; writing-review and editing, I.P., S.H., S.J., M.I., and N.H.; visualization, I.P. All authors have read and agreed to the published version of the manuscript.

Funding: This research was financially supported by Japan Oil, Gas, and Metals National Corporation (JOGMEC).

Conflicts of Interest: The authors declare no conflict of interest.

\section{References}

1. John, D.A.; Ayuso, R.A.; Barton, M.D.; Blakely, R.J.; Bodnar, R.J.; Dilles, J.H.; Gray, F.; Graybeal, F.T.; Mars, J.C.; McPhee, D.K.; et al. Porphyry Copper Deposit Model: Chapter B of Mineral Deposit Models for Resource Assessment; Scientific Investigations Report 2010-5070-B; US Geological Survey: Menlo Park, CA, USA, 2010; 169p.

2. John, D.A.; Taylor, R.D. By-products of porphyry copper and molybdenum deposits. Rev. Econ. Geol. 2016, 18, 137-164.

3. Lee, C.-T.A.; Tang, M. How to make porphyry copper deposits. Earth Planet. Sci. Lett. 2020, 529, 115868. [CrossRef]

4. Seedorff, E.; Dilles, J.H.; Proffett, J.M., Jr.; Einaudi, M.T.; Zurcher, L.; Stavast, W.J.A.; Johnson, D.A.; Barton, M.D. Porphyry deposits: Characteristics and origin of hypogene features. Econ. Geol. 2005, 100, 251-298.

5. Sinclair, W.D. Porphyry deposits. In Mineral Deposits of Canada: A Synthesis of Major Deposit-Types, District Metallogeny, the Evolution of Geological Provinces, and Exploration Methods, Geological Association of Canada, Mineral Deposits Division; Goodfellow, W.D., Ed.; Special Publication: London, UK, 2007; Volume 5, pp. 223-243.

6. Bulatovic, S.M. 12-Flotation of Copper Sulfide Ores. In Handbook of Flotation Reagents; Bulatovic, S.M., Ed.; Elsevier: Amsterdam, The Netherlands, 2007; pp. 235-293, ISBN 978-0-444-53029-5.

7. Amelunxen, P.; Schmitz, C.; Hill, L.; Goodweiler, N.; Andres, J. Molybdenum. In SME Mineral Processing E Extractive Metallurgy Handbook; Dunne, R.C., Komar Kawatra, S., Young, C.A., Eds.; Society for Mining, Metallurgy \& Exploration (SME): Littleton, CO, USA, 2019; Volume 2, pp. 1891-1916.

8. Liu, G.; Lu, Y.; Zhong, H.; Cao, Z.; Xu, Z. A novel approach for preferential flotation recovery of molybdenite from a porphyry copper-molybdenum ore. Miner. Eng. 2012, 36, 37-44. [CrossRef]

9. Peterson, J.A.; Saran, M.S.; Wisnouskas, J.S. Differential Flotation Reagent for Molybdenum Separation. U.S. Patent No. 4,575,419, 11 March 1986.

10. Yin, Z.; Sun, W.; Hu, Y.; Zhai, J.; Qingjun, G. Evaluation of the replacement of NaCN with depressant mixtures in the separation of copper-molybdenum sulphide ore by flotation. Sep. Purif. Technol. 2017, 173, 9-16. [CrossRef]

11. Sutherland, K.L.; Wark, I.W. Principles of Flotation, 2nd ed.; Australasian Inst. Mining \& Metallurgy: Melbourne, Australia, 1955

12. Mu, Y.; Peng, Y.; Lauten, R.A. The depression of pyrite in selective flotation by different reagent systems-A literature review. Miner. Eng. 2016, 96-97, 143-156. [CrossRef]

13. Hirajima, T.; Miki, H.; Suyantara, G.P.W.; Matsuoka, H.; Elmahdy, A.M.; Sasaki, K.; Imaizumi, Y.; Kuroiwa, S. Selective flotation of chalcopyrite and molybdenite with $\mathrm{H}_{2} \mathrm{O}_{2}$ oxidation. Miner. Eng. 2017, 100, 83-92. [CrossRef]

14. Napier-Munn, T.; Wills, B.A. Wills' Mineral Processing Technology: An Introduction to the Practical Aspects of Ore Treatment and Mineral Recovery, 7th ed.; Butterworth-Heinemann: Oxford, UK, 2006. 
15. Zhao, Q.; Liu, W.; Wei, D.; Wang, W.; Cui, B.; Liu, W. Effect of copper ions on the flotation separation of chalcopyrite and molybdenite using sodium sulfide as a depressant. Miner. Eng. 2018, 115, 44-52. [CrossRef]

16. Guo, B.; Peng, Y.; Espinosa-Gomez, R. Cyanide chemistry and its effect on mineral flotation. Miner. Eng. 2014, 66-68, 25-32. [CrossRef]

17. Sinozaki, H.; Hara, R.; Mitsukuri, S. The vapour pressures of hydrogen cyanide. Bull. Chem. Soc. Jpn. 1926, 1, 59-61. [CrossRef]

18. Stull, D.R. Vapor pressure of pure substances. Organic and inorganic compounds. Ind. Eng. Chem. 1947, 39, 517-540. [CrossRef]

19. Milby, T.H.; Baselt, R.C. Hydrogen sulfide poisoning: Clarification of some controversial issues. Am. J. Ind. Med. 1999, 35, 192-195. [CrossRef]

20. National Research Council. Acute Exposure Guideline Levels for Selected Airborne Chemicals: Volume 2; The National Academies Press: Washington, DC, USA, 2002. [CrossRef]

21. Johnston, A.; Meadows, D.G.; Cappuccitti, F. Copper mineral processing. In SME Mineral Processing $\mathcal{E}$ Extractive Metallurgy Handbook; Dunne, R.C., Komar Kawatra, S., Young, C.A., Eds.; Society for Mining, Metallurgy \& Exploration (SME): Littleton, CO, USA, 2019; Volume 2, pp. 1615-1642.

22. Hernlund, R.W. Extraction of molybdenite from copper flotation products. Q. J. Colo. Sch. Mines 1961, 56, 177-196.

23. Blanco, M.; Coello, J.; Iturriaga, H.; Maspoch, S.; González Bañó, R. On-line monitoring of starch enzymatic hydrolysis by near-infrared spectroscopy. Analyst 2000, 125, 749-752. [CrossRef]

24. Wie, J.M.; Fuerstenau, D.W. The effect of dextrin on surface properties and the flotation of molybdenite. Int. J. Miner. Process. 1974, 1, 17-32. [CrossRef]

25. Beaussart, A.; Mierczynska-Vasilev, A.; Beattie, D.A. Adsorption of dextrin on hydrophobic minerals. Langmuir 2009, 25, 9913-9921. [CrossRef]

26. Jorjani, E.; Barkhordari, H.R.; Tayebi Khorami, M.; Fazeli, A. Effects of aluminosilicate minerals on copper-molybdenum flotation from Sarcheshmeh porphyry ores. Miner. Eng. 2011, 24, 754-759. [CrossRef]

27. Ansari, A.; Pawlik, M. Floatability of chalcopyrite and molybdenite in the presence of lignosulfonates. Part I. Adsorption studies. Miner. Eng. 2007, 20, 600-608. [CrossRef]

28. Ansari, A.; Pawlik, M. Floatability of chalcopyrite and molybdenite in the presence of lignosulfonates. Part II. Hallimond tube flotation. Miner. Eng. 2007, 20, 609-616. [CrossRef]

29. Buza, T.B.; Hiscox, T.O.; Kuhn, M.C. Use of lignin sulphonate as moly depressant boosts recovery at Twin Buttes. Eng. Min. J. 1975, 176, 87-91.

30. Mathieu, G.; Bruce, R. Getting the talc out of molybdenite ores. Can. Min. J. 1974, 95, 75-77.

31. Yuan, D.; Cadien, K.; Liu, Q.; Zeng, H. Separation of talc and molybdenite: Challenges and opportunities. Miner. Eng. 2019, 143, 105923. [CrossRef]

32. Yuan, D.; Cadien, K.; Liu, Q.; Zeng, H. Flotation separation of Cu-Mo sulfides by O-Carboxymethyl chitosan. Miner. Eng. 2019, 134, 202-205. [CrossRef]

33. Yuan, D.; Cadien, K.; Liu, Q.; Zeng, H. Adsorption characteristics and mechanisms of O-Carboxymethyl chitosan on chalcopyrite and molybdenite. J. Colloid Interface Sci. 2019, 552, 659-670. [CrossRef] [PubMed]

34. Yuan, D.; Cadien, K.; Liu, Q.; Zeng, H. Selective separation of copper-molybdenum sulfides using humic acids. Miner. Eng. 2019, 133, 43-46. [CrossRef]

35. Kor, M.; Korczyk, P.M.; Addai-Mensah, J.; Krasowska, M.; Beattie, D.A. Carboxymethylcellulose adsorption on molybdenite: The effect of electrolyte composition on adsorption, bubble-surface collisions, and flotation. Langmuir 2014, 30, 11975-11984. [CrossRef]

36. Mierczynska-Vasilev, A.; Beattie, D.A. Adsorption of tailored carboxymethyl cellulose polymers on talc and chalcopyrite: Correlation between coverage, wettability, and flotation. Miner. Eng. 2010, 23, 985-993. [CrossRef]

37. Qui, X.; Yang, H.; Chen, G.; Luo, W. An Alternative Depressant of Chalcopyrite in Cu-Mo Differential Flotation and Its Interaction Mechanism. Minerals 2019, 9, 1.

38. Bulatovic, S.M. Use of organic polymers in the flotation of polymetallic ores: A review. Miner. Eng. 1999, 12, 341-354. [CrossRef] 
39. Grano, S.; Ralston, J.; Smart, R.S.C. Influence of electrochemical environment on the flotation behavior of Mt. Isa copper and lead-zinc ore. Int. J. Miner. Process. 1990, 30, 69-97. [CrossRef]

40. Heyes, G.W.; Trahar, W.J. The natural flotability of chalcopyrite. Int. J. Miner. Process. 1977, 4, 317-344. [CrossRef]

41. Ralston, J. Eh and its consequences in sulphide mineral flotation. Miner. Eng. 1991, 4, 859-878. [CrossRef]

42. Richardson, P.E.; Walker, G.W. The flotation of chalcocite, bornite, chalcopyrite, and pyrite in an electrochemical-flotation cell. In Proceedings of the XV International Mineral Processing Congress, Cannes, France, 2-9 June 1985; pp. 198-210.

43. Guy, P.J.; Trahar, W.J. The effects of oxidation and mineral interaction on sulphide flotation. In Flotation of Sulphide Minerals; Forrsberg, K.S.E., Ed.; Elsevier: Amsterdam, The Netherlands, 1985; pp. 91-110.

44. Miki, H.; Hirajima, T.; Muta, Y.; Suyantara, G.P.W.; Sasaki, K. Effect of sodium sulfite on floatability of chalcopyrite and molybdenite. Minerals 2018, 8, 172. [CrossRef]

45. Grano, S.R.; Sollaart, M.; Skinner, W.; Prestidge, C.A.; Ralston, J. Surface modification in the chalcopyrite-sulphite ion system. I. collectorless flotation, XPS and dissolution study. Int. J. Miner. Process. 1997, 50, 1-26. [CrossRef]

46. Castro, S.; Laskowski, J.S. Froth flotation in saline water. KONA Powder Part. J. 2011, 29, 4-15. [CrossRef]

47. Castro, S. Challenges in flotation of $\mathrm{Cu}-\mathrm{Co}$ sulfide ores in sea water. In The First International Symposium on Water in Mineral Processing; Drelich, J., Ed.; Society for Mining, Metallurgy \& Exploration (SME): Littleton, CO, USA, 2012; pp. 29-40.

48. Laskowski, J.S.; Castro, S.; Ramos, O. Effect of seawater main components on frothability in the flotation of Cu-Mo sulfide ore. Physicochem. Probl. Miner. Process. 2013, 50, 17-29.

49. Suyantara, G.P.W.; Hirajima, T.; Miki, H.; Sasaki, K. Floatability of molybdenite and chalcopyrite in artificial seawater. Miner. Eng. 2018, 115, 117-130. [CrossRef]

50. Castro, S.; Rioseco, P.; Laskowski, J.S. Depression of molybdenite in sea water. In Proceedings of the XXVI International Mineral Processing Congress, New Delhi, India, 24-28 September 2012; pp. 737-752.

51. Laskowski, J.S.; Castro, S. Flotation in concentrated electrolyte solutions. Int. J. Miner. Process. 2015, 144, 50-55. [CrossRef]

52. Ramos, O.; Castro, S.; Laskowski, J.S. Copper-molybdenum ores flotation in sea water: Floatability and frothability. Miner. Eng. 2013, 53, 108-112. [CrossRef]

53. Qui, Z.; Liu, G.; Liu, Q.; Zhong, H. Understanding the roles of high salinity in inhibiting the molybdenite flotation. Colloids Surf. A Physicochem. Eng. Asp. 2016, 509, 123-129.

54. Hirajima, T.; Suyantara, G.P.W.; Ichikawa, O.; Elmahdy, A.M.; Miki, H.; Sasaki, K. Effect of $\mathrm{Mg}^{2+}$ and Ca ${ }^{2+}$ as divalent seawater cations on the floatability of molybdenite and chalcopyrite. Miner. Eng. 2016, 96-97, 83-93. [CrossRef]

55. Nagaraj, D.R.; Farinato, R. Chemical factor effects in saline and hypersaline waters in the flotation of $\mathrm{Cu}$ and Cu-Mo ores. In Proceedings of the XXVII International Mineral Processing Congress, Santiago, Chile, 20-24 October 2014; pp. 20-24.

56. Li, W.; Li, Y.; Wei, Z.; Xiao, Q.; Song, S. Fundamental Studies of SHMP in Reducing Negative Effects of Divalent Ions on Molybdenite Flotation. Minerals 2018, 8, 404. [CrossRef]

57. Rebolledo, E.; Laskowski, J.S.; Gutierrez, L.; Castro, S. Use of dispersants in flotation of molybdenite in seawater. Miner. Eng. 2017, 100, 71-74. [CrossRef]

58. Jeldres, R.I.; Arancibia-Bravo, M.P.; Reyes, A.; Aguirre, C.E.; Cortes, L.; Cisternas, L.A. The impact of seawater with calcium and magnesium removal for the flotation of copper-molybdenum sulphide ores. Miner. Eng. 2017, 109, 10-13. [CrossRef]

59. Chen, J.; Lan, L.; Liao, X. Depression effect of pseudo glycolythiourea acid in flotation separation of copper-molybdenum. Trans. Nonferrous Met. Soc. China 2013, 23, 824-831. [CrossRef]

60. Li, M.; Wei, D.; Shen, Y.; Liu, W.; Gao, S.; Liang, G. Selective depression effect in flotation separation of copper-molybdenum sulfides using 2,3-disulfanylbutanedioic acid. Trans. Nonferrous Met. Soc. China 2015, 25, 3126-3132. [CrossRef] 
61. Yin, Z.; Sun, X.; Hu, Y.; Guan, Q.; Zhang, C.; Gao, Y.; Zhai, J. Depressing behaviors and mechanism of disodium bis (carboxymethyl) trithiocarbonate on separation of chalcopyrite and molybdenite. Trans. Nonferrous Met. Soc. China 2017, 27, 883-890. [CrossRef]

62. Li, M.; Wei, D.; Liu, Q.; Liu, W.; Zheng, J.; Sun, H. Flotation separation of copper-molybdenum sulfides using chitosan as a selective depressant. Miner. Eng. 2015, 83, 217-222. [CrossRef]

63. Yin, Z.; Sun, W.; Hu, Y.; Zhang, C.; Guan, Q.; Zhang, C. Separation of molybdenite from chalcopyrite in the presence of novel depressant 4-amino-3-thioxo-3,4-dihydro-1,2,4-triazin-5(2H)-one. Minerals 2017, 7, 146.

64. Yin, Z.; Sen, W.; Hu, Y.; Zhang, C.; Guan, Q.; Liu, R.; Chen, P.; Tian, M. Utilization of acetic acid-[(hydrazinylthioxomethyl)thio]-sodium as a novel selective depressant for chalcopyrite in the flotation separation of molybdenite. Sep. Purif. Technol. 2017, 179, 248-256. [CrossRef]

65. Huang, P.; Cao, M.; Liu, Q. Using chitosan as a selective depressant in the differential flotation $\mathrm{Cu}-\mathrm{Pb}$ sulfides. Int. J. Miner. Process. 2012, 106-109, 8-15. [CrossRef]

66. Huang, P.; Cao, M.; Liu, Q. Adsorption of chitosan on chalcopyrite and galena from aqueous suspensions. Colloids Surf. A Physicochem. Eng. Asp. 2012, 409, 167-175. [CrossRef]

67. Crini, G.; Badot, P.-M. Application of chitosan, a natural aminopolysaccharide, for dye removal from aqueous solutions by adsorption processes using batch studies: A review of recent literature. Prog. Polym. Sci. 2008, 33, 399-447. [CrossRef]

68. Miller, J.D.; Ye, Y.; Jang, W.-H. Molybdenite Flotation from Copper Sulfide/Molybdenite Containing Materials by Ozone Conditioning. U.S. Patent No. 5,068,028, 26 November 1991.

69. Ye, Y.; Jang, W.H.; Yalamanchili, M.R.; Miller, J.D. Molybdenite flotation from copper/molybdenum concentrates by ozone conditioning. Miner. Metall. Process. 1990, 7, 173-179. [CrossRef]

70. Da Silva, L.M.; Jardim, W.F. Trends and strategies of ozone application in environmental problems. Quim. Nova 2006, 29, 310-317. [CrossRef]

71. Kasprzyk-Hordern, B.; Ziółek, M.; Nawrocki, J. Catalytic ozonation and methods of enhancing molecular ozone reactions in water treatment. Appl. Catal. B Environ. 2003, 46, 639-669. [CrossRef]

72. Huang, C.P.; Dong, C.; Tang, Z. Advanced chemical oxidation: Its present role and potential future in hazardous waste treatment. Waste Manag. 1993, 13, 361-377. [CrossRef]

73. Castro, S.; Lopez-Valdivieso, A.; Laskowski, J.S. Review of the flotation of molybdenite. Part I: Surface properties and floatability. Int. J. Miner. Process. 2016, 148, 48-58. [CrossRef]

74. Hirajima, T.; Mori, M.; Ichikawa, O.; Sasaki, K.; Miki, H.; Farahat, M.; Sawada, M. Selective flotation of chalcopyrite and molybdenite with plasma. Miner. Eng. 2014, 66-68, 102-111. [CrossRef]

75. Suyantara, G.P.W.; Hirajima, T.; Miki, H.; Sasaki, K.; Yamane, M.; Takida, E.; Kuroiwa, S.; Imaizumi, Y. Selective flotation of chalcopyrite and molybdenite using $\mathrm{H}_{2} \mathrm{O}_{2}$ oxidation method with the addition of ferrous sulfate. Miner. Eng. 2018, 122, 312-326. [CrossRef]

76. Lin, S.-S.; Gurol, M.D. Catalytic decomposition of hydrogen peroxide on iron oxide: Kinetics, mechanism, and implications. Environ. Sci. Technol. 1998, 32, 1417-1423. [CrossRef]

77. Li, X.; Huang, Y.; Li, C.; Shen, J.; Deng, Y. Degradation of pCNB by Fenton like process using $\alpha$-FeOOH. Chem. Eng. J. 2015, 260, 28-36. [CrossRef]

78. Miki, H.; Matsuoka, H.; Hirajima, T.; Suyantara, G.P.W.; Sasaki, K. Electrolysis oxidation of chalcopyrite and molybdenite for selective flotation. Mater. Trans. 2017, 58, 761-767. [CrossRef]

79. Jha, R.K.T.; Satur, J.; Hiroyoshi, N.; Ito, M.; Tsunekawa, M. Carrier-microencapsulation using Si-catechol complex for suppressing pyrite floatability. Miner. Eng. 2008, 21, 889-893. [CrossRef]

80. Li, X.; Hiroyoshi, N.; Tabelin, C.B.; Naruwa, K.; Harada, C.; Ito, M. Suppressive effects of ferric-catecholate complexes on pyrite oxidation. Chemosphere 2019, 214, 70-78. [CrossRef]

81. Park, I.; Tabelin, C.B.; Magaribuchi, K.; Seno, K.; Ito, M.; Hiroyoshi, N. Suppression of the release of arsenic from arsenopyrite by carrier-microencapsulation using Ti-catechol complex. J. Hazard. Mater. 2018, 344, 322-332. [CrossRef]

82. Park, I.; Tabelin, C.B.; Seno, K.; Jeon, S.; Ito, M.; Hiroyoshi, N. Simultaneous suppression of acid mine drainage and arsenic release by carrier-microencapsulation using aluminum-catecholate complexes. Chemosphere 2018, 205, 414-425. [CrossRef] [PubMed] 
83. Park, I.; Tabelin, C.B.; Jeon, S.; Li, X.; Seno, K.; Ito, M.; Hiroyoshi, N. A review of recent strategies for acid mine drainage prevention and mine tailings recycling. Chemosphere 2019, 219, 588-606. [CrossRef]

84. Park, I.; Tabelin, C.B.; Seno, K.; Jeon, S.; Inano, H.; Ito, M.; Hiroyoshi, N. Carrier-microencapsulation of arsenopyrite using $\mathrm{Al}$-catecholate complex: Nature of oxidation products, effects on anodic and cathodic reactions, and coating stability under simulated weathering conditions. Heliyon 2020, 6, e03189. [CrossRef]

(C) 2020 by the authors. Licensee MDPI, Basel, Switzerland. This article is an open access article distributed under the terms and conditions of the Creative Commons Attribution (CC BY) license (http://creativecommons.org/licenses/by/4.0/). 


\title{
Flotation Separation of Chalcopyrite and Molybdenite Assisted by Microencapsulation Using Ferrous and Phosphate Ions: Part I. Selective Coating Formation
}

\author{
Ilhwan Park ${ }^{1, *}$, Seunggwan Hong ${ }^{2}$, Sanghee Jeon ${ }^{1}$, Mayumi Ito ${ }^{1}$ and Naoki Hiroyoshi ${ }^{1}$ \\ 1 Division of Sustainable Resources Engineering, Faculty of Engineering, Hokkaido University, \\ Sapporo 060-8628, Japan; shjun1121@eng.hokudai.ac.jp (S.J.); itomayu@eng.hokudai.ac.jp (M.I.); \\ hiroyosi@eng.hokudai.ac.jp (N.H.) \\ 2 Cooperative Program for Resources Engineering, Graduate School of Engineering, Hokkaido University, \\ Sapporo 060-8628, Japan; seunggwan.hong.s4@elms.hokudai.ac.jp \\ * Correspondence: i-park@eng.hokudai.ac.jp; Tel.: +81-11-706-6315
}

Received: 6 November 2020; Accepted: 9 December 2020; Published: 13 December 2020

\begin{abstract}
Porphyry $\mathrm{Cu}-\mathrm{Mo}$ deposits, which are the most important sources of copper and molybdenum, are typically processed by flotation. In order to separate $\mathrm{Cu}$ and Mo minerals (mostly chalcopyrite and molybdenite), the strategy of depressing chalcopyrite while floating molybdenite has been widely adopted by using chalcopyrite depressants, such as $\mathrm{NaHS}, \mathrm{Na}_{2} \mathrm{~S}$, and Nokes reagent. However, these depressants are potentially toxic due to their possibility to emit $\mathrm{H}_{2} \mathrm{~S}$ gas. Thus, this study aims at developing a new concept for selectively depressing chalcopyrite via microencapsulation while using $\mathrm{Fe}^{2+}$ and $\mathrm{PO}_{4}{ }^{3-}$ forming $\mathrm{Fe}^{(\mathrm{III})} \mathrm{PO}_{4}$ coating. The cyclic voltammetry results indicated that $\mathrm{Fe}^{2+}$ can be oxidized to $\mathrm{Fe}^{3+}$ on the chalcopyrite surface, but not on the molybdenite surface, which arises from their different electrical properties. As a result of microencapsulation treatment using $1 \mathrm{mmol} / \mathrm{L} \mathrm{Fe}^{2+}$ and $1 \mathrm{mmol} / \mathrm{L} \mathrm{PO}_{4}{ }^{3-}$, chalcopyrite was much more coated with $\mathrm{FePO}_{4}$ than molybdenite, which indicated that selective depression of chalcopyrite by the microencapsulation technique is highly achievable.
\end{abstract}

Keywords: porphyry deposits; chalcopyrite; molybdenite; flotation; microencapsulation; $\mathrm{FePO}_{4}$ coating

\section{Introduction}

Porphyry Cu-Mo deposits are the most important sources of copper ( $\mathrm{Cu}$ ) and molybdenum (Mo), because they account for about $60 \%$ and $50 \%$ of the world's $\mathrm{Cu}$ and Mo productions [1]. In porphyry $\mathrm{Cu}$-Mo deposits, chalcopyrite $\left(\mathrm{CuFeS}_{2}\right)$ and molybdenite $\left(\mathrm{MoS}_{2}\right)$ are the predominant $\mathrm{Cu}$ and Mo minerals [2,3], and they are separately recovered as $\mathrm{Cu}$ and Mo concentrates via a two-step process: (i) bulk flotation in order to produce $\mathrm{Cu}-\mathrm{Mo}$ bulk concentrates; (ii) the selective flotation of molybdenite from Cu-Mo bulk concentrates. Bulk flotation is conducted with the assistance of proper collectors, such as xanthate for chalcopyrite and insoluble nonpolar oily collectors (e.g., diesel, kerosene, or fuel oil) for molybdenite $[4,5]$, and $\mathrm{pH}$ adjuster (e.g., quick lime $(\mathrm{CaO})$ or slaked lime $\left(\mathrm{Ca}(\mathrm{OH})_{2}\right)$ to increase the pulp $\mathrm{pH}$ at $>10$ where iron sulfides (mostly pyrite $\left(\mathrm{FeS}_{2}\right)$ ) are depressed due to the competitive adsorption of $\mathrm{OH}^{-}$that inhibits xanthate adsorption on the surface of iron sulfides [6]. After this, the $\mathrm{Cu}-\mathrm{Mo}$ bulk concentrates are treated with chalcopyrite depressant (e.g., sodium hydrosulfide (NaHS), sodium sulfide $\left(\mathrm{Na}_{2} \mathrm{~S}\right)$, and Nokes reagent $\left(\mathrm{P}_{2} \mathrm{~S}_{5}+\mathrm{NaOH}\right)$ ) in order to depress chalcopyrite while floating molybdenite [5]. These reagents function as chalcopyrite depressants by producing HS $^{-}$that desorbs the adsorbed xanthate on the chalcopyrite surface and/or reduces the pulp potential, in which chalcopyrite does not float [7].

Although the conventional chalcopyrite depressants are effective in separating $\mathrm{Cu}$ and Mo minerals from bulk $\mathrm{Cu}-\mathrm{Mo}$ bulk concentrates, these have the potential to generate toxic hydrogen sulfide gas 
$\left(\mathrm{H}_{2} \mathrm{~S}_{(\mathrm{g})}\right)$ when pulp $\mathrm{pH}$ is not properly controlled [3,5,8]. At a $\mathrm{pH}$ below 10 , for example, $\mathrm{H}_{2} \mathrm{~S}_{(\mathrm{aq})}$ species starts forming and it is readily vaporized due to its high vapor pressure [7]. Thus, the flotation circuits should consist of covered flotation cells with an active ventilation system to avoid the accident that is caused by $\mathrm{H}_{2} \mathrm{~S}$ emission $[5,7,9]$. Moreover, the corrosive nature of $\mathrm{H}_{2} \mathrm{~S}$ that destroys pipelines and imperfect molybdenite recovery are other drawbacks of using conventional depressants $[3,7,8,10]$.

Because of the above-mentioned limitations, there have been many attempts to replace the conventional chalcopyrite depressants with alternative depressants for molybdenite (e.g., dextrin [11,12], lignosulfonates [13], O-carboxymethyl chitosan [14,15], carboxymethylcellulose [16], humic acid [17], etc.) and chalcopyrite (e.g., sodium sulfite $\left(\mathrm{Na}_{2} \mathrm{SO}_{3}\right)$ [3], pseudo-glycolythiourea acid (PGA) [18], 2,3-disulfanylbutanedioic acid (DMSA) [19], disodium bis (carboxymethyl) trithiocarbonate (DBT) [20], chitosan [21], etc.). Between these two approaches, the strategy of depressing chalcopyrite is more preferred than depressing molybdenite, because, in porphyry deposits, the amount of molybdenite is lower when compared to that of chalcopyrite (i.e., Cu grade, $0.44 \%$; Mo grade, $0.018 \%$ ) [2]. In the case that molybdenite depresses while chalcopyrite floats, the mechanical entrainment of molybdenite could occur within a large volume of froth products, resulting in the loss of valuable molybdenite, which is critical, because molybdenite recovery is of importance for $\mathrm{Cu}-\mathrm{Mo}$ processing plants to be economically viable [22].

Miki et al. [9] reported that the difference in electrical resistivity between chalcopyrite and molybdenite can be utilized for reducing the floatability of chalcopyrite selectively. The electrical resistances of chalcopyrite and molybdenite are $234 \Omega$ and 1.2-1.5 M $\Omega$, respectively, so electrochemical reactions occur more preferably on the surface of chalcopyrite than that of molybdenite [9]. Based on these distinctively different electrical properties of minerals, this study investigated the application of microencapsulation technique while using ferrous $\left(\mathrm{Fe}^{2+}\right)$ and phosphate $\left(\mathrm{PO}_{4}{ }^{3-}\right)$ ions as a pretreatment for depressing the floatability of chalcopyrite. Due to the extremely high electrical resistivity of molybdenite, $\mathrm{Fe}^{2+}$ is hardly oxidized to ferric ion $\left(\mathrm{Fe}^{3+}\right)$; however, chalcopyrite has a low electrical resistivity and, thus, $\mathrm{Fe}^{2+}$ can be oxidized to $\mathrm{Fe}^{3+}$, which then reacts with $\mathrm{PO}_{4}{ }^{3-}$ and forms ferric phosphate $\left(\mathrm{FePO}_{4}\right)$ on the surface of chalcopyrite, rendering it hydrophilic. This is the first part of a two-part paper, the aim of which is to investigate whether microencapsulation while using $\mathrm{Fe}^{2+}$ and $\mathrm{PO}_{4}{ }^{3-}$ can selectively create $\mathrm{FePO}_{4}$ coating on the surface of chalcopyrite rather than that of molybdenite. Specifically, the overall scope of this part is as follows: (i) elucidating the mechanism of selective coating formation via an electrochemical technique (i.e., cyclic voltammetry (CV)) and (ii) confirming whether chalcopyrite is selectively coated with $\mathrm{FePO}_{4}$ via shake-flask experiments that are coupled with surface characterizations (i.e., scanning electron microscopy with energy-dispersive X-ray spectroscopy (SEM-EDX) and X-ray photoelectron spectroscopy (XPS)). A follow-up paper will discuss the effect of microencapsulation using $\mathrm{Fe}^{2+}$ and $\mathrm{PO}_{4}{ }^{3-}$ on the selective depression of chalcopyrite in $\mathrm{Cu}-\mathrm{Mo}$ flotation separation.

\section{Materials and Methods}

\subsection{Mineral Samples}

Chalcopyrite and molybdenite were obtained from Copper Queen Mine, Cochise County, AZ, USA and Spain Mine, Renfrew County, ON, Canada, respectively. The samples were crushed by a jaw crusher (BB 51, Retsch Inc. Haan, Germany), ground by a vibratory disc mill (RS 100, Retsch Inc., Haan, Germany), and then screened in order to obtain a size fraction of less than $75 \mu \mathrm{m}$. Mineralogical and chemical compositions of the samples were determined by X-ray diffraction (XRD; Figure 1) and X-ray fluorescence (XRF; Table 1). The chalcopyrite sample is composed of mainly chalcopyrite with pyrite and silicate minerals (e.g., quartz $\left(\mathrm{SiO}_{2}\right)$, amesite $\left(\mathrm{Mg}_{2} \mathrm{Al}_{2} \mathrm{SiO}_{5}(\mathrm{OH})_{4}\right)$, and actinolite $\left.\left(\mathrm{Ca}_{2}\left(\mathrm{Mg}, \mathrm{Fe}^{2+}\right)_{5} \mathrm{Si}_{8} \mathrm{O}_{22}(\mathrm{OH})_{2}\right)\right)$ as impurities, while molybdenite sample is highly pure and only contains trace amounts of impurities, as can be seen. 

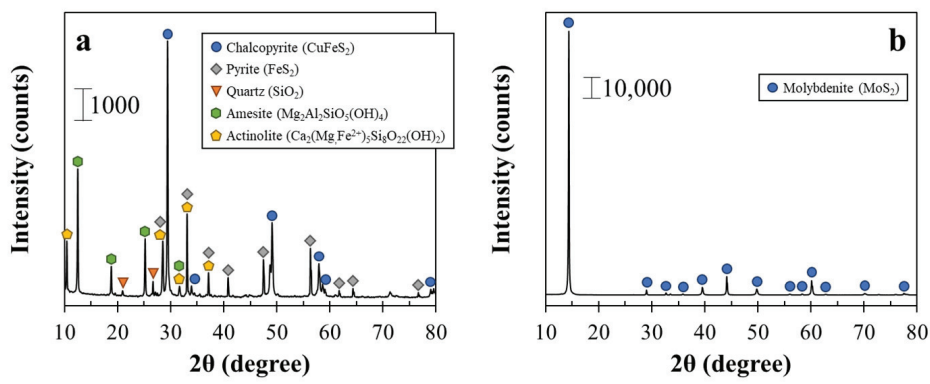

Figure 1. X-ray diffraction (XRD) patterns of (a) chalcopyrite and (b) molybdenite.

Table 1. Elemental compositions of chalcopyrite and molybdenite.

\begin{tabular}{cccc}
\hline \multicolumn{2}{c}{ Chalcopyrite } & \multicolumn{2}{c}{ Molybdenite } \\
\hline Elements & wt. $\%$ & Elements & wt.\% \\
\hline $\mathrm{Cu}$ & 23.2 & Mo & 56.8 \\
$\mathrm{Fe}$ & 32.6 & $\mathrm{~S}$ & 43.0 \\
$\mathrm{~S}$ & 29.4 & Others & 0.2 \\
$\mathrm{Si}$ & 9.5 & - & - \\
Others & 5.3 & - & - \\
\hline
\end{tabular}

\subsection{Stability of $\mathrm{Fe}^{2+}$ in the Presence of $\mathrm{PO}_{4}{ }^{3-}$ vs. $\mathrm{pH}$}

The stability of $\mathrm{Fe}^{2+}$ in the presence of $\mathrm{PO}_{4}{ }^{3-}$ was investigated as a function of $\mathrm{pH}$ in order to decide the suitable $\mathrm{pH}$ condition for $\mathrm{FePO}_{4}$ coating formation on chalcopyrite to be selective. For this, a solution containing $1 \mathrm{mmol} / \mathrm{L} \mathrm{FeSO} 4 \cdot 7 \mathrm{H}_{2} \mathrm{O}$ and $1 \mathrm{mmol} / \mathrm{L} \mathrm{KH}_{2} \mathrm{PO}_{4}$ was prepared, and its $\mathrm{pH}$ was adjusted in the $\mathrm{pH}$ range of 2-6 while using dilute $\mathrm{HCl}$ and $\mathrm{NaOH}$. All of the chemicals used in this study were of reagent grade (Wako Pure Chemical Industries, Ltd., Osaka, Japan). After pH adjustment, the solution was allowed to stabilize for $10 \mathrm{~min}$. at room temperature under magnetic stirring $(400 \mathrm{rpm})$. Afterwards, the solutions were filtered through $0.2 \mu \mathrm{m}$ syringe-driven membrane filters (LMS Co. Ltd., Tokyo, Japan), and then analyzed by inductively coupled plasma atomic emission spectrometer (ICP-AES, ICPE-9820, Shimadzu Corporation, Kyoto, Japan) in order to identify the changes in dissolved Fe concentration.

\subsection{Electrochemical Behaviors of $\mathrm{Fe}^{2+}$ on Chalcopyrite and Molybdenite}

The electrochemical behaviors of $\mathrm{Fe}^{2+}$ on chalcopyrite and molybdenite were investigated by CV while using an electrochemical measurement unit (SI 1280B, Solartron Analytical, Farnborough, UK) with a conventional three-electrode system consisting of a mineral (chalcopyrite or molybdenite) working electrode, a platinum $(\mathrm{Pt})$ counter electrode, and an $\mathrm{Ag} / \mathrm{AgCl}$ (saturated $\mathrm{KCl}$ ) reference electrode. The mineral electrodes were prepared in an identical way that was illustrated in our previous works [23,24]. Two types of electrolyte solutions were prepared: (i) $0.1 \mathrm{~mol} / \mathrm{L} \mathrm{Na}_{2} \mathrm{SO}_{4}$ and (ii) $1 \mathrm{mmol} / \mathrm{L} \mathrm{FeSO}_{4} \cdot 7 \mathrm{H}_{2} \mathrm{O}$ and $0.1 \mathrm{~mol} / \mathrm{L} \mathrm{Na}_{2} \mathrm{SO}_{4}$, both of which were adjusted to $\mathrm{pH} 4$. The solution was equilibrated at $25^{\circ} \mathrm{C}$ and then deoxygenated by $\mathrm{N}_{2}$ purging for $30 \mathrm{~min}$. After this, three electrodes were inserted and equilibrated at open circuit potential (OCP), and then $\mathrm{CV}$ was measured under the following conditions: initial scan polarity, positive; potential scan range, -0.8 to $+0.8 \mathrm{~V}$; scan rate, $30 \mathrm{mV} / \mathrm{s}$.

\subsection{Microencapsulation Treatment}

Prior to the microencapsulation treatment, mineral samples were washed in order to remove the effects that are caused by the presence of oxidized layers formed during sample preparation. 
The washing procedure is as follows: ultrasonic cleaning in ethanol, acid washing $\left(1.0 \mathrm{M} \mathrm{HNO}_{3}\right)$, triple rinsing with de-ionized (DI) water $(18.2 \mathrm{M} \Omega \cdot \mathrm{cm})$, dewatering with acetone, and drying in a vacuum desiccator [25].

For the microencapsulation treatment, $1 \mathrm{~g}$ of washed mineral (e.g., chalcopyrite or molybdenite) and $10 \mathrm{~mL}$ of a solution containing $1 \mathrm{mmol} / \mathrm{L} \mathrm{Fe}^{2+}$ and $1 \mathrm{mmol} / \mathrm{L} \mathrm{PO}_{4}{ }^{3-}(\mathrm{pH} 4)$ were put into a $50-\mathrm{mL}$ Erlenmeyer flask and then shaken in a constant temperature water bath at $25^{\circ} \mathrm{C}$ and $120 \mathrm{~min}^{-1}$ for 1-6 h. After predetermined time intervals, the suspensions were filtered through $0.2 \mu \mathrm{m}$ syringe-driven membrane filters and then analyzed by ICP-AES. Treated minerals were thoroughly washed with DI water, dried in a vacuum dry oven $\left(40^{\circ} \mathrm{C}\right)$, and then analyzed by SEM-EDX (JSM-IT200, JEOL Ltd., Tokyo, Japan) and XPS (JPS-9200, JEOL Ltd., Tokyo, Japan). The XPS analysis was conducted using an $\mathrm{Al} \mathrm{K \alpha}$ X-ray source operated at $100 \mathrm{~W}$ (Voltage, $10 \mathrm{kV}$; Current, $10 \mathrm{~mA}$ ) under ultrahigh vacuum conditions (approximately $10^{-7} \mathrm{~Pa}$ ). The narrow scan spectra were calibrated while using the binding energy of adventitious carbon (C 1s) $(285.0 \mathrm{eV})$ for charge correction. For deconvolutions of the spectra, XPSPEAK version 4.1 (Raymond WM Kwok, Chinese University of Hong Kong, Hong Kong, China) was used with an $80 \%$ Gaussian-20\% Lorentzian peak model and a true Shirley background [26,27].

\section{Results}

\subsection{Stability of $\mathrm{Fe}^{2+}$ in the Presence of $\mathrm{PO}_{4}{ }^{3-}$ vs. $\mathrm{pH}$}

The oxidation rate of $\mathrm{Fe}^{2+}$ to $\mathrm{Fe}^{3+}$ by dissolved oxygen (DO) is known to be $\mathrm{pH}$-dependent $[28,29]$. $\mathrm{Fe}^{2+}$ oxidation rate under acidic conditions (i.e., $\mathrm{pH}<4$ ) is very slow and independent of $\mathrm{pH}$, as shown in Figure 2a. However, at $\mathrm{pH} \geq 5 \mathrm{Fe}^{2+}$, the $\mathrm{Fe}^{2+}$ oxidation rate shows the second order dependence on $\left[\mathrm{OH}^{-}\right]$, indicating that a 100-fold increase in the rate occurs for a unit increase in $\mathrm{pH}$ [28]. In the studied system, not only $\mathrm{Fe}^{2+}$, but also $\mathrm{PO}_{4}{ }^{3-}$ coexist, so the stability of $\mathrm{Fe}^{2+}$ in the presence of $\mathrm{PO}_{4}{ }^{3-}$ as a function of $\mathrm{pH}$ was investigated (Figure $2 \mathrm{~b}$ ). The concentration of $\mathrm{Fe}^{2+}$ was almost not changed between $\mathrm{pH} 2$ and 4, but above which $\mathrm{Fe}^{2+}$ concentration decreases rapidly. This result is identical to that reported by previous works $[28,29]$, indicating that $\mathrm{Fe}^{2+}$ is stable at $\mathrm{pH}<4$, even in the presence of $\mathrm{PO}_{4}{ }^{3-}$. The oxidation of $\mathrm{Fe}^{2+}$ by DO is not preferred, because the selective coating formation could only be achieved when $\mathrm{Fe}^{2+}$ oxidation occurs on the surface of chalcopyrite. Thus, $\mathrm{pH} 4$ was selected for microencapsulation treatment to be selective.
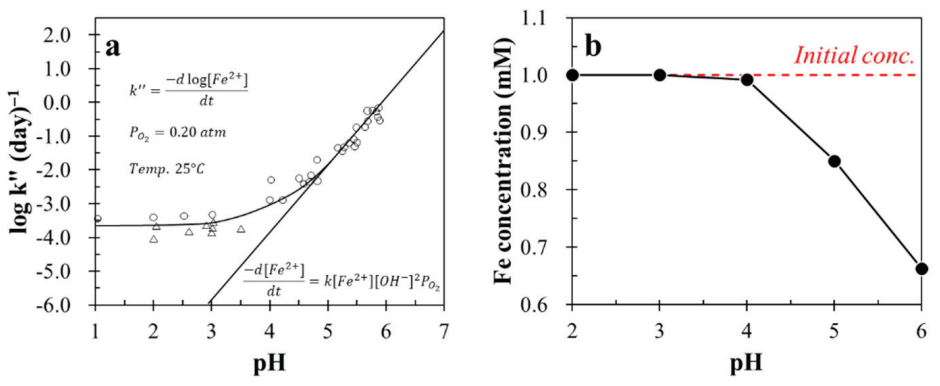

Figure 2. (a) Oxidation rate of ferrous iron species as a function of $\mathrm{pH}$ (reprinted with permission from Morgan and Lahav [29], copyright (2007) Elsevier) and (b) the change in dissolved Fe concentration $\left(\left[\mathrm{Fe}^{2+}\right]_{\text {initial }}=1 \mathrm{mmol} / \mathrm{L}\right)$ in the presence of $1 \mathrm{mmol} / \mathrm{L} \mathrm{PO}_{4}{ }^{3-}$ as a function of $\mathrm{pH}$.

\subsection{Electrochemical Behavior of $\mathrm{Fe}^{2+}$ on Chalcopyrite and Molybdenite}

Figure 3 shows the cyclic voltammograms of chalcopyrite (Figure 3a) and molybdenite (Figure 3b) in the absence and presence of $1 \mathrm{mmol} / \mathrm{L} \mathrm{Fe}^{2+}$. The current density was continuously increased as the applied potential increased, which means that chalcopyrite as well as its oxidation products (e.g., $\mathrm{Fe}^{2+}$ ) were oxidized (Equations (1) and (2)), as shown in the first anodic scan of chalcopyrite in the absence 
of $\mathrm{Fe}^{2+}$ (Figure 3(a2)) [30-32]. When $1 \mathrm{mmol} / \mathrm{L} \mathrm{Fe}^{2+}$ was present, the current density was apparently increased as compared to that without $\mathrm{Fe}^{2+}$. This increase in current density most likely resulted from the oxidation of $\mathrm{Fe}^{2+}$ to $\mathrm{Fe}^{3+}$ (Equation (2)).

$$
\begin{gathered}
\mathrm{CuFeS}_{2} \rightarrow \mathrm{Cu}_{(1-\mathrm{x})} \mathrm{Fe}_{(1-\mathrm{y})} \mathrm{S}_{(2-\mathrm{z})}+\mathrm{xCu}^{2+}+\mathrm{yFe}^{2+}+\mathrm{zS}^{0}+2(\mathrm{x}+\mathrm{y}) \mathrm{e}^{-} \\
\mathrm{Fe}^{2+} \rightarrow \mathrm{Fe}^{3+}+\mathrm{e}^{-}
\end{gathered}
$$
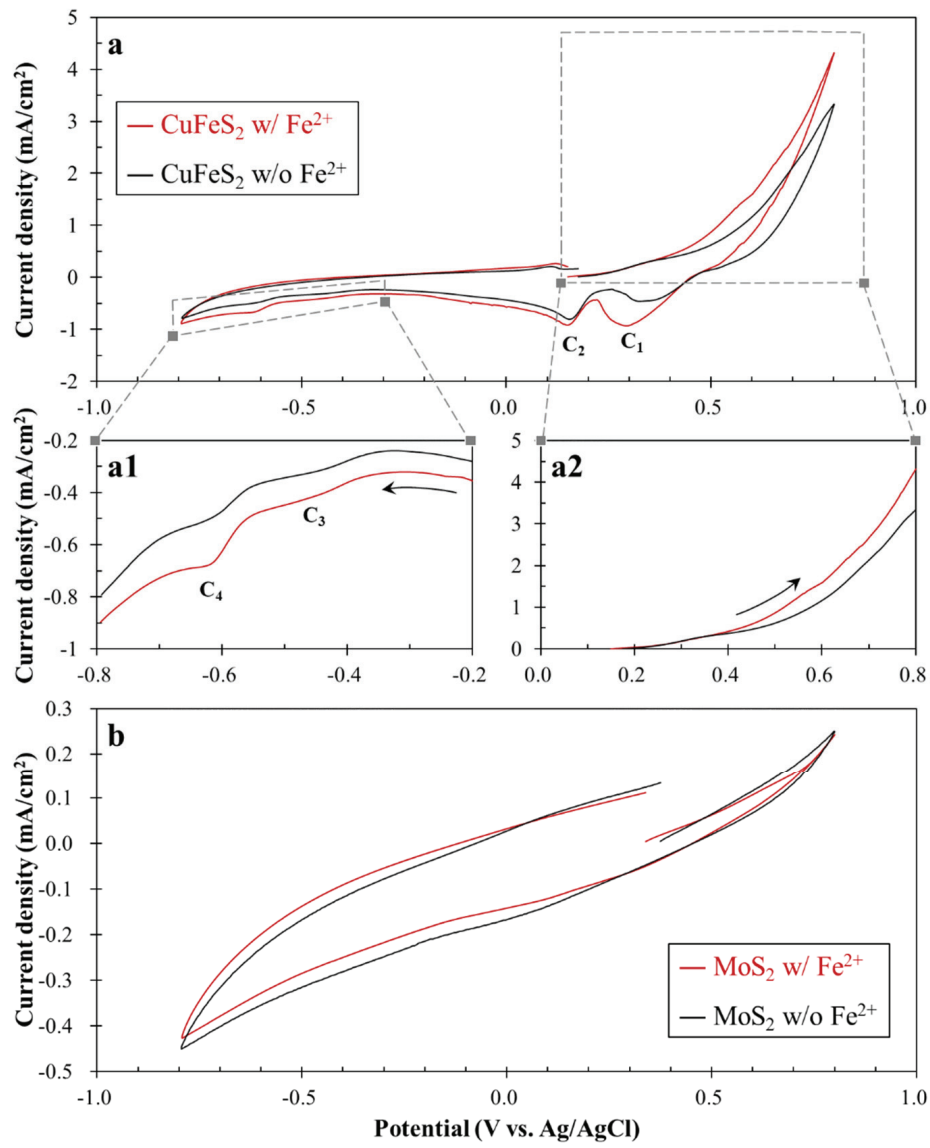

Figure 3. Cyclic voltammograms of (a) chalcopyrite (a1: cathodic scan from -0.2 to $-0.8 \mathrm{~V}$, a2: anodic scan from open circuit potential (OCP) to $0.8 \mathrm{~V}$ ) and (b) molybdenite in the absence and presence of $1 \mathrm{mmol} / \mathrm{L} \mathrm{Fe}^{2+}$. Note that the arrows in Figure 3(a1,a2) denote the sweep direction.

During the cathodic scan in the absence of $1 \mathrm{mmol} / \mathrm{L} \mathrm{Fe}^{2+}$, it exhibited four cathodic peaks $\left(\mathrm{C}_{1}, \mathrm{C}_{2}\right.$, $\mathrm{C}_{3}$, and $\mathrm{C}_{4}$ ), as shown in Figure $3 \mathrm{a},(\mathrm{a} 1)$. According to Holiday and Richmond [31], the first two cathodic peaks $\left(\mathrm{C}_{1}\right.$ and $\left.\mathrm{C}_{2}\right)$ were due to the reduction of dissolved species, like $\mathrm{Fe}^{3+}$ and $\mathrm{Cu}^{2+}$. Holiday and Richmond [31] executed cathodic linear-sweep voltammetry while using stationary and rotating chalcopyrite electrodes, both of which were pretreated at $0.65 \mathrm{~V}$ vs. SCE for 2 min., and found out that two cathodic peaks at 0.38 and $0.15 \mathrm{~V}$ vs. SCE observed in the voltammogram using a stationary electrode were absent when the electrode was rotated. Thus, the appearance of $C_{1}$ and $C_{2}$ can be explained by the reduction of $\mathrm{Fe}^{3+}$ to $\mathrm{Fe}^{2+}$ at $0.3-0.4 \mathrm{~V}$ (Equation (3)) and the formation of covellite 
(CuS) at $0.1-0.2 \mathrm{~V}$ (Equation (4)), respectively. At the applied potential between -0.4 and $-0.7 \mathrm{~V}$, two additional peaks $\left(C_{3}\right.$ and $C_{4}$ ) were observed (Figure 3(a1)), which resulted from the reduction of $\mathrm{CuS}$ to chalcocite $\left(\mathrm{Cu}_{2} \mathrm{~S}\right)$ and $\mathrm{S}^{0}$ to $\mathrm{H}_{2} \mathrm{~S}$, as illustrated in Equations (5) and (6) [30-32].

$$
\begin{gathered}
\mathrm{Fe}^{3+}+\mathrm{e}^{-} \rightarrow \mathrm{Fe}^{2+} \\
\mathrm{Cu}^{2+}+\mathrm{S}^{0}+2 \mathrm{e}^{-} \rightarrow \mathrm{CuS} \\
2 \mathrm{CuS}+2 \mathrm{H}^{+}+2 \mathrm{e}^{-} \rightarrow \mathrm{Cu}_{2} \mathrm{~S}+\mathrm{H}_{2} \mathrm{~S} \\
\mathrm{~S}^{0}+2 \mathrm{H}^{+}+2 \mathrm{e}^{-} \rightarrow \mathrm{H}_{2} \mathrm{~S}
\end{gathered}
$$

Similarly, these four cathodic peaks $\left(\mathrm{C}_{1}, \mathrm{C}_{2}, \mathrm{C}_{3}\right.$, and $\left.\mathrm{C}_{4}\right)$ were also observed in the voltammogram in the presence of $1 \mathrm{mmol} / \mathrm{L} \mathrm{Fe}^{2+}$; however, it is important to note that the current density of $\mathrm{C}_{1}$ was obviously increased. This indicates that more $\mathrm{Fe}^{3+}$ was generated during the anodic scan of chalcopyrite in the presence of $1 \mathrm{mmol} / \mathrm{L} \mathrm{Fe}^{2+}$ as compared to that of control. On the other hand, cyclic voltammograms of molybdenite showed that there is no clear difference between the absence and presence of $1 \mathrm{mmol} / \mathrm{L} \mathrm{Fe}^{2+}$ (Figure 3b). It is most likely attributed to the low electrical conductivity of molybdenite, making the electrochemical reactions of $\mathrm{Fe}^{2+} / \mathrm{Fe}^{3+}$ redox couple hard to occur on its surface. Therefore, the cyclic voltammetry results imply that the selective oxidation of $\mathrm{Fe}^{2+}$ on the chalcopyrite surface is highly possible.

\subsection{Microencapsulation Treatment for Chalcopyrite and Molybdenite}

Figure 4 shows the precipitation rates of dissolved Fe and $\mathrm{P}$ during microencapsulation treatment for chalcopyrite and molybdenite. The precipitation rate is calculated by the following equation:

$$
\text { Precipitation rate }(\%)=(\mathrm{Ci}-\mathrm{Ct}) / \mathrm{Ci} \times 100 \%
$$

where $C_{i}$ is the initial concentration of dissolved Fe or $P$ in $m g / L$, and $C_{t}$ is the concentration of dissolved Fe or $\mathrm{P}$ in $\mathrm{mg} / \mathrm{L}$ at time $\mathrm{t}$. As shown in Figure 4a, the precipitation of dissolved Fe considerably occurred in the presence of chalcopyrite; that is, around $60 \%$ of $\mathrm{Fe}^{2+}$ was precipitated after $1 \mathrm{~h}$ treatment and it reached $93 \%$ after $6 \mathrm{~h}$. Similarly, dissolved $\mathrm{P}$ was also significantly precipitated with chalcopyrite (Figure $4 \mathrm{~b}$ ). When compared to the precipitation rate of dissolved $\mathrm{P}$, the precipitated amount of dissolved Fe was a bit low. This is probably due to chalcopyrite dissolution that releases $\mathrm{Fe}^{2+/ 3+}$, resulting in the lowering of the Fe precipitation rate. These results indicate that $\mathrm{Fe}^{2+}$ is oxidized to $\mathrm{Fe}^{3+}$ on the surface of chalcopyrite, then, the resultant product (i.e., $\mathrm{Fe}^{3+}$ ) reacts with $\mathrm{H}_{2} \mathrm{PO}_{4}^{-}$, a dominant species of phosphate at $\mathrm{pH}$, forming $\mathrm{FePO}_{4}$, as shown in the following equation:

$$
\mathrm{Fe}^{3+}+\mathrm{H}_{2} \mathrm{PO}_{4}^{-} \rightarrow \mathrm{FePO}_{4} \downarrow+2 \mathrm{H}^{+}
$$

It is interesting to note that, even during microencapsulation treatment for molybdenite, around $20-40 \%$ of dissolved Fe and P were precipitated (Figure $4 \mathrm{a}, \mathrm{b}$ ). Although the CV results indicated that $\mathrm{Fe}^{2+}$ oxidation could not occur on the surface of molybdenite (Figure $3 \mathrm{~b}$ ), the precipitation of dissolved Fe and $\mathrm{P}$ apparently occurred in the presence of molybdenite. These opposite results are attributed to the different electrical resistivity of different sides (e.g., basal and edge planes) of molybdenite [9]. Miki et al. [9] investigated electrolysis oxidation treatment while using basaland edge-plane-oriented molybdenite electrodes and confirmed that electron transfer was actively pursued through the edge plane when compared to that through the basal plane. At an applied potential of $1.0 \mathrm{~V}$ vs. SHE, for example, the current density of the edge-plane electrode was around $0.1 \mathrm{~mA} / \mathrm{cm}^{2}$, lasting for $800 \mathrm{~s}$, while it was closed to $0 \mathrm{~mA} / \mathrm{cm}^{2}$ in the case of the basal-plane electrode. The particle size of molybdenite used in this study is less than $75 \mu \mathrm{m}$. As the size of molybdenite particle reduces, the ratio of basal-plane/edge-plane also decreases [33]. This means that electron transfer reactions, like $\mathrm{Fe}^{2+}$ oxidation on fine molybdenite, become easier to occur when compared to 
coarse molybdenite. Thus, approximately $20-40 \%$ of dissolved Fe and P were precipitated during the reaction with molybdenite (Figure 4 ).
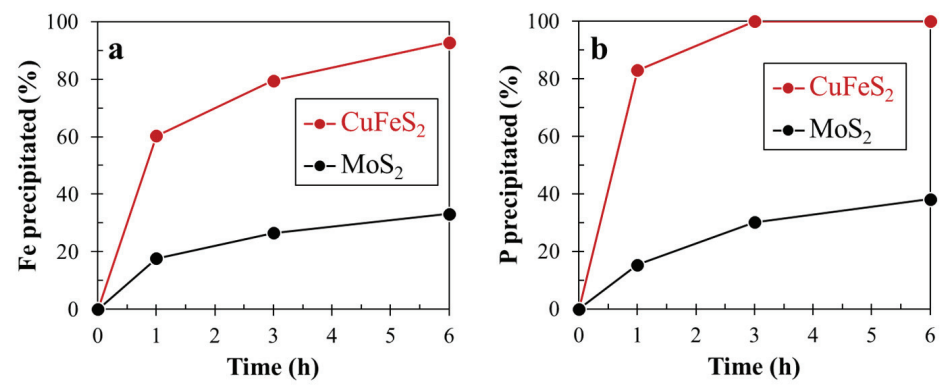

Figure 4. Precipitation rates of dissolved Fe (a) and P (b).

Figure 5 shows the SEM-EDX results of untreated- and treated-chalcopyrite. As can be seen in the SEM image of untreated chalcopyrite, its surface was smooth and clear; however, after microencapsulation treatment, the surface morphology dramatically changed the secondary precipitates that covered the surface of chalcopyrite. Untreated chalcopyrite exhibited strong signals of $\mathrm{Cu}, \mathrm{Fe}$, and $\mathrm{S}$, while treated chalcopyrite showed that the signals of $\mathrm{Cu}$ and $\mathrm{S}$ were decreased, but signals of $\mathrm{Fe}$ and $\mathrm{O}$ were increased, as shown in the EDX spectra of these samples. In addition, the P signal appeared in the spectrum of treated chalcopyrite. These increased (i.e., Fe, P, and O) and decreased (i.e., $\mathrm{Cu}$ and S) signals were also found in the elemental maps of treated chalcopyrite. These results indicate that, after microencapsulation treatment, $\mathrm{Fe}-\mathrm{P}-\mathrm{O}$-containing coatings were formed on the chalcopyrite surface. On the other hand, the SEM-EDX results of molybdenite with and without treatment (Figure 6) showed that there is no clear difference between the two samples, although $40 \%$ of dissolved Fe and $\mathrm{P}$ were precipitated (Figure 4). It could be speculated that the signals of Fe and $\mathrm{P}$ are almost noise levels due to the small amount of precipitate present on the molybdenite surface or the precipitates do not exist on the molybdenite surface.

In order to further characterize the surfaces of untreated and treated minerals, XPS analysis was adopted, which can analyze a very thin layer of coating (around $\sim 6 \mathrm{~nm}$ ) and give the information on the chemical state of the element. Figure 7a shows the XPS P 2p spectra of untreated and treated chalcopyrite. As it can be seen, treated chalcopyrite exhibited a broad peak that was centered at around $133.5 \mathrm{eV}$ composed of adsorbed $\mathrm{PO}_{4}{ }^{3-}(130.0,131.4$ and $132.8 \mathrm{eV})[34]$ and $\mathrm{P}^{(\mathrm{V})}$ of $\mathrm{FePO}_{4}(133.7 \mathrm{eV})[34,35]$, which support that $\mathrm{FePO}_{4}$ coating was formed on the chalcopyrite surface by microencapsulation while using $\mathrm{Fe}^{2+}$ and $\mathrm{PO}_{4}{ }^{3-}$. In the case of the XPS spectrum of treated molybdenite (Figure $7 \mathrm{~b}$ ), a weak and gentle peak of $\mathrm{FePO}_{4}$ was observed. The peak area of $\mathrm{FePO}_{4}$ in the XPS spectrum of treated chalcopyrite was three times higher than that of treated molybdenite, which indicated that more $\mathrm{FePO}_{4}$ is present on the chalcopyrite surface, as confirmed by Figures 4-6. All of the results that were obtained in this study imply that $\mathrm{Fe}^{2+}$ oxidation, followed by $\mathrm{FePO}_{4}$ precipitation, preferably occurs on the chalcopyrite surface rather than on the molybdenite surface, so the selective depression of chalcopyrite in the flotation of bulk concentrates is highly achievable, which will be evaluated in detail in Part 2 of this study. 

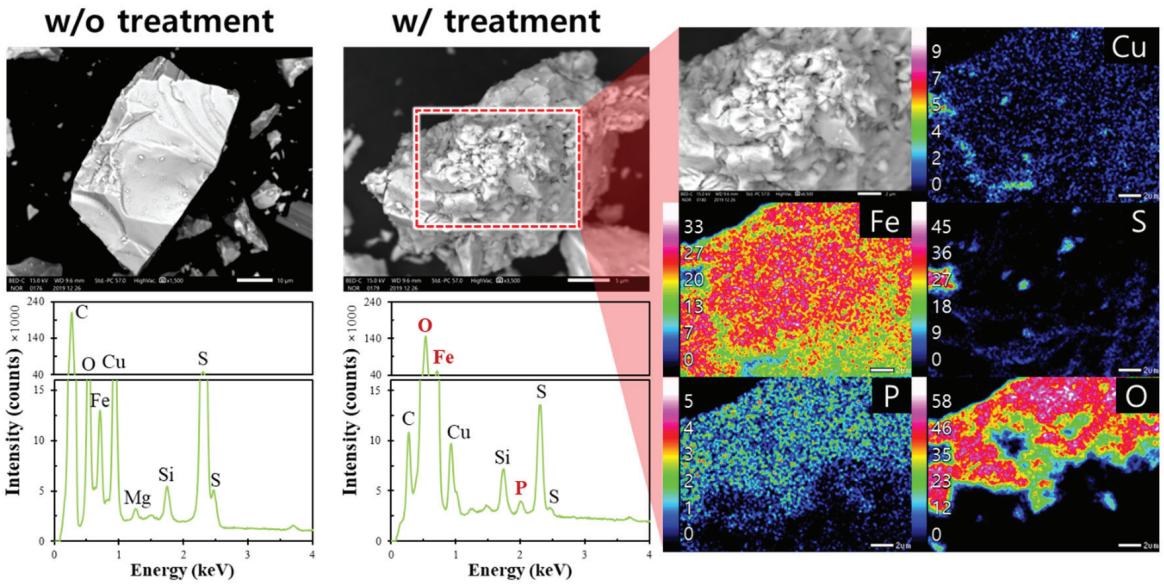

Figure 5. Scanning electron microscopy with energy-dispersive X-ray spectroscopy (SEM-EDX) results of chalcopyrite with and without microencapsulation treatment.
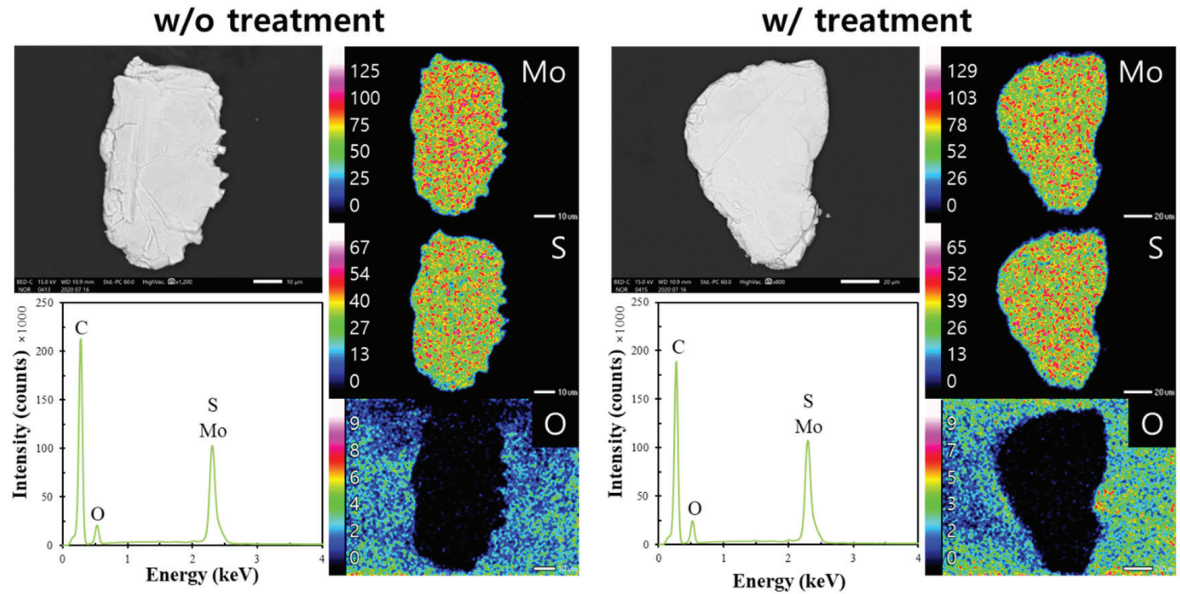

Figure 6. SEM-EDX results of molybdenite with and without microencapsulation treatment.
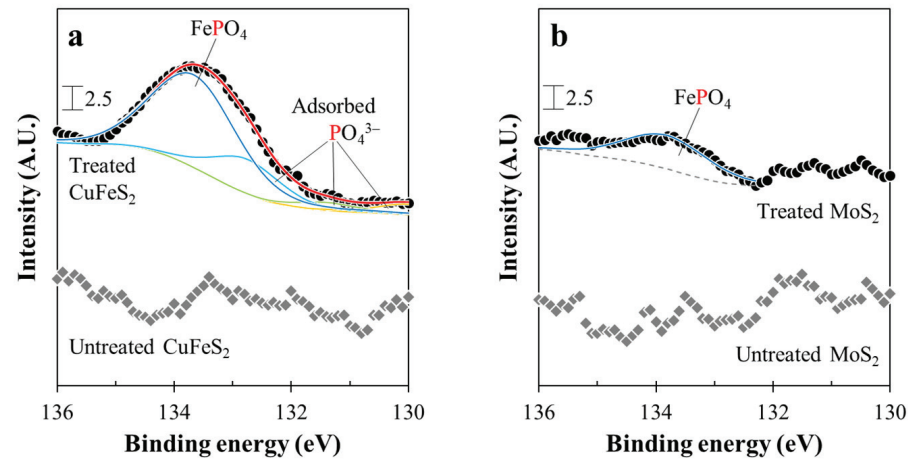

Figure 7. X-ray photoelectron spectroscopy (XPS) P 2p spectra of (a) chalcopyrite and (b) molybdenite with and without microencapsulation treatment. 


\section{Conclusions}

This study investigated microencapsulation while using $\mathrm{Fe}^{2+}$ and $\mathrm{PO}_{4}{ }^{3-}$ in order to selectively coat chalcopyrite with $\mathrm{FePO}_{4}$ with the aim of improving $\mathrm{Cu}-\mathrm{Mo}$ flotation separation. The findings of this study are summarized, as follows:

1. In the presence of phosphate ion, $\mathrm{Fe}^{2+}$ was stable at $\mathrm{pH} \leq 4$, above which, however, $\mathrm{Fe}^{2+}$ became unstable due to its rapid oxidation to $\mathrm{Fe}^{3+}$, which was then precipitated as $\mathrm{FePO}_{4}$ and/or $\mathrm{FeO}(\mathrm{OH})$. Thus, microencapsulation treatment using $\mathrm{Fe}^{2+}$ and $\mathrm{PO}_{4}{ }^{3-}$ is recommended to be conducted at $\mathrm{pH} 4$ in order to achieve the selective $\mathrm{Fe}^{2+}$ oxidation on chalcopyrite surface.

2. The CV results indicated that $\mathrm{Fe}^{2+}$ oxidation can occur on the chalcopyrite surface, but not on the molybdenite surface, due to their different electrical properties.

3. After microencapsulation treatment using $\mathrm{Fe}^{2+}$ and $\mathrm{PO}_{4}{ }^{3-}$, SEM-EDX and XPS analyses confirmed that chalcopyrite was more coated with $\mathrm{FePO}_{4}$ than molybdenite.

Author Contributions: Conceptualization, I.P., S.J., M.I. and N.H.; methodology, I.P.; investigation, I.P. and S.H.; data curation, I.P. and S.H.; writing —original draft preparation, I.P.; writing-review and editing, I.P., S.H., S.J., M.I. and N.H. All authors have read and agreed to the published version of the manuscript.

Funding: This study is financially supported by Japan Oil, Gas and Metals National Corporation (JOGMEC).

Conflicts of Interest: The authors declare no conflict of interest.

\section{References}

1. Bulatovic, S.M. 12-Flotation of Copper Sulfide Ores. In Handbook of Flotation Reagents; Bulatovic, S.M., Ed.; Elsevier: Amsterdam, The Netherlands, 2007; pp. 235-293. ISBN 978-0-444-53029-5.

2. Ayuso, R.A.; Barton, M.D.; Blakely, R.J.; Bodnar, R.J.; Dilles, J.H.; Gray, F.; Graybeal, F.T.; Mars, J.L.; McPhee, D.K.; Seal II, R.R.; et al. Porphyry Copper Deposit Model: Chapter B in Mineral Deposit Models for Resource Assessment; Scientific Investigations Report; U.S. 2010-5070-B; Geological Survey: Reston, VA, USA, 2010.

3. Miki, H.; Hirajima, T.; Muta, Y.; Suyantara, G.P.W.; Sasaki, K. Effect of Sodium Sulfite on Floatability of Chalcopyrite and Molybdenite. Minerals 2018, 8, 172. [CrossRef]

4. Johnston, A.; Meadows, D.G.; Cappuccitti, F. Copper Mineral Processing. In SME Mineral Processing $\mathcal{E}$ Extractive Metallurgy Handbook; Society for Mining, Metallurgy \& Exploration (SME): Englewood, CO, USA, 2019; Volume 2, pp. 1615-1641.

5. Amelunxen, P.; Schmitz, C.; Hill, H.; Goodweiler, N.; Andres, J. Molybdenum. In SME Mineral Processing $\mathcal{E}$ Extractive Metallurgy Handbook; Society for Mining, Metallurgy \& Exploration (SME): Englewood, CO, USA, 2019; Volume 2, pp. 1891-1916.

6. Sutherland, K.L.; Wark, I.W. Depressants. In Principles of Flotation; Australasian Institute of Mining and Metallurgy: Melbourne, Australia, 1955; pp. 113-153.

7. Park, I.; Hong, S.; Jeon, S.; Ito, M.; Hiroyoshi, N. A Review of Recent Advances in Depression Techniques for Flotation Separation of Cu-Mo Sulfides in Porphyry Copper Deposits. Metals 2020, 10, 1269. [CrossRef]

8. Hirajima, T.; Miki, H.; Suyantara, G.P.W.; Matsuoka, H.; Elmahdy, A.M.; Sasaki, K.; Imaizumi, Y.; Kuroiwa, S. Selective flotation of chalcopyrite and molybdenite with $\mathrm{H}_{2} \mathrm{O}_{2}$ oxidation. Miner. Eng. 2017, 100, 83-92. [CrossRef]

9. Miki, H.; Matsuoka, H.; Hirajima, T.; Suyantara, G.P.W.; Sasaki, K. Electrolysis Oxidation of Chalcopyrite and Molybdenite for Selective Flotation. Mater. Trans. 2017, 58, 761-767. [CrossRef]

10. Yin, Z.; Sun, W.; Hu, Y.; Zhang, C.; Guan, Q.; Zhang, C. Separation of Molybdenite from Chalcopyrite in the Presence of Novel Depressant 4-Amino-3-thioxo-3,4-dihydro-1,2,4-triazin-5(2H)-one. Minerals 2017, 7, 146. [CrossRef]

11. Wie, J.M.; Fuerstenau, D.W. The effect of dextrin on surface properties and the flotation of molybdenite. Int. J. Miner. Process. 1974, 1, 17-32. [CrossRef] 
12. Jorjani, E.; Barkhordari, H.R.; Tayebi Khorami, M.; Fazeli, A. Effects of aluminosilicate minerals on copper-molybdenum flotation from Sarcheshmeh porphyry ores. Miner. Eng. 2011, 24, 754-759. [CrossRef]

13. Ansari, A.; Pawlik, M. Floatability of chalcopyrite and molybdenite in the presence of lignosulfonates. Part II. Hallimond tube flotation. Miner. Eng. 2007, 20, 609-616. [CrossRef]

14. Yuan, D.; Cadien, K.; Liu, Q.; Zeng, H. Flotation separation of Cu-Mo sulfides by O-Carboxymethyl chitosan. Miner. Eng. 2019, 134, 202-205. [CrossRef]

15. Yuan, D.; Cadien, K.; Liu, Q.; Zeng, H. Adsorption characteristics and mechanisms of O-Carboxymethyl chitosan on chalcopyrite and molybdenite. J. Colloid Interface Sci. 2019, 552, 659-670. [CrossRef]

16. Kor, M.; Korczyk, P.M.; Addai-Mensah, J.; Krasowska, M.; Beattie, D.A. Carboxymethylcellulose Adsorption on Molybdenite: The Effect of Electrolyte Composition on Adsorption, Bubble-Surface Collisions, and Flotation. Langmuir 2014, 30, 11975-11984. [CrossRef] [PubMed]

17. Yuan, D.; Cadien, K.; Liu, Q.; Zeng, H. Selective separation of copper-molybdenum sulfides using humic acids. Miner. Eng. 2019, 133, 43-46. [CrossRef]

18. Chen, J.; Lan, L.; Liao, X. Depression effect of pseudo glycolythiourea acid in flotation separation of copper-molybdenum. Trans. Nonferrous Met. Soc. China 2013, 23, 824-831. [CrossRef]

19. Li, M.; Wei, D.; Shen, Y.; Liu, W.; Gao, S.; Liang, G. Selective depression effect in flotation separation of copper-molybdenum sulfides using 2,3-disulfanylbutanedioic acid. Trans. Nonferrous Met. Soc. China 2015, 25, 3126-3132. [CrossRef]

20. Yin, Z.; Sun, W.; Hu, Y.; Guan, Q.; Zhang, C.; Gao, Y.; Zhai, J. Depressing behaviors and mechanism of disodium bis (carboxymethyl) trithiocarbonate on separation of chalcopyrite and molybdenite. Trans. Nonferrous Met. Soc. China 2017, 27, 883-890. [CrossRef]

21. Li, M.; Wei, D.; Liu, Q.; Liu, W.; Zheng, J.; Sun, H. Flotation separation of copper-molybdenum sulfides using chitosan as a selective depressant. Miner. Eng. 2015, 83, 217-222. [CrossRef]

22. Laskowski, J.S.; Castro, S.; Ramos, O. Effect of seawater main components on frothability in the flotation of Cu-Mo sulfide ore. Physicochem. Probl. Miner. Process. 2013, 17-29. [CrossRef]

23. Park, I.; Tabelin, C.B.; Seno, K.; Jeon, S.; Inano, H.; Ito, M.; Hiroyoshi, N. Carrier-microencapsulation of arsenopyrite using Al-catecholate complex: Nature of oxidation products, effects on anodic and cathodic reactions, and coating stability under simulated weathering conditions. Heliyon 2020, 6, e03189. [CrossRef]

24. Park, I.; Tabelin, C.B.; Seno, K.; Jeon, S.; Ito, M.; Hiroyoshi, N. Simultaneous suppression of acid mine drainage formation and arsenic release by Carrier-microencapsulation using aluminum-catecholate complexes. Chemosphere 2018, 205, 414-425. [CrossRef]

25. McKibben, M.A.; Barnes, H.L. Oxidation of pyrite in low temperature acidic solutions: Rate laws and surface textures. Geochim. Cosmochim. Acta 1986, 50, 1509-1520. [CrossRef]

26. Shirley, D.A. High-Resolution X-Ray Photoemission Spectrum of the Valence Bands of Gold. Phys. Rev. B 1972, 5, 4709-4714. [CrossRef]

27. Nesbitt, H.W.; Muir, I.J. X-ray photoelectron spectroscopic study of a pristine pyrite surface reacted with water vapour and air. Geochim. Cosmochim. Acta 1994, 58, 4667-4679. [CrossRef]

28. Stumm, W.; Morgan, J.J. Aquatic Chemistry: Chemical Equilibria and Rates in Natural Waters; Wiley-Interscience: New York, NY, USA, 1996.

29. Morgan, B.; Lahav, $\mathrm{O}$. The effect of $\mathrm{pH}$ on the kinetics of spontaneous $\mathrm{Fe}(\mathrm{II})$ oxidation by $\mathrm{O}_{2}$ in aqueous solution-basic principles and a simple heuristic description. Chemosphere 2007, 68, 2080-2084. [CrossRef] [PubMed]

30. Qin, W.Q.; Yang, C.R.; Wang, J.; Zhang, Y.; Jiao, F.; Zhao, H.B.; Zhu, S. Effect of $\mathrm{Fe}^{2+}$ and $\mathrm{Cu}^{2+}$ Ions on the Electrochemical Behavior of Massive Chalcopyrite in Bioleaching System. Adv. Mater. Res. 2013, 825, 472-476. [CrossRef]

31. Holliday, R.I.; Richmond, W.R. An electrochemical study of the oxidation of chalcopyrite in acidic solution. J. Electroanal. Chem. Interfacial Electrochem. 1990, 288, 83-98. [CrossRef]

32. Liang, C.-L.; Xia, J.-L.; Yang, Y.; Nie, Z.-Y.; Zhao, X.-J.; Zheng, L.; Ma, C.-Y.; Zhao, Y.-D. Characterization of the thermo-reduction process of chalcopyrite at $65^{\circ} \mathrm{C}$ by cyclic voltammetry and XANES spectroscopy. Hydrometallurgy 2011, 107, 13-21. [CrossRef]

33. Castro, S.; Lopez-Valdivieso, A.; Laskowski, J.S. Review of the flotation of molybdenite. Part I: Surface properties and floatability. Int. J. Miner. Process. 2016, 148, 48-58. [CrossRef] 
34. Park, I.; Higuchi, K.; Tabelin, C.B.; Jeon, S.; Ito, M.; Hiroyoshi, N. Suppression of arsenopyrite oxidation by microencapsulation using ferric-catecholate complexes and phosphate. Chemosphere, under review.

35. Zeng, L.; Li, X.; Shi, Y.; Qi, Y.; Huang, D.; Tadé, M.; Wang, S.; Liu, S. FePO 4 based single chamber air-cathode microbial fuel cell for online monitoring levofloxacin. Biosens. Bioelectron. 2017, 91, 367-373. [CrossRef]

Publisher's Note: MDPI stays neutral with regard to jurisdictional claims in published maps and institutional affiliations.

(C) 2020 by the authors. Licensee MDPI, Basel, Switzerland. This article is an open access article distributed under the terms and conditions of the Creative Commons Attribution (CC BY) license (http://creativecommons.org/licenses/by/4.0/). 



\title{
Article \\ Flotation Separation of Chalcopyrite and Molybdenite Assisted by Microencapsulation Using Ferrous and Phosphate Ions: Part II. Flotation
}

\author{
Ilhwan Park ${ }^{1, *}$, Seunggwan Hong ${ }^{2}$, Sanghee Jeon ${ }^{1}$, Mayumi Ito ${ }^{1}$ and Naoki Hiroyoshi ${ }^{1}$ \\ 1 Division of Sustainable Resources Engineering, Faculty of Engineering, Hokkaido University, \\ Sapporo 060-8628, Japan; shjun1121@eng.hokudai.ac.jp (S.J.); itomayu@eng.hokudai.ac.jp (M.I.); \\ hiroyosi@eng.hokudai.ac.jp (N.H.) \\ 2 Cooperative Program for Resources Engineering, Graduate School of Engineering, Hokkaido University, \\ Sapporo 060-8628, Japan; seunggwan.hong.s4@elms.hokudai.ac.jp \\ * Correspondence: i-park@eng.hokudai.ac.jp; Tel.: +81-11-706-6315
}

Citation: Park, I.; Hong, S.; Jeon, S.; Ito, M.; Hiroyoshi, N. Flotation Separation of Chalcopyrite and Molybdenite Assisted by Microencapsulation Using Ferrous and Phosphate Ions: Part II. Flotation. Metals 2021, 11, 439. https:// doi.org/10.3390/met11030439

Academic Editor: Man Seung Lee

Received: 19 February 2021

Accepted: 5 March 2021

Published: 7 March 2021

Publisher's Note: MDPI stays neutral with regard to jurisdictional claims in published maps and institutional affiliations.

Copyright: (c) 2021 by the authors. Licensee MDPI, Basel, Switzerland. This article is an open access article distributed under the terms and conditions of the Creative Commons Attribution (CC BY) license (https:// creativecommons.org/licenses/by/ $4.0 /)$.

\begin{abstract}
Porphyry-type deposits are the major sources of copper and molybdenum, and flotation has been adopted to recover them separately. The conventional reagents used for depressing copper minerals, such as $\mathrm{NaHS}, \mathrm{Na}_{2} \mathrm{~S}$, and Nokes reagent, have the potential to emit toxic $\mathrm{H}_{2} \mathrm{~S}$ gas when pulp $\mathrm{pH}$ was not properly controlled. Thus, in this study the applicability of microencapsulation (ME) using ferrous and phosphate ions as an alternative process to depress the floatability of chalcopyrite was investigated. During ME treatment, the use of high concentrations of ferrous and phosphate ions together with air introduction increased the amount of $\mathrm{FePO}_{4}$ coating formed on the chalcopyrite surface, which was proportional to the degree of depression of its floatability. Although ME treatment also reduced the floatability of molybdenite, $\sim 92 \%$ Mo could be recovered by utilizing emulsified kerosene. Flotation of chalcopyrite/molybdenite mixture confirmed that the separation efficiency was greatly improved from $10.9 \%$ to $66.8 \%$ by employing ME treatment as a conditioning process for $\mathrm{Cu}$-Mo flotation separation.
\end{abstract}

Keywords: porphyry deposits; chalcopyrite; molybdenite; microencapsulation; flotation

\section{Introduction}

Porphyry-type deposits are the major sources of copper $(\mathrm{Cu})$ and molybdenum $(\mathrm{Mo})$ approximately $60 \%$ of $\mathrm{Cu}$ and $50 \%$ of Mo are annually produced from these deposits [1-3]. Apart from $\mathrm{Cu}$ and $\mathrm{Mo}$, precious metals (e.g., gold (Au), silver (Ag), and platinum group elements (PGEs)) and several strategic/high-tech elements (e.g., rhenium (Re), tungsten (W), bismuth (Bi), indium (In), tellurium (Te), and selenium (Se)) may reach economic concentrations, thus being recovered as by-products during porphyry ore processing [3,4]. Typically, porphyry-type deposits are developed via a series of processes: (i) open-pit mining to excavate the ores, (ii) closed-circuit comminution to liberate valuable and non-valuable minerals, (iii) bulk flotation to recover $\mathrm{Cu}$ and Mo minerals (i.e., mainly chalcopyrite $\left(\mathrm{CuFeS}_{2}\right)$ and molybdenite $\left.\left(\mathrm{MoS}_{2}\right)\right)$ as $\mathrm{Cu}$-Mo bulk concentrates, and (iv) Mo flotation to separate $\mathrm{Cu}$ and Mo minerals from bulk concentrates [2].

At the final stage of porphyry ore processing (i.e., flotation separation of $\mathrm{Cu}$ and $\mathrm{Mo}$ minerals), $\mathrm{Cu}-\mathrm{Mo}$ bulk concentrates are conditioned with $\mathrm{Cu}$ depressants (e.g., sodium hydrosulfide (NaHS), sodium sulfide $\left(\mathrm{Na}_{2} \mathrm{~S}\right)$, and Nokes reagent $\left(\mathrm{P}_{2} \mathrm{~S}_{5}+\mathrm{NaOH}\right)$ ) to reduce the floatability of chalcopyrite while floating molybdenite [1,2]. Although effective, these reagents have the potential to emit hydrogen sulfide $\left(\mathrm{H}_{2} \mathrm{~S}\right)$ gas-known as toxic and deadly gas-when the pulp $\mathrm{pH}$ is not properly maintained; for example, at $\mathrm{pH}<10$, $\mathrm{HS}^{-}$ ion derived from $\mathrm{Cu}$ depressants starts forming $\mathrm{H}_{2} \mathrm{~S}_{(\mathrm{aq})}$ species, which is then readily transformed into the gaseous phase, i.e., $\mathrm{H}_{2} \mathrm{~S}_{(\mathrm{g})}$, due to its extremely high vapor pressure $\left(\mathrm{P}_{\mathrm{H}_{2} \mathrm{~S}}=20.03 \mathrm{~atm}\right.$ at $\left.25^{\circ} \mathrm{C}\right)[2,5]$. To avoid the accident that is caused by $\mathrm{H}_{2} \mathrm{~S}$ emission, the 
flotation circuits should consist of covered flotation cells together with active ventilation systems as well as a $\mathrm{NaOH}$-solution scrubber treating any process off-gas [6]. However, the use of covered flotation cells obviously obstructs visual inspection of the froth, which lowers the efficiency of operations of flotation process [6]. Not only this, but the use of above-mentioned reagents may destroy the pipelines due to the corrosive nature of $\mathrm{H}_{2} \mathrm{~S}$ and yield imperfect molybdenite recovery [7-9], so the attention should be paid to the development of alternative techniques.

This paper is Part II of a two-part basic study to investigate how the application of microencapsulation technique affects flotation behaviors of chalcopyrite and molybdenite. Microencapsulation is a technique that encloses the target material with coatings composed of small discrete solid particles or small liquid droplets. It has been reported that microencapsulation using redox-sensitive compounds has an ability to selectively form the coating on the surface of conductive minerals [10-14]. In Part I of this study, microencapsulation using ferrous and phosphate ions was investigated with the aim of creating ferric phosphate $\left(\mathrm{FePO}_{4}\right)$ coating selectively on the chalcopyrite surface [15]. Electrochemical study revealed that ferrous oxidation occurred preferably on the surface of chalcopyrite rather than molybdenite. Moreover, the results of shake-flask experiments coupled with surface characterizations were consistent with electrochemical study; that is, ferrous oxidation followed by $\mathrm{FePO}_{4}$ formation occurred predominantly on the chalcopyrite surface. However, it remains unclear how $\mathrm{FePO}_{4}$ coating formed via microencapsulation affects the floatability of chalcopyrite and molybdenite. In Part II, thus, flotation tests of chalcopyrite and/or molybdenite with and without microencapsulation treatment were carried out to evaluate its effect on the floatability of chalcopyrite and molybdenite as well as their separation efficiency.

\section{Materials and Methods}

\subsection{Mineral Samples}

Chalcopyrite and molybdenite were obtained from Copper Queen Mine, Cochise County, AZ, USA and Spain Mine, Renfrew County, ON, Canada, respectively. The samples were crushed by a jaw crusher (BB 51, Retsch Inc. Haan, Germany), ground by a vibratory disc mill (RS 100, Retsch Inc., Haan, Germany), and then screened in order to obtain a size fraction of 38-75 $\mu \mathrm{m}$. Chalcopyrite sample mainly consists of chalcopyrite $(\sim 70 \%)$ with minor amounts of impurities like pyrite $\left(\mathrm{FeS}_{2}\right)$ and silicate minerals (e.g., quartz $\left(\mathrm{SiO}_{2}\right)$, amesite $\left(\mathrm{Mg}_{2} \mathrm{Al}_{2} \mathrm{SiO}_{5}(\mathrm{OH})_{4}\right)$, and actinolite $\left.\left(\mathrm{Ca}_{2}\left(\mathrm{Mg}, \mathrm{Fe}^{2+}\right)_{5} \mathrm{Si}_{8} \mathrm{O}_{22}(\mathrm{OH})_{2}\right)\right)$, while molybdenite sample is highly pure ( $99.8 \%)$. The detailed sample characterizations can be found in Part I of this study [15].

\subsection{Microencapsulation Treatment}

Prior to microencapsulation (ME) treatment, mineral samples were deslimed by ultrasonication in ethanol for $1 \mathrm{~min}$, followed by decantation after 1 min sedimentation. Afterward, the sediments were rinsed with acetone four times and dried in vacuum desiccators.

Microencapsulation treatments were conducted using an agitator-type flotation machine (FT-1000, Heiko, Japan). In a 400-mL flotation cell, $20 \mathrm{~g}$ of mineral sample (i.e., chalcopyrite, molybdenite, or chalcopyrite/molybdenite mixture $(1: 1, w / w))$ and $200 \mathrm{~mL}$ of coating solution containing ferrous and phosphate ions were mixed at $1000 \mathrm{rpm}$ for $1 \mathrm{~h}$. Coating solution was prepared using $\mathrm{FeSO}_{4} \cdot 7 \mathrm{H}_{2} \mathrm{O}$ and $\mathrm{KH}_{2} \mathrm{PO}_{4}$, and its $\mathrm{pH}$ was adjusted to $4.0 \pm 0.1$ while using dilute $\mathrm{HCl}$ and $\mathrm{NaOH}$. All the chemicals used in this study were of reagent grade (Wako Pure Chemical Industries, Ltd., Osaka, Japan). To investigate the suitable conditions for depressing the floatability of chalcopyrite, the effects of the concentrations of ferrous and phosphate ions $(1$ and $10 \mathrm{mM})$ and the introduction of air (1 L/min) during ME treatment were examined.

After ME treatment, the suspension was filtered and washed with deionized (DI) water 4 times to remove the remaining ferrous and phosphate ions, and then used for flotation experiments. Filtrates were collected using $0.2 \mu \mathrm{m}$ syringe-driven filters (LMS Co. Ltd., 
Tokyo, Japan) and analyzed by inductively coupled plasma atomic emission spectrometer (ICP-AES, ICPE9820, Shimadzu Corporation, Kyoto, Japan) in order to identify the changes in dissolved $\mathrm{Fe}$ and $\mathrm{P}$ concentrations.

\subsection{Flotation Tests}

Flotation tests were conducted using an agitator-type flotation machine (FT-1000, Heiko, Japan) equipped with a 400-mL flotation cell in which $20 \mathrm{~g}$ of washed sample, $10 \mathrm{~g}$ of quartz (99.9\% $\mathrm{SiO}_{2}$, Wako Pure Chemical Industries, Ltd., Osaka, Japan), and $400 \mathrm{~mL}$ DI water were added. The purpose of adding quartz is to measure the amounts of chalcopyrite/molybdenite recovered by entrainment. The pulp was suspended at $1000 \mathrm{rpm}$ for $3 \mathrm{~min}$, and then conditioned with $25 \mu \mathrm{L} / \mathrm{L}$ of frother (methyl isobutyl carbinol, MIBC, Tokyo Chemical Industry Co., Ltd., Tokyo, Japan) for another $3 \mathrm{~min}$. In the flotation of molybdenite and chalcopyrite/molybdenite mixture, $2.5 \mathrm{~L} / \mathrm{t}$ of emulsified kerosene was added as a collector for molybdenite and conditioned for $3 \mathrm{~min}$. Emulsified kerosene was prepared as follows: (i) kerosene (Wako Pure Chemical Industries, Ltd., Osaka, Japan) was mixed with distilled water in the concentration of $20 \mathrm{wt}$ \%; (ii) emulsification was carried out using an ultrasonic homogenizer (ULTRA-TURRAX, IKA, Königswinter, Germany) for $60 \mathrm{~s}[16,17]$. Afterward, air was injected into the suspension at a flow rate of $1 \mathrm{~L} / \mathrm{min}$, and flotation was carried out for $3 \mathrm{~min}$ (for the case of flotation of chalcopyrite/molybdenite mixture, it was conducted for up to $6 \mathrm{~min}$ ). Froth products and tailings obtained after flotation were weighed after drying at $105^{\circ} \mathrm{C}$ for $24 \mathrm{~h}$, and their elemental compositions were determined using X-ray fluorescence spectrometer (XRF, EDXL300, Rigaku Corporation, Tokyo, Japan).

\subsection{Contact Angle Measurements}

Contact angle measurements were carried out in order to estimate the changes in the surface wettability of molybdenite before and after ME treatment (with and without kerosene addition). For this, molybdenite specimen was cut using a diamond cutter to obtain a small cuboid crystal $(\sim 5 \mathrm{~mm}(\mathrm{w}) \times 5 \mathrm{~mm}(\mathrm{~d}) \times 10 \mathrm{~mm}(\mathrm{~h}))$, which was then polished using a polishing machine (SAPHIR 250 M1, ATM GmbH, Mammelzen, Germany) with a series of silicon carbide papers (P320, P600, and P1200) and diamond suspensions (3 and $1 \mu \mathrm{m}$ ). Afterward, the contact angles of (i) untreated molybdenite, (ii) ME-treated molybdenite with $10 \mathrm{mM} \mathrm{Fe}{ }^{2+} / \mathrm{H}_{2} \mathrm{PO}_{4}^{-}$at $1 \mathrm{~L} / \mathrm{min}$ air introduction for $1 \mathrm{~h}$, and (iii) MEtreated molybdenite with conditioning using $2.5 \mathrm{~L} / \mathrm{t}$ of emulsified kerosene for 3 min were measured by a high-magnification digital microscope (VHX-1000, Keyence Corporation, Osaka, Japan) with built in image analysis capability. Each measurement was repeated 3 times at different spots on the mineral surface to ascertain that the differences observed were statistically significant.

\section{Results and Discussion}

\subsection{Flotation of Chalcopyrite}

Figure 1 shows the effect of ME treatment on the floatability of chalcopyrite. For the case of untreated chalcopyrite, about $77 \%$ of $\mathrm{Cu}$ was recovered after 3 min flotation even in the absence of any collector. When chalcopyrite was treated by $\mathrm{ME}$ with $1 \mathrm{mM} \mathrm{Fe} \mathrm{F}^{2+}$ and $1 \mathrm{mM} \mathrm{H}_{2} \mathrm{PO}_{4}^{-}$prior to flotation, $\mathrm{Cu}$ recovery was almost the same as the one without ME treatment. In Part I of this study [15], it was confirmed that after ME treatment using $1 \mathrm{mM} \mathrm{Fe}^{2+}$ and $1 \mathrm{mM} \mathrm{H}_{2} \mathrm{PO}_{4}^{-}$, chalcopyrite was obviously coated with $\mathrm{FePO}_{4}$; however, its floatability was not affected by $\mathrm{FePO}_{4}$ coating.

One of the possible reasons for why ME treatment did not affect the floatability of chalcopyrite could be due to the insufficient amount of $\mathrm{FePO}_{4}$ coating for depressing chalcopyrite. After $1 \mathrm{~h} \mathrm{ME}$ treatment, $80 \%$ of dissolved Fe and $\mathrm{P}$ were precipitated as $\mathrm{FePO}_{4}$, indicating that the wt. $\%$ of $\mathrm{FePO}_{4}$ present on the chalcopyrite surface was approximately $0.12 \%$ [15]. If chalcopyrite is covered with a large amount of $\mathrm{FePO}_{4}$ coating (i.e., $>0.12 \%$ ), its floatability may be decreased. Thus, an attempt was made to increase the amount of 
$\mathrm{FePO}_{4}$ coating formed on the chalcopyrite surface by increasing the concentrations of $\mathrm{Fe}^{2+}$ and $\mathrm{H}_{2} \mathrm{PO}_{4}^{-}$from 1 to $10 \mathrm{mM}$ during $\mathrm{ME}$ treatment. As shown in Figure 2, Cu recovery was decreased from $\sim 80 \%$ to $\sim 70 \%$ when $\mathrm{Fe}^{2+} / \mathrm{H}_{2} \mathrm{PO}_{4}^{-}$concentrations increased from 1 to $10 \mathrm{mM}$. Although increasing $\mathrm{Fe}^{2+} / \mathrm{H}_{2} \mathrm{PO}_{4}^{-}$concentrations during $\mathrm{ME}$ treatment could reduce the floatability of chalcopyrite, the degree of chalcopyrite depression is not enough for separating chalcopyrite and molybdenite.

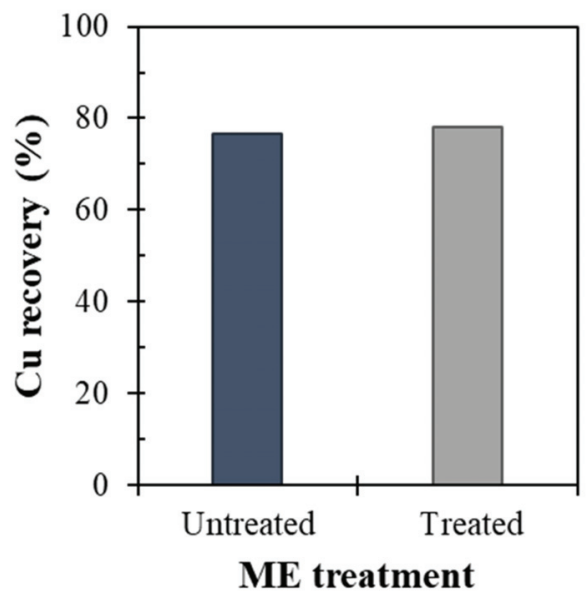

Figure 1. Effect of ME treatment on the floatability of chalcopyrite.

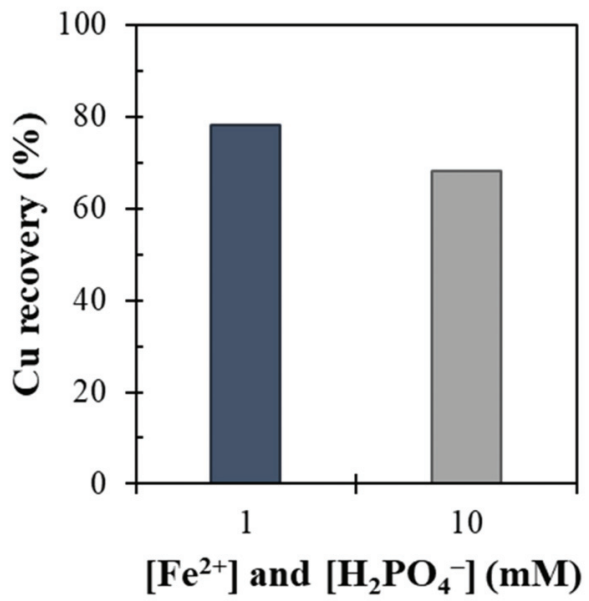

Figure 2. Effect of the concentration of $\mathrm{Fe}^{2+}$ and $\mathrm{H}_{2} \mathrm{PO}_{4}^{-}$on the floatability of chalcopyrite.

The concentration of $\mathrm{FePO}_{4}$ formed after $\mathrm{ME}$ treatment was $0.66 \mathrm{mM}$ for the case using $1 \mathrm{mM} \mathrm{Fe}^{2+} / \mathrm{H}_{2} \mathrm{PO}_{4}^{-}$, while $\sim 1 \mathrm{mM}$ of $\mathrm{FePO}_{4}$ was formed when $10 \mathrm{mM} \mathrm{Fe} e^{2+} / \mathrm{H}_{2} \mathrm{PO}_{4}^{-}$was used. These results support our deduction that increasing the amount of $\mathrm{FePO}_{4}$ coating can enhance the depression of chalcopyrite. However, there are large amounts of unreacted ferrous and phosphate ions that remained in the solution after ME treatment. As illustrated in Equation (1), oxygen is an essential reactant for ferrous oxidation.

$$
2 \mathrm{Fe}^{2+}+2 \mathrm{H}^{+}+1 / 2 \mathrm{O}_{2}=2 \mathrm{Fe}^{3+}+\mathrm{H}_{2} \mathrm{O}
$$


To facilitate the formation of more coatings on the surface of chalcopyrite, thus, the air was introduced during $\mathrm{ME}$ treatment in the presence of $10 \mathrm{mM} \mathrm{Fe} \mathrm{e}^{2+} / \mathrm{H}_{2} \mathrm{PO}_{4}^{-}$. As shown in Figure 3, air introduction during ME treatment obviously improved the depression of chalcopyrite floatability; that is, $\mathrm{Cu}$ recovery decreased from about 70\% (without air introduction) to $<15 \%$ (with air introduction). Control experiment-flotation of chalcopyrite treated under air introduction $(1 \mathrm{~L} / \mathrm{min})$ for $1 \mathrm{~h}$ in the absence of $\mathrm{Fe}^{2+} / \mathrm{H}_{2} \mathrm{PO}_{4}^{-}$- confirmed that air introduction did not play an important role in depressing the floatability of chalcopyrite because $\mathrm{Cu}$ recovery was almost the same as that of untreated chalcopyrite (data not shown). The main role of introducing air is to promote the cathodic half-cell reaction occurring on the surface of chalcopyrite (i.e., oxygen reduction reaction; Equation (2)), thereby enhancing the anodic half-cell reaction (i.e., ferrous oxidation reaction; Equation (3)). When

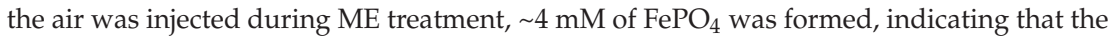
formation of large amounts of $\mathrm{FePO}_{4}$ coating is effective in depressing chalcopyrite.

$$
\begin{gathered}
2 \mathrm{H}^{+}+1 / 2 \mathrm{O}_{2}+2 \mathrm{e}^{-}=\mathrm{H}_{2} \mathrm{O} \\
\mathrm{Fe}^{2+}=\mathrm{Fe}^{3+}+\mathrm{e}^{-}
\end{gathered}
$$

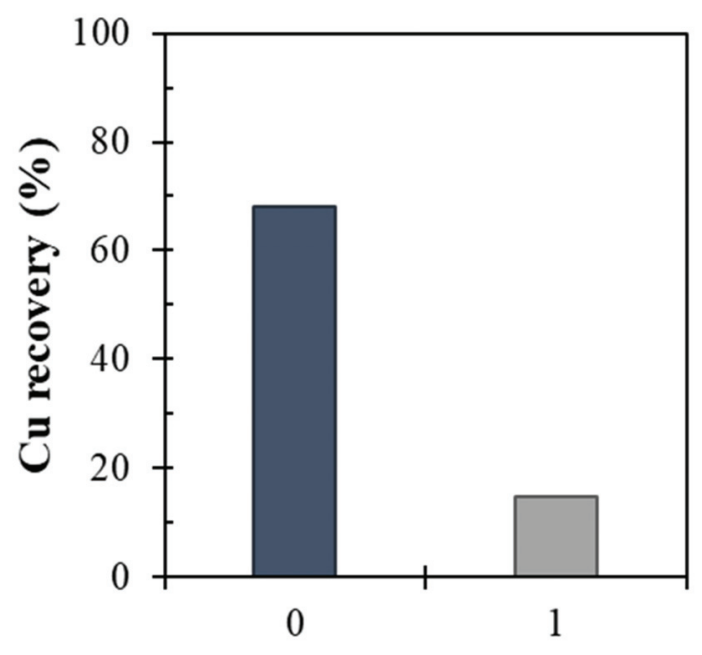

\section{Air introduction (L/min)}

Figure 3. Effect of air introduction during ME treatment with $10 \mathrm{mM} \mathrm{Fe}^{2+} / \mathrm{H}_{2} \mathrm{PO}_{4}^{-}$on the floatability of chalcopyrite.

\subsection{Flotation of Molybdenite}

The main purpose of ME treatment is to depress the floatability of chalcopyrite, so molybdenite was also treated by ME under the same conditions where chalcopyrite was effectively depressed (i.e., $10 \mathrm{mM} \mathrm{Fe}{ }^{2+} / \mathrm{H}_{2} \mathrm{PO}_{4}^{-} ; 1 \mathrm{~L} / \mathrm{min}$ air introduction). As shown in Figure 4, ME treatment had a detrimental effect on the floatability of molybdenite; that is, after ME treatment, Mo recovery decreased from $\sim 45 \%$ to $\sim 6 \%$. For the flotation separation of chalcopyrite and molybdenite, the former should be depressed while floating the latter; thus, this is an unwelcome result because molybdenite was also depressed after ME treatment. As confirmed by XPS analysis of ME-treated chalcopyrite and molybdenite shown in Part I of this study [15], the amount of $\mathrm{FePO}_{4}$ coating formed on the molybdenite surface was obviously smaller than that formed on the chalcopyrite surface; however, molybdenite was strongly depressed as much as chalcopyrite was (Figures 3 and 4). 


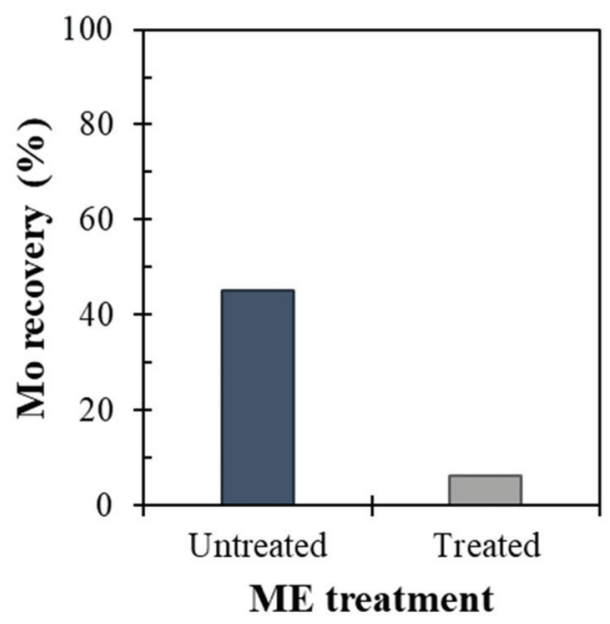

Figure 4. Effect of ME treatment on the floatability of molybdenite. Note that ME treatment was conducted with $10 \mathrm{mM} \mathrm{Fe} e^{2+} / \mathrm{H}_{2} \mathrm{PO}_{4}^{-}$and $1 \mathrm{~L} /$ min air introduction.

The presence of precipitates on the molybdenite surface has been reported to reduce its floatability; for example, (i) flotation of $\mathrm{Cu}$-Mo ores in seawater where seawater precipitates (e.g., $\mathrm{Mg}(\mathrm{OH})_{2}$ and $\mathrm{CaCO}_{3}$ ) formed at $\mathrm{pH}>9.5$ are accumulated on the molybdenite surface [18-21]; (ii) flotation of chalcopyrite/molybdenite mixture after plasma pretreatment resulting in the formation of $\mathrm{Cu} / \mathrm{Fe}$ oxyhydroxides on the surface of molybdenite [22]. Hirajima and coworkers [20-22] reported that the reduced floatability of molybdenite caused by precipitates can be healed by adding kerosene- a commonly used collector for molybdenite. In this study, thus, kerosene was also adopted after ME treatment to improve the recovery of molybdenite. As can be seen in Figure 5, the addition of kerosene was remarkably effective in improving the floatability of ME-treated molybdenite; that is, Mo recovery was increased from $\sim 6 \%$ to $\sim 92 \%$ when $2.5 \mathrm{~L} / \mathrm{t}$ of kerosene was added.

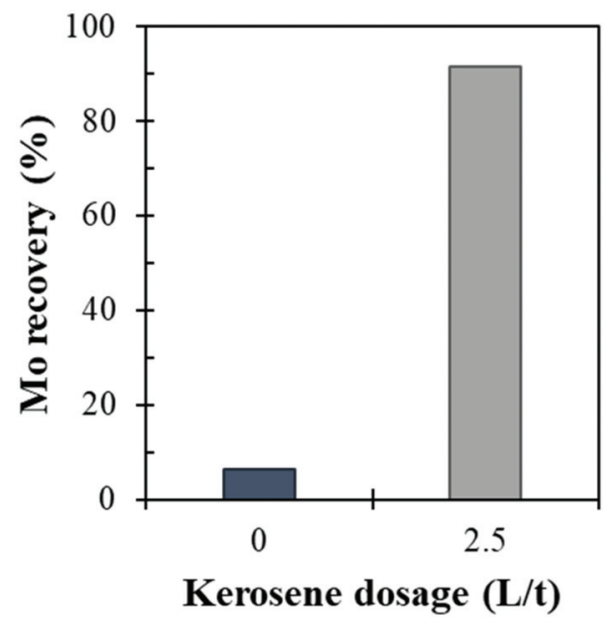

Figure 5. Effect of kerosene dosage on the floatability of ME-treated molybdenite.

The increased Mo recovery achieved by kerosene addition most likely resulted from the improvement of hydrophobicity of molybdenite surface. As illustrated in Figure 6, 
the contact angle of untreated molybdenite was $\sim 94^{\circ}$ but decreased to $\sim 39^{\circ}$ after ME treatment due to the presence of hydrophilic $\mathrm{FePO}_{4}$ precipitates on its surface. When MEtreated molybdenite reacted with kerosene, however, the contact angle increased to $\sim 109^{\circ}$, indicating that the hydrophobicity of molybdenite was improved, even better than that of bare molybdenite surface. This increased hydrophobicity of ME-treated molybdenite can be explained as follows: kerosene is adsorbed on molybdenite surface where $\mathrm{FePO}_{4}$ is not present and/or covers not only molybdenite but also the attached $\mathrm{FePO}_{4}$ precipitates.

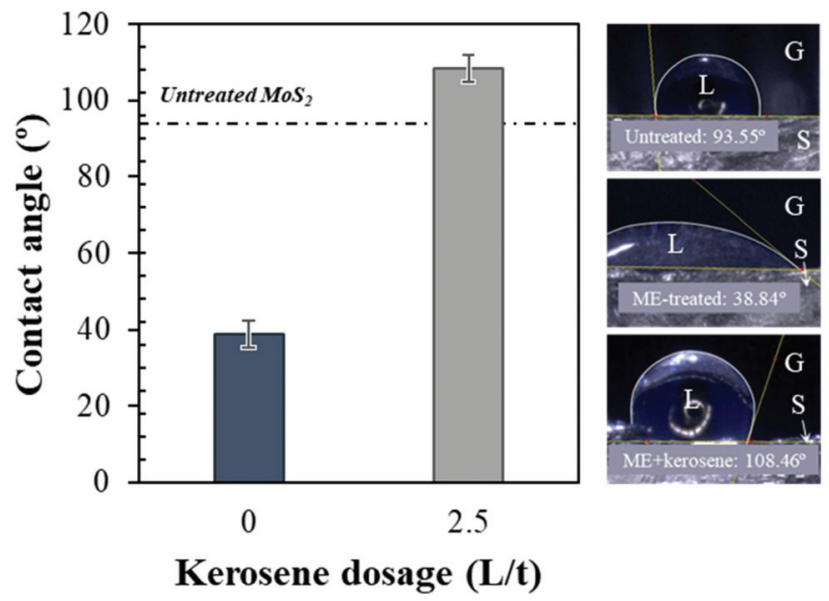

Figure 6. Effect of kerosene dosage on the contact angle of ME-treated molybdenite. Note that G, L, and $S$ on the right side of the photos indicate gas (air), liquid (water droplet), and solid (molybdenite) phases, respectively.

Based on the results of Sections 3.1 and 3.2, Cu-Mo flotation separation could be achievable under the following conditions: $\mathrm{ME}$ treatment with $10 \mathrm{mM} \mathrm{Fe}{ }^{2+} / \mathrm{H}_{2} \mathrm{PO}_{4}^{-}$while introducing air at $1 \mathrm{~L} / \mathrm{min}$ air introduction, and flotation with $2.5 \mathrm{~L} / \mathrm{t}$ kerosene. Although ME treatment followed by flotation of single minerals (i.e., chalcopyrite or molybdenite) looked promising, flotation results can be differed when they are mixed, so the following section deals with the mixed minerals system.

\subsection{Flotation of Chalcopyrite/Molybdenite Mixture}

Figure 7 shows flotation results of chalcopyrite/molybdenite mixture with and without ME treatment. As illustrated in Figure 7a, flotation of untreated chalcopyrite/molybdenite mixture showed that both minerals were floated well and, after $6 \mathrm{~min}$ flotation, the recovery of $\mathrm{Cu}$ and Mo reached about $83 \%$ and $92 \%$, respectively. On the other hand, $\mathrm{Cu}$ and Mo recoveries after 6 min flotation of ME-treated mixture were $\sim 33 \%$ and $\sim 93 \%$, respectively (Figure $7 \mathrm{~b}$ ). In the case of ME-treated mixture, froth products with higher Mo grade (46.33-49.3\%) and lower $\mathrm{Cu}$ grade (3.8-5.2\%) compared to those of untreated mixture (i.e., Mo grade, 33.8-34.6\%; Cu grade, 9.6-9.8\%) were obtained. These results indicate that the application of ME treatment prior to flotation of chalcopyrite/molybdenite mixture could selectively depress the floatability of chalcopyrite.

The effect of ME treatment on flotation of chalcopyrite/molybdenite mixture was evaluated by the classical first-order flotation kinetic model (Equation (4)) [23]:

$$
\mathrm{R}(\mathrm{t})=\mathrm{R}_{\infty}[1-\exp (-\mathrm{kt})],
$$

where $R(t)$ and $R_{\infty}$ are the recovery of chalcopyrite/molybdenite at time $t$ and an infinite time, and $\mathrm{k}$ is the first-order rate constant. A nonlinear least square regression was used to calculate $R_{\infty}$ and $k$ from the best fit with experimental data. The obtained $R_{\infty}$ and $k$ were 
used for calculating the modified rate constant (Equation (5)) and the selectivity index of mineral I over mineral II (Equation (6)) [24]:

$$
\mathrm{K}_{\mathrm{M}}=\mathrm{R}_{\infty} \cdot \mathrm{k},
$$

S.I. $(\mathrm{I} / \mathrm{II})=\left(\mathrm{K}_{\mathrm{M}}\right.$ of mineral $\left.\mathrm{I}\right) /\left(\mathrm{K}_{\mathrm{M}}\right.$ of mineral II $)$.

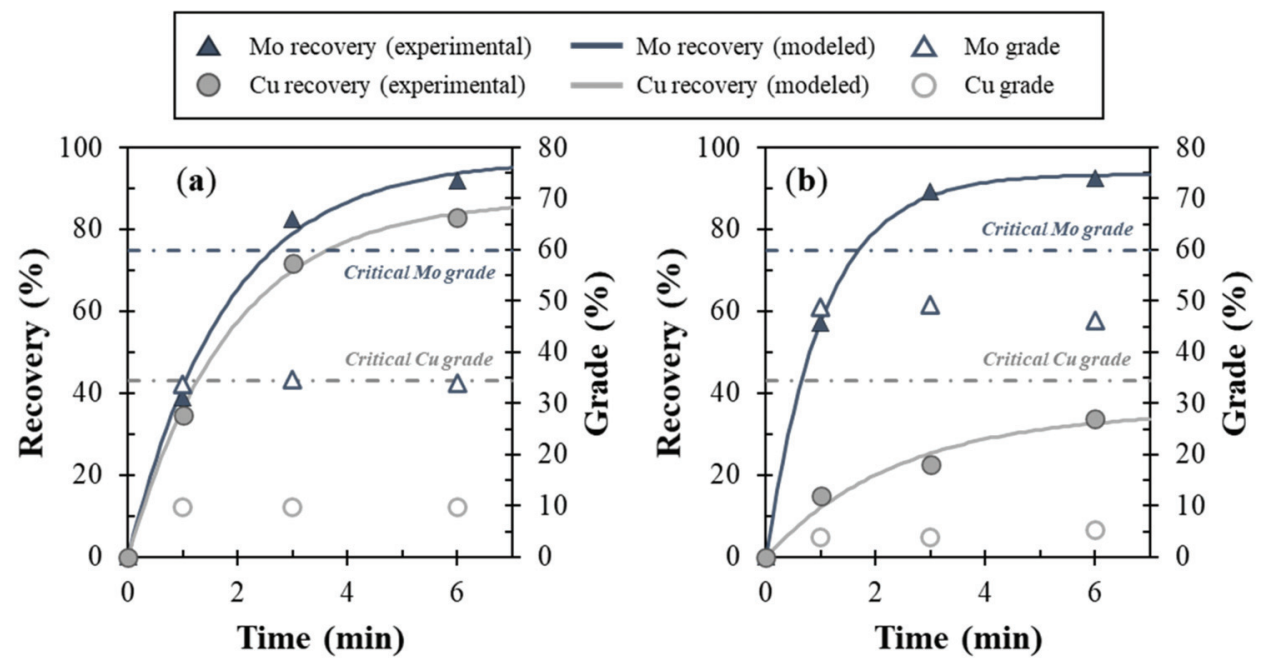

Figure 7. Effect of ME treatment on the floatability of chalcopyrite and molybdenite in the mixed mineral flotation: (a) untreated and (b) treated chalcopyrite/molybdenite mixture. Note that makers indicate experimental data while lines denote calculated values based on the first-order flotation kinetic model (Equation (4)).

The regression coefficients (e.g., $\mathrm{R}_{\infty}$ and $\mathrm{k}$ ), $\mathrm{K}_{\mathrm{M}}$, and S.I. $(\mathrm{Mo} / \mathrm{Cu}$ ) were summarized in Table 1 . The maximum recovery $\left(\mathrm{R}_{\infty}\right)$ of molybdenite was almost the same irrespective of ME treatment (i.e., $97.0 \%$ without ME; $93.5 \%$ with $\mathrm{ME}$ ), whereas $\mathrm{R}_{\infty}$ of ME-treated chalcopyrite decreased significantly from $87.3 \%$ to $35.7 \%$. After ME treatment, the rate constant $(\mathrm{k})$ and modified rate constant $\left(\mathrm{K}_{\mathrm{M}}\right)$ increased for molybdenite but decreased for chalcopyrite. Moreover, the selectivity index of Mo/Cu of ME-treated chalcopyrite/molybdenite mixture was about five-fold higher than that of untreated mixture, indicating that ME treatment has an ability to selectively depress the floatability of chalcopyrite.

Table 1. Non-linear regression results for the first-order kinetic model fitting to the experimental data (Figure 6).

\begin{tabular}{ccccc}
\hline \multirow{2}{*}{ Parameters } & \multicolumn{2}{c}{ Untreated } & \multicolumn{2}{c}{ Treated } \\
\cline { 2 - 5 } & Chalcopyrite & Molybdenite & Chalcopyrite & Molybdenite \\
\hline $\mathrm{R}^{2}$ & 0.99 & 0.99 & 0.93 & 0.99 \\
$\mathrm{R}_{\infty}(\%)$ & 87.3 & 97.0 & 35.7 & 93.5 \\
$\mathrm{k}\left(\mathrm{min}^{-1}\right)$ & 0.54 & 0.56 & 0.41 & 0.96 \\
$\mathrm{~K}_{\mathrm{M}}\left(\mathrm{min}^{-1}\right)$ & 0.47 & 0.54 & 0.15 & 0.89 \\
\hline S.I. $(\mathrm{Mo} / \mathrm{Cu})$ & & 1.16 & & 6.08 \\
\hline
\end{tabular}


Figure 8 shows the relationship between Mo recovery in the froth and Cu recovery in the tailing after flotation with and without ME treatment, which is often used for the assessment of the separation efficiency (Equation (7)) [16,25-27]:

$$
\eta=R_{c}-\left(1-R_{t}\right),
$$

where $\eta$ is Newton's efficiency, $R_{c}$ is the recovery of molybdenite in the froth, and $R_{t}$ is the recovery of chalcopyrite in the tailing. For the case of untreated chalcopyrite/molybdenite mixture, the separation efficiencies were in the range of 4.0-10.9\% (Figure 8). Compared to this, the application of ME treatment greatly improved the separation efficiency. Until 3 min of flotation, Mo recovery was rapidly increased up to $90 \%$ but, afterward, slightly increased up to $93.5 \%$. On the other hand, $\mathrm{Cu}$ recovery was apparently lower than Mo recovery but continuously increased up to $35.7 \%$ with time, which results in the highest separation efficiency at $3 \mathrm{~min}$. In short, the separation efficiencies of untreated and treated mixture obtained after $3 \mathrm{~min}$ flotation were $10.9 \%$ and $66.8 \%$, respectively. This suggests that the application of $\mathrm{ME}$ treatment as a $\mathrm{Cu}$ depression process prior to $\mathrm{Cu}-\mathrm{Mo}$ flotation separation is effective in improving $\mathrm{Mo} / \mathrm{Cu}$ separation efficiency.

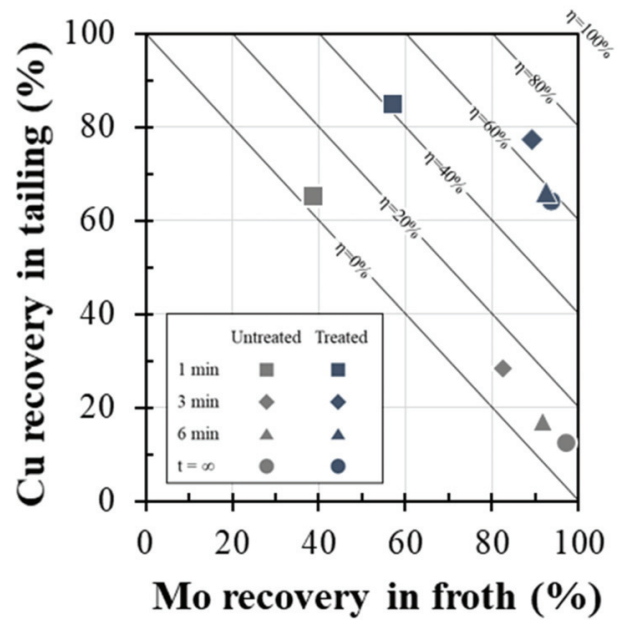

Figure 8. Relationship between Mo recovery in froth and Co recovery in tailing obtained in the mixed mineral flotation.

\section{Conclusions}

This study investigated the effect of microencapsulation using $\mathrm{Fe}^{2+} / \mathrm{H}_{2} \mathrm{PO}_{4}^{-}$as a pretreatment for $\mathrm{Cu}-\mathrm{Mo}$ flotation separation. The findings of this study are summarized, as follows:

1. $\mathrm{ME}$ treatment using $10 \mathrm{mM} \mathrm{Fe}{ }^{2+} / \mathrm{H}_{2} \mathrm{PO}_{4}^{-}$had a negligible effect on the depression of chalcopyrite floatability, but air introduction during ME treatment dramatically reduced Cu recovery from $\sim 70 \%$ to $\sim 15 \%$. The air introduction played an important role in enhancing ferrous oxidation occurring on the surface of chalcopyrite, thereby improving the formation of $\mathrm{FePO}_{4}$ coating on its surface.

2. Not only chalcopyrite, but the floatability of molybdenite was also depressed after ME treatment. The reduced floatability of ME-treated molybdenite, however, could be improved by utilizing emulsified kerosene during flotation.

3. The application of ME treatment was also effective for mixed minerals system that the separation efficiency increased from $10.9 \%$ (without ME treatment) to $66.8 \%$ (with ME treatment). 
Author Contributions: Conceptualization, I.P., S.J., M.I. and N.H.; methodology, I.P.; investigation, I.P. and S.H.; data curation, I.P. and S.H.; writing - original draft preparation, I.P.; writing-review and editing, I.P., S.H., S.J., M.I. and N.H.; funding acquisition, I.P. All authors have read and agreed to the published version of the manuscript.

Funding: This study is financially supported by Japan Oil, Gas and Metals National Corporation (JOGMEC).

Institutional Review Board Statement: Not applicable.

Informed Consent Statement: Not applicable.

Data Availability Statement: Data available on request due to restrictions, as the research is ongoing.

Conflicts of Interest: The authors declare no conflict of interest.

\section{References}

1. Bulatovic, S.M. 12-Flotation of Copper Sulfide Ores. In Handbook of Flotation Reagents; Bulatovic, S.M., Ed.; Elsevier: Amsterdam, The Netherlands, 2007; pp. 235-293. ISBN 978-0-444-53029-5.

2. Park, I.; Hong, S.; Jeon, S.; Ito, M.; Hiroyoshi, N. A Review of Recent Advances in Depression Techniques for Flotation Separation of Cu-Mo Sulfides in Porphyry Copper Deposits. Metals 2020, 10, 1269. [CrossRef]

3. John, D.A.; Ayuso, R.A.; Barton, M.D.; Blakely, R.J.; Bodnar, R.J.; Dilles, J.H.; Gray, F.; Graybeal, F.T.; Mars, J.L.; McPhee, D.K.; et al. Porphyry Copper Deposit Model: Chapter B in Mineral Deposit Models for Resource Assessment; Scientific Investigations Report 2010-5070-B; U.S. Geological Survey: Menlo Park, CA, USA, 2010; 169p.

4. Cioacă, M.-E.; Munteanu, M.; Lynch, E.P.; Arvanitidis, N.; Bergqvist, M.; Costin, G.; Ivanov, D.; Milu, V.; Arvidsson, R.; IorgaPavel, A.; et al. Mineralogical Setting of Precious Metals at the Assarel Porphyry Copper-Gold Deposit, Bulgaria, as Supporting Information for the Development of New Drill Core 3D XCT-XRF Scanning Technology. Minerals 2020, 10, 946. [CrossRef]

5. Stull, D.R. Vapor Pressure of Pure Substances. Organic and Inorganic Compounds. Ind. Eng. Chem. 1947, 39, 517-540. [CrossRef]

6. Amelunxen, P.; Schmitz, C.; Hill, H.; Goodweiler, N.; Andres, J. Molybdenum. In SME Mineral Processing E Extractive Metallurgy Handbook; Society for Mining, Metallurgy \& Exploration (SME): Englewood, CO, USA, 2019; Volume 2, pp. $1891-1916$.

7. Hirajima, T.; Miki, H.; Suyantara, G.P.W.; Matsuoka, H.; Elmahdy, A.M.; Sasaki, K.; Imaizumi, Y.; Kuroiwa, S. Selective Flotation of Chalcopyrite and Molybdenite with $\mathrm{H}_{2} \mathrm{O}_{2}$ Oxidation. Miner. Eng. 2017, 100, 83-92. [CrossRef]

8. Miki, H.; Matsuoka, H.; Hirajima, T.; Suyantara, G.P.W.; Sasaki, K. Electrolysis Oxidation of Chalcopyrite and Molybdenite for Selective Flotation. Mater. Trans. 2017, 58, 761-767. [CrossRef]

9. Yin, Z.; Sun, W.; Hu, Y.; Zhang, C.; Guan, Q.; Zhang, C. Separation of Molybdenite from Chalcopyrite in the Presence of Novel Depressant 4-Amino-3-Thioxo-3,4-Dihydro-1,2,4-Triazin-5(2H)-One. Minerals 2017, 7, 146. [CrossRef]

10. Park, I.; Tabelin, C.B.; Magaribuchi, K.; Seno, K.; Ito, M.; Hiroyoshi, N. Suppression of the Release of Arsenic from Arsenopyrite by Carrier-Microencapsulation Using Ti-Catechol Complex. J. Hazard. Mater. 2018, 344, 322-332. [CrossRef] [PubMed]

11. Park, I.; Tabelin, C.B.; Seno, K.; Jeon, S.; Ito, M.; Hiroyoshi, N. Simultaneous Suppression of Acid Mine Drainage Formation and Arsenic Release by Carrier-Microencapsulation Using Aluminum-Catecholate Complexes. Chemosphere 2018, 205, 414-425. [CrossRef] [PubMed]

12. Li, X.; Hiroyoshi, N.; Tabelin, C.B.; Naruwa, K.; Harada, C.; Ito, M. Suppressive Effects of Ferric-Catecholate Complexes on Pyrite Oxidation. Chemosphere 2019, 214, 70-78. [CrossRef] [PubMed]

13. Park, I.; Tabelin, C.B.; Seno, K.; Jeon, S.; Inano, H.; Ito, M.; Hiroyoshi, N. Carrier-Microencapsulation of Arsenopyrite Using Al-Catecholate Complex: Nature of Oxidation Products, Effects on Anodic and Cathodic Reactions, and Coating Stability under Simulated Weathering Conditions. Heliyon 2020, 6, e03189. [CrossRef] [PubMed]

14. Park, I.; Higuchi, K.; Tabelin, C.B.; Jeon, S.; Ito, M.; Hiroyoshi, N. Suppression of Arsenopyrite Oxidation by Microencapsulation Using Ferric-Catecholate Complexes and Phosphate. Chemosphere 2021, 269, 129413. [CrossRef] [PubMed]

15. Park, I.; Hong, S.; Jeon, S.; Ito, M.; Hiroyoshi, N. Flotation Separation of Chalcopyrite and Molybdenite Assisted by Microencapsulation Using Ferrous and Phosphate Ions: Part I. Selective Coating Formation. Metals 2020, 10, 1667. [CrossRef]

16. Hornn, V.; Ito, M.; Shimada, H.; Tabelin, C.B.; Jeon, S.; Park, I.; Hiroyoshi, N. Agglomeration-Flotation of Finely Ground Chalcopyrite and Quartz: Effects of Agitation Strength during Agglomeration Using Emulsified Oil on Chalcopyrite. Minerals 2020, 10, 380. [CrossRef]

17. Hornn, V.; Ito, M.; Shimada, H.; Tabelin, C.B.; Jeon, S.; Park, I.; Hiroyoshi, N. Agglomeration-Flotation of Finely Ground Chalcopyrite Using Emulsified Oil Stabilized by Emulsifiers: Implications for Porphyry Copper Ore Flotation. Metals 2020, 10, 912. [CrossRef]

18. Castro, S. Challenges in flotation of $\mathrm{Cu}-\mathrm{Co}$ sulfide ores in sea water. In The First International Symposium on Water in Mineral Processing; Society for Mining, Metallurgy \& Exploration (SME): Littleton, CO, USA, 2012; pp. 29-40.

19. Jeldres, R.I.; Arancibia-Bravo, M.P.; Reyes, A.; Aguirre, C.E.; Cortes, L.; Cisternas, L.A. The Impact of Seawater with Calcium and Magnesium Removal for the Flotation of Copper-Molybdenum Sulphide Ores. Miner. Eng. 2017, 109, 10-13. [CrossRef] 
20. Hirajima, T.; Suyantara, G.P.W.; Ichikawa, O.; Elmahdy, A.M.; Miki, H.; Sasaki, K. Effect of $\mathrm{Mg}^{2+}$ and Ca ${ }^{2+}$ as Divalent Seawater Cations on the Floatability of Molybdenite and Chalcopyrite. Miner. Eng. 2016, 96-97, 83-93. [CrossRef]

21. Suyantara, G.P.W.; Hirajima, T.; Miki, H.; Sasaki, K. Floatability of Molybdenite and Chalcopyrite in Artificial Seawater. Miner. Eng. 2018, 115, 117-130. [CrossRef]

22. Hirajima, T.; Mori, M.; Ichikawa, O.; Sasaki, K.; Miki, H.; Farahat, M.; Sawada, M. Selective Flotation of Chalcopyrite and Molybdenite with Plasma Pre-Treatment. Miner. Eng. 2014, 66-68, 102-111. [CrossRef]

23. King, R.P. Flotation. In Modeling and Simulation of Mineral Processing Systems; Butterworth Heinemann: Oxford, UK, 2001; pp. 289-350.

24. Xu, M. Modified Flotation Rate Constant and Selectivity Index. Miner. Eng. 1998, 11, 271-278. [CrossRef]

25. Bilal, M.; Ito, M.; Koike, K.; Hornn, V.; Ul Hassan, F.; Jeon, S.; Park, I.; Hiroyoshi, N. Effects of Coarse Chalcopyrite on Flotation Behavior of Fine Chalcopyrite. Miner. Eng. 2021, 163, 106776. [CrossRef]

26. Farahat, M.; Hirajima, T.; Sasaki, K.; Doi, K. Adhesion of Escherichia Coli onto Quartz, Hematite and Corundum: Extended DLVO Theory and Flotation Behavior. Colloids Surf. B Biointerfaces 2009, 74, 140-149. [CrossRef] [PubMed]

27. Aikawa, K.; Ito, M.; Kusano, A.; Park, I.; Oki, T.; Takahashi, T.; Furuya, H.; Hiroyoshi, N. Flotation of Seafloor Massive Sulfide Ores: Combination of Surface Cleaning and Deactivation of Lead-Activated Sphalerite to Improve the Separation Efficiency of Chalcopyrite and Sphalerite. Metals 2021, 11, 253. [CrossRef] 

Article

\title{
Agglomeration-Flotation of Finely Ground Chalcopyrite Using Emulsified Oil Stabilized by Emulsifiers: Implications for Porphyry Copper Ore Flotation
}

\author{
Vothy Hornn ${ }^{1, *}$, Mayumi Ito ${ }^{2}$, Hiromasa Shimada ${ }^{1}$, Carlito Baltazar Tabelin ${ }^{3}$, Sanghee Jeon ${ }^{2}$ \\ Ilhwan Park ${ }^{2}$ and Naoki Hiroyoshi ${ }^{2}$ \\ 1 Division of Sustainable Resources Engineering, Graduate School of Engineering, Hokkaido University, \\ Sapporo 060-8628, Japan; simada.hiromasa.2525@gmail.com \\ 2 Division of Sustainable Resources Engineering, Faculty of Engineering, Hokkaido University, \\ Sapporo 060-8628, Japan; itomayu@eng.hokudai.ac.jp (M.I.); shjun1121@gmail.com (S.J.); \\ i-park@eng.hokudai.ac.jp (I.P.); hiroyosi@eng.hokudai.ac.jp (N.H.) \\ 3 School of Minerals and Energy Resources Engineering, The University of New South Wales, \\ 2052 Sydney, NSW, Australia; c.tabelin@unsw.edu.au \\ * Correspondence: vothytalis1102@yahoo.com; Tel.: +81-011-706-6315
}

Received: 24 June 2020; Accepted: 7 July 2020; Published: 8 July 2020

\begin{abstract}
Flotation is the conventional method for processing porphyry copper deposits, one of the most economically important sources of copper $(\mathrm{Cu})$ worldwide. The rapidly decreasing grade of this type of $\mathrm{Cu}$ ore in recent years, however, presents serious problems with fine particle recovery using conventional flotation circuits. This low recovery could be attributed to the low collision efficiency of fine particles and air bubbles during flotation. To improve collision efficiency and flotation recovery, agglomeration of finely ground chalcopyrite $\left(\mathrm{CuFeS}_{2}\right)\left(\mathrm{D}_{50}=3.5 \mu \mathrm{m}\right)$ using emulsified oil stabilized by emulsifiers was elucidated in this study. Specifically, the effects of various types of anionic (sodium dodecyl sulfate (SDS), potassium amyl xanthate (KAX)), cationic (dodecyl amine acetate (DAA)), and non-ionic (polysorbate 20 (Tween 20)) emulsifiers on emulsified oil stability and agglomeration-flotation efficiency were investigated. When emulsifiers were added, the average size of agglomerates increased, resulting in higher $\mathrm{Cu}$ recovery during flotation. This dramatic improvement in flotation efficiency could be attributed to the smaller oil droplet size in emulsified oil and their higher stability in the presence of emulsifiers. The utilization of emulsifiers during agglomeration-flotation not only lowered the required agitation strength for agglomeration but also shortened the agglomeration time, both of which made the process easier to incorporate in existing flotation circuits.
\end{abstract}

Keywords: agglomeration; emulsified oil; emulsifiers; flotation; fine chalcopyrite

\section{Introduction}

Porphyry copper deposits are economically the most important source of copper $(\mathrm{Cu})$ worldwide because of their wide distribution and enormous volume of minable ore materials. Some porphyry copper deposits have over 1 billion metric tons ( $t$ ) of ore at $>0.5 \%$ of $\mathrm{Cu}$ [1], and many of these deposits typically contain other valuable metals aside from $\mathrm{Cu}$, such as gold $(\mathrm{Au})$ and molybdenum $(\mathrm{Mo})$, making their exploitation economically attractive. For example, the largest open pit porphyry copper mine in the world-the Escondida mine in Chile-processes a porphyry copper deposit containing $0.25 \mathrm{~g} / \mathrm{t} \mathrm{Au}$ and $0.0062 \mathrm{wt} \% \mathrm{Mo}$ [2]. The conventional technique used to recover valuable minerals from porphyry copper ores is flotation, a technique whereby fine particles of $\mathrm{Cu}$-bearing minerals 
like chalcopyrite $\left(\mathrm{CuFeS}_{2}\right)$ are separated from gangue minerals and collected by bubbles after surface modifications using emulsifiers called collectors [3,4]. Flotation, including its concept of using bubbles to induce separation of materials with different surface wettability properties, is a popular and widely used technique not only in the mineral processing and coal cleaning/washing industries but also in electronic waste and plastic recycling industries [5-11].

Despite its popularity and widespread application, one major drawback of flotation is the dramatic drop in its efficiency when particle sizes become very small [12]. The low recovery of fine particles during flotation is attributed to the low collision probability between fine mineral particles and air bubbles [13-15]. Many studies have suggested ways to overcome the poor fine particle recovery during flotation using two approaches: (1) bubble size reduction, and (2) particle aggregation. Column flotation [16], microbubble flotation [17], electro-flotation [18], and dissolved air flotation [19] are some examples of bubble size reduction approaches, while particle aggregation strategies include shear flocculation [20], carrier flotation [21], polymer flocculation [22], and oil agglomeration [13].

All of these techniques have their own advantages and disadvantages, but from the perspective of economics, oil agglomeration - a method to increase the apparent particle size using oil as a "bridging" liquid under intense mixing - is considered as one of the most promising techniques for industrial-scale applications. Oil is relatively inexpensive, and the process could be easily integrated into existing flotation circuits. Although oil agglomeration has been extensively studied for coal cleaning [23,24], there is still one serious issue with this technique when applied to porphyry copper ores: the amount of oil required remains huge (up to $5-10 \%$ of total weight of coal for agglomeration-screening technique or around $0.1-1.0 \%$ for agglomeration-flotation technique) [25]. To address this problem, agglomeration-flotation using emulsified oil instead of simply adding oil during the agglomeration step has been proposed [26-28]. Emulsification of oil reduces the size of oil droplets, which lowers the amount of oil required for agglomeration dramatically.

With the decreasing grade and quality of porphyry copper deposits, flotation is increasingly becoming less efficient because of the smaller grain size of $\mathrm{Cu}$-bearing minerals that require finer grinding for sufficient liberation [29]. As a result, fine particles cannot be recovered by conventional flotation, resulting in loss of valuable minerals. Trahar [15], for example, studied chalcopyrite-quartz flotation and reported that the recovery of chalcopyrite was lower when the median particle size decreased from 20 to $3 \mu \mathrm{m}$. In the previous work of the authors, agglomeration-flotation using emulsified oil instead of directly adding oil during the agglomeration step was conducted using finely ground chalcopyrite [4]. The results showed that the stability of emulsified oil was relatively short, so strong agitation strength is required to disperse oil droplets into water, maintain the small size of oil droplets, and facilitate particle agglomeration [4]. This strong agitation during agglomeration requires high energy, which make the process costly and problematic when integrated into actual flotation circuits.

One way to address this issue is to stabilize emulsified oil using emulsifiers during agglomeration-flotation. Emulsifiers are compounds that lower the surface tension between two immiscible liquids and have been reported to enhance not only the formation of small oil droplets but also stabilize them in aqueous medium [30]. To the best of our knowledge, agglomeration-flotation using emulsified oil stabilized by emulsifiers on finely ground chalcopyrite has never been studied before. In this study, the effects of emulsified oil stabilized by various types of emulsifiers on agglomeration and flotation of finely ground chalcopyrite were investigated. 


\section{Materials and Methods}

\subsection{Materials}

The chalcopyrite sample used in this study was obtained from Copper Queen Mine, Arizona, USA. The sample was characterized by X-ray fluorescence (XRF) (EDXL300, Rigaku Corporation, Tokyo, Japan), X-ray powder diffraction (XRD, MultiFlex, Rigaku Corporation, Tokyo, Japan), and scanning electron microscopy (SEM, SM-IT200, JEOL Ltd., Tokyo, Japan).

The sample was crushed using a jaw crusher (1023-A, Yoshida Manufacturing Co., Ltd, Sapporo, Japan) and ground by a vibratory disc mill (RS100, Retsch Inc., Haan, Germany), then screened to obtain a size fraction of less than $75 \mu \mathrm{m}$. The ground sample $(<75 \mu \mathrm{m})$ was ground again in the vibratory disc mill to obtain fine particles. The particle size distribution of the chalcopyrite sample used in this study was measured in water after ultrasonication using laser diffraction (Microtrac®MT3300SX, Nikkiso Co., Ltd., Tokyo, Japan).

Potassium amyl xanthate (KAX) (Tokyo Chemical Industry Co., Ltd., Tokyo, Japan), kerosene (Wako Pure Chemical Industries, Ltd., Osaka, Japan), methyl isobutyl carbinol (MIBC) (Tokyo Chemical Industry Co., Ltd., Tokyo, Japan), sodium dodecyl sulfate (SDS) (Tokyo Chemical Industry Co., Ltd., Japan), dodecyl amine acetate (DAA) (Tokyo Chemical Industry Co., Ltd., Tokyo, Japan), and polysorbate 20 (Tween20) (Tokyo Chemical Industry Co., Ltd., Tokyo Japan) were used in this study. The chemical structures of the four emulsifiers (SDS, KAX, DAA, and Tween 20) used in this study are shown in Figure 1.

(a)<smiles>CCCCCCCCCCCCOS(=O)(=O)[OH2+]</smiles>

(c)

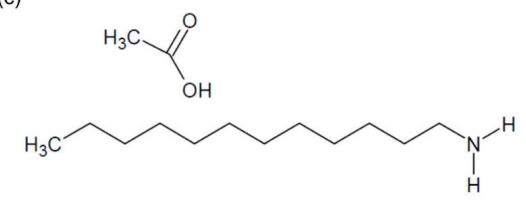

(b)<smiles>CCCCCOC(=S)[Se]</smiles>

(d)

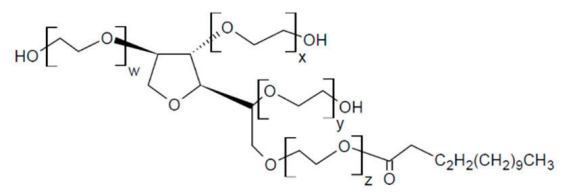

Figure 1. Chemical structures of emulsifiers: (a) SDS, (b) KAX, (c) DAA, and (d) Tween 20.

\subsection{Methods}

\subsubsection{Preparation of Emulsified Oil with Emulsifiers}

Anionic (SDS, KAX), cationic (DAA), and non-ionic (Tween 20) emulsifiers were used as emulsifying reagents. First, $10 \mathrm{~mL}$ of kerosene was mixed with $40 \mathrm{~mL}$ of deionized (DI) water, and then $0.1 \mathrm{~g}$ of the emulsifiers (SDS, KAX, DAA, or Tween 20) was added (i.e., concentration of emulsifiers, $2000 \mathrm{ppm}$ ). Emulsification of the mixture was then carried out before agglomeration using an ultrasonic homogenizer (ULTRA-TURRAX, IKA, Königswinter, Germany) for $60 \mathrm{~s}$. After emulsification, oil droplet size was measured using laser diffraction.

\subsubsection{Stability Tests of Emulsified Oil}

Stability tests of emulsified oil containing different emulsifiers were carried out to evaluate the stability of the suspensions [31]. The emulsified oil after emulsification was equilibrated for 5 min until the bubble foams disappeared. Then, $50 \mathrm{~mL}$ of emulsified oil was centrifuged at $3500 \mathrm{rpm}$ for $20 \mathrm{~min}$. The volume ratios of oil and emulsion layer were calculated by measuring the thickness of oil layer. 


\subsubsection{KAX Conditioning and Agglomeration}

Two conditions were evaluated during KAX conditioning and agglomeration as follows:

(a) Agglomeration at an agitation speed of $1000 \mathrm{rpm}$

i. KAX conditioning: Before agglomeration, $20 \mathrm{~g}$ of sample $\left(\mathrm{D}_{50}=3.5 \mu \mathrm{m}\right)$ was suspended in $400 \mathrm{~mL}$ of distilled water and then conditioned with the surface modifier, $\mathrm{KAX}(200 \mathrm{~g} / \mathrm{t})$, to improve hydrophobicity for $5 \mathrm{~min}$ at $1000 \mathrm{rpm}$ in the flotation cell (FT-1000, Heiko, Tokyo, Japan).

ii. Agglomeration: After conditioning, emulsified oil (15 L kerosene/t sample, with and without surfactant) was added to the suspension, and agitation was carried out at $1000 \mathrm{rpm}$ for $30 \mathrm{~min}$ in the flotation cell.

(b) Agglomeration at an agitation speed of 15,000 rpm

i. KAX conditioning: Before agglomeration, $20 \mathrm{~g}$ of sample $\left(\mathrm{D}_{50}=3.5 \mu \mathrm{m}\right)$ was suspended in $400 \mathrm{~mL}$ of distilled water and then conditioned with the surface modifier, KAX (200 g/t) for 5 min at $1000 \mathrm{rpm}$ in the flotation cell.

ii. Agglomeration: After conditioning, the suspension was transferred to an agglomeration vessel (high speed mixer with a s-shaped impeller, SPB-600J, Cuisinart, Stamford, CT, USA; fixed rotation speed of 15,000 rpm), emulsified oil (15 L kerosene/t sample, with and without surfactant) was added, and agitation was carried out for $30 \mathrm{~min}$. Suspension after agglomeration was then transferred to a $500 \mathrm{~mL}$ flotation cell.

The emulsified oil with emulsifiers was allowed to equilibrate for $5 \mathrm{~min}$ after emulsification prior to its use in the agglomeration step. In contrast, emulsified oil without any surfactant was used immediately because of the short stability of suspension. After agglomeration, the particle size distribution was measured by laser diffraction.

\subsubsection{Flotation Tests}

Flotation was carried out using a mechanical flotation machine (FT-1000, Heiko, Tokyo, Japan). MIBC $(25 \mu \mathrm{L} / \mathrm{L})$ was added as a frother, and the suspension was stirred for 3 min with an impeller speed of $1000 \mathrm{rpm}$. Air was then injected into the suspension at a flow rate of $1 \mathrm{~L} / \mathrm{min}$, and flotation was carried out (total flotation time of $10 \mathrm{~min}$ ). Froths were collected at predetermined time intervals, and both froth products and tailings were weighed after drying at $105^{\circ} \mathrm{C}$ for $24 \mathrm{~h}$, and their chemical compositions were determined by XRF.

\section{Results and Discussion}

\subsection{Characteristics of Chalcopyrite Samples}

Chalcopyrite sample used in this study were characterized by XRF, XRD, SEM-EDX, and laser diffraction sizer. The chemical composition of the chalcopyrite sample (XRF) is shown in Table 1. Figure 2a,b shows the results of XRD and SEM-EDX analysis, respectively, of finely ground chalcopyrite. XRD analysis showed that the sample was mainly composed of chalcopyrite with minor amounts of actinolite $\left(\mathrm{Ca}_{2} \mathrm{Mg}_{3} \mathrm{Fe}_{2} \mathrm{Si}_{8} \mathrm{O}_{22}(\mathrm{OH})_{2}\right)$ and quartz. Figure 3 shows the particle size distributions of finely ground chalcopyrite (median particle diameter $\left(\mathrm{D}_{50}\right)$ of $\left.3.5 \mu \mathrm{m}\right)$, which was used in this study.

Table 1. Chemical composition of chalcopyrite sample.

\begin{tabular}{ccccccc}
\hline Elements & Cu & Fe & S & Zn & Si & Ca \\
\hline${ }^{*} \mathrm{t} \%$ & 26 & 27 & 26 & 0.8 & 6 & 2 \\
\hline
\end{tabular}



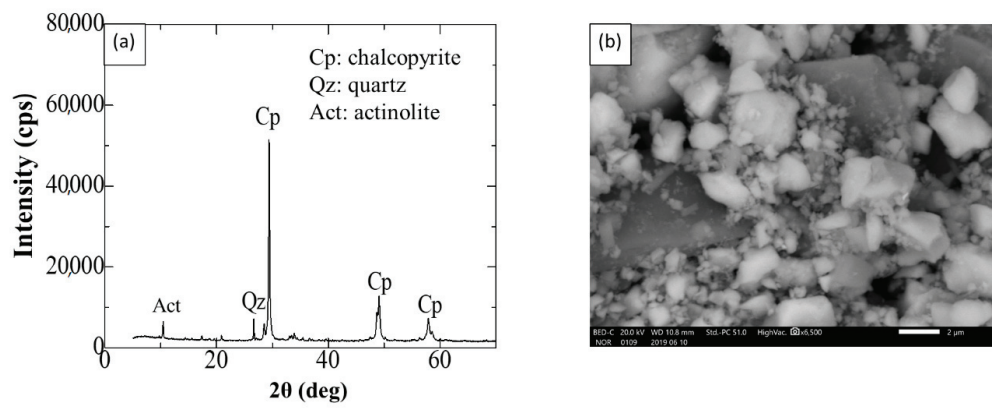

Figure 2. Chalcopyrite sample: (a) XRD patterns, and (b) SEM image.

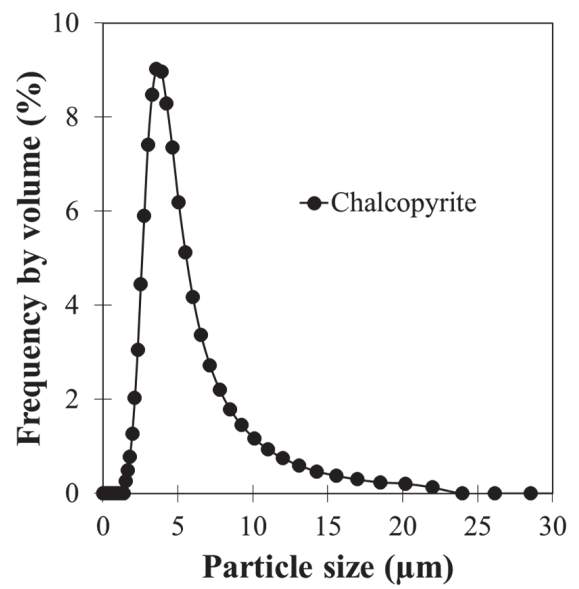

Figure 3. Particle size distribution of chalcopyrite sample.

\subsection{Effects of Emulsifiers on Emulsified Oil Droplet Size and Stability}

Anionic emulsifiers (SDS, KAX), cationic surfactant (DAA), and non-ionic surfactant (Tween 20) were used as emulsifying agents during the preparation of emulsified oil. These emulsifiers were chosen to represent three main types of flotation collector that have great potential to be used as emulsifying agents. Figure 4 shows the size distribution of oil droplets with and without addition of emulsifiers, and the results indicate that the mode size of oil droplets became smaller with emulsifiers. The smaller oil droplet generated in the presence of emulsifiers could be attributed to the reduction in interfacial tension of oil-water [32]. In the previous study of the authors [4], emulsified oil was added to the agglomeration vessel immediately because emulsified oil without surfactant was unstable. In a commercial plant, stability of emulsified oil is important to maintain the small size of oil droplets for oil agglomeration. To check the stability of the suspensions, stability tests were carried out. In this test, centrifugation was used to accelerate oil droplet coalescence, and because the thickness of oil layer relies on ease of coalescence and oil droplet size, this technique could be used to estimate the stability of emulsion. The volume ratios of oil and emulsion layers are shown in Figure 5. The volume of the oil layer after centrifugation was smaller when emulsifiers were present, indicating that these compounds were effective in stabilizing oil droplets and prolonging the usability of emulsified oil. Chen and Tao [32] defined the stability of an emulsion as the resistance by the dispersed oil droplets against coalescence and noted that emulsifying agents maintain the emulsion by forming a thin interfacial film between the two liquids that minimize contact, coalescence, and aggregation of the internal dispersed phase. 


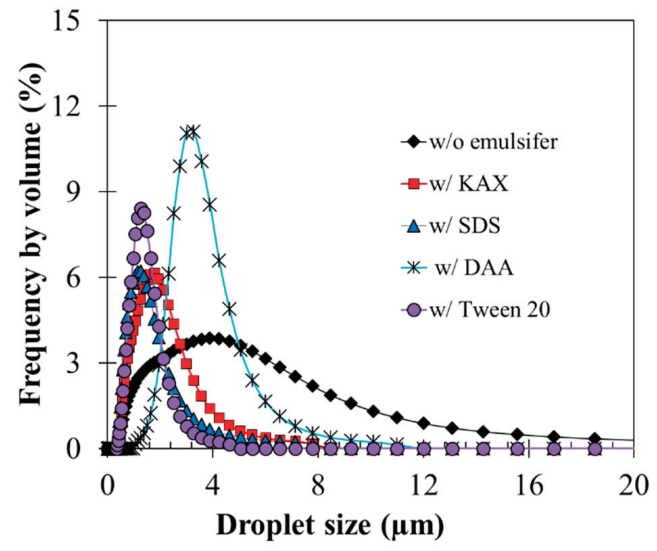

Figure 4. Size distribution of oil droplets after emulsification with and without addition of emulsifiers.

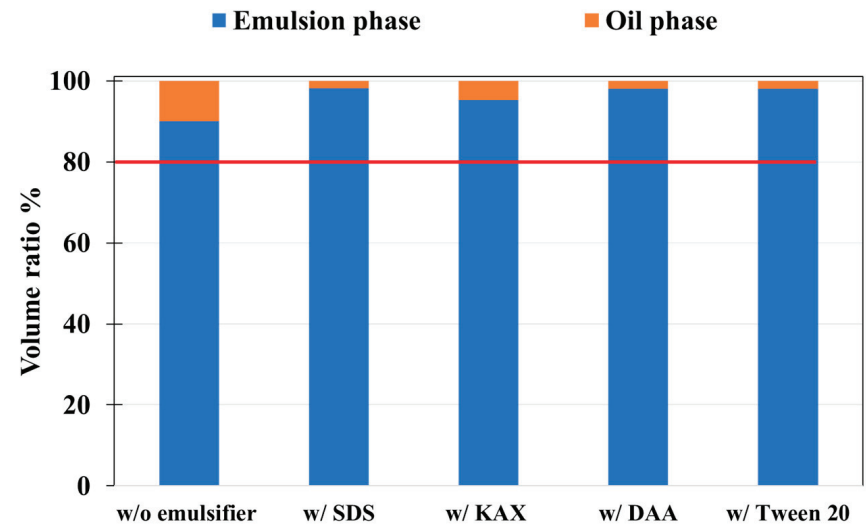

Figure 5. Volume ratio of oil and emulsion layers with and without emulsifiers after emulsification and centrifugation. Note that the red line indicates volume ratio without emulsification ( $80 \%$ water, $20 \%$ oil).

\subsection{Effects of Emulsifiers on Agglomeration}

In the previous section, SDS, KAX, DAA, and Tween 20 were shown to reduce the size of oil droplets and sustain the stability of emulsified oil. The effects of theses emulsifiers on agglomeration of chalcopyrite were investigated. Agglomeration in this study consisted of two stages: (1) conditioning in the flotation cell with $200 \mathrm{~g} / \mathrm{t}$ of KAX, and (2) agglomeration using emulsified oil containing $2000 \mathrm{ppm}$ of emulsifier (15 L kerosene/t). Figure 6 shows the apparent particle size distribution after agglomeration (1000 or 15,000 rpm for $30 \mathrm{~min}$ ). The results showed that when SDS, KAX, and DAA were used, the mode size of agglomerate increased more than that without emulsifiers even at a high agitation speed (15,000 rpm). As shown in Figure 4, the droplet size of emulsified oil containing emulsifiers were relatively smaller than that without emulsifiers. When the size of oil droplets decreased, the number of droplets in the agitator increased. Because the frequency of collisions of the oil droplets and particles during agglomeration is proportional to the number of oil droplets, it is reasonable to deduce that the number of oil droplets attached to particle surfaces increased due to the higher collision probability between oil droplets and particles. Because of this, agglomerate size became bigger when emulsified oil containing emulsifiers were used. 


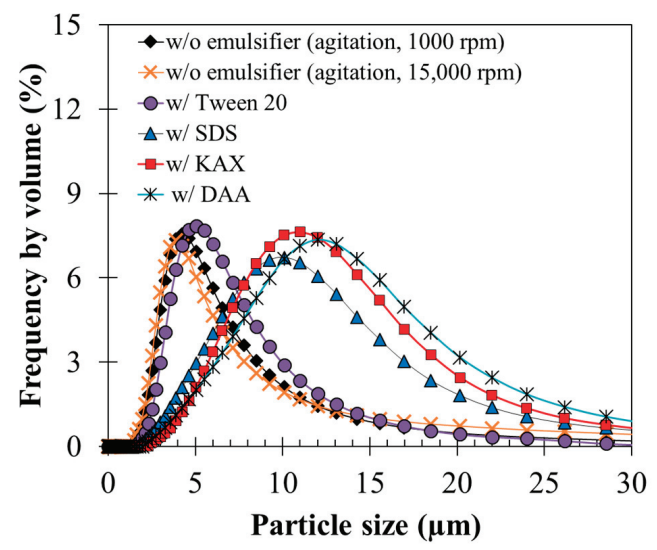

Figure 6. Size distribution after agglomeration (agglomeration conditions: $30 \mathrm{~min}$; $1000 \mathrm{rpm}$ with emulsifiers, 1000 and 15,000 rpm without emulsifiers).

When Tween 20 was used, the mode size of agglomerates was similar to that without surfactant. Agglomeration kinetics and agglomerate size are mainly determined by three processes: (1) particle-particle collision, (2) particle-particle attraction, and (3) decomposition of agglomerate [33]. As shown in Figure 4, the size of droplets with Tween 20 were similar to those with other types of emulsifiers, indicating that the probability of collision between particles and oil droplets may be similar. However, the probability of attraction of particles and oil droplets stabilized by Tween 20 may be lower than those with the other emulsifiers.

\subsection{Effects of Emulsifiers on Flotation}

In this flotation test, agglomeration using emulsified oil with and without emulsifiers was carried out, and flotation of the agglomerates was conducted. Figure 7 shows the $\mathrm{Cu}$ recovery with time (agglomeration conditions: $30 \mathrm{~min}$; $1000 \mathrm{rpm}$ with emulsifiers, 1000 and 15,000 rpm without emulsifiers). Without emulsifiers, Cu recovery with agglomeration using high agitation strength (15,000 rpm) was higher than that with low agitation strength $(1000 \mathrm{rpm})$, indicating that intense agitation is required for agglomeration-flotation without emulsifiers due to the low stability of emulsified oil.

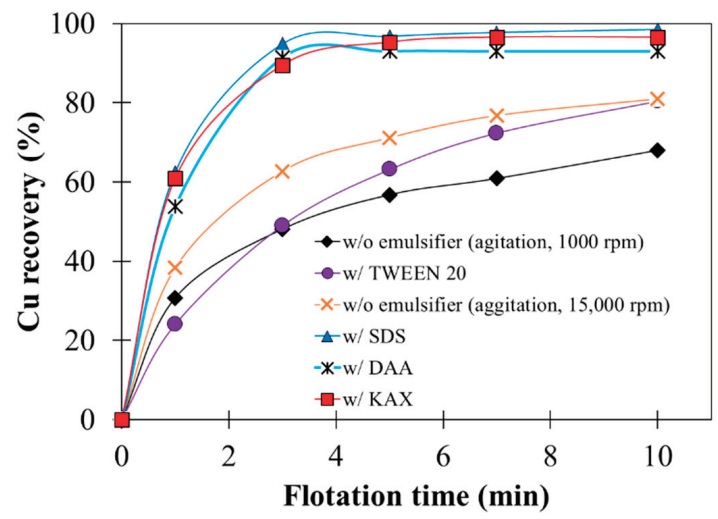

Figure 7. Cu recovery with time (agglomeration conditions: $30 \mathrm{~min}$; $1000 \mathrm{rpm}$ with emulsifiers, 1000 and 15,000 rpm without emulsifiers). 
In the case of agglomeration-flotation with Tween 20, Cu recovery showed a similar trend with that without emulsifiers. This result is in-line with the result of size distribution of agglomerate; that is, the size of agglomerate using Tween 20 was almost the same as that without emulsifier. The recovery rate of chalcopyrite treated with Tween 20 was lower than those treated with other emulsifiers. Cu recovery rate was affected by the size of agglomerate, as described before and agglomerate size may have been influenced by the affinity between the oil-emulsion and the KAX-adsorbed chalcopyrite surface (KAX was used as the surface modifier to increase the hydrophobicity). Interaction forces between hydrophobic minerals surface and oil emulsion may be determined by the balance of hydrophobic interaction, van der Waals attraction, and steric repulsion of the structure of the hydrophilic head of surfactants. Hydrophilic lipophilic balance (HLB), an indicator of the balance of hydrophilic and hydrophobic groups of surfactants, strongly affects the properties of emulsions, including oil droplet size. HLB values of Tween 20 and SDS are similar, resulting in similar oil droplets sizes [34,35]. However, the size of agglomerate in Tween 20-stabilized emulsion was smaller than that with SDS, indicating that interactions between chalcopyrite and oil droplets with Tween 20 or SDS were different. One possible explanation for the low efficiency of Tween 20 in agglomerating finely ground chalcopyrite is its complex structure consisting of numerous types of hydrophilic heads compared to SDS, as shown in Figure 1. In other words, Tween 20, having hydrophilic heads, may have lowered the hydrophobicity of the oil-emulsion, thereby decreasing the affinity between oil droplets and chalcopyrite.

In the case of agglomeration-flotation with SDS, DAA, and KAX, Cu recovery with agglomeration using these emulsifiers was higher than that in agglomeration with intense agitation strength $(15,000 \mathrm{rpm})$ without emulsifiers. These results indicate that less intense agitation strength (1000 rpm) was sufficient for agglomeration-flotation when emulsifiers were present because of the smaller droplet size and better stability of emulsified oil. This means that when emulsifiers are used, specialized equipment with high agitation strengths are not required, and the process could be easily integrated into existing flotation circuits.

Figure 8 shows the Cu recovery of agglomerate with SDS at agglomeration times of 15 and $30 \mathrm{~min}$, and the results showed that $\mathrm{Cu}$ recovery was very similar, indicating that agglomeration for $15 \mathrm{~min}$ was enough to achieve high $\mathrm{Cu}$ recovery. In other words, utilization of emulsifiers-stabilized oil emulsion could shorten the agglomeration time.

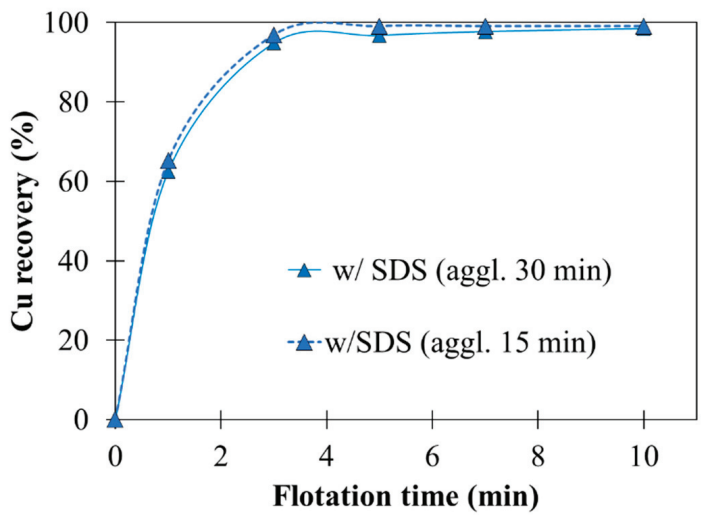

Figure 8. Cu recovery of agglomerate with SDS at agglomeration time of 15 and $30 \mathrm{~min}$. 


\section{Conclusions}

The following conclusions can be drawn from the agglomeration-flotation study using emulsified oil with emulsifiers:

- $\quad$ Addition of emulsifiers (e.g., SDS, KAX, DAA, and Tween 20) reduced the size of oil droplets and maintained the stability of emulsified oil longer.

- Addition of emulsifiers (SDS, KAX, and DAA) to emulsified oil contributed to the formation of bigger agglomerates, thus improving $\mathrm{Cu}$ recovery by agglomeration-flotation even at low agitation strength and shorter agglomeration time.

- When emulsified oil with emulsifiers is used, specialized equipment with higher agitation strength during agglomeration is not required, and thus the process could be easily integrated into existing flotation circuits.

Author Contributions: V.H., M.I., S.J., I.P., and N.H. conceived and designed the experiments; V.H. and H.S. performed the experiments and analyzed the data; V.H. wrote the paper. M.I., C.B.T., S.J., and I.P. reviewed and edited the paper. All authors have read and agreed to the published version of the manuscript.

Funding: This research received no external funding.

Conflicts of Interest: The authors declare no conflict of interest.

\section{References}

1. Brown, T.J.; Bide, T.; Walters, A.S.; Idoine, N.E.; Shaw, R.A.; Hannis, S.D.; Lusty, P.A.J.; Kendall, R.; MacKenzie, A.C. World Mineral Production 2005-09; British Geological Survey: Nottingham, UK, 2011; pp. 29-31.

2. Richards, J.P.; Boyce, A.J.; Pringle, M.S. Geologic Evolution of the Escondida Area, Northern Chile: A Model for Spatial and Temporal Localization of Porphyry Cu Mineralization. Econ. Geol. Bull. Soc. Econ. Geol. 2001, 96, 271-305. [CrossRef]

3. Aikawa, K.; Ito, M.; Segawa, T.; Jeon, S.; Park, I.; Tabelin, C.B.; Hiroyoshi, N. Depression of Lead-Activated Sphalerite by Pyrite via Galvanic Interactions: Implications to the Selective Flotation of Complex Sulfide Ores. Miner. Eng. 2020, 152, 106367. [CrossRef]

4. Hornn, V.; Ito, M.; Shimada, H.; Tabelin, C.B.; Jeon, S.; Park, I.; Hiroyoshi, N. Agglomeration-Flotation of Finely Ground Chalcopyrite and Quartz: Effects of Agitation Strength during Agglomeration Using Emulsified Oil on Chalcopyrite. Minerals 2020, 10, 380. [CrossRef]

5. Ito, M.; Saito, A.; Murase, N.; Phengsaart, T.; Kimura, S.; Tabelin, C.B.; Hiroyoshi, N. Development of Suitable Product Recovery Systems of Continuous Hybrid Jig for Plastic-Plastic Separation. Miner. Eng. 2019, 141, 105839. [CrossRef]

6. Ito, M.; Takeuchi, M.; Saito, A.; Murase, N.; Phengsaart, T.; Tabelin, C.B.; Hiroyoshi, N.; Tsunekawa, M. Improvement of Hybrid Jig Separation Efficiency Using Wetting Agents for the Recycling of Mixed-Plastic Wastes. J. Mater. Cycles Waste Manag. 2019, 21, 1376-1383. [CrossRef]

7. Jeon, S.; Ito, M.; Tabelin, C.B.; Pongsumrankul, R.; Kitajima, N.; Park, I.; Hiroyoshi, N. Gold Recovery from Shredder Light Fraction of E-Waste Recycling Plant by Flotation-Ammonium Thiosulfate Leaching. Waste Manag. 2018, 77, 195-202. [CrossRef]

8. Jeon, S.; Ito, M.; Tabelin, C.B.; Pongsumrankul, R.; Tanaka, S.; Kitajima, N.; Saito, A.; Park, I.; Hiroyoshi, N. A Physical Separation Scheme to Improve Ammonium Thiosulfate Leaching of Gold by Separation of Base Metals in Crushed Mobile Phones. Miner. Eng. 2019, 138, 168-177. [CrossRef]

9. Phengsaart, T.; Ito, M.; Azuma, A.; Tabelin, C.B.; Hiroyoshi, N. Jig Separation of Crushed Plastics: The Effects of Particle Geometry on Separation Efficiency. J. Mater. Cycles Waste Manag. 2020, 22, 787-800. [CrossRef]

10. Phengsaart, T.; Ito, M.; Hamaya, N.; Tabelin, C.B.; Hiroyoshi, N. Improvement of Jig Efficiency by Shape Separation, and a Novel Method to Estimate the Separation Efficiency of Metal Wires in Crushed Electronic Wastes Using Bending Behavior and "Entanglement Factor". Miner. Eng. 2018, 129, 54-62. [CrossRef]

11. Seng, S.; Tabelin, C.B.; Makino, Y.; Chea, M.; Phengsaart, T.; Park, I.; Hiroyoshi, N.; Ito, M. Improvement of Flotation and Suppression of Pyrite Oxidation Using Phosphate-Enhanced Galvanic Microencapsulation (GME) in a Ball Mill with Steel Ball Media. Miner. Eng. 2019, 143, 105931. [CrossRef] 
12. Jiangang, F.; Kaida, C.; Hui, W.; Chao, G.; Wei, L. Recovering Molybdenite from Ultrafine Waste Tailings by Oil Agglomerate Flotation. Miner. Eng. 2012, 39, 133-139. [CrossRef]

13. Dai, Z.; Fornasiero, D.; Ralston, J. Particle-Bubble Collision Models-a Review. Adv. Colloid Interface Sci. 2000, 85, 231-256. [CrossRef]

14. Miettinen, T.; Ralston, J.; Fornasiero, D. The Limits of Fine Particle Flotation. Miner. Eng. 2010, 23, $420-437$. [CrossRef]

15. Trahar, W.J.; Warren, L.J. The Flotability of Very Fine Particles-A Review. Int. J. Miner. Process. 1976, 3, 103-131. [CrossRef]

16. Finch, J.A. Column Flotation: A Selected Review- Part IV: Novel Flotation Devices. Miner. Eng. 1995, 8, 587-602. [CrossRef]

17. Yoon, R.H. Microbubble Flotation. Miner. Eng. 1993, 6, 619-630. [CrossRef]

18. Bhaskar Raju, G.; Khangaonkar, P.R. Electro-Flotation of Chalcopyrite Fines. Int. J. Miner. Process. 1982, 9, 133-143. [CrossRef]

19. Rodrigues, R.T.; Rubio, J. DAF-Dissolved Air Flotation: Potential Applications in the Mining and Mineral Processing Industry. Int. J. Miner. Process. 2007, 82, 1-13. [CrossRef]

20. Warren, L.J. Shear-Flocculation of Ultrafine Scheelite in Sodium Oleate Solutions. J. Colloid Interface Sci. 1975, 50, 307-318. [CrossRef]

21. Rubio, J.; Hoberg, H. The Process of Separation of Fine Mineral Particles by Flotation with Hydrophobic Polymeric Carrier. Int. J. Miner. Process. 1993, 37, 109-122. [CrossRef]

22. Sresty, G.C.; Somasundaran, P. Selective Flocculation of Synthetic Mineral Mixtures Using Modified Polymers. Int. J. Miner. Process. 1980, 6, 303-320. [CrossRef]

23. Alonso, M.I.; Valdés, A.F.; Martínez-Tarazona, R.M.; Garcia, A.B. Coal Recovery from Coal Fines Cleaning Wastes by Agglomeration with Vegetable Oils: Effects of Oil Type and Concentration. Fuel 1999, 78, 753-759. [CrossRef]

24. Slaghuis, J.H.; Ferreira, L.C. Selective Spherical Agglomeration of Coal. Fuel 1987, 66, 1427-1430. [CrossRef]

25. Laskowski, J.S.; Liu, Q.; Bolin, N.J. Flotation of Sulphide Minerals 1990 Polysaccharides in Flotation of Sulphides. Part I. Adsorption of Polysaccharides onto Mineral Surfaces. Int. J. Miner. Process. 1991, 33, 223-234. [CrossRef]

26. Bensley, C.N.; Swanson, A.R.; Nicol, S.K. The Effect of Emulsification on the Selective Agglomeration of Fine Coal. Int. J. Miner. Process. 1977, 4, 173-184. [CrossRef]

27. Van Netten, K.; Moreno-Atanasio, R.; Galvin, K.P. Fine Particle Beneficiation through Selective Agglomeration with an Emulsion Binder. Ind. Eng. Chem. Res. 2014, 53, 15747-15754. [CrossRef]

28. Sahinoglu, E.; Uslu, T. Use of Ultrasonic Emulsification in Oil Agglomeration for Coal Cleaning. Fuel 2013, 113, 719-725. [CrossRef]

29. Johnson, N.W. Liberated 0-10 $\mu$ m Particles from Sulphide Ores, Their Production and Separation-Recent Developments and Future Needs. Miner. Eng. 2006, 19, 666-674. [CrossRef]

30. Stang, M.; Karbstein, H.; Schubert, H. Adsorption Kinetics of Emulsifiers at Oil-Water Interfaces and Their Effect on Mechanical Emulsification. Chem. Eng. Process. Process Intensif. 1994, 33, 307-311. [CrossRef]

31. Chen, G.; Tao, D. An Experimental Study of Stability of Oil-Water Emulsion. Fuel Process. Technol. 2005, 86, 499-508. [CrossRef]

32. Oh, S.G.; Shah, D.O. Effect of counterions on the interfacial tension and emulsion droplet size in the oil/water/dodecyl sulfate system. J. Phys. Chem. 1993, 97, 284-286. [CrossRef]

33. Darelius, A.; Rasmuson, A.; Björn, I.N.; Folestad, S. High shear wet granulation modelling-a mechanistic approach using population balances. Powder Technol. 2005, 160, 209-218. [CrossRef]

34. Kunieda, H.; Hanno, K.; Yamaguchi, S.; Shinoda, K. The Three-Phase Behavior of a Brine/Ionic Surfactant/Nonionic Surfactant/Oil System: Evaluation of the Hydrophile-Lipophile Balance (HLB) of Ionic Surfactant. J. Colloid Interface Sci. 1985, 107, 129-137. [CrossRef]

35. Kunieda, H.; Ishikawa, N. Evaluation of the Hydrophile-Lipophile Balance (HLB) of Nonionic Surfactants. II. Commercial-Surfactant Systems. J. Colloid Interface Sci. 1985, 107, 122-128. [CrossRef]

(C) 2020 by the authors. Licensee MDPI, Basel, Switzerland. This article is an open access article distributed under the terms and conditions of the Creative Commons Attribution (CC BY) license (http://creativecommons.org/licenses/by/4.0/). 


\title{
Flotation of Seafloor Massive Sulfide Ores: Combination of Surface Cleaning and Deactivation of Lead-Activated Sphalerite to Improve the Separation Efficiency of Chalcopyrite and Sphalerite
}

\author{
Kosei Aikawa ${ }^{1, *}$, Mayumi Ito ${ }^{2}$, Atsuhiro Kusano ${ }^{1}$, Ilhwan Park ${ }^{2}$, Tatsuya Oki ${ }^{3}$, Tatsuru Takahashi ${ }^{4}$, \\ Hisatoshi Furuya ${ }^{5}$ and Naoki Hiroyoshi ${ }^{2}$
}

\author{
Citation: Aikawa, K.; Ito, M.; \\ Kusano, A.; Park, I.; Oki, T.; \\ Takahashi, T.; Furuya, H.; Hiroyoshi, \\ N. Flotation of Seafloor Massive \\ Sulfide Ores: Combination of Surface \\ Cleaning and Deactivation of \\ Lead-Activated Sphalerite to Improve \\ the Separation Efficiency of \\ Chalcopyrite and Sphalerite. Metals \\ 2021, 11, 253. https://doi.org/ \\ $10.3390 /$ met 11020253
}

Academic Editor: Fernando Castro Received: 28 December 2020 Accepted: 29 January 2021 Published: 2 February 2021

Publisher's Note: MDPI stays neutral with regard to jurisdictional claims in published maps and institutional affiliations.

Copyright: (c) 2021 by the authors. Licensee MDPI, Basel, Switzerland. This article is an open access article distributed under the terms and conditions of the Creative Commons Attribution (CC BY) license (https:// creativecommons.org/licenses/by/ $4.0 /)$.
1 Division of Sustainable Resources Engineering, Graduate School of Engineering, Hokkaido University, Sapporo 060-8628, Japan; kusano.atsuhiro.z2@elms.hokudai.ac.jp

2 Division of Sustainable Resources Engineering, Faculty of Engineering, Hokkaido University, Sapporo 060-8628, Japan; itomayu@eng.hokudai.ac.jp (M.I.); i-park@eng.hokudai.ac.jp (I.P.); hiroyosi@eng.hokudai.ac.jp (N.H.)

3 Environmental Management Research Institute, National Institute of Advanced Industrial Science and Technology (AIST), Tsukuba 305-8569, Japan; t-oki@aist.go.jp

4 Seafloor Mineral Resources Research \& Development Division, Seafloor Mineral Resources Department, Japan Oil, Gas and Metals National Corporation (JOGMEC), Tokyo 105-0001, Japan; takahashi-tatsuru@jogmec.go.jp

5 Metals Technology Division, Metals Development Department, Japan Oil, Gas and Metals National Corporation (JOGMEC), Tokyo 105-0001, Japan; furuya-hisatoshi@jogmec.go.jp

* Correspondence: k88a28_tennis@eis.hokudai.ac.jp; Tel.: +81-11-706-6315

Abstract: The purpose of this study is to propose the flotation procedure of seafloor massive sulfide (SMS) ores to separate chalcopyrite and galena as froth and sphalerite, pyrite, and other gangue minerals as tailings, which is currently facing difficulties due to the presence of water-soluble compounds. The obtained SMS ore sample contains $\mathrm{CuFeS}_{2}, \mathrm{ZnS}, \mathrm{FeS}_{2}, \mathrm{SiO}_{2}$, and $\mathrm{BaSO}_{4}$ in addition to $\mathrm{PbS}$ and $\mathrm{PbSO}_{4}$ as $\mathrm{Pb}$ minerals. Soluble compounds releasing $\mathrm{Pb}, \mathrm{Zn}^{2+}, \mathrm{Pb}^{2+}$, and $\mathrm{Fe}^{2+/ 3+}$ are also contained. When anglesite co-exists, lead activation of sphalerite occurred, and thus sphalerite was recovered together with chalcopyrite as froth. To remove soluble compounds (e.g., anglesite) that have detrimental effects on the separation efficiency of chalcopyrite and sphalerite, surface cleaning pretreatment using ethylene diamine tetra acetic acid (EDTA) was applied before flotation. Although most of anglesite were removed and the recovery of chalcopyrite was improved from $19 \%$ to $81 \%$ at $20 \mathrm{~g} / \mathrm{t}$ potassium amyl xanthate (KAX) after EDTA washing, the floatability of sphalerite was not suppressed. When zinc sulfate was used as a depressant for sphalerite after EDTA washing, the separation efficiency of chalcopyrite and sphalerite was improved due to deactivation of leadactivated sphalerite by zinc sulfate. The proposed flotation procedure of SMS ores-a combination of surface cleaning with EDTA to remove anglesite and the depression of lead-activated sphalerite by using zinc sulfate-could achieve the highest separation efficiency of chalcopyrite and sphalerite; that is, at $200 \mathrm{~g} / \mathrm{t} \mathrm{KAX}$, the recoveries of chalcopyrite and sphalerite were $86 \%$ and $17 \%$, respectively.

Keywords: seafloor massive sulfide; flotation; lead-activated sphalerite; anglesite; EDTA

\section{Introduction}

Seafloor massive sulfide (SMS) deposits, also referred to as submarine hydrothermal polymetallic sulfide deposits, have gained increasing attention as new metal resources because they consist of various forms of polymetallic sulfide including $\mathrm{Cu}, \mathrm{Pb}, \mathrm{Zn}, \mathrm{Au}, \mathrm{Ag}$, etc. SMS deposits were found in a variety of volcanic and tectonic settings on the modern ocean floor in worldwide [1,2]. A number of scholars have studied SMS deposits, examples of which include formation mechanisms [3-5], exploration [6-8], mining methods [9-12], 
and environmental impacts [13-15]; however, only a few studies on mineral processing of SMS ores have been carried out $[16,17]$.

In Japan, the program for the development of SMS deposits around Japan has been conducted by the Ministry of Economic, Trade and Industry (METI) and Japan Oil, Gas and Metals National Corporation (JOGMEC). Not only seafloor mining, but also mineral processing and extractive metallurgy of SMS ores have been studied. Masuda (2011) [18] reported that SMS resembles the Kuroko on land in terms of deposit origin, which implies that similar processing and refining technologies applied to Kuroko can also be utilized for SMS ores. However, the previous studies on mineral processing of SMS ores conducted by JOGMEC indicated that mineral processing behaviors of the SMS ores are quite different compared to those of Kuroko [17]. METI and JOGMEC (2018) [16] reported distinct features of SMS ores obtained from around Japan: (1) lead minerals in the SMS ores are mostly present as anglesite $\left(\mathrm{PbSO}_{4}\right)$ with a minor amount of galena $(\mathrm{PbS})$, and (2) metal ions are highly dissolved from the SMS ores (e.g., $\left[\mathrm{Zn}^{2+}\right], 1700-3000 \mathrm{ppm}$ ). Moreover, some researchers reported various metal ions like $\mathrm{Cu}^{2+}, \mathrm{Pb}^{2+}$, and $\mathrm{Zn}^{2+}$ are released from the SMS ores obtained from the Trans-Atlantic Geotraverse active mound on the Mid-Atlantic Ridge [10] and the Izena Hole in the middle Okinawa Trough, Japan [11]. These distinct features of SMS ores around Japan - the presence of anglesite and the release of metal ions-would make mineral processing of $\mathrm{SMS}$ ores composed of $\mathrm{Cu}-\mathrm{Pb}-\mathrm{Zn}$ sulfide minerals complicated.

$\mathrm{Cu}-\mathrm{Pb}-\mathrm{Zn}$ sulfide minerals are generally processed via two flotation stages whereby $\mathrm{Cu}$ - and $\mathrm{Pb}$-sulfide minerals are first recovered, followed by floating $\mathrm{Zn}$-sulfide minerals [19]. When anglesite is contained in $\mathrm{Cu}-\mathrm{Pb}-\mathrm{Zn}$ sulfide minerals, it is readily dissolved and releases $\mathrm{Pb}^{2+}$ that activates sphalerite via the formation of PbS-like compounds on sphalerite surface, as explained in Equation (1). Activation of sphalerite by $\mathrm{Pb}^{2+}$ is known to increase the sphalerite floatability because the PbS-like compound has a higher affinity with xanthate than sphalerite [20-23].

$$
\mathrm{ZnS}(\mathrm{s})+\mathrm{Pb}^{2+}=\mathrm{PbS}(\mathrm{s})+\mathrm{Zn}^{2+}
$$

Thus, activation of sphalerite by $\mathrm{Pb}^{2+}$ is an unwelcomed side reaction because it dramatically limits the separation of $\mathrm{Cu}-\mathrm{Pb}-\mathrm{Zn}$ sulfide minerals. To improve their separation efficiency in the presence of anglesite, depression of lead-activated sphalerite is necessary. In practice, zinc sulfate and sulfoxy reagents (e.g., sulfite, metabisulfite, and bisulfate) are used as depressants for sphalerite [24] and, moreover, the former can also be used for the depression of lead-activated sphalerite $[25,26]$. The aim of this study is to propose a flotation procedure of SMS ores that is facing difficulty of separating chalcopyrite and sphalerite due to the presence of water-soluble compounds like anglesite. To improve the separation efficiency of chalcopyrite and sphalerite, depression effects of sodium sulfite and zinc sulfate on sphalerite floatability in the flotation of SMS ores were examined. In addition, a chemical pretreatment using ethylene diamine tetra acetic acid (EDTA) to remove anglesite and other soluble species (e.g., oxidation products) having potentials to affect flotation process was investigated. Finally, a flotation procedure of SMS ores to separate chalcopyrite and sphalerite in the presence of soluble compounds like anglesite using a combination of surface cleaning with EDTA and depression of lead-activated sphalerite by zinc sulfate was proposed.

\section{Materials and Methods}

\subsection{Samples}

A submarine hydrothermal polymetallic sulfide ore sample (named as sample A) obtained from around Japan and provided by JOGMEC, and seven types of minerals were used in this study: chalcopyrite $\left(\mathrm{CuFeS}_{2}\right.$, Copper Queen Mine, Cochise County, AZ, USA), sphalerite (ZnS, Kamioka Mine, Hida, Japan), galena (PbS, Beni Tadjit, Figuig, Morocco), anglesite $\left(\mathrm{PbSO}_{4}\right.$, Puit 9 Touissit, Oujda,, Morocco), pyrite $\left(\mathrm{FeS}_{2}\right.$, Huanzala Mine, Huanuco, Peru), quartz $\left(\mathrm{SiO}_{2}, 99 \%\right.$ purity, Wako Pure Chemical Industries Co., Ltd., Tokyo, Japan), and barite $\left(\mathrm{BaSO}_{4}\right.$, Jungcheon Changdo Mine, Kimhwa County, South Korea). The mixtures of 
chalcopyrite, sphalerite, pyrite, quartz, and barite with galena or anglesite were used as model samples for flotation experiments. Sample A and the above-mentioned mineral samples were characterized using X-ray fluorescence spectroscopy (XRF, EDXL300, Rigaku Corporation, Tokyo, Japan) and X-ray powder diffraction (XRD, MultiFlex, Rigaku Corporation, Tokyo, Japan), and the chemical and mineralogical compositions of these samples are summarized in Table 1 and shown in Figure 1, respectively. The XRD pattern of the submarine hydrothermal polymetallic sulfide ore sample (sample A) shows that it contains chalcopyrite, sphalerite, galena, anglesite, barite, pyrite, and quartz (Figure 1a).

Table 1. Chemical composition of sample A based on X-ray fluorescence spectroscopy (XRF).

\begin{tabular}{cccccccc}
\hline \multirow{2}{*}{ Sample } & \multicolumn{7}{c}{ Mass Fraction (\%) } \\
\cline { 2 - 8 } & $\mathbf{C u}$ & $\mathbf{Z n}$ & $\mathbf{P b}$ & $\mathbf{F e}$ & $\mathbf{S}$ & $\mathbf{S i}$ & $\mathbf{B a}$ \\
\hline Sample A & 7.4 & 13.6 & 7.1 & 24.5 & 35.7 & 3.5 & 1.5 \\
Chalcopyrite & 24.5 & 0.7 & - & 34.1 & 26.0 & 8.8 & - \\
Sphalerite & - & 66.5 & 0.1 & 3.5 & 24.8 & 2.7 & - \\
Galena & - & - & 84.8 & - & 8.3 & 1.5 & - \\
Anglesite & 1.3 & 0.7 & 88.0 & 0.2 & 7.6 & 0.7 & - \\
Pyrite & - & - & - & 42.3 & 52.5 & 1.0 & - \\
Barite & - & - & - & - & 17.9 & 0.3 & 67.8 \\
\hline
\end{tabular}

The samples were ground by using a vibratory disc mill (RS 100, Retsch Inc., Haan, Germany) and were screened to obtain a size fraction of $-75 \mu \mathrm{m}$. For the flotation experiments, potassium amyl xanthate (KAX, Tokyo Chemical Industry Co., Ltd., Tokyo, Japan) as a collector, Methyl Isobutyl Carbinol (MIBC, Tokyo Chemical Industry Co., Ltd., Tokyo, Japan) as a frother, and sodium sulfite $\left(\mathrm{Na}_{2} \mathrm{SO}_{3}\right.$, Wako Pure Chemical Industries, Ltd., Osaka, Japan) and zinc sulfate $\left(\mathrm{ZnSO}_{4}\right.$, Wako Pure Chemical Industries Ltd., Osaka, Japan) as depressants were used. Sodium hydroxide ( $\mathrm{NaOH}$, Wako Pure Chemical Industries Ltd., Osaka, Japan) and sulfuric acid $\left(\mathrm{H}_{2} \mathrm{SO}_{4}\right.$, Wako Pure Chemical Industries, Ltd., Osaka, Japan) were used as $\mathrm{pH}$ adjusters. For surface cleaning to remove the oxidation products present on mineral surface and/or contained in sample A, ethylene diamine tetra acetic acid (EDTA, Wako Pure Chemical Industries, Ltd., Osaka, Japan) was used [27,28].

\subsection{Experimental Methods}

\subsubsection{Flotation}

Prior to flotation tests, samples were deslimed by the following procedure: (1) a $20 \mathrm{~g}$ sample was added into $300 \mathrm{~mL}$ distilled water and then ultrasonication using high-speed switching oscillation between $24 \mathrm{kHz}$ and $31 \mathrm{kHz}$ (W-113 MK-II, Honda Electronics Co., Ltd., Toyohashi, Japan) was carried out for $1 \mathrm{~min}$, (2) the suspension was allowed to be settled down for $5 \mathrm{~min}$, and then the supernatant was removed. These treatments were done in triplicate, and the settled portion was used for flotation experiments.

An agitator-type flotation machine (FT-1000, Heiko-Seisakusyo, Tokyo, Japan) equipped with a 400-mL flotation cell was used and flotation experiments were conducted under the following conditions: $\mathrm{pH}, 6.5$; temperature, $25^{\circ} \mathrm{C}$; pulp density, $5 \%$; impeller speed, $1000 \mathrm{rpm}$; air flow rate, $1 \mathrm{~L} / \mathrm{min}$. After flotation, froth and tailing products were dried in an oven at $105^{\circ} \mathrm{C}$ for $24 \mathrm{~h}$ and analyzed by XRF to determine the recovery of $\mathrm{Cu}, \mathrm{Zn}, \mathrm{Pb}, \mathrm{Fe}, \mathrm{Si}$, and $\mathrm{Ba}$. Flotation experiments were carried out based on the flowchart, as illustrated in Figure 2. 

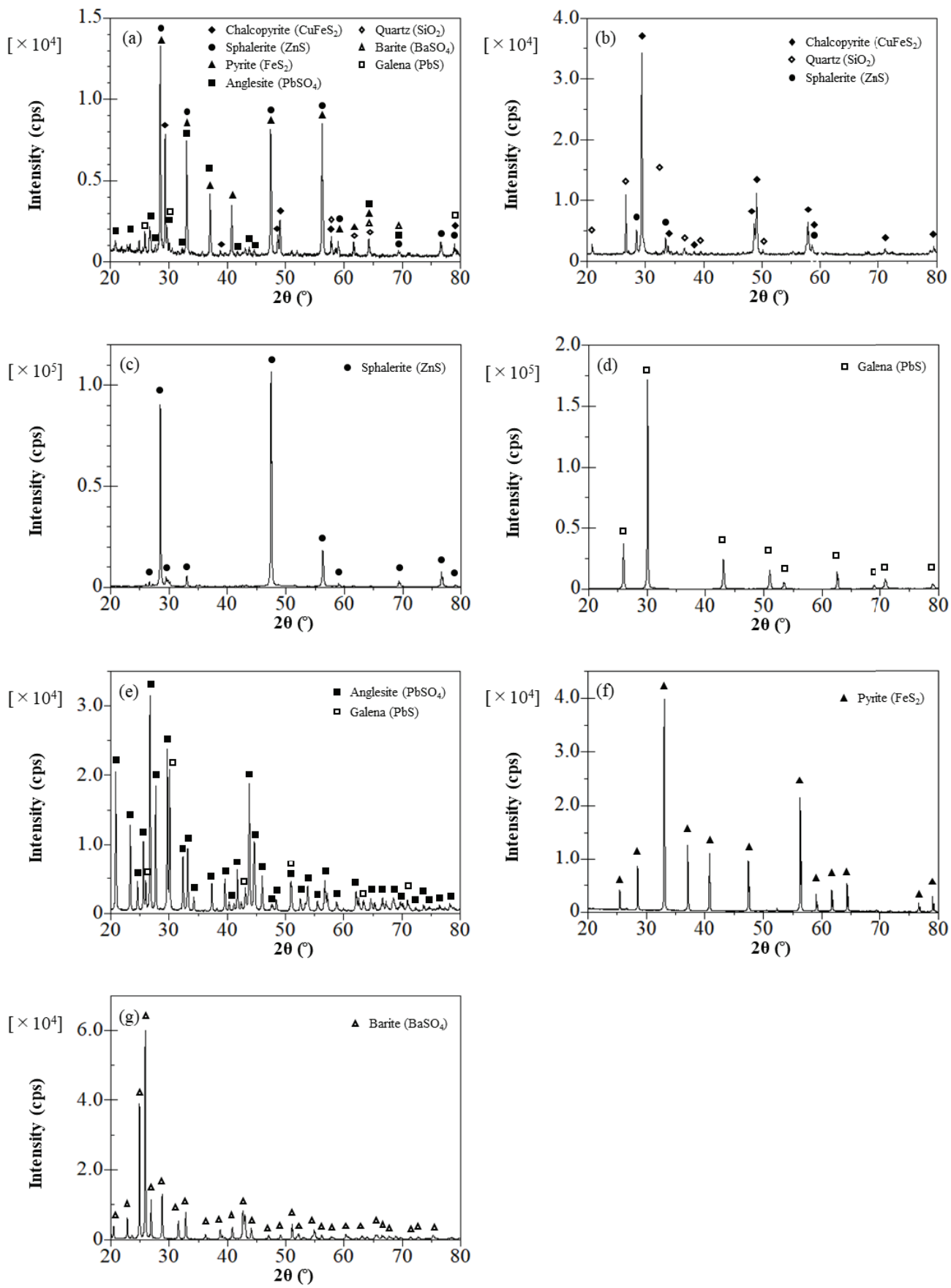

Figure 1. The X-ray powder diffraction (XRD) patterns of (a) sample A, (b) chalcopyrite, (c) sphalerite, (d) galena, (e) anglesite, (f) pyrite, and (g) barite. Note differences in the scale of the y-axes. 


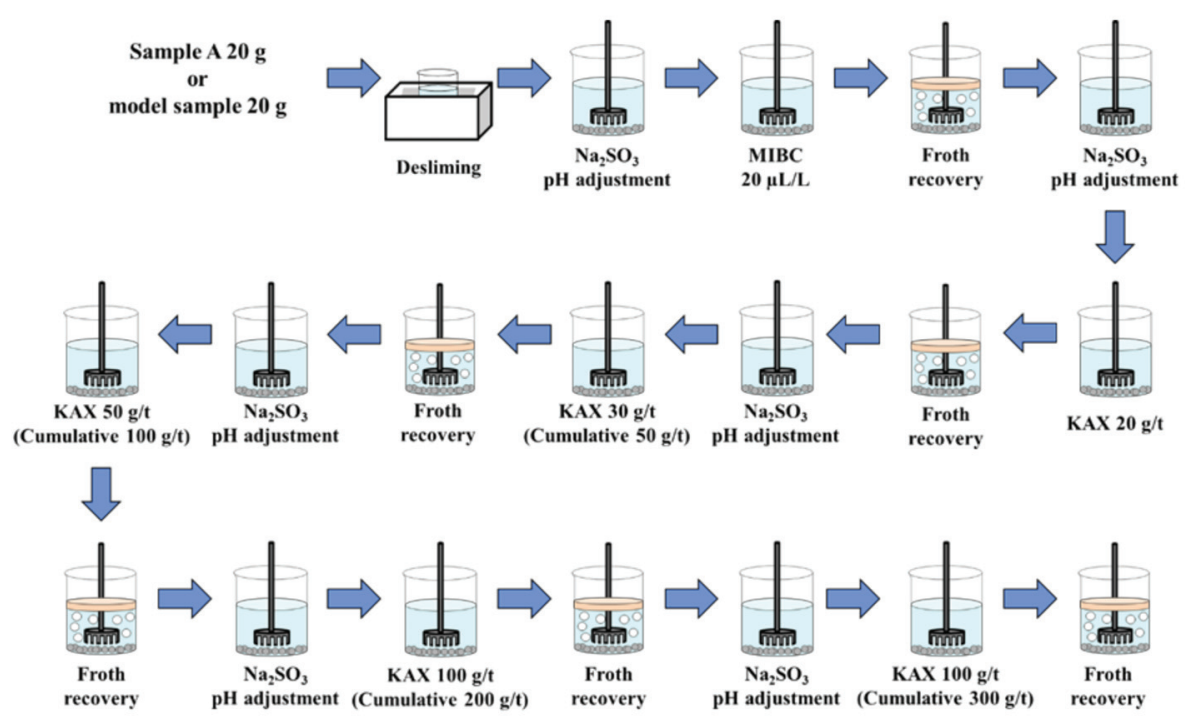

Figure 2. Flotation procedure with sequential addition of collector (KAX).

\subsubsection{Surface Cleaning of Sample A}

Surface cleaning with EDTA: (1) a $20 \mathrm{~g}$ sample was added into $300 \mathrm{~mL}$ solution containing EDTA ( $25 \mathrm{~g} / \mathrm{L}$ ) and then ultrasonicated for $1 \mathrm{~min}$, (2) the supernatant of the suspension was removed after settling for $5 \mathrm{~min}$. These treatments were done in triplicate and flotation experiments were conducted immediately after this surface cleaning.

\subsubsection{Leachability Test of Sample A with DI Water}

To check the amounts of soluble species in sample A, a leachability test was carried out. To achieve this, $0.4 \mathrm{~g}$ of sample $\mathrm{A}$ and $40 \mathrm{~mL}$ distilled water (i.e., pulp density: $1 \%$ ) were added into a 50-mL centrifuge tube and shaken by a roller shaker (MIX ROTOR VMR-5R, AS ONE Co., Ltd., Osaka, Japan) at $100 \mathrm{rpm}$ for $10 \mathrm{~min}$. Afterward, the leachate was collected by filtration using $0.2 \mu \mathrm{m}$ syringe-driven membrane filters and immediately analyzed by an inductively coupled plasma atomic emission spectrometer (ICP-AES, ICPE 9820, Shimadzu Corporation, Kyoto, Japan) (margin of error $= \pm 2 \%$ ) to measure the concentration of $\mathrm{Cu}^{2+}, \mathrm{Pb}^{2+}, \mathrm{Zn}^{2+}$, and $\mathrm{Fe}^{2+/ 3+}$ released from sample A.

\section{Results and Discussion}

3.1. Effect of Sodium Sulfite on the Separation of Chalcopyrite and Sphalerite in the Flotation of Sample A

Figure 3 shows the flotation results of sample A with various dosages of sodium sulfite $(0,5$, or $20 \mathrm{~kg} / \mathrm{t})$ to evaluate its suppressive effect on the floatability of pyrite as well as sphalerite. The floatability of pyrite was apparently suppressed as $\mathrm{Na}_{2} \mathrm{SO}_{3}$ dosage increased; that is, about $45 \%$ of pyrite was recovered at $100 \mathrm{~g} / \mathrm{t} \mathrm{KAX}$ in the absence of $\mathrm{Na}_{2} \mathrm{SO}_{3}$ (Figure 3a), but it decreased to $\sim 30 \%$ with $5 \mathrm{~kg} / \mathrm{t} \mathrm{Na}{ }_{2} \mathrm{SO}_{3}$ and $\sim 22 \%$ with $20 \mathrm{~kg} / \mathrm{t} \mathrm{Na}{ }_{2} \mathrm{SO}_{3}$ (Figure $3 \mathrm{~b}, \mathrm{c}$ ). However, sphalerite was recovered as froth together with chalcopyrite, irrespective of the amount of depressant added. In the case of $\mathrm{Pb}$ minerals (i.e., anglesite and galena), their recovery was low at around 30-40\%, suggesting that anglesite is most likely the main $\mathrm{Pb}$ mineral in sample $\mathrm{A}$. As mentioned earlier, the presence of anglesite can dramatically change the flotation behavior of sphalerite because of $\mathrm{Pb}^{2+}$ released from anglesite that activates sphalerite. 
(a)

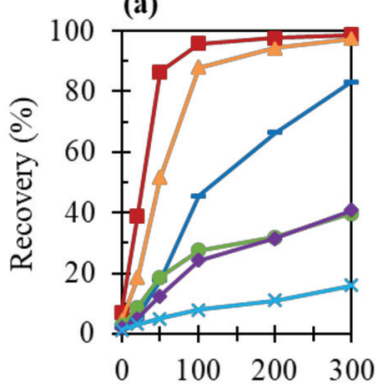

(b)

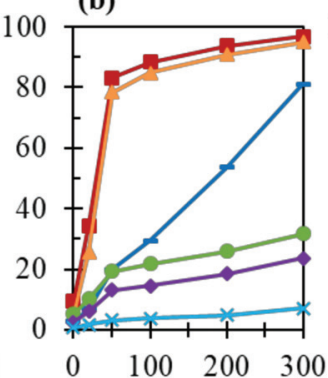

(c)

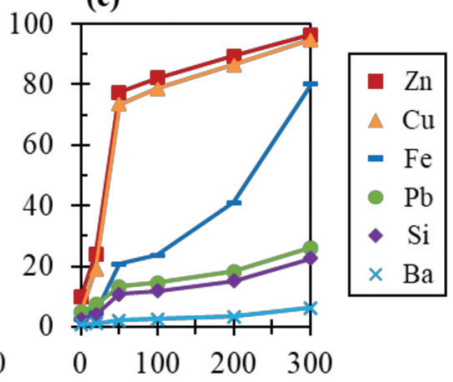

Cumulative collector addition $(\mathrm{g} / \mathrm{t})$

Figure 3. Flotation results of sample A with sodium sulfite (a) $0 \mathrm{~kg} / \mathrm{t}$, (b) $5 \mathrm{~kg} / \mathrm{t}$, and (c) $20 \mathrm{~kg} / \mathrm{t}$.

To clarify the effects of $\mathrm{Pb}$ minerals on the floatability of sphalerite, flotation tests were conducted using model samples, prepared based on the actual mineralogical composition of sample A obtained by norm calculation (Table 2).

Table 2. Norm calculation results of sample A.

\begin{tabular}{cccccc}
\hline \multicolumn{7}{c}{ Mass Fraction (\%) } \\
\hline $\mathrm{CuFeS}_{2}$ & $\mathrm{ZnS}$ & $\mathrm{PbS}$ & $\mathrm{FeS}_{2}$ & $\mathrm{SiO}_{2}$ & $\mathbf{B a S O}_{4}$ \\
\hline 21.7 & 20.6 & 8.4 & 39.2 & 7.5 & 2.6 \\
\hline
\end{tabular}

Specifically, two types of model samples (PbS-type and $\mathrm{PbSO}_{4}$-type) were prepared considering $\mathrm{PbS}_{\text {or }} \mathrm{PbSO}_{4}$ as the only $\mathrm{Pb}$ mineral. Flotation experiments using the PbS-type or the $\mathrm{PbSO}_{4}$-type model sample were carried out with $5 \mathrm{~kg} / \mathrm{t} \mathrm{Na} \mathrm{SO}_{3}$. As shown in Figure 4, chalcopyrite and galena were floated first followed by sphalerite in the flotation of the PbS-type model sample, whereas sphalerite was floated together with chalcopyrite in the flotation of the $\mathrm{PbSO}_{4}$-type model sample. In general, $\mathrm{Cu}$ - $\mathrm{Pb}$ - $\mathrm{Zn}$ sulfide ores are processed via two flotation stages whereby $\mathrm{Cu}$ - and $\mathrm{Pb}$-sulfide minerals are first recovered, followed by $\mathrm{Zn}$-sulfide minerals. The flotation result of the PbS-type model sample (Figure 4a) is in good agreement with the report of Woodcock et al. (2007) [19]. On the other hand, $\mathrm{Zn}$ was floated together with $\mathrm{Cu}$ in the flotation of the $\mathrm{PbSO}_{4}$-type model sample (Figure $4 \mathrm{~b}$ ), indicating that the floatability of sphalerite increased in the presence of anglesite, and this increased floatability of sphalerite was also observed in the real sample (sample A, Figure 3). In the case of the $\mathrm{PbSO}_{4}$-type model sample (Figure $4 \mathrm{~b}$ ), the recovery of $\mathrm{Pb}$ was lower than $20 \%$ because anglesite has low affinity with xanthate $[29,30]$. Trahar et al. (1997) [23] and Wills and Napier-Munn (2005) [31] reported that the floatability of sphalerite can be increased by metal ions (e.g., $\mathrm{Cu}^{2+}$ and $\mathrm{Pb}^{2+}$ ) due to the formation of $\mathrm{CuS} / \mathrm{PbS}$-like compounds which have higher affinity with xanthate than $\mathrm{ZnS}$. In the case of the $\mathrm{PbSO}_{4}$-type model sample, sphalerite may be activated by $\mathrm{Pb}^{2+}$ released from anglesite because of its higher solubility than that of $\mathrm{PbS}$ (Ksp of anglesite and galena are $10^{-7.79}$ and $10^{-26.77}$, respectively) [32]. These results indicate that the conventional flotation procedure of $\mathrm{Cu}-\mathrm{Pb}-\mathrm{Zn}$ ores is not applicable for SMS ores and needs to be modified to minimize the effect of anglesite on the floatability of sphalerite. 
(a)

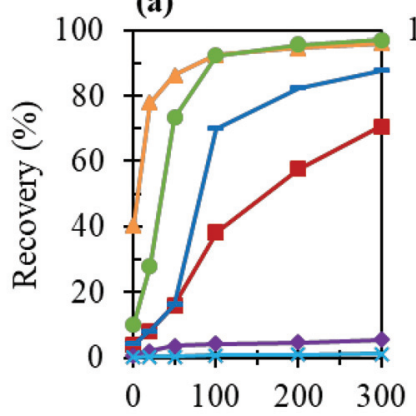

(b)

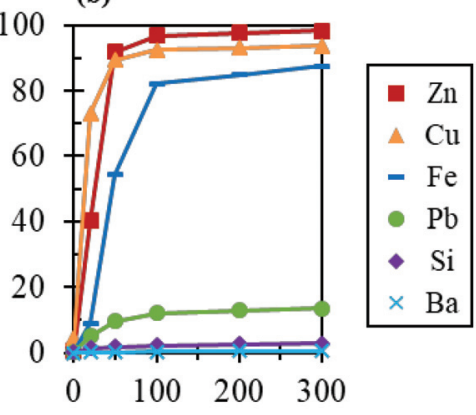

Cumulative collector addition $(\mathrm{g} / \mathrm{t})$

Figure 4. Flotation results of (a) PbS-type model sample and (b) $\mathrm{PbSO}_{4}$-type model sample.

\subsection{Leachability Test of Sample A with DI Water}

Leachability test of sample A with DI water was conducted to confirm how much dissolved metal ions are released from sample A. As shown in Table 3, the concentrations of $\mathrm{Pb}^{2+}$ and $\mathrm{Zn}^{2+}$ were $38 \mathrm{ppm}$ and $20 \mathrm{ppm}$, respectively, while the concentrations of $\mathrm{Cu}^{2+}$ and $\mathrm{Fe}^{2+/ 3+}$ were below the detection limit of ICP-AES (final pH: 5.12). Fuchida et al. (2018) [11] reported that $\mathrm{Pb}^{2+}$ and $\mathrm{Zn}^{2+}$ were released in the saline water from sulfide samples collected by seafloor drilling from the Izena Hole in the middle Okinawa Trough, Japan. Other authors also reported the release of metal ions like $\mathrm{Cu}^{2+}, \mathrm{Pb}^{2+}$ and $\mathrm{Zn}^{2+}$ from the samples obtained from SMS deposits such as the Trans-Atlantic Geotraverse (TAG) active mound on the Mid-Atlantic Ridge [10] and Hakurei Site in the Okinawa Trough, Japan [16]. These suggest that metal ions are released from SMS ores, which supports our deduction that $\mathrm{Pb}^{2+}$ and $\mathrm{Zn}^{2+}$ are released from sample A. According to Aikawa et al. (2020) [33], Rashchi et al. (2002) [22], and Trahar et al. (1997) [23], lead activation of sphalerite can occur above $5 \mathrm{ppm}$ of $\mathrm{Pb}^{2+}$, resulting in dramatic increase in the floatability of sphalerite. This indicates that activation of sphalerite by $\mathrm{Pb}^{2+}$ would occur during flotation of sample A, making not only $\mathrm{CuFeS}_{2}$ but also ZnS float, so their separation becomes difficult in the presence of soluble $\mathrm{Pb}$ minerals like anglesite.

Table 3. Results of leaching tests of sample A with DI water.

\begin{tabular}{ccccc}
\hline \multicolumn{4}{c}{ Concentration (ppm) } & \multirow{2}{*}{ Final pH } \\
\cline { 1 - 4 } $\mathbf{C u}$ & $\mathbf{Z n}$ & $\mathbf{P b}$ & $\mathbf{F e}$ & \\
\hline- & 20 & 38 & - & 5.12 \\
\hline Note: "-" denotes below the detection limit. & & &
\end{tabular}

3.3. Effect of Surface Cleaning Pretreatment Using EDTA on the Separation of Chalcopyrite and Sphalerite in the Flotation of Sample A

The SMS ores have undergone the natural oxidation process under atmosphere and/or seafloor, resulting in the formation of oxidized phases [10,34]. According to Fuchida et al. (2019) [35] who compared metal leaching of both non-oxidized (non-exposed to atmosphere before and during exploitation) and oxidized (exposed to atmosphere after lifting and recovery) seafloor hydrothermal sulfides, the oxidized sulfides readily released large amounts of various metal(loid)s (e.g., $\mathrm{Mn}, \mathrm{Fe}, \mathrm{Zn}, \mathrm{Cu}, \mathrm{As}, \mathrm{Sb}$, and $\mathrm{Pb}$ ) compared to nonoxidized ones. These suggest that oxidation products (e.g., oxide, hydroxide, sulfate, and carbonate) may be deposited on the surface of minerals and/or contained in sample A. These oxidation products present on mineral surface would contribute to the decrease in the floatability of sulfide minerals, especially chalcopyrite [36-39]. In addition, sample A contains the oxidation product, anglesite (lead sulfate), which makes the separation of 
chalcopyrite and sphalerite difficult due to the improved floatability of the latter by lead activation. To minimize the effects of oxidation products, surface cleaning pretreatment using EDTA was applied prior to flotation tests with the aim of improving the floatability of chalcopyrite, as well as depressing the floatability of sphalerite. EDTA was used for surface cleaning because of its ability to form stable complexes with metal ions dissolved from anglesite (lead sulfate) - a problematic mineral for $\mathrm{Cu}$-Zn separation-as well as other oxidation products, while it does not react with metal sulfides [37,40-42].

Figure 5 shows the flotation results of sample A with and without surface cleaning pretreatment using EDTA. The dosage of sodium sulfite as a depressant in this flotation experiment was fixed at $20 \mathrm{~kg} / \mathrm{t}$. After EDTA washing, chalcopyrite was floated first followed by sphalerite (Figure $5 \mathrm{~b}$ ). Moreover, the recovery of $\mathrm{Pb}$ minerals was high (i.e., $\sim 80 \%$ at $100 \mathrm{~g} / \mathrm{t} \mathrm{KAX)}$ compared to that without EDTA washing (Figure 5a). This increase in the floatability of $\mathrm{Pb}$ minerals is due most likely to the dissolution of most of anglesite after EDTA washing. Comparing the XRD patterns of sample A before and after EDTA washing (Figure 6), the latter showed that the peak intensity of anglesite apparently decreased while that of galena was not changed. This implies that the ratio of galena/anglesite increased, so the recovery of $\mathrm{Pb}$ minerals became high. Not only $\mathrm{Pb}$ minerals, but also the recovery of chalcopyrite at $20 \mathrm{~g} / \mathrm{t} \mathrm{KAX}$ increased from $19 \%$ to $81 \%$ after EDTA washing (Figure $5 \mathrm{a}, \mathrm{b}$ ). This may have been achieved by the removal of oxidation products present on the surface of chalcopyrite by EDTA. After EDTA washing, leachate contains a large amount of dissolved $\mathrm{Pb}(3200 \mathrm{ppm})$ with minor amounts of other metals (e.g., $\left[\mathrm{Cu}^{2+}\right], 9 \mathrm{ppm} ;\left[\mathrm{Zn}^{2+}\right], 137 \mathrm{ppm} ;\left[\mathrm{Fe}^{2+/ 3+}\right], 6 \mathrm{ppm}$ ) (Table 4), confirming that oxidation products and anglesite were dissolved after EDTA washing (Figure 6).

Due to the increase in the floatability of chalcopyrite, the separation efficiency of chalcopyrite and sphalerite was improved; however, the depressive effect of EDTA washing on the floatability of sphalerite was limited. In the flotation of sample A with EDTA washing, $\mathrm{Zn}$ was recovered as froth together with $\mathrm{Pb}$, suggesting that sphalerite may be activated by $\mathrm{Pb}^{2+}$ forming PbS-like compounds on the surface of sphalerite. To further improve the separation efficiency of chalcopyrite and sphalerite, the depression of leadactivated sphalerite by zinc sulfate, a common depressant for sphalerite, was investigated in the next subsection.

Table 4. The concentrations of dissolved metals in the supernatant after surface cleaning with EDTA.

\begin{tabular}{cccc}
\hline \multicolumn{5}{c}{ Concentration $(\mathrm{ppm})$} \\
\hline $\mathrm{Cu}$ & $\mathrm{Zn}$ & $\mathrm{Pb}$ & $\mathrm{Fe}$ \\
\hline 9 & 137 & 3200 & 6 \\
\hline
\end{tabular}

(a)

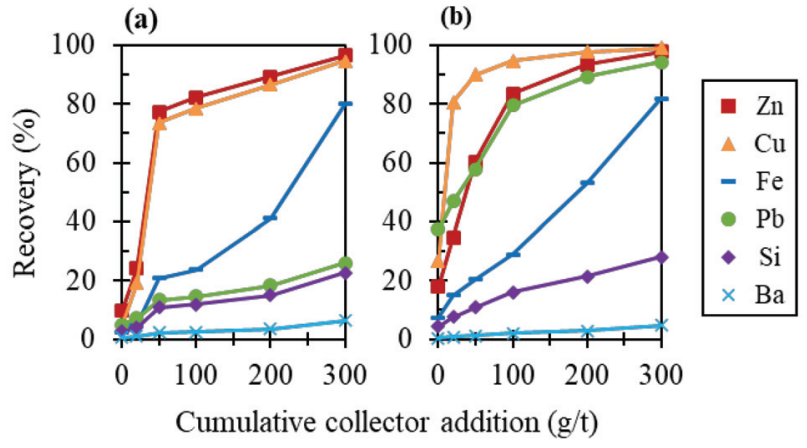

Figure 5. Flotation results of sample A (a) without surface cleaning and (b) with ethylene diamine tetra acetic acid (EDTA) washing. 


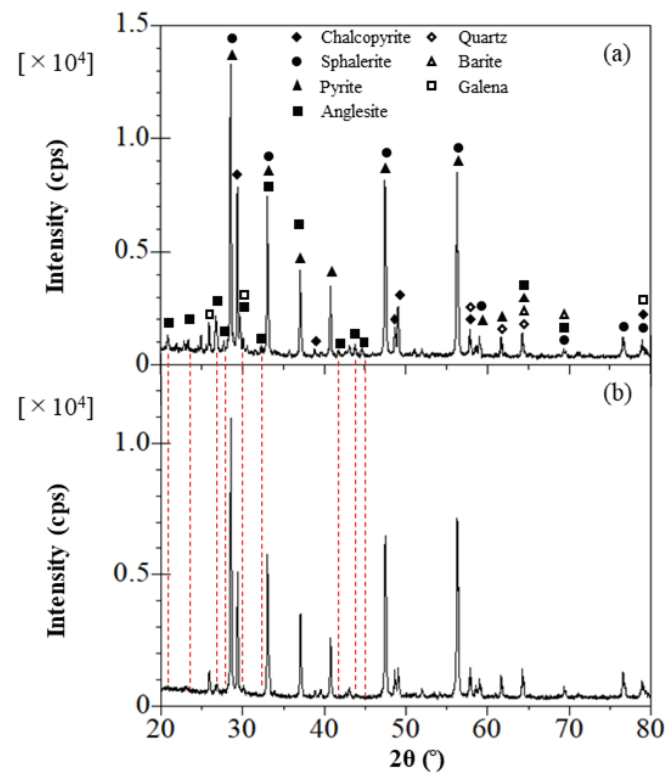

Figure 6. XRD patterns of sample A (a) without and (b) with EDTA washing.

\subsection{Suppression of Lead-Activated Sphalerite by Zinc Sulfate after EDTA Washing}

Figure $7 \mathrm{a}-\mathrm{c}$ show the flotation results of sample A without both EDTA washing and the addition of zinc sulfate (a), with the addition of zinc sulfate (1000 ppm of $\mathrm{Zn}^{2+}$ ) (b), and with EDTA washing followed by the addition of zinc sulfate (1000 ppm of $\mathrm{Zn}^{2+}$ ) (c). As illustrated in Figure 7a,b, the effect of zinc sulfate in depressing the floatability of sphalerite was almost negligible; that is, sphalerite was recovered as froth together with chalcopyrite. However, when EDTA washing was adopted prior to the addition of zinc sulfate, the floatability of chalcopyrite was not affected, while it had a detrimental effect on the floatability of sphalerite (Figure 7c); for example, the recovery of sphalerite at $100 \mathrm{~g} / \mathrm{t}$ KAX decreased from $88 \%$ to $8 \%$ by employing EDTA washing and the addition of zinc sulfate (Figure $7 \mathrm{~b}, \mathrm{c}$ ). These results indicate that EDTA washing followed by $\mathrm{Zn}^{2+}$ addition could be an effective approach to depress the floatability of lead-activated sphalerite in the flotation of SMS ores which contain anglesite.

(a)

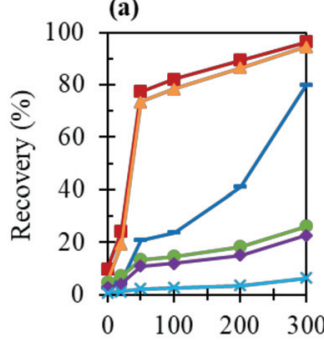

(b)

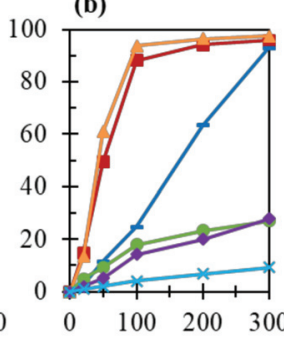

(c)

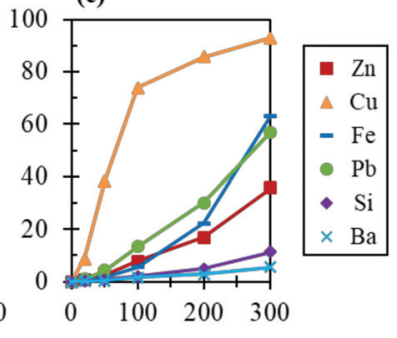

Cumulative collector addition $(\mathrm{g} / \mathrm{t})$

Figure 7. Flotation results of sample A (a) without both EDTA washing and the addition of zinc sulfate, (b) with the addition of zinc sulfate, and (c) with EDTA washing followed by the addition of zinc sulfate. Note that the recoveries of all minerals at $0 \mathrm{~g} / \mathrm{t}$ of collector in Figure $7 \mathrm{~b}, \mathrm{c}$ were assumed to be zero due to the lack of froth amounts for the XRF analysis. 
El-Shall et al. (2000) [25] calculated the change in free energy based on the equilibrium constant (Equations (1) and (2), where $\mathrm{K}=1000$ ) to evaluate the possibility of depression of lead-activated sphalerite in the presence of $1 \times 10^{-4} \mathrm{~mol} / \mathrm{L}$ of $\mathrm{Pb}^{2+}$ and $1 \times 10^{-4} \mathrm{~mol} / \mathrm{L}$ of $\mathrm{Zn}^{2+}$ at about $\mathrm{pH}$ 7.0. It was concluded that depression of lead-activated sphalerite by zinc sulfate is most probably due to the following reaction: $\mathrm{PbS}_{\text {surface }}+\mathrm{Zn}^{2+} \rightarrow \mathrm{ZnS}$ $+\mathrm{Pb}^{2+}$. Basilio et al. (1996) [43] also calculated the equilibrium constant of Equation (1) to evaluate the possibility of lead activation of sphalerite based on the change in free energy (Equation (2)); however, the calculated value of $\mathrm{K}$ was different from the one used by El-Shall et al. (2000) [25]. As confirmed by the above two cases, the free energy strongly depends on the conditions (e.g., $\mathrm{pH}$ and concentrations of reactants and products), so the change in free energy in our flotation system needs to be calculated using the measured values in this study-4.08 ppm of $\mathrm{Pb}^{2+}$ and $1070 \mathrm{ppm}$ of $\mathrm{Zn}^{2+}$ obtained from the suspension after addition of zinc sulfate in the flotation without EDTA washing (Figure $7 \mathrm{~b}$ ), and $1.21 \mathrm{ppm}$ of $\mathrm{Pb}^{2+}$ and $949 \mathrm{ppm}$ of $\mathrm{Zn}^{2+}$ obtained from that with EDTA washing (Figure 7c). For calculating the change in free energy in the flotation system of this study, the following equilibrium constants were considered: 1000 [25], 704 [44], 1059 [45], and 1127 [46] - the last three values were calculated based on Equation (3) using $K_{s p}$ values of $\mathrm{ZnS}$ and $\mathrm{PbS}$ summarized in Table 5 [43-46].

$$
\begin{gathered}
\Delta \mathrm{G}=-R T \ln K+R T \ln \left(\mathrm{Zn}^{2+} / \mathrm{Pb}^{2+}\right) \\
K=\frac{K_{s p}^{Z n S}}{K_{s p}^{P b S}}
\end{gathered}
$$

Table 5. Ksp values of $\mathrm{ZnS}$ and $\mathrm{PbS}$ in the literature.

\begin{tabular}{ccc}
\hline $\boldsymbol{K}_{s p}^{Z n S}$ & $\boldsymbol{K}_{s p}^{P b S}$ & Reference \\
\hline $1.9 \times 10^{-26}$ & $2.7 \times 10^{-29}$ & Helgeson (1969) [44] \\
$7.2 \times 10^{-26}$ & $6.8 \times 10^{-29}$ & Latimer (1952) [45] \\
$7.1 \times 10^{-26}$ & $6.3 \times 10^{-29}$ & Leckie \& James (1974) [46] \\
\hline
\end{tabular}

As shown in Table 6, the calculated values of change in free energy in the flotation with the addition of zinc sulfate (Figure $7 \mathrm{~b}$ ) were negative except the value using the equilibrium constant reported by Helgeson (1969) [44]. On the other hand, those in the flotation with the addition of zinc sulfate after EDTA washing (Figure 7c) were all positive. These results support our flotation results that the depression of lead-activated sphalerite was only achieved by the combination of EDTA washing which decreased $\mathrm{Pb}^{2+}$ concentration due to the removal of anglesite and the addition of zinc sulfate due to the reverse reaction of Equation (1).

Table 6. The calculation results of the change in free energy at $\mathrm{pH} 6.5$ in the flotation system of sample A.

\begin{tabular}{ccc}
\hline K & $\begin{array}{c}\Delta \mathrm{G}(\mathbf{k J} / \mathrm{mol}) \\
\text { With Zinc Sulfate and Without EDTA } \\
\text { Washing (Figure 7b) }\end{array}$ & $\begin{array}{c}\Delta \mathrm{G}(\mathbf{k J} / \mathbf{m o l}) \\
\text { With Zinc Sulfate after EDTA } \\
\text { Washing (Figure 7c) }\end{array}$ \\
\hline 1000 & -0.46 & 2.26 \\
704 & 0.41 & 3.13 \\
1059 & -0.60 & 2.11 \\
1127 & -0.76 & 1.96 \\
\hline
\end{tabular}

Figure 8 shows the relationship between $\mathrm{Cu}$ recovery and $\mathrm{Zn}$ recovery in flotation experiments using EDTA washing and/or zinc sulfate addition. The efficiencies of pretreatments on the separation of $\mathrm{Cu}$ and $\mathrm{Zn}$ were in the following orders: with zinc sulfate after EDTA washing > with EDTA washing > with zinc sulfate. Thus, it can be concluded that EDTA washing improves the recovery of chalcopyrite, removes anglesite, and enables the 
depression of lead-activated sphalerite by the addition of zinc sulfate. This proposed flotation procedure to separate chalcopyrite and sphalerite in the presence of soluble compounds like anglesite could be applied to not only SMS ores but also $\mathrm{Cu}-\mathrm{Pb}-\mathrm{Zn}$ ores in terrestrial deposits, which contain soluble compounds formed by the natural oxidations of minerals.

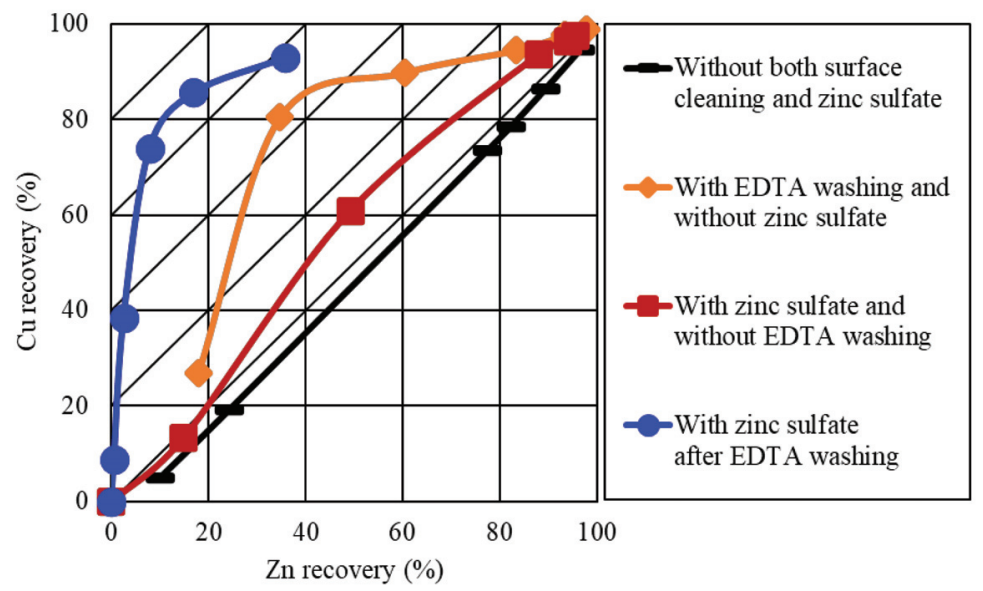

Figure 8. Relationship between $\mathrm{Cu}$ recovery and $\mathrm{Zn}$ recovery in flotation experiments with sodium sulfite $20 \mathrm{~kg} / \mathrm{t}$.

While El-Shall et al. (2000) [25] and Basilio et al. (1996) [43] estimated the possibility of lead activation of sphalerite using the measured ion concentration of $\mathrm{Pb}^{2+}$ and $\mathrm{Zn}^{2+}$, Trahar et al. (1997) [23] reported that lead activation of sphalerite may occur even when solubility of $\mathrm{Pb}^{2+}$ is extremely low (e.g., at $\mathrm{pH} 10$ ) where $\mathrm{Pb}$ precipitates like lead hydroxide are present. This means that sphalerite would be activated by not only $\mathrm{Pb}^{2+}$ but also $\mathrm{Pb}$ precipitates (e.g., lead hydroxide and lead sulfate (anglesite)), and thus it is impossible to estimate whether lead activation of sphalerite occurs or not based on the concentration of dissolved $\mathrm{Pb}$ species. In other words, the required amount of $\mathrm{Zn}^{2+}$ to facilitate the depression of lead-activated sphalerite may increase when Pb-precipitates co-exist. As described above, sample A contains secondary products (e.g., oxidation products) and soluble Pb-bearing minerals (e.g., anglesite), both of which could be almost removed by EDTA washing. When the contents of soluble Pb-bearing minerals are high, however, EDTA washing cannot completely remove all the soluble Pb-bearing minerals, indicating that large amounts of residual $\mathrm{Pb}$-bearing minerals most likely remain in the system. Therefore, detailed studies addressing the effects of co-existence of soluble $\mathrm{Pb}$ - bearing minerals on the suppression of sphalerite flotability by zinc sulfate will be of topical importance in the future.

\section{Conclusions}

This study investigated the applicability of surface cleaning with the addition of depressants for flotation separation of chalcopyrite and sphalerite from SMS ores. The findings of this study can be summarized as follows:

1. The obtained $\mathrm{SMS}$ ore sample contains $\mathrm{CuFeS}_{2}, \mathrm{ZnS}, \mathrm{FeS}_{2}, \mathrm{SiO}_{2}$, and $\mathrm{BaSO}_{4}$ in addition to $\mathrm{PbS}$ and $\mathrm{PbSO}_{4}$ as $\mathrm{Pb}$ minerals. Not only these minerals but soluble compounds which release $\mathrm{Cu}^{2+}, \mathrm{Zn}^{2+}, \mathrm{Pb}^{2+}$, and $\mathrm{Fe}^{2+/ 3+}$ are also contained in the sample.

2. When anglesite co-existed, lead activation of sphalerite occurred, which made the floatability of sphalerite increase.

3. In the flotation of sample A with sodium sulfite as a depressant for $\mathrm{Zn}$ - and Feminerals, the floatability of pyrite could be suppressed, while it was not able to depress the floatability of sphalerite because $\mathrm{Pb}^{2+}$ released from anglesite and other soluble compounds activated sphalerite. 
4. Surface cleaning using EDTA was effective in removing anglesite and improving the recovery of chalcopyrite by dissolving secondary products formed via natural oxidation processes. However, sphalerite was floated together with chalcopyrite, even after EDTA washing.

5. The proposed flotation procedure of SMS ores, a combination of surface cleaning with EDTA to improve chalcopyrite floatability and remove anglesite and the depression of lead-activated sphalerite by using zinc sulfate, could achieve high separation efficiency of chalcopyrite and sphalerite.

Author Contributions: Conceptualization, K.A., M.I., I.P., T.O., T.T., H.F., and N.H.; methodology, K.A. and M.I.; investigation, K.A. and A.K.; data curation, K.A., A.K., and I.P.; writing-original draft preparation, K.A.; writing—review and editing, M.I. and I.P., T.O., T.T., H.F., and N.H. All authors have read and agreed to the published version of the manuscript.

Funding: This research was funded by the Agency for Natural Resources and Energy, the Ministry of Economy, Trade and Industry (METI).

Data Availability Statement: Restrictions apply to the availability of these data. Data was obtained from the Ministry of Economy, Trade and Industry (METI) and are available from the authors with the permission of METI.

Acknowledgments: This work was carried out as commissioned business by the Agency for Natural Resources and Energy, the Ministry of Economy, Trade and Industry (METI). The authors are grateful to the agency and all of the persons engaged in its duties.

Conflicts of Interest: The authors declare no conflict of interest.

\section{References}

1. Boschen, R.E.; Rowden, A.A.; Clark, M.R.; Gardner, J.P.A. Mining of deep-sea seafloor massive sulfides: A review of the deposits, their benthic communities, impacts from mining, regulatory frameworks and management strategies. Ocean Coast. Manag. 2013, 84, 54-67. [CrossRef]

2. Herzig, P.M.; Hannington, M.D. Polymetallic massive sulfides at the modern seafloor a review. Ore Geol. Rev. 1995, 10, 95-115. [CrossRef]

3. Halbach, P.; Pracejus, B.; Maerten, A. Geology and mineralogy of massive sulfide ores from the central Okinawa Trough, Japan. Econ. Geol. 1993, 88, 2210-2225. [CrossRef]

4. Janecky, D.R.; Seyfried, W.E. Formation of massive sulfide deposits on oceanic ridge crests: Incremental reaction models for mixing between hydrothermal solutions and seawater. Geochim. Cosmochim. Acta 1984, 48, 2723-2738. [CrossRef]

5. Leybourne, M.I.; de Ronde, C.E.J.; Wysoczanski, R.J.; Walker, S.L.; Timm, C.; Gibson, H.L.; Layton-Matthews, D.; Baker, E.T.; Clark, M.R.; Tontini, F.C.; et al. Geology, Hydrothermal Activity, and Sea-Floor Massive Sulfide Mineralization at the Rumble II West Mafic Caldera. Econ. Geol. 2012, 107, 1649-1668. [CrossRef]

6. German, C.R.; Petersen, S.; Hannington, M.D. Hydrothermal exploration of mid-ocean ridges: Where might the largest sulfide deposits be forming? Chem. Geol. 2016, 420, 114-126. [CrossRef]

7. Hannington, M.; Jamieson, J.; Monecke, T.; Petersen, S.; Beaulieu, S. The abundance of seafloor massive sulfide deposits. Geology 2011, 39, 1155-1158. [CrossRef]

8. Monecke, T.; Petersen, S.; Hannington, M.D. Constraints on Water Depth of Massive Sulfide Formation: Evidence from Modern Seafloor Hydrothermal Systems in Arc-Related Settings. Econ. Geol. 2014, 109, 2079-2101. [CrossRef]

9. Asakawa, E.; Murakami, F.; Tsukahara, H.; Mizohata, S. Development of vertical cable seismic (VCS) system for seafloor massive sulfide (SMS). In Proceedings of the 2014 Oceans-St. John's, St. John's, NL, Canada, 14-19 September 2014; pp. 1-7.

10. Fallon, E.K.; Niehorster, E.; Brooker, R.A.; Scott, T.B. Experimental leaching of massive sulphide from TAG active hydrothermal mound and implications for seafloor mining. Mar. Pollut. Bull. 2018, 126, 501-515. [CrossRef]

11. Fuchida, S.; Ishibashi, J.; Shimada, K.; Nozaki, T.; Kumagai, H.; Kawachi, M.; Matsushita, Y.; Koshikawa, H. Onboard experiment investigating metal leaching of fresh hydrothermal sulfide cores into seawater. Geochem. Trans. 2018, 19, 15. [CrossRef] [PubMed]

12. Zha, L.; Li, H.; Wang, N. Electrochemical Study of Galena Weathering in NaCl Solution: Kinetics and Environmental Implications. Minerals 2020, 10, 416. [CrossRef]

13. Collins, P.C.; Croot, P.; Carlsson, J.; Colaço, A.; Grehan, A.; Hyeong, K.; Kennedy, R.; Mohn, C.; Smith, S.; Yamamoto, H.; et al. A primer for the Environmental Impact Assessment of mining at seafloor massive sulfide deposits. Mar. Policy 2013, 42, 198-209. [CrossRef]

14. Narita, T.; Oshika, J.; Toyohara, T.; Okamoto, N.; Shirayama, Y. The Environmental Impact Assessment for Mining Seafloor Massive Sulphides in Japan. J. MMIJ 2015, 131, 634-638. [CrossRef] 
15. Van Dover, C.L. Impacts of anthropogenic disturbances at deep-sea hydrothermal vent ecosystems: A review. Mar. Environ. Res. 2014, 102, 59-72. [CrossRef] [PubMed]

16. Ministry of Economic, Trade and Industry (METI); Japan Oil, Gas and Metals National Corporation (JOGMEC). Summary Report on Comprehensive Evaluations of Development Plan of Seafloor Massive Sulfide Deposits. Available online: http: / / www.jogmec.go.jp/content/300359550.pdf (accessed on 26 January 2021).

17. Oki, T.; Nishisu, Y.; Hoshino, M. Characteristics of The Existing Mineral Phases of Japanese Submarine Hydrothermal Polymetallic Sulfides and Their Influence on Respective Mineral Processing Properties. J. MMIJ 2015, 131, 619-626. [CrossRef]

18. Masuda, N. Challenges toward the sea-floor massive sulfide mining with more advanced technologies. In Proceedings of the 2011 IEEE Symposium on Underwater Technology and Workshop on Scientific Use of Submarine Cables and Related Technologies, Tokyo, Japan, 5-8 April 2011; pp. 1-4.

19. Woodcock, J.T.; Sparrow, G.J.; Bruckard, W.J.; Johnson, N.W.; Dunne, R. Plant Practice: Sulfide Minerals and Precious Metals. In Froth Flotation a Century of Innovation; Fuerstenau, M., Jameson, G., Yoon, R.H., Eds.; SME: Littleton, CO, USA, 2007 ; pp. 781-843. ISBN 978-0-873-35252-9.

20. Houot, R.; Raveneau, P. Activation of sphalerite flotation in the presence of lead ions. Int. J. Miner. Process. 1992, 35, $253-271$. [CrossRef]

21. Laskowski, J.S.; Liu, Q.; Zhan, Y. Sphalerite activation: Flotation and electrokinetic studies. Miner. Eng. 1997, 10, 787-802. [CrossRef]

22. Rashchi, F.; Sui, C.; Finch, J.A. Sphalerite activation and surface Pb ion concentration. Int. J. Miner. Process. 2002, 67, 43-58. [CrossRef]

23. Trahar, W.J.; Senior, G.D.; Heyes, G.W.; Creed, M.D. The activation of sphalerite by lead-A flotation perspective. Int. J. Miner. Process. 1997, 49, 121-148. [CrossRef]

24. Wang, H.; Wen, S.; Han, G.; Xu, L.; Feng, Q. Activation mechanism of lead ions in the flotation of sphalerite depressed with zinc sulfate. Miner. Eng. 2020, 146, 106132. [CrossRef]

25. El-Shall, H.E.; Elgillani, D.A.; Abdel-Khalek, N.A. Role of zinc sulfate in depression of lead-activated sphalerite. Int. J. Miner. Process. 2000, 58, 67-75. [CrossRef]

26. Fuerstenau, D.W.; Metzger, P.H.; Fuerstenau, D.W.; Metzger, P.H. Activation of sphalerite with lead ions in the presence of zinc salts. Trans. Am. Inst. Min. Metall. Eng. 1960, 217, 119-123.

27. Cao, Q.; Cheng, J.; Feng, Q.; Wen, S.; Luo, B. Surface cleaning and oxidative effects of ultrasonication on the flotation of oxidized pyrite. Powder Technol. 2017, 311, 390-397. [CrossRef]

28. Clarke, P.; Fornasiero, D.; Ralston, J.; Smart, R.S.C. A study of the removal of oxidation products from sulfide mineral surfaces. Miner. Eng. 1995, 8, 1347-1357. [CrossRef]

29. Fuerstenau, M.C.; Olivas, S.A.; Herrera-Urbina, R.; Han, K.N. The surface characteristics and flotation behavior of anglesite and cerussite. Int. J. Miner. Process. 1987, 20, 73-85. [CrossRef]

30. Rashchi, F.; Dashti, A.; Arabpour-Yazdi, M.; Abdizadeh, H. Anglesite flotation: A study for lead recovery from zinc leach residue. Miner. Eng. 2005, 18, 205-212. [CrossRef]

31. Wills, B.A.; Napier-Munn, T.J. Froth flotation. In Mineral Processing Technology, 8th ed.; Elsevier: Oxford, UK, 2016; pp. 265-380. ISBN 978-0-08-097053-0.

32. Ball, J.W.; Nordstrom, D.K. User's Manual for WATEQ4F, with Revised Thermodynamic Data Base and Text Cases for Calculating Speciation of Major, Trace, and Redox Elements in Natural Waters; USGS Numbered Series Open-File Report 91-183; U.S. Geological Survey: Reston, VA, USA, 1991; p. 37. [CrossRef]

33. Aikawa, K.; Ito, M.; Segawa, T.; Jeon, S.; Park, I.; Tabelin, C.B.; Hiroyoshi, N. Depression of lead-activated sphalerite by pyrite via galvanic interactions: Implications to the selective flotation of complex sulfide ores. Miner. Eng. 2020, 152, 106367. [CrossRef]

34. Seal, R.R.; Foley, N.K. Progress on Geoenvironmental Models for Selected Mineral Deposit Types; USGS Numbered Series Open-File Report 02-195; U.S. Geological Survey: Reston, VA, USA, 2002; pp. 196-212. [CrossRef]

35. Fuchida, S.; Ishibashi, J.; Nozaki, T.; Matsushita, Y.; Kawachi, M.; Koshikawa, H. Metal Mobility from Hydrothermal Sulfides into Seawater During Deep Seafloor Mining Operations. In Environmental Issues of Deep-Sea Mining; Sharma, R., Ed.; Springer: Cham, Switzerland, 2019; pp. 213-229. ISBN 978-3-030-12695-7.

36. Senior, G.D.; Trahar, W.J. The influence of metal hydroxides and collector on the flotation of chalcopyrite. Int. J. Miner. Process. 1991, 33, 321-341. [CrossRef]

37. Kant, C.; Rao, S.R.; Finch, J.A. Distribution of surface metal ions among the products of chalcopyrite flotation. Miner. Eng. 1994, 7, 905-916. [CrossRef]

38. Park, I.; Hong, S.; Jeon, S.; Ito, M.; Hiroyoshi, N. A Review of Recent Advances in Depression Techniques for Flotation Separation of $\mathrm{Cu}-\mathrm{Mo}$ Sulfides in Porphyry Copper Deposits. Metals 2020, 10, 1269. [CrossRef]

39. Park, I.; Hong, S.; Jeon, S.; Ito, M.; Hiroyoshi, N. Flotation Separation of Chalcopyrite and Molybdenite Assisted by Microencapsulation Using Ferrous and Phosphate Ions: Part I. Selective Coating Formation. Metals 2020, 10, 1667. [CrossRef]

40. Bicak, O. A technique to determine ore variability in a sulphide ore. Miner. Eng. 2019, 142, 105927. [CrossRef]

41. Grano, S.R.; Ralston, J.; Johnson, N.W. Characterization and treatment of heavy medium slimes in the Mt. Isa mines lead-zinc concentrator. Miner. Eng. 1988, 1, 137-150. [CrossRef] 
42. Rumball, J.A.; Richmond, G.D. Measurement of oxidation in a base metal flotation circuit by selective leaching with EDTA. Int. J. Miner. Process. 1996, 48, 1-20. [CrossRef]

43. Basilio, C.; Kartio, I.; Yoon, R.-H. Lead activation of sphalerite during galena flotation. Miner. Eng. 1996, 9, 869-879. [CrossRef]

44. Helgeson, H.C. Thermodynamics of hydrothermal systems at elevated temperatures and pressures. Am. J. Sci. 1969, 267, 729-804. [CrossRef]

45. Latimer, W.M. The Oxidation States of the Elements and Their Potentials in Aqueous Solutions, 2nd ed.; Prentice-Hall, Inc.: Upper Saddle River, NJ, USA, 1952; pp. 72, 152, 169. ISBN 978-0-758-15876-5.

46. Leckie, J.O.; James, R.O. Aqueous Environmental Chemistry of Metals; Rubin, A.J., Ed.; Ann Arbor Science Publishers: Ann Arbor, MI, USA, 1974; pp. 1-76. ISBN 978-0-250-40060-7. 
Article

\title{
Fine Bauxite Recovery Using a Plate-Packed Flotation Column
}

\author{
Pengyu Zhang ${ }^{1,2}$, Saizhen Jin ${ }^{1,2}$, Leming Ou ${ }^{1,2, *}$, Wencai Zhang ${ }^{3, *}$ and Yuteng Zhu ${ }^{1,2}$ \\ 1 School of Minerals Processing and Bioengineering, Central South University, Changsha 410083, China; \\ pengyu7765@csu.edu.cn (P.Z.); jinsaizhen@csu.edu.cn (S.J.); zhuyuteng@csu.edu.cn (Y.Z.) \\ 2 Key Laboratory of Hunan Province for Clean and Efficient Utilization of Strategic Calcium-Containing \\ Mineral Resources, Central South University, Changsha 410083, China \\ 3 Department of Mining and Minerals Engineering, Virginia Polytechnic Institute and State University, \\ Blacksburg, VA 24061, USA \\ * Correspondence: olmpaper@csu.edu.cn (L.O.); wencaizhang@vt.edu (W.Z.); \\ Tel.: +86-0731-8883-0913 (L.O.); +540-231-6671 (W.Z.)
}

Received: 2 August 2020; Accepted: 24 August 2020; Published: 2 September 2020

\begin{abstract}
In this investigation, the fine-grained bauxite ore flotation was conducted in a plate-packed flotation column. This paper evaluated the effects of packing-plates on recovering fine bauxite particles and revealed the fundamental mechanisms. Bubble coalescence and break-up behaviors in the packed and unpacked flotation columns were characterized by combining Computational Fluid Dynamics (CFD) and Population Balance Model (PBM) techniques. Flotation experiments showed that packing-plates in the collection zone of a column can improve bauxite flotation performance and increase the smaller bauxite particles recovery. Using packing-plates, the recovery of $\mathrm{Al}_{2} \mathrm{O}_{3}$ increased by $2.11 \%$, and the grade of $\mathrm{Al}_{2} \mathrm{O}_{3}$ increased by $1.85 \%$. The fraction of $-20 \mu \mathrm{m}$ mineral particles in concentrate increased from $47.31 \%$ to $54.79 \%$. CFD simulation results indicated that the packing-plates optimized the bubble distribution characteristics and increased the proportion of microbubbles in the flotation column, which contributed to improving the capture probability of fine bauxite particles.
\end{abstract}

Keywords: plate-packed flotation column; fine bauxite particles; bubble characteristics

\section{Introduction}

Most of the valuable minerals in ores are required concentration to reduce the operation costs of downstream extractive metallurgical processes. The concentration process is known as the key step of mineral processing. In the field of mineral processing, recovering fine minerals is difficult thus resulting in a lot of economic losses [1,2]. To solve these problems, column flotation technology has been developed in the past few decades [3,4]. Due to the structural features, flotation columns usually provide a higher recovery of fine minerals compared with other flotation equipment [5]. The mechanism of a traditional countercurrent flotation column is to make bubbles and mineral particles move towards each other, and then the hydrophobic particles are captured by the bubbles from the slurry, and rise with the bubbles to a froth zone. With the continuous flow of bubbles, these captured mineral particles gradually get out of the column. Consequently, the bubble size and distribution characteristics in flotation column have significant effects on the concentration performance.

After decades of progress, many different types of flotation columns have been derived and used in the industrial processing of various minerals [6-8]. Flotation columns packed with plates have specific internal structures, which impose direct effects on the flow characteristics of slurry inside the column, thereby affecting the flotation process of minerals [9-11]. For instance, a honeycomb tube is designed as packing-plates in previous research works [12,13]. Experimental results showed that 
honeycomb tube can promote the generation of smaller bubbles, thereby increasing gas content, as well as particle-bubble collision probability. Moreover, the honeycomb tube packing causes turbulent rotating flow into a mild flow in the column, forming a static hydrodynamic environment and reducing the probability of detachment. The bubble behaviors was also investigated in a lab-scale cyclonic-static micro-bubble flotation column packed by sieve plates [14]. Based on Particle Image Velocimetry (PIV) and Charge-Coupled Device (CCD) camera techniques, it was found that packing non-uniform sieve plates was more effective in terms of bubble distribution equalization, air column inhabitation, and non-axial velocity decreasing.

In a previous study of fine bauxite ore column flotation [15], square packed-plates were installed in the collection zone of a flotation column in a multi-layer packing manner. Based on flotation experiments, the addition of packing-plates led to a better separation of bauxite from gangue minerals and a higher recovery of fine mineral particles. Computational Fluid Dynamics (CFD) simulation results indicated that the original intensively turbulent environment was weakened and dispersed into several units with different turbulent intensities in axial, which enhanced the separation of mineral particles with different properties. But the mechanism of improved recovery of fine mineral particles by the packing-plates has not been fully described and presented. In this present work, CFD combined with Population Balance Model (PBM) simulations were performed to characterize the bubble coalescence and break-up behaviors in the unpacked flotation column (UFC) and the plate-packed flotation column (PFC). Additionally, the effects of bubble diameter on recovering finer bauxite particles was also evaluated.

\section{Materials and Methods}

\subsection{Flotation Apparatus and Procedures}

Flotation experiments were conducted using a squared-plates column flotation apparatus (Figure 1). The flotation column has a dimension of $\varphi 80 \mathrm{~mm} \times 2000 \mathrm{~mm}$. This apparatus primarily consists of three subsystems: a Plexiglas flotation column, an air injection system, and a slurry circulation system. The packing-plates was made by polyethylene plates (thickness $\delta=1 \mathrm{~mm}$ ); its structure was shown in different viewpoints (see Figure 1). Three layers of packing-plates were evenly installed along the column between the slurry inlet and air inlet.

Experimental procedures of the column flotation tests were described as follows:

(1) Grind $2 \mathrm{~kg}$ of the bauxite ore (collected from a bauxite mine located in Henan Province, Luoyang, China) until its average particle size $\left(D_{50}\right)$ reaches about $20 \mu \mathrm{m}$;

(2) Condition the feed slurry in the slurry mixing tank at room temperature and $\mathrm{pH} 9.5$ (sodium carbonate as $\mathrm{pH}$ modifier). Add $100 \mathrm{~g} / \mathrm{t}$ hexametaphosphate into the feed slurry then stir for $3 \mathrm{~min}$. Followed by adding $1200 \mathrm{~g} / \mathrm{t}$ sodium oleate and conditioning for $4 \mathrm{~min}$. All three reagents are analytical grade supplied by Aladdin Biochem. Tech., Shanghai, China. The initial slurry solid concentration is $15 \%$;

(3) Turn on the air compressor ( $0.6 \mathrm{MPa})$, and adjust air inlet flowrate to $2.5 \mathrm{~L} / \mathrm{min}$; Turn on the peristaltic pump, and adjust feed flowrate to $3.34 \mathrm{~L} / \mathrm{min}$. When foams start to flow out from the top of the column, collect the froth product as concentrate $\mathrm{K}$ for a period of $12 \mathrm{~min}$, after which the slurry remaining in the column is collected in mixing tank as tailings $\mathrm{X}$. The column flotation test is running at batch mode;

(4) Filter and dry the concentrate $\mathrm{K}$ and tailings $\mathrm{X}$, followed by elemental analysis using X-ray fluorescence. Additionally, perform particle size analysis on the concentrate K using a laser particle size analyzer (Mastersize 2000). Both instruments are from Malver Panalytical, Malvern, UK.

Additionally, bubbles were observed in an area circled in the red box shown in Figure 1. Due to the problem of poor light transmittance during the flotation process of the bauxite ore, it was hard to directly observe the distribution characteristics of bubbles. Therefore, bubbles were only observed in 
the tests without adding any mineral particles. Photos of the bubbles were captured using a Canon camera (EOS 800D, Canon, Tokyo, Japan).

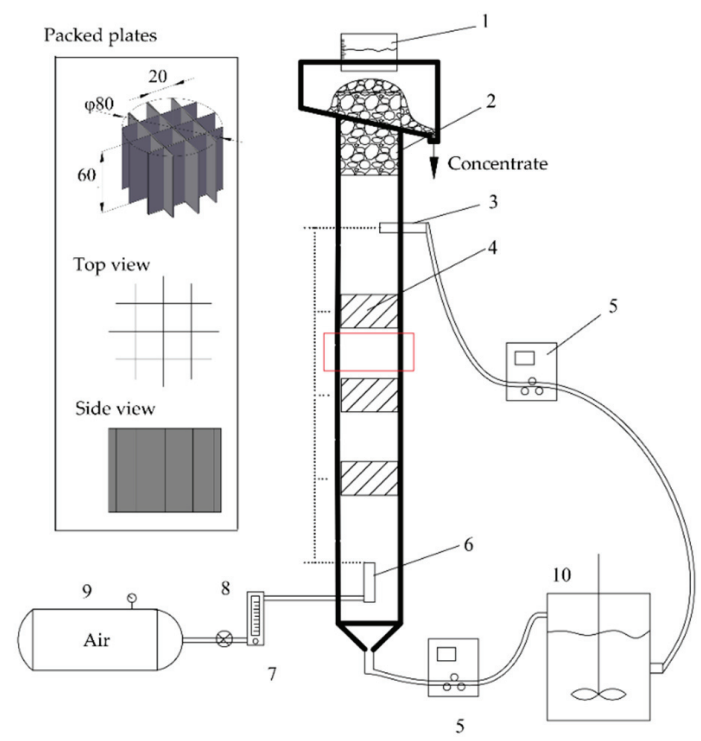

Figure 1. Experiment apparatus used for fine bauxite ore flotation: 1-Washing water device; 2-Plexiglass column; 3-Slurry inlet; 4-Packed plates; 5-Peristaltic pump; 6-Air-bubble sparger; 7-Air flowmeter; 8-Regulating valve; 9-Air compressor; 10-Slurry mixing tank.

The bauxite ore used in this research contains $44.67 \%$ of $\mathrm{Al}_{2} \mathrm{O}_{3}$ and $20.68 \%$ of $\mathrm{SiO}_{2}$, corresponding to an aluminum oxide to silicon oxide grade $\left(\mathrm{Al}_{2} \mathrm{O}_{3} / \mathrm{SiO}_{2}\right)$ ratio of 2.16. Due to the relatively high content of $\mathrm{SiO}_{2}$, the ore needs to be concentrated to improve the $\mathrm{Al} / \mathrm{Si}$ ratio in order to meet the requirements on feed grade of the Bayer process. Other major components of the ore included $\mathrm{Fe}(5.19 \%), \mathrm{TiO}_{2}(3.76 \%)$, $\mathrm{CaO}(2.77 \%), \mathrm{K}_{2} \mathrm{O}(2.76 \%)$, and S (0.97\%). Mica, siderite, kaolinite, anatase, quartz, calcite, and pyrite were the dominant gangue minerals.

\subsection{Simulation Procedures}

The simulation work was conducted in water-air two phase system using ANSYS Fluent 18.2 software (Ansys Inc., Canonsburg, PA, USA). Detailed procedures were as follows: (a) pre-processing uses ICEM for model extraction and meshing; (b) numerical calculation uses Fluent; and (c) post-processing uses CFD-post for data processing and output. This research focus on bubble characteristics affected by packing-plates in the flotation column. The collection zone of flotation column was selected as the computing domain. A geometric model of the flotation column used in the experimental apparatus was set-up as shown in Figure 2. Due to symmetry of the column in axial direction, simulation was only performed on half of the column. Additionally, boundary conditions of the calculation were based on flotation parameters. The mesh dependent tests for CFD simulation of flow calculation were conducted. The test results showed that 380,000 grids are an appropriate number to be used for UFC. Thus, a total of 380,000 grids were used for simulating flow in UFC. In case of PFC, the grid surrounding the plates was refined using the function of density box. Eulerian-Eulerian multiphase model and standard k-epsilon model were used for calculation. The bubble coalescence and break-up processes were simulated by population balance model (PBM). Parameter settings of the PBM are given in Table 1. 


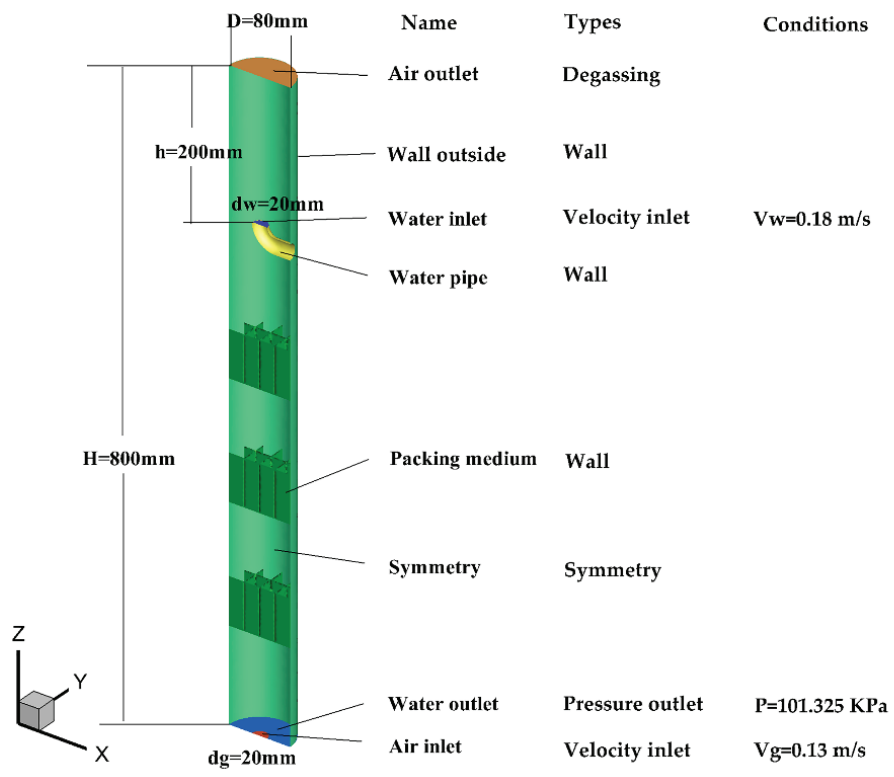

Figure 2. Geometry and boundary conditions of the flotation column for simulation.

Table 1. The parameters of population balance model (PBM).

\begin{tabular}{cc}
\hline Parameters & Value \\
\hline Method & Discrete \\
Kv & 0.52 \\
Bubble Diameter Range & $0.40 \sim 4.03 \mathrm{~mm}$ \\
Initial Bubble Diameter & $1 \mathrm{~mm}$ \\
Aggregation Kernel & Luo model [16] \\
Breakage Kernel & Frequency-Luo model [16]; Formulation-Hagesather \\
Surface Tension & $0.04 \mathrm{~N} / \mathrm{m}$ \\
\hline
\end{tabular}

\section{Results}

\subsection{Flotation Results}

Flotation experiments were performed using both UFC and PFC to evaluate the effects of packing-plates on bauxite flotation performance. Figure 3 presents the flotation grade and recovery of $\mathrm{Al}_{2} \mathrm{O}_{3}$, as well as $\mathrm{Al}_{2} \mathrm{O}_{3} / \mathrm{SiO}_{2}$ ratio, obtained by using UFC and PFC. It can be seen that a concentrate containing 58.4\% $\mathrm{Al}_{2} \mathrm{O}_{3}$ was obtained using PFC at a recovery of 52.68\%. Compared UFC, $\mathrm{Al}_{2} \mathrm{O}_{3}$ recovery and $\mathrm{Al}_{2} \mathrm{O}_{3}$ grade were increased by $2.11 \%$ and $1.85 \%$, respectively, by using PFC. These results indicated that flotation performance of the bauxite ore was improved by packing-plates. More aluminum-enriched particles were recovered using PFC. $\mathrm{Al}_{2} \mathrm{O}_{3} / \mathrm{SiO}_{2}$ ratio of the concentrated obtained using PFC reached 9.72, which is much higher than UFC. Therefore, it could be inferred that the packing-plates was able to improve the separation of aluminum minerals from silicon minerals occurring in the bauxite ore.

Particle size analysis was conducted on the concentrate obtained by using UFC and PFC. As shown in Figure 4, the fraction of $-20 \mu \mathrm{m}$ particles in UFC concentrate was 47.31 (volumetric fraction, \%), however for PFC concentrate, the fraction increased up to 54.79. For particles of $20 \sim 37 \mu \mathrm{m}$ size range, the volumetric fraction was increased by 3.06 by using PFC. Totally, the fraction of $-37 \mu \mathrm{m}$ particles in the concentrate generated from PFC increased by 10.54. Moreover, the flotation experimental results showed 
that $\mathrm{PFC}$ concentrate had a higher $\mathrm{Al}_{2} \mathrm{O}_{3}$ grade with improved recovery (see Figure 3). Based on these findings, it can be concluded that the preferential recovery of $\mathrm{Al}_{2} \mathrm{O}_{3}$ enriched particles is attributable to the increased fraction of finer bauxite particles in the flotation concentrate. The packing-plates inside the flotation column led to improvements in the recovery of fine bauxite particles.

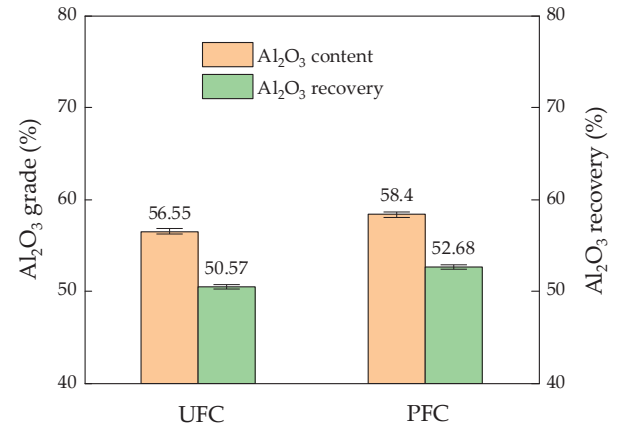

(a)

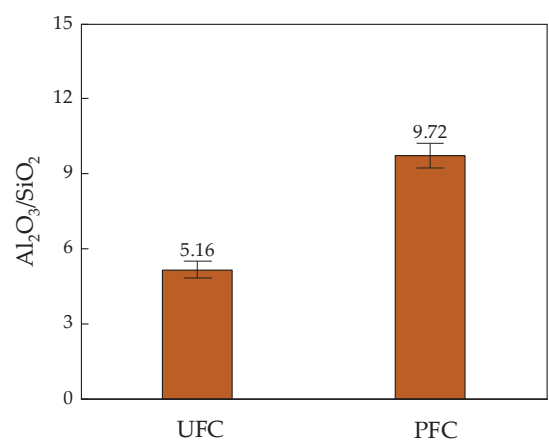

(b)

Figure 3. Flotation concentrate obtained by using unpacked flotation column (UFC) and plate-packed flotation column (PFC): (a) $\mathrm{Al}_{2} \mathrm{O}_{3}$ grade and recovery; (b) $\mathrm{Al}_{2} \mathrm{O}_{3} / \mathrm{SiO}_{2}$ ratio.

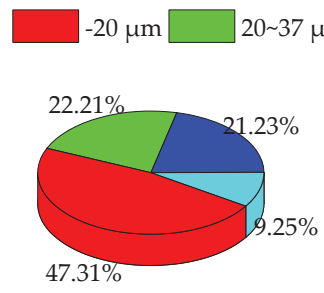

(a) UFC

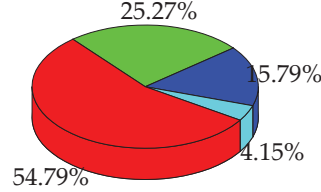

(b) PFC

Figure 4. Particle size distribution of flotation concentrate by using (a) UFC and (b) PFC.

\subsection{Bubble Characteristics}

Figure $5 \mathrm{a}, \mathrm{b}$ present the bubble size distribution of flows in UFC and PFC, respectively. It can be seen that bubble size increased along the axial direction and decreased along the radial direction. The bubble sizes were distributed in the range of around $0 \sim 4.2 \mathrm{~mm}$. When the packing-plates was used, the bubble diameter decreased in the entire flotation zone of the column. Comparing the distribution of bubbles in UFC and PFC, it can be seen that in the presence of packing-plates, bubbles in PFC have more obvious size differences, and the proportion of bubbles with smaller diameters increased. According to the simulation results, it was calculated that the mean diameter of bubbles was reduced from $3.03 \mathrm{~mm}$ (in UFC) to $2.80 \mathrm{~mm}$ (in PFC). The fractional distribution of bubbles in the column were also studied based on the simulation data. The results are shown in Figure 5c,d. It can be seen that the bubble diameter in UFC was primarily concentrated in the range of $2.5 \sim 4 \mathrm{~mm}$. Bubbles with a diameter of $3.5 \mathrm{~mm}$ or larger accounted for the largest proportion, reaching $37.17 \%$. When the column used packing-plates, the proportion of small-sized bubbles increased significantly, and the bubbles were primarily concentrated in the size range of $2.3 \sim 3.7 \mathrm{~mm}$. It indicates that packing-plates could increase the proportion of microbubbles and reduce the average diameter of bubbles. 


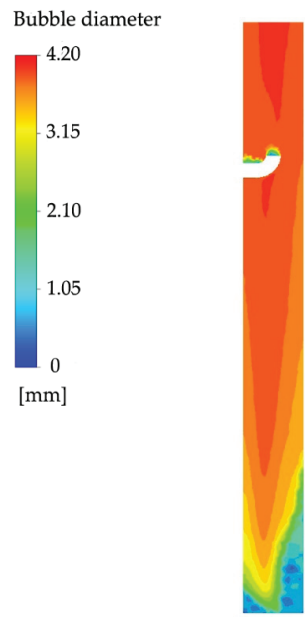

(a) UFC

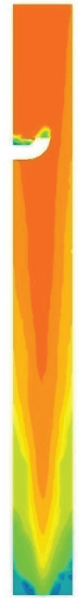

(b) PFC
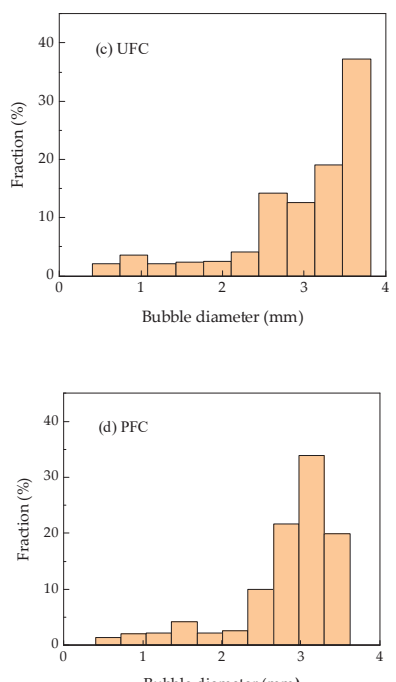

Figure 5. Bubble distribution in UFC and PFC: (a,b) Bubble size distribution in specific plane $Y=2 \mathrm{~mm}$; (c,d) the fractional distribution of bubble size.

In order to verify the simulation results of bubble distribution in UFC and PFC, images of the bubbles generated in the columns under conditions similar to those used for the simulation were captured. Flows in the flotation column are three dimensional, however the images obtained using a digital camera are two dimensional. Therefore, only qualitative analysis was completed in this study. Based on the images shown in Figure 6, it can be observed that the fraction of large-size bubbles in UFC was less than PFC. Moreover, the coalescence between bubbles was reduced after packed-plates were used. This is consistent with the numerical simulation results. It is inferred that packing-plates in flotation column will inhibit bubble coalescence and promote the formation of small-size bubbles.

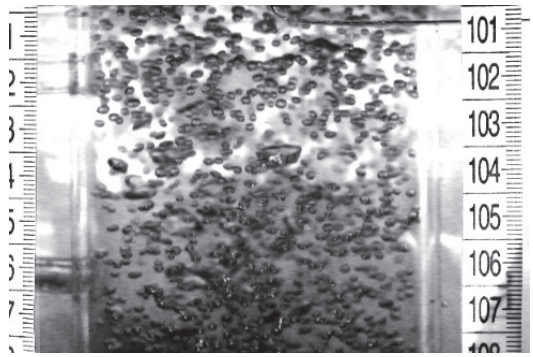

(a)

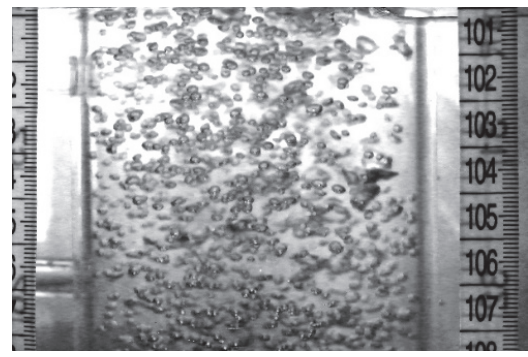

(b)

Figure 6. Images of the bubbles captured in UFC and PFC: (a) Bubbles in UFC; (b) Bubbles in PFC.

\subsection{Turbulence Characteristics}

The movement and collision of bubbles and particles are mainly caused by fluid pulsation. In fluid mechanics, turbulent kinetic energy $k$ is used to characterize the pulsation of large-scale vortex. The larger the value of $k$, the higher the pulsation velocity of large-scale vortex. Figure 7 presents the turbulent kinetic energy (TKE) distribution characteristics in UFC and PFC. It can be seen from the figure that without packing, the areas with high values of TKE were concentrated near the central axis, and decreased along both the axial and the radial direction. TKE was higher than $1 \times 10^{-2} \mathrm{~m}^{2} / \mathrm{s}^{2}$. 
After adding the packing-plates to the flotation column, the TKE inside the entire flotation column was significantly reduced. The area associated with high-value TKE was obviously reduced, and the TKE in the plates-filled area was reduced to $3.75 \times 10^{-3} \mathrm{~m}^{2} / \mathrm{s}^{2}$. This showed that the packed plates could effectively reduce the TKE in the collection area of the flotation column, reduce the pulsating velocity of the turbulent vortex, and form a relatively mild turbulent environment.

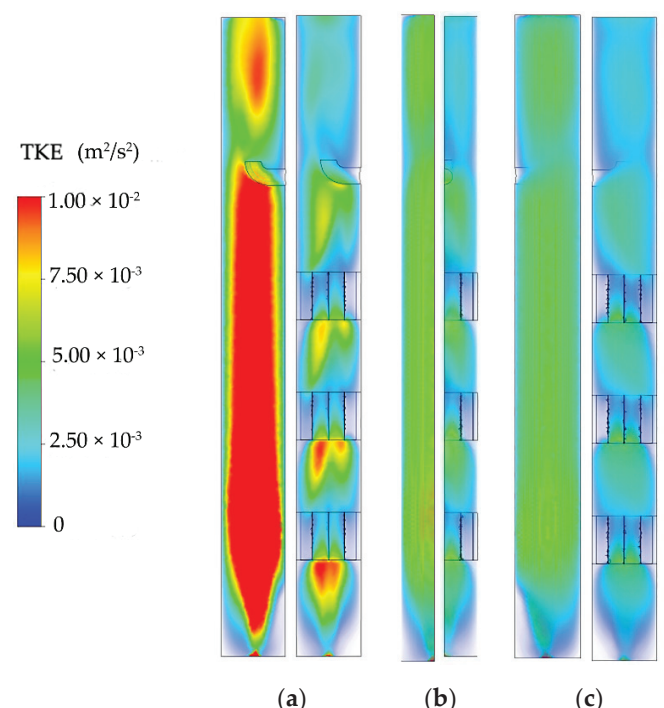

Figure 7. Turbulent kinetic energy (TKE) distribution characteristics in UFC and PFC: (a) Front view; (b) Sside view; (c) Rear view.

According to the simulation results, the cumulative curves of the volumetric percent of different turbulent kinetic energies are shown in Figure 8. From the results, it can be seen that the TKE in PFC was evenly distributed in the majority of the flotation column collection area. Rapid rises in the energy occurred at volume percent of 90 , indicating that the volume of the area with high turbulence occupied about $10 \%$ of the collection area. In this area, the value of TKE was concentrated, the pulsating velocity of the fluid was greater, and the intensity of turbulence was greater. Compared with PFC, UFC had a higher cumulative TKE of about $0.03 \mathrm{~m}^{2} / \mathrm{s}^{2}$, which was about 3 times the value of the TKE of PFC. It showed that packing-plates in the flotation column could significantly reduce the TKE.

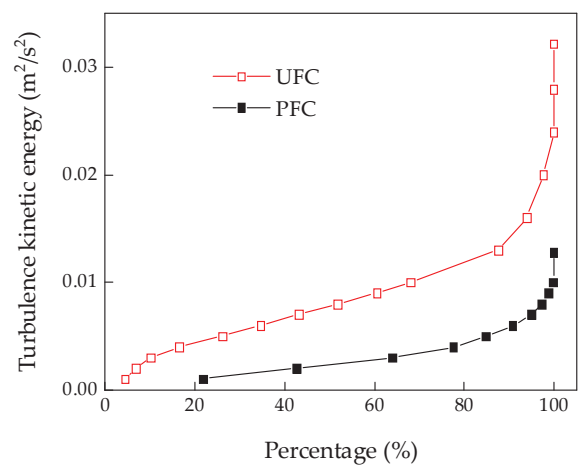

Figure 8. Turbulence kinetic energy of cumulative volume as the function of UFC and PFC. 


\section{Discussion}

In a multiphase flow, the coalescence and break-up behaviors of bubbles are mainly affected by the surface tension of liquid phase and the hydrodynamic environment as stated by Laari and Turunen, as well as Sattar et al. $[17,18]$. Based on this point, a series of mathematical models about bubble coalescence and break-up have been developed by Luo and Svendsen, as well as Lehr et al. [16,19]. The main factor leading to bubble breakage is the turbulent vortex generated by the pulsation of fluid. When the turbulent vortex carries more energy than the surface energy of newly-formed bubbles, the bubble break-up may occur, and the TKE of the vortex is converted into the surface energy of the newly formed bubble. The high-energy turbulent pulsation will aggravate the collision, merging, and fragmentation behaviors of bubbles, leading to an increase in the average geometric size of the bubbles. The addition of packing-plates in the collection area of flotation column weakens the turbulent energy of flows, thus forming a milder turbulent environment (see Figure 8). Consequently, it contributes to the formation of small-size bubbles in flotation column.

According to the reports of Zhang et al. [12,13], using packed-honeycomb tubes in flotation column can increase the gas holdup of column and generate small-size bubbles. Thereby, the packed cyclonic-static micro bubble flotation column performs better in copper sulfide flotation. Xia et al. [10] performed a two-dimensional Euler-Lagrangian model to simulate the multiphase flow for some cases of baffled and packed columns. It has been found that the presence of baffles and packing will trap bubbles or hinder the upward movement of bubbles and increase the gas hold up. Combined with the simulation and test results in this study, the average diameter of the bubble group decreased after the flotation column was packed with a plates. It is easy to infer that the number of bubbles in the collection area was increased after use of packing-plates. For mineral flotation process, a higher bubble number and a smaller bubble size usually mean that the mineral particles have a higher capture rate. For fine mineral particles, the capture rate can be calculated as

$$
P=P_{c} P_{a} .
$$

The particle collision rate formula is given by Tao et al. [20]:

$$
P_{c}=\left(\frac{3}{2}+\frac{4 \mathrm{Re}_{b}^{0.72}}{15}\right)\left(\frac{R_{p}}{R_{b}}\right)^{2} .
$$

The particle adhesion rate formula is given by Yoon and Luttrell [21]:

$$
P_{a}=\sin ^{2}\left\{2 \arctan \exp \left[\frac{-\left(45+8 \mathrm{Re}_{b}^{0.72}\right) U_{b} t_{i}}{30 R_{b}\left(R_{b} / R_{p}+1\right)}\right]\right\}
$$

where $\operatorname{Re}_{b}$ is the Reynolds number of bubble, and the formula is as follows:

$$
\operatorname{Re}_{b}=\frac{\rho_{f} U_{b} d_{b}}{\mu_{f}}
$$

The relative velocity of bubble is calculated using the following formula given by Schubert, as well as Shubert and Bischofberger [22,23]:

$$
\sqrt{U_{b}^{2}}=0.33 \frac{\varepsilon^{4 / 9} d_{b}^{7 / 9}}{v_{f}^{1 / 3}}\left(\frac{\rho_{b}-\rho_{f}}{\rho_{f}}\right)^{2 / 3} .
$$

The particle induction time formula given by Koh and Schwarz [24] is

$$
t_{i}=\frac{75}{\theta} d_{p}^{0.6}
$$


An approximate relationship exists between the particle capture rate $P_{P F C}$ with packing and the capture rate $P_{U F C}$ without packing. It can be expressed as

$$
P_{P F C}=C P_{U F C}
$$

where $\mathrm{C}$ is "Correlation coefficient". According to simulation results given above, the specific values are given as follows: $\mu_{f}=1.003 \times 10^{-3} \mathrm{~Pa} \cdot \mathrm{s} ; v_{f}=1.004 \times 10^{-6} \mathrm{~m}^{2} / \mathrm{s} ; \rho_{f}=998.2 \mathrm{~kg} / \mathrm{m}^{3} ; \rho_{b}=1.225 \mathrm{~kg} / \mathrm{m}^{3}$; and $d_{p}=20 \mu \mathrm{m} ; \theta=60^{\circ}$. Turbulent dissipation rate $\varepsilon$ and bubble diameter $d_{b}$ are calculated based on the average value from the numerical simulation results. For UFC $\varepsilon_{1}=3 \times 10^{-5} \mathrm{~m}^{2} / \mathrm{s}^{3}, d_{b 1}=3.03 \mathrm{~mm}$; for PFC $\varepsilon_{2}=1 \times 10^{-5} \mathrm{~m}^{2} / \mathrm{s}^{3}, d_{b 2}=2.80 \mathrm{~mm}$. Substituting the specific values into the formula, it can be calculated $C=1.14$. As shown in Equation (7), this means, for a mineral particle with a diameter of $20 \mu \mathrm{m}$, the capture probability with packing-plates is 1.14 times that of without packing.

In flotation process, reducing the size of the bubbles can not only improve the collection capacity of finer mineral particles, but also increase the volumetric concentration of bubbles in the slurry and improve the capture probability. Giving an analysis of bauxite flotation concentrate results (Figure 3) and the particle size distribution results (Figure 4), it can be seen that in PFC, the recovery of particles of smaller than $37 \mu \mathrm{m}$ was increased by $10.54 \%$. Among them, the proportion of particles smaller than $20 \mu \mathrm{m}$ increased by $7.48 \%$. The $\mathrm{Al}_{2} \mathrm{O}_{3}$ grade in the concentrate increased by $1.85 \%$, and the recovery increased by $2.11 \%$. These findings collectively confirmed that packing-plates inside the flotation column can increased the recovery of fine-grained mineral particles by reducing bubble diameters.

\section{Conclusions}

In this research, PBM incorporated with CFD techniques was performed to characterize the bubble coalescence and break-up behaviors in UFC and PFC. The effects due to application of the squared packed-plates on recovering fine bauxite particles was evaluated, and understanding of the fundamental mechanisms are achieved. The conclusions are as follows:

1. The packing-plates can significantly reduce the turbulent kinetic energy and promote the formation of a milder turbulent environment in the collection area. This will weaken the collision, merging, and fragmentation behaviors of bubbles, contributing to the formation of small-sized bubbles in flotation column.

2. Packing-plates can optimize bubble size distribution in the flotation column, and increase the proportion of micro-bubbles. According to the simulation results, the mean diameter of bubbles was reduced from $3.03 \mathrm{~mm}$ to $2.80 \mathrm{~mm}$ by packing-plates in flotation column. For mineral particles with a diameter of $20 \mu \mathrm{m}$, the capture probability with packing-plates is 1.14 times that of without packing.

3. Packing-plates in the collection zone of a column can improve bauxite flotation performance and enhance the recovery of fine bauxite particles. With packing, the $\mathrm{Al}_{2} \mathrm{O}_{3}$ recovery increased by $2.11 \%$, and the $\mathrm{Al}_{2} \mathrm{O}_{3}$ grade increased by $1.85 \%$.

Author Contributions: Conceptualization, methodology and formal analysis, P.Z.; investigation, S.J. and Y.Z.; writing-original draft preparation, P.Z.; formal analysis and writing—review and editing, W.Z.; supervision and project administration, L.O. All authors have read and agreed to the published version of the manuscript.

Funding: This work was financially supported by the National Natural Science Foundation of China (No. 51674291), and the Fundamental Research Funds for the Central Universities of Central South University (No. 2017zzts009). Key Laboratory of Hunan Province for Clean and Efficient Utilization of Strategic Calcium-containing Mineral Resources (No. 2018TP1002).

Acknowledgments: We acknowledge Beijing Lanwei Technology Co., Ltd. for providing access to ANSYSFluent program.

Conflicts of Interest: The authors declare no conflict of interest. 


\section{Nomenclature}

$\varphi \quad$ Diameter of column (mm)

$\delta \quad$ Thickness of plate $(\mathrm{mm})$

$k \quad$ Turbulent kinetic energy $\left(\mathrm{m}^{2} / \mathrm{s}^{2}\right)$

$P \quad$ Capture rate (\%)

$P_{c} \quad$ Collision rate (\%)

$P_{a} \quad$ Adhesion rate (\%)

$R_{p} \quad$ Particle radius ( $\left.\mu \mathrm{m}\right)$

$R_{b} \quad$ Bubble radius ( $\mathrm{mm}$ )

$\operatorname{Re}_{b} \quad$ Reynolds number of bubbles

$U_{b} \quad$ Relative velocity of bubble $(\mathrm{m} / \mathrm{s})$

$t_{i} \quad$ Induction time (s)

$\theta \quad$ Contact angle of mineral $\left({ }^{\circ}\right)$

$\varepsilon \quad$ Turbulent energy dissipation rate $\left(\mathrm{m}^{2} / \mathrm{s}^{3}\right)$

$\rho_{f} \quad$ Fluid density $\left(\mathrm{Kg} / \mathrm{m}^{3}\right)$

$\mu_{f} \quad$ Dynamic viscosity of fluid (Pa.s)

$v_{f} \quad$ Kinematic viscosity of fluid $\left(\mathrm{m}^{2} / \mathrm{s}\right)$

$d_{b} \quad$ Bubble diameter $(\mathrm{mm})$

$\rho_{b} \quad$ Bubble density $\left(\mathrm{Kg} / \mathrm{m}^{3}\right)$

$P_{P F C} \quad$ Capture rate of PFC

$P_{U F C} \quad$ Capture rate of UFC

\section{References}

1. Miettinen, T.; Ralston, J.C.; Fornasiero, D. The limits of fine particle flotation. Miner. Eng. 2010, 23, 420-437. [CrossRef]

2. Santana, R.C.; Duarte, C.R.; Ataíde, C.H.; Barrozo, M.A.S. Flotation selectivity of phosphate ore: Effects of particle size and reagent concentration. Sep. Sci. Technol. 2011, 46, 1511-1518. [CrossRef]

3. Harbort, G.; Clarke, D. Fluctuations in the popularity and usage of flotation columns-An overview. Miner. Eng. 2017, 100, 17-30. [CrossRef]

4. Prakash, R.; Majumder, S.K.; Singh, A. Flotation technique: Its mechanisms and design parameters. Chem. Eng. Process. Process Intensif. 2018, 127, 249-270. [CrossRef]

5. Yianatos, J.B. Fluid flow and kinetic modelling in flotation related processes: Columns and mechanically agitated cells-A review. Chem. Eng. Res. Des. 2007, 85, 1591-1603. [CrossRef]

6. Cheng, G.; Cao, Y.; Zhang, C.; Jiang, Z.; Yu, Y.; Mohanty, M.K. Application of novel flotation systems to fine coal cleaning. Int. J. Coal Prep. Util. 2020, 40, 24-36. [CrossRef]

7. Moys, M.; Engelbrecht, J. Simulation of the behaviour of flexible baffles in flotation columns. Chem. Eng. J. Biochem. Eng. J. 1995, 59, 33-38. [CrossRef]

8. Vashisth, S.; Bennington, C.P.; Grace, J.R.; Kerekes, R.J. Column flotation deinking: State-of-the-art and opportunities. Resour. Conserv. Recycl. 2011, 55, 1154-1177. [CrossRef]

9. Ding, Y.; Wu, Y.; Li, D.; Zheng, J. Technical note a study on the mixing characteristics of a packed flotation column. Miner. Eng. 2001, 14, 1101-1105. [CrossRef]

10. Xia, Y.; Peng, F.; Wolfe, E. CFD simulation of alleviation of fluid back mixing by baffles in bubble column. Miner. Eng. 2006, 19, 925-937. [CrossRef]

11. Farzanegan, A.; Khorasanizadeh, N.; Sheikhzadeh, G.A.; Khorasanizadeh, H. Laboratory and CFD investigations of the two-phase flow behavior in flotation columns equipped with vertical baffle. Int. J. Miner. Process. 2017, 166, 79-88. [CrossRef]

12. Zhang, M.; Li, T.; Wang, G. A CFD study of the flow characteristics in a packed flotation column: Implications for flotation recovery improvement. Int. J. Miner. Process. 2017, 159, 60-68. [CrossRef]

13. Zhang, M.; Li, T.; Ma, S.; Wang, G. An experimental study of copper sulfide flotation in a packed cyclonic-static microbubble flotation column. Sep. Sci. Technol. 2018, 53, 2238-2248. [CrossRef]

14. Yan, X.; Shi, R.; Xu, Y.; Wang, A.; Liu, Y.; Wang, L.; Cao, Y. Bubble behaviors in a lab-scale cyclonic-static micro-bubble flotation column. Asia-Pacific J. Chem. Eng. 2016, 11, 939-948. [CrossRef] 
15. Zhang, P.; Zhang, W.; Ou, L.; Zhu, Y.; Zhu, Z. Enhanced bauxite recovery using a flotation column packed with multilayers of medium. Minerials 2020, 10, 594. [CrossRef]

16. Luo, H.; Svendsen, H.F. Theoretical model for drop and bubble breakup in turbulent dispersions. AIChE J. 1996, 42, 1225-1233. [CrossRef]

17. Laari, A.; Turunen, I. Experimental determination of bubble coalescence and break-up rates in a bubble column reactor. Can. J. Chem. Eng. 2003, 81, 395-401. [CrossRef]

18. Sattar, M.; Naser, J.; Brooks, G. Numerical simulation of two-phase flow with bubble break-up and coalescence coupled with population balance modeling. Chem. Eng. Process. 2013, 70, 66-76. [CrossRef]

19. Lehr, F.; Millies, M.; Mewes, D. Bubble-size distributions and flow fields in bubble columns. AIChE J. 2002, 48, 2426-2443. [CrossRef]

20. Tao, D.; Luttrell, G.; Yoon, R.-H. A parametric study of froth stability and its effect on column flotation of fine particles. Int. J. Miner. Process. 2000, 59, 25-43. [CrossRef]

21. Yoon, R.H.; Luttrell, G.H. The effect of bubble size on fine particle flotation. Miner. Process. Extr. Metall. Rev. 1989, 5, 101-122. [CrossRef]

22. Schubert, H. On the turbulence-controlled microprocesses in flotation machines. Int. J. Miner. Process. 1999, 56, 257-276. [CrossRef]

23. Schubert, H.; Bischofberger, C. On the microprocesses air dispersion and particle-bubble attachment in flotation machines as well as consequences for the scale-up of macroprocesses. Int. J. Miner. Process. 1998, 52, 245-259. [CrossRef]

24. Koh, P.; Schwarz, M. CFD modelling of bubble-particle attachments in flotation cells. Miner. Eng. 2006, 19, 619-626. [CrossRef]

(C) 2020 by the authors. Licensee MDPI, Basel, Switzerland. This article is an open access article distributed under the terms and conditions of the Creative Commons Attribution (CC BY) license (http://creativecommons.org/licenses/by/4.0/). 



\title{
Flotation Performance, Structure-Activity Relationship and Adsorption Mechanism of O-Isopropyl-N-Ethyl Thionocarbamate Collector for Elemental Sulfur in a High-Sulfur Residue
}

\author{
Guiqing Liu ${ }^{1,2}$, Bangsheng Zhang ${ }^{2}$, Zhonglin Dong ${ }^{3, *}$, Fan Zhang ${ }^{2}$, Fang Wang ${ }^{2}$, Tao Jiang ${ }^{3}$ and Bin Xu ${ }^{3, *}$ \\ 1 School of Metallurgy, Northeastern University, Shenyang 110819, China; Charles_liu32@163.com \\ 2 Jiangsu BGRIMM Metal Recycling Science \& Technology Co. Ltd., Xuzhou 221121, China; \\ zbsvictory@163.com (B.Z.); bkyzhangfan@126.com (F.Z.); wangfang224444@126.com (F.W.) \\ 3 School of Minerals Processing and Bioengineering, Central South University, Changsha 410000, China; \\ jiangtao@csu.edu.cn \\ * Correspondence: dongzhonglincsu@csu.edu.cn (Z.D.); xubincsu@csu.edu.cn (B.X.); \\ Tel.: +86-183-7315-0200 (Z.D.); +86-150-8493-3770 (B.X.)
}

Citation: Liu, G.; Zhang, B.; Dong, Z.; Zhang, F.; Wang, F.; Jiang, T.; Xu, B. Flotation Performance, StructureActivity Relationship and Adsorption Mechanism of O-Isopropyl-N-Ethyl Thionocarbamate Collector for Elemental Sulfur in a High-Sulfur Residue. Metals 2021, 11, 727. https://doi.org/10.3390/met 11050727

Academic Editors: Ilhwan Park and Anna H. Kaksonen

Received: 11 April 2021

Accepted: 25 April 2021

Published: 28 April 2021

Publisher's Note: MDPI stays neutral with regard to jurisdictional claims in published maps and institutional affiliations.

Copyright: (C) 2021 by the authors Licensee MDPI, Basel, Switzerland. This article is an open access article distributed under the terms and conditions of the Creative Commons Attribution (CC BY) license (https:// creativecommons.org/licenses/by/ $4.0 /)$.
Abstract: O-isopropyl-N-ethyl thionocarbamate (IPETC) collector was used to selectively recover elemental sulfur from a high-sulfur residue, and its flotation performance, structure-property relationship and adsorption mechanism to elemental sulfur were studied. The raw ore flotation test showed that IPETC displayed superior flotation performance to the elemental sulfur compared with sodium ethyl xanthate (SEX) and ammonium dibutyl dithiophosphate (ADDTP) collectors. Pure mineral flotation and adsorption experiments further demonstrated that among the three collectors, IPETC had the strongest collecting power and the optimum selectivity towards elemental sulfur. The structure-property relationship research based on density functional theory (DFT) calculation supported the above conclusion. The adsorption mechanism analysis manifested that IPETC adsorption on elemental sulfur surface was a chemical process by separately generating normal covalent bond between carbonyl $\mathrm{S}$ atom and $\mathrm{S}$ atom and a backdonation covalent bond between $\mathrm{O}$ atom and $\mathrm{S}$ atom, which was confirmed by the FTIR spectrum analysis result. IPETC exhibits excellent collecting ability and selectivity for elemental sulfur and therefore it has bright application prospects.

Keywords: O-isopropyl-N-ethyl thionocarbamate (IPETC); elemental sulfur; flotation performance; structure-property relationship; adsorption mechanism

\section{Introduction}

Elemental sulfur is an important chemical material and has been widely used for producing sulfuric acid and other products such as fertilizers, matches, food preservation agents, carbon disulfide, cement, gun powder, surfactants, detergents, pharmaceuticals, pesticides and vulcanized rubbers [1-7]. Elemental sulfur is usually the by-product of hydrometallurgical leaching of nonferrous sulfide ores. For example, oxygen pressure acid leaching of zinc concentrate (sphalerite) can yield large amounts of elemental sulfur [8-14], and the overall reaction is shown in Equation (1).

$$
\mathrm{ZnS}+\mathrm{H}_{2} \mathrm{SO}_{4}+0.5 \mathrm{O}_{2}=\mathrm{ZnSO}_{4}+\mathrm{H}_{2} \mathrm{O}+\mathrm{S}
$$

As indicated, zinc in sphalerite is transformed into zinc sulfate which can be used to produce zinc metal through electrowinning and sulfur remains in the residue in the form of elemental sulfur [15-18]. The residue is considered to be acid-producing since its sulfur component can react with oxygen and water to generate thiosalts and sulfuric acid [19]. At present, the produced high-sulfur residue is usually subjected to safe storage for most 
zinc refineries in China, which not only causes serious resource waste but also poses huge threat to the environment and human health $[20,21]$. Therefore, it is necessary to recover elemental sulfur from the residue with effective technology.

Elemental sulfur has good natural hydrophobicity, and therefore without the use of any additional agent, it can be efficiently enriched by froth flotation, an extensively used technology in mineral processing for separating target mineral from gangue mineral by using their natural hydrophobicity difference [22-25]. However, the nonferrous metal sulfides $\left(\mathrm{ZnS}, \mathrm{FeS}_{2}, \mathrm{PbS}\right.$ and $\left.\mathrm{Ag}_{2} \mathrm{~S}\right)$ that are not completely oxidized during pressure leaching also remain in the residue [26], and inevitably they will float upward together with elemental sulfur and enter the concentrate because of their similar floatability and intimate association relationship $[27,28]$. This leads to the decrease of elemental sulfur grade in the concentrate product. To enhance the grade, a hot filtration procedure is usually implemented for the concentrate, which can realize the efficient separation of elemental sulfur from the concentrate by melting and filtration at $115-155^{\circ} \mathrm{C}$ [19]. Nevertheless, a significant portion of the elemental sulfur is still hard to separate from the concentrate with hot filtration since this process generally needs raw material whose elemental sulfur content is more than $70 \%$ to ensure a satisfactory performance [26]. The elemental sulfur content in most of the high-sulfur residue is usually in 40-60\% [15], and thus it is difficult to obtain a high elemental sulfur recovery. A feasible method to solve the above problem is to add suitable collector during the flotation procedure to realize the selective flotation of elemental sulfur.

The study aims to find an efficient collector to selectively separate elemental sulfur from a high-sulfur pressure acid leaching residue of zinc sulfide concentrate. First, the flotation performance of O-Isopropyl-N-Ethyl thionocarbamate (IPETC), ammonium dibutyl dithiophosphate (ADDTP) and sodium ethyl xanthate (SEX) for elemental sulfur were compared through a raw ore flotation experiment. Then, pure mineral flotation and adsorption tests were performed to further compare their flotation properties. After that, the structure-activity relationships of three collectors were researched using density functional theory (DFT) calculation through comparing their geometric configurations, electronic structures and corresponding flotation performances. Based on the above results, IPETC was selected as the optimum elemental sulfur collector, and its adsorption mechanism on the elemental sulfur surface was investigated using adsorption simulation calculation and Fourier-transform infrared spectroscopy (FTIR) analysis.

\section{Experimental}

\subsection{Material and Reagents}

The pressure acid leaching residue of zinc sulfide concentrate used in this study was provided by Hulun Buir Chihong Mining Industry Co., Inner Mongolia, China, and it has been used in our previous work [15]. The chemical composition analysis showed that the sulfur content arrived at $46.21 \%$, and $81.97 \%$ of the sulfur occurred in the form of elemental sulfur. Therefore, it was a high-sulfur residue and used for closed-circuit flotation experiment to recover elemental sulfur.

Previous literature showed that natural minerals and minerals after leaching have similar surface properties $[29,30]$, and thus natural minerals are usually adopted as the raw materials for mineral flotation study. According to the result of the X-ray diffraction (XRD) spectra analysis [15], elemental sulfur, sphalerite, pyrite, chalcopyrite, albite and anglesite were the main minerals in the residue, and therefore these pure mineral samples obtained from Guangdong Province in China were chosen for the pure mineral flotation experiment. The high-purity minerals were first collected by handpicking, and then crushed and ground in a porcelain ball mill. Afterwards, the samples were dry-sieved to obtain the $-74+38 \mu \mathrm{m}$ fractions for the flotation experiment, and the fractions of less than $5 \mu \mathrm{m}$ were used for FTIR spectrum measurement. The X-ray fluorescence (XRF) analysis results for the samples in Tables 1-3 showed that their purities were over $96 \%$, which could meet the desirable requirement in this study. 
Table 1. Chemical compositions of pure minerals of elemental sulfur, sphalerite, pyrite and chalcopyrite (wt \%).

\begin{tabular}{ccccccc}
\hline Mineral & $\mathbf{C u}$ & $\mathbf{P b}$ & $\mathbf{Z n}$ & $\mathbf{F e}$ & $\mathbf{S}$ & Purity \\
\hline Elemental sulfur & - & - & - & 0.02 & 98.68 & 98.68 \\
Sphalerite & - & 0.04 & 66.20 & 0.52 & 32.9 & 98.65 \\
Pyrite & - & 0.21 & 0.07 & 45.25 & 53.26 & 97.21 \\
Chalcopyrite & 34.13 & 0.01 & 0.27 & 30.10 & 34.22 & 98.76 \\
\hline
\end{tabular}

Note: "—_" indicates that the element was not detected.

Table 2. Chemical composition of pure albite mineral (wt \%).

\begin{tabular}{ccccc}
\hline Mineral & $\mathrm{Na}_{2} \mathbf{O}$ & $\mathbf{A l}_{2} \mathbf{O}_{3}$ & $\mathrm{SiO}_{2}$ & Purity \\
\hline Albite & 11.36 & 19.19 & 67.86 & 96.27 \\
\hline
\end{tabular}

Table 3. Chemical composition of pure anglesite mineral (wt \%).

\begin{tabular}{ccccc}
\hline Mineral & $\mathrm{PbO}$ & $\mathrm{SO}_{3}$ & $\mathrm{Fe}_{2} \mathrm{O}_{3}$ & Purity \\
\hline Anglesite & 69.32 & 28.23 & 0.052 & 96.27 \\
\hline
\end{tabular}

In order to investigate the difference of flotation property of pure minerals and pure minerals after oxygen pressure acid leaching, a comparative experiment was conducted, and the result is shown in Table 4. The method of the flotation test was the same as that in Section Pure Mineral Flotation, and the collector (IPETC) dosage and pulp pH value are $3 \times 10^{-5} \mathrm{~mol} / \mathrm{L}$ and 8.0 , respectively. The recoveries of pure minerals of elemental sulfur, sphalerite, pyrite, chalcopyrite, albite and anglesite were $99.2 \%, 51.6 \%, 78.3 \%, 82.5 \%, 23.6 \%$ and $13.3 \%$, respectively, while the recoveries of the above pure minerals after leaching were $99.0 \%, 51.3 \%, 78.2 \%, 82.1 \%, 23.4 \%$ and $13.5 \%$, respectively. Thus, a very close flotation recovery was obtained for each pure mineral and pure mineral after leaching, which can be ascribed to their close floatability. Therefore, it can be deduced that the physical and chemical properties of the surfaces of the pure minerals and pure minerals after leaching are very close.

Table 4. The flotation results of pure minerals and pure minerals after oxygen pressure acid leaching whose conditions are the following: initial sulfuric acid concentration, $60 \mathrm{~g} / \mathrm{L}$, temperature, $150{ }^{\circ} \mathrm{C}$, oxygen partial pressure, $1.0 \mathrm{MPa}$ and time, $2.5 \mathrm{~h}$.

\begin{tabular}{|c|c|c|c|c|c|c|}
\hline \multirow{2}{*}{ Raw Material } & \multicolumn{6}{|c|}{ Recovery (\%) } \\
\hline & Elemental Sulfur & Sphalerite & Pyrite & Chalcopyrite & Anglesite & Albite \\
\hline Pure minerals & 99.2 & 51.6 & 78.3 & 82.5 & 23.6 & 13.3 \\
\hline Pure minerals after oxygen pressure acid leaching & 99.0 & 51.3 & 78.2 & 82.1 & 23.4 & 13.5 \\
\hline
\end{tabular}

The analytically pure O-Isopropyl-N-Ethyl thionocarbamate (IPETC), ammonium dibutyl dithiophosphate (ADDTP) and sodium ethyl xanthate (SEX) were bought from a commercial company of Hunan Province, China, and used as the collector. Methyl isobutyl carbinol (MIBC) from the same company was used as the foaming agent. The other reagents used are also analytically pure. Ultrapure water was used throughout all experiments.

\subsection{Experimental Methods}

\subsubsection{Flotation Experiment}

Raw Ore Flotation

The flotation experiment of pressure acid leaching residue was carried out in a selfaeration XFD-63 flotation machine from Jilin Prospecting Machinery Factory, China [31]. The residue and ultrapure water were first put into the cell to form the pulp with $25 \%$ 
density, and then slime was added to adjust the pulp $\mathrm{pH}$ to about 8.0. Afterwards, the inhibitor $\left(\mathrm{Na}_{2} \mathrm{~S}+\mathrm{Na}_{2} \mathrm{SO}_{3}+\mathrm{ZnSO}_{4}\right)$, collector and foaming agent (MIBC) were successively added into the pulp which was agitated at $1650 \mathrm{rpm}$ for $3 \mathrm{~min}$ after adding each reagent. The flotation was conducted for $5 \mathrm{~min}$, and elemental sulfur concentrate and tailing were collected, filtrated, dried, weighed and assayed to calculate elemental sulfur recovery.

\section{Pure Mineral Flotation}

The pure mineral flotation experiment was performed in an XFG5-35 flotation machine (Jilin Prospecting Machinery Factory, Jilin, china) with a $40 \mathrm{~mL}$ plexiglass cell [32]. The agitating speed was kept at $1650 \mathrm{r} \mathrm{min}^{-1}$ with a mechanical impeller. In each test, $2.0 \mathrm{~g}$ pure mineral sample was placed into an ultrasonic bath for 5 min of cleaning, and then transferred into the flotation cell. After that, the pulp $\mathrm{pH}$ was adjusted to a desired value with dilute $\mathrm{NaOH}$ or $\mathrm{H}_{2} \mathrm{SO}_{4}$ solution. Finally, the collector and the foaming agent were sequentially added into the pulp which was agitated for $2 \mathrm{~min}$. The flotation was carried out for $5 \mathrm{~min}$, and the obtained concentrate and tailing were weighted and analyzed after filtration and drying to calculate mineral recovery.

\subsubsection{FTIR Spectrum}

IPETC solution $\left(1 \times 10^{-2} \mathrm{~mol} / \mathrm{L}\right)$ was first mixed with elemental sulfur sample $(0.5 \mathrm{~g}$, $-38 \mu \mathrm{m})$. After magnetically stirring for $60 \mathrm{~min}$, the solution was filtered, and the obtained solid product was dried at $35^{\circ} \mathrm{C}$ under vacuum for $24 \mathrm{~h}$ for subsequent infrared detection. The Fourier-transform infrared (FTIR) spectra were recorded by a G510PFTIR infrared spectrometer (Nicolet Company, Madison, USA) in the wavenumber range from $400 \mathrm{~cm}^{-1}$ to $4000 \mathrm{~cm}^{-1}$ using the $\mathrm{KBr}$ technique.

\subsubsection{DFT Calculation}

The initial molecular/ion model of collector was constructed and then optimized by MM2 and PM3 methods in Chemoffice 2008 program. The obtained geometry was further optimized by DFT method at the B3LYP/6-31G $(\mathrm{d}, \mathrm{p})$ level in the Gaussian 03 program [31]. Finally, periodic structure optimization was completed in the CASTEP module of Materials Studio 4.4 and then the optimized structure was subjected to DFT calculations.

The calculations of mineral plane and crystal were completed by CASTEP and Dmol3 modules in Materials Studio 4.4 program, in which CASTEP module was used for the establishment of plane and crystal models as well as geometric structure optimization, state density analysis and Mulliken population analysis, and Dmol3 module was used to analyze frontier orbital energy. The plane wave basis set and DND basis set were separately implemented in the CASTEP and Dmol3 modules for the DFT calculations. The establishment and optimization of adsorption model of IPETC on elemental sulfur surface and related calculation were both performed in the CASTEP module of Materials Studio 4.4

\subsection{Analytical Methods}

The elemental sulfur content in the high-sulfur residue and flotation concentrate was detected by carbon tetrachloride dissolution followed by gravimetric analysis [33]. The concentrations of sulfhydryl collectors were determined by UV-Vis spectroscopy [34].

\section{Results and Discussion}

\subsection{Flotation Performance of Collectors}

Before the use of three collectors IPETC, ADDTP and SEX, single foaming agent MIBC and non-polar collector kerosene were separately used for recovering elemental sulfur from the high-sulfur residue. The flotation sheets are displayed in Figure $1 \mathrm{a}, \mathrm{b}$, and the flotation results are shown in Table 5. It can be seen that a low and close elemental sulfur recovery was obtained for MIBC and kerosene. Furthermore, the elemental sulfur grades in the concentrate were low, which is because large amounts of sulfide minerals such as sphalerite, pyrite, chalcopyrite in the residue entered the concentrate with elemental sulfur. 
The above results indicated that the selective and effective separation of elemental sulfur from the high-sulfur residue cannot be realized using MIBC and kerosene.
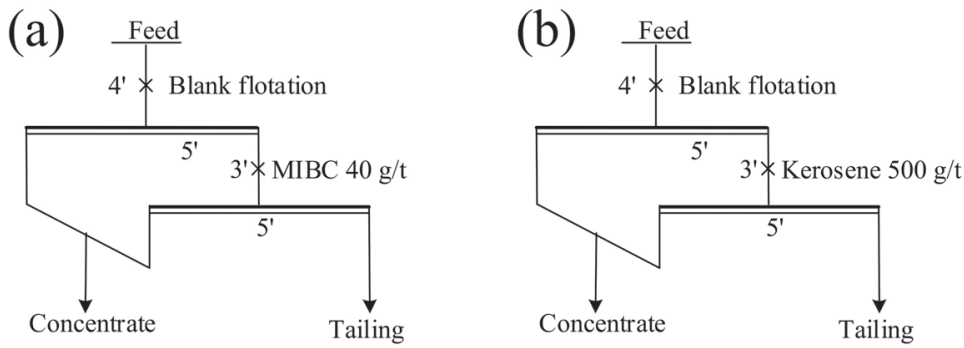

Figure 1. The flotation sheets of high-sulfur residue with MIBC (a) and kerosene (b).

Table 5. The flotation results of high-sulfur residue with MIBC and kerosene.

\begin{tabular}{ccccc}
\hline Collector & Product & Yield (\%) & Elemental Sulfur Grade (\%) & Elemental Sulfur Recovery (\%) \\
\hline \multirow{3}{*}{ MIBC } & Elemental sulfur concentrate & 57.31 & 71.17 & 88.83 \\
& Tailing & 42.69 & 12.02 & 11.17 \\
& Feed residue & 100.00 & 45.92 & 100.00 \\
\multirow{2}{*}{ Kerosene } & Elemental sulfur concentrate & 56.70 & 71.24 & 88.00 \\
& Tailing & 43.30 & 12.72 & 12.00 \\
& Feed residue & 100.00 & 45.90 & 100.00 \\
\hline
\end{tabular}

The flotation performances of IPETC, ADDTP and SEX collectors for elemental sulfur in the high-sulfur residue were compared. After detailed conditional experiment in our laboratory, the closed-circuit flotation flowchart in Figure 2 was ascertained and adopted, and the obtained results are listed in Table 6. Despite the high pulp $\mathrm{pH}$, the collectors will also adsorb a small amount of sphalerite. Thus, zinc sulfate is added to increase the inhibitory effect on sphalerite, even though some zinc ions are present in the pulp itself. It is not necessary to inhibit the gangue minerals in the residue, such as albite and anglesite, because they have poor natural floatability and the sulfhydryl collector (i.e., IPETC) hardly adsorbs on their surfaces.

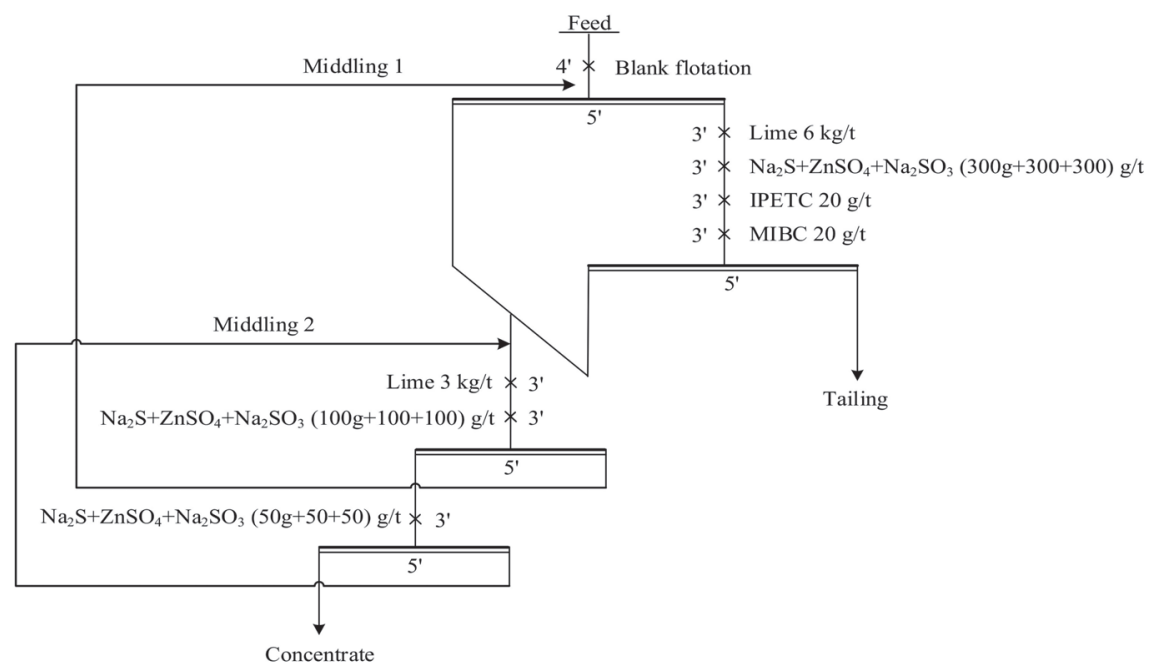

Figure 2. Flowchart of closed-circuit flotation of high-sulfur residue with IPETC, ADDTP and SEX collectors. 
Table 6. The result of closed-circuit flotation of the high-sulfur residue with IPETC, ADDTP and SEX collectors.

\begin{tabular}{|c|c|c|c|c|c|c|}
\hline \multirow{2}{*}{ Collector } & \multirow{2}{*}{ Product } & \multirow{2}{*}{ Yield (\%) } & \multicolumn{2}{|c|}{ Grade (\%) } & \multicolumn{2}{|c|}{ Recovery (\%) } \\
\hline & & & Elemental Sulfur & Zinc & Elemental Sulfur & Zinc \\
\hline \multirow{3}{*}{ SEX } & Elemental sulfur concentrate & 43.55 & 81.53 & 1.33 & 93.67 & 13.33 \\
\hline & Tailing & 56.45 & 4.25 & 6.67 & 6.33 & 86.67 \\
\hline & Feed residue & 100 & 37.91 & 4.34 & 100 & 100 \\
\hline \multirow{3}{*}{ ADDTP } & Elemental sulfur concentrate & 45.47 & 82.25 & 1.15 & 97.83 & 12.08 \\
\hline & Tailing & 54.53 & 1.52 & 6.98 & 2.17 & 87.92 \\
\hline & Feed residue & 100 & 38.23 & 4.33 & 100 & 100 \\
\hline \multirow{3}{*}{ IPETC } & Elemental sulfur concentrate & 44.78 & 84.47 & 0.88 & 99.87 & 9.06 \\
\hline & Tailing & 55.22 & 0.09 & 7.16 & 0.13 & 90.94 \\
\hline & Feed residue & 100 & 37.88 & 4.35 & 100 & 100 \\
\hline
\end{tabular}

From Table 6, the elemental sulfur recoveries for SEX, ADDTP and IPETC were 93.67\%, $97.83 \%$ and $99.87 \%$ while their elemental sulfur grades in the concentrate were $81.53 \%$, $82.25 \%$ and $84.47 \%$, respectively. Thus, both the maximum elemental sulfur recovery and grade were achieved using IPETC collector. The zinc flotation result was also shown in Table 6 . The zinc grades in the elemental sulfur concentrate were $1.33 \%, 1.15 \%$ and $0.88 \%$ for SEX, ADDTP and IPETC, and their recoveries were $13.33 \%, 12.08 \%$ and $9.06 \%$, respectively. Thus, compared with elemental sulfur, only a small amount of zinc was floated and entered the concentrate. Moreover, the zinc grade in the concentrate and its recovery were the lowest for IPETC. The above results indicated that in comparison with SEX and ADDTP, IPETC exhibited more excellent collecting ability and selectivity for elemental sulfur in the high-sulfur residue, and thus it has good industrial application potential.

\subsection{Pure Mineral Flotation and Adsorption Experiments}

\subsubsection{Pure Mineral Flotation Experiment}

The collecting performances of IPETC, ADDTP and SEX for pure minerals of elemental sulfur, sphalerite, pyrite, chalcopyrite, albite and anglesite were compared, and the results of effects of collector dosage and pulp $\mathrm{pH}$ on pure mineral recovery are displayed in Figures $3 \mathrm{a}-\mathrm{c}$ and $4 \mathrm{a}-\mathrm{c}$.

As shown in Figure $3 \mathrm{a}-\mathrm{c}$, the recoveries of elemental sulfur, sphalerite, pyrite and chalcopyrite went up with the increase of IPETC, ADDTP and SEX dosages in their initial ranges of $(2-3) \times 10^{-5},(0.4-1.2) \times 10^{-4}$ and $(0.4-1.2) \times 10^{-4} \mathrm{~mol} / \mathrm{L}$. Afterwards, no obvious increases of the recoveries of four pure minerals were observed with the further increase of collector dosage. Therefore, the optimal IPETC, ADDTP and SEX dosages were separately $3 \times 10^{-5}, 1.2 \times 10^{-4}$ and $1.2 \times 10^{-4} \mathrm{~mol} / \mathrm{L}$. The recoveries of albite and anglesite were low in the whole abscissa range, and collector dosage had little effect on them, which could be ascribed to their poor natural floatability.

As indicated in Figure $4 \mathrm{a}-\mathrm{c}$, the recoveries of elemental sulfur and three sulfides were all augmented as the pulp pH increased in the initial range of 2-8. Nevertheless, further increase of pulp pH from 8 to 12 resulted in the decrease of the recoveries, but the decrease degrees of recoveries of three sulfides were larger than that of elemental sulfur, suggesting that increased $\mathrm{pH}$ had less negative impact on elemental sulfur flotation in this $\mathrm{pH}$ range. Thus, the optimal pulp $\mathrm{pH}$ for the four minerals was 8 . The pulp $\mathrm{pH}$ exerted similar effect on anglesite recovery, but its optimum $\mathrm{pH}$ was 6 where the maximum recovery was achieved. The albite recovery gradually dropped in the pulp $\mathrm{pH}$ range of 2-8 and then basically remained steady.

In addition, for each collector, both the maximum elemental sulfur recovery and the differences between the maximum recoveries of elemental sulfur and the other five pure minerals followed the order of IPETC $>$ ADDTP $>$ SDD. Therefore, among the three collectors, IPETC presented the optimal collecting ability and selectivity to elemental sulfur. 

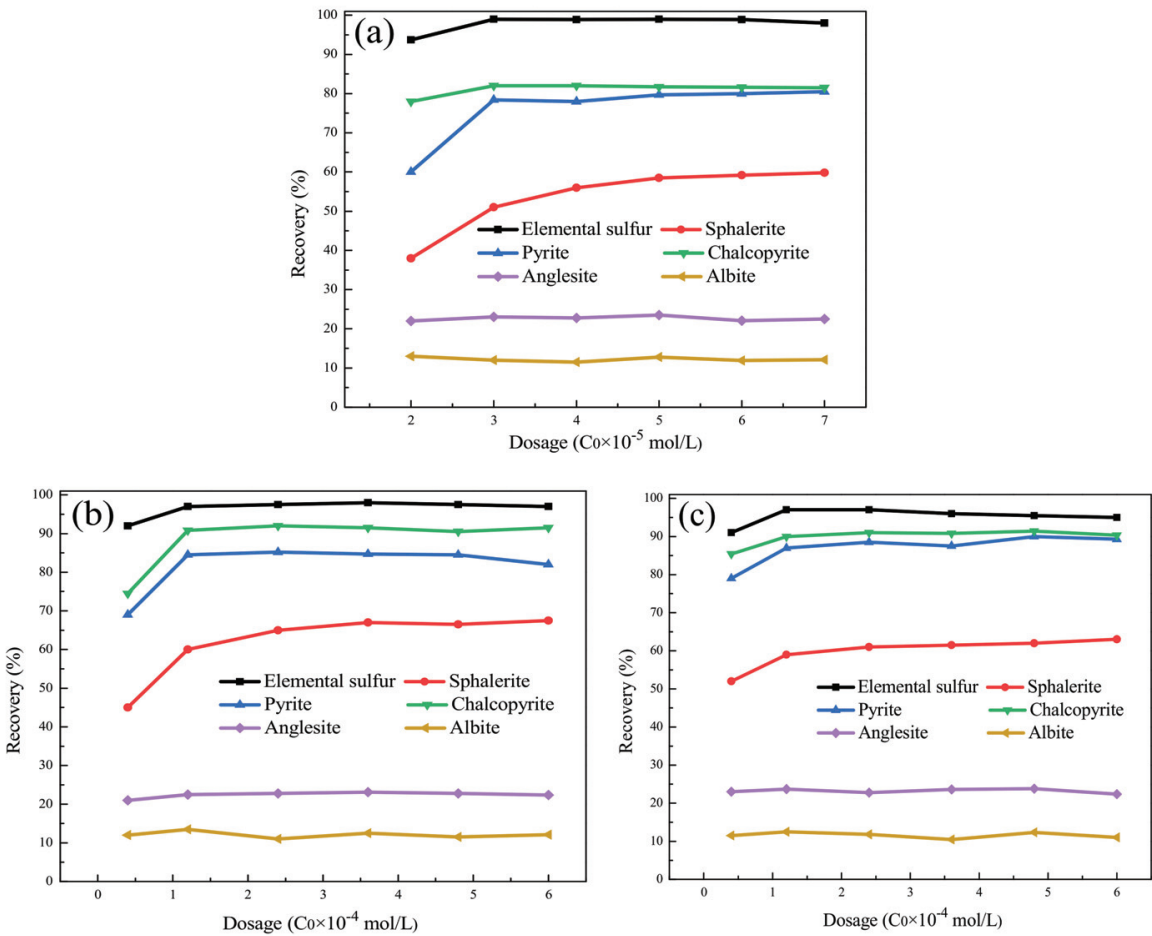

Figure 3. Effect of collector dosage on pure mineral recovery at pulp pH value 8 ((a) IPETC; (b) ADDTP; (c) SEX).
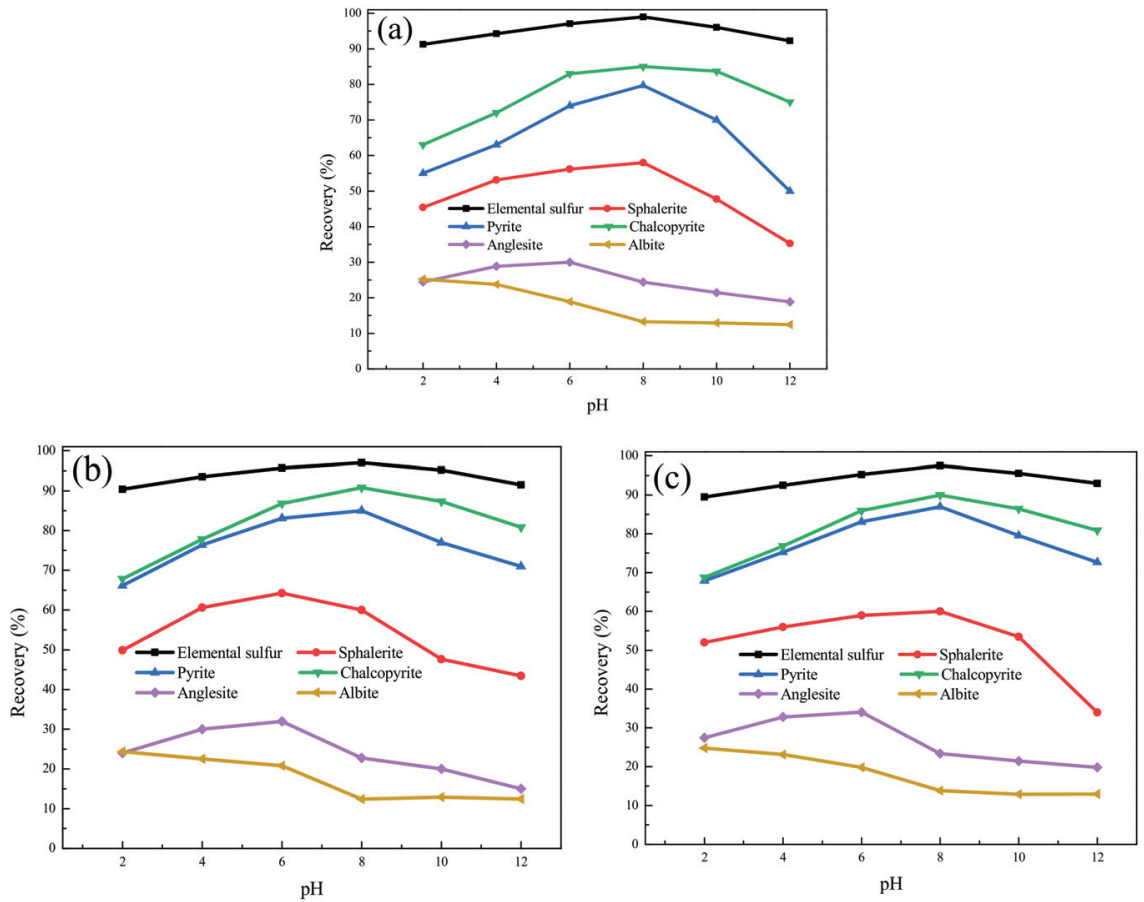

Figure 4. Effect of pulp pH on pure mineral recovery at oģtimum collector dosage ((a) IPETC; (b) ADDTP; (c) SEX). 


\subsubsection{Pure Mineral Adsorption Experiment}

The adsorption amounts of IPETC, ADDTP and SEX on pure mineral surfaces were also compared, and the effect of initial collector concentration is shown in Figure 5a-c. With the increase of concentrations of three collectors, their adsorption amounts on the surfaces of elemental sulfur, albite and anglesite basically remained steady, but the adsorption amount on elemental sulfur surface kept at a high level while those on the surfaces of albite and anglesite were very low. For sphalerite, pyrite and chalcopyrite, the adsorption amounts of three collectors on their surfaces first increased and then were roughly unchanged.
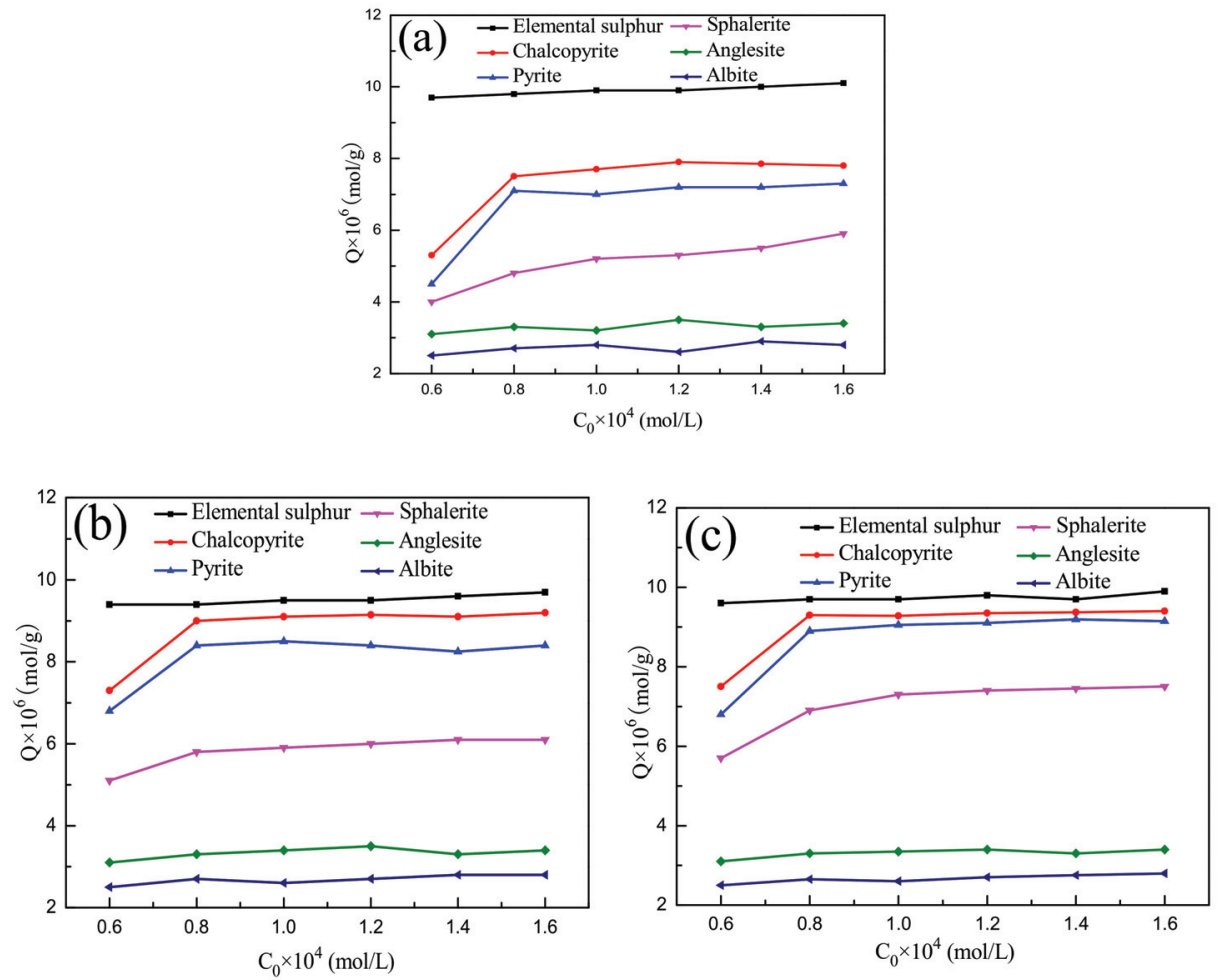

Figure 5. Effect of initial collector concentration on their adsorption amounts on pure mineral surfaces at pulp pH 8 ((a) IPETC; (b) ADDTP; (c) SEX).

However, among the three collectors, the adsorption amount of IPETC on elemental sulfur surface was the biggest under the same collector concentration, suggesting that IPETC possessed the strongest interaction with elemental sulfur surface. Moreover, IPETC exhibited the greatest difference between adsorption quantities on elemental sulfur surface and the surfaces of other pure minerals. The above results indicated that IPETC not only possessed the biggest adsorption amount on elemental sulfur surface but also displayed the best adsorption selectivity for elemental sulfur, which is consistent with the result of the pure mineral flotation test in Section 3.2.1.

\subsection{Structure-Property Relationships of Collectors}

\subsubsection{Geometry Configuration}

The simulation calculations of collector molecules/ion were carried to study their structure-property relationships. The optimized geometry configurations of ADDTP, SEX 
and IPETC are presented in Figure $6 \mathrm{a}-\mathrm{c}$, and the bond lengths and dihedral angles are displayed in Table 7.

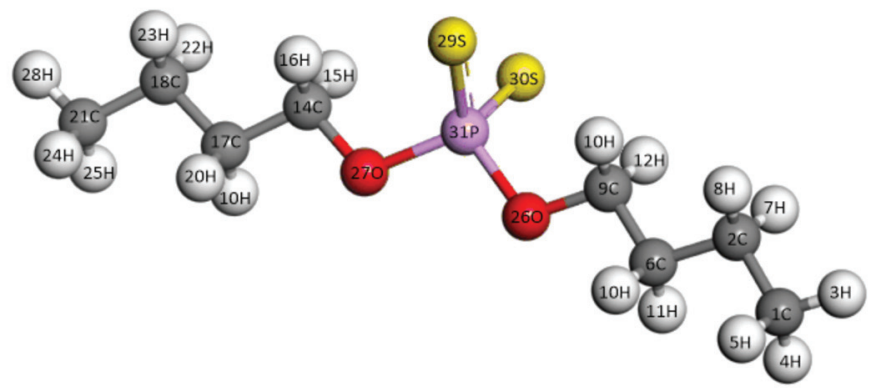

(a)

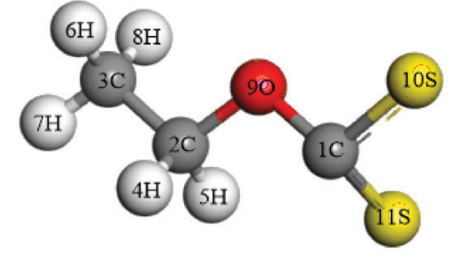

(b)

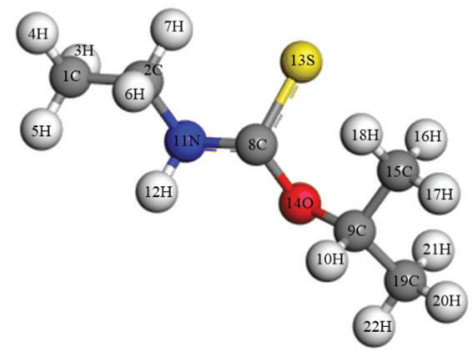

(c)

Figure 6. Optimized geometry configurations of collector molecules or ions ((a) IPETC; (b) ADDTP; (c) SEX).

Table 7. Bond lengths and dihedral angles of collectors.

\begin{tabular}{ccccc}
\hline Collector & \multicolumn{2}{c}{ Bond Length $(\AA)$} & \multicolumn{2}{c}{ Dihedral Angle $\left(^{\circ}\right)$} \\
\hline \multirow{2}{*}{ SEX } & $1 \mathrm{C}-10 \mathrm{~S}$ & $1 \mathrm{C}-11 \mathrm{~S}$ & \multicolumn{2}{c}{$9 \mathrm{O}-1 \mathrm{C}-10 \mathrm{~S}-11 \mathrm{~S}$} \\
& 1.707 & 1.699 & \multicolumn{2}{c}{-179.992} \\
\hline \multirow{2}{*}{ ADDTP } & $29 \mathrm{~S}-31 \mathrm{P}$ & $30 \mathrm{~S}-31 \mathrm{P}$ & $14 \mathrm{C}-27 \mathrm{O}-31 \mathrm{P}-29 \mathrm{~S}$ & $9 \mathrm{C}-26 \mathrm{O}-31 \mathrm{P}-30 \mathrm{~S}$ \\
& 2.006 & 2.006 & -59.008 & -59.003 \\
\hline \multirow{2}{*}{ IPETC } & \multicolumn{2}{c}{$8 \mathrm{C}-13 \mathrm{~S}$} & $13 \mathrm{~S}-8 \mathrm{C}-11 \mathrm{~N}-2 \mathrm{C}$ & $11 \mathrm{~N}-8 \mathrm{C}-14 \mathrm{O}-9 \mathrm{C}$ \\
& \multicolumn{2}{c}{1.679} & -178.654 & 177.847 \\
\hline
\end{tabular}

The bond length of carbonyl S atom in SEX is longer than that in IPETC, indicating that carbonyl $S$ in IPETC is less likely to lose electrons. As a result of this, normal covalent bond is easier to be generated in SEX, which is not unbeneficial to its selectivity. Therefore, 
IPETC presents a better collecting selectivity for elemental sulfur in terms of bond length of carbonyl $S$ atom. The carbonyl S atom in ADDTP bonds with the $\mathrm{P}$ atom to form a $\mathrm{P}=\mathrm{S}$ bond which is different with $\mathrm{C}=\mathrm{S}$ bond in SEX and IPETC, and thus their bond lengths are not comparable.

Judging from the dihedral angle of three collectors, the atoms of $-\mathrm{S}-\mathrm{C}=\mathrm{N}-\mathrm{C}-$ and $-\mathrm{N}$ $\mathrm{C}=\mathrm{O}-\mathrm{C}$ - groups in IPETC and $-\mathrm{O}-\mathrm{C}(=\mathrm{S})-\mathrm{S}$ - group in SEX are nearly located in the same plane, respectively. Furthermore, the $\mathrm{p}$ orbitals that are not involved in hybridization exist in the valence electron layers of these atoms. Thus, conjugated big $\pi$-bond is easy to be formed in the three groups.

\subsubsection{Electronic Structure}

Mulliken Population Analysis

The Mulliken populations of bond and atom charge of SEX, ADDTP and IPETC are indicated in Table 8. The sequence of bond populations of $\mathrm{C}=\mathrm{S}$ or $\mathrm{P}=\mathrm{S}$ bonds in the three collectors is IPETC > ADDTP $>$ SEX. A larger population means stronger covalency of the covalent bond. Thus, in comparison with IPETC, it is more likely for the carbonyl S atoms in ADDTP and SEX to offer electrons, leading to the easier generation of a normal covalent bond between collector and mineral surface. Therefore, in terms of the bond population, IPETC shows better selectivity to elemental sulfur.

Table 8. Mulliken populations of $\mathrm{C}=\mathrm{S}$ or $\mathrm{P}=\mathrm{S}$ bond and atom charge of collectors.

\begin{tabular}{ccccccc}
\hline Collector & \multicolumn{2}{c}{ Bond Population } & \multicolumn{4}{c}{ Atom Charge Population } \\
\hline \multirow{2}{*}{ SEX } & 10 S-1C & $11 S-1 C$ & $1 \mathrm{C}$ & $9 \mathrm{O}$ & $10 \mathrm{~S}$ & $11 \mathrm{~S}$ \\
& 0.41 & 0.31 & -0.099 & -0.174 & -0.379 & -0.405 \\
\hline \multirow{2}{*}{ ADDTP } & $29 \mathrm{~S}-31 \mathrm{P}$ & $30 \mathrm{~S}-31 \mathrm{P}$ & $27 \mathrm{O}$ & $29 \mathrm{~S}$ & $30 \mathrm{~S}$ & $31 \mathrm{P}$ \\
& 0.72 & 0.74 & -0.729 & -0.759 & -0.811 & 1.521 \\
\hline \multirow{2}{*}{ IPETC } & \multicolumn{2}{c}{$8 \mathrm{C}-13 \mathrm{~S}$} & $8 \mathrm{C}$ & $11 \mathrm{~N}$ & $13 \mathrm{~S}$ & $14 \mathrm{O}$ \\
& \multicolumn{2}{c}{1.00} & 0.067 & 0.022 & -0.206 & -0.238 \\
\hline
\end{tabular}

The absolute values of Mulliken charge populations of carbonyl S atoms follow the order of ADDTP > SEX > IPETC. A larger absolute value means stronger electrostatic attraction between carbonyl $\mathrm{S}$ atom in collector and $\mathrm{S}$ atom in elemental sulfur surface. Nevertheless, electrostatic interaction has no directivity, and therefore the larger absolute value is unfavorable to the collector selectivity. Thus, in terms of atom charge population, IPETC also exhibits better selectivity for elemental sulfur than ADDTP and SEX.

Density of States Analysis

The densities of states of three collectors are indicated in Figure 7a-c. The valence band tops of SEX, ADDTP and IPETC are mainly comprised of 3p orbitals of 10S and 11S, $29 S$ and 30S, and 13S atoms, respectively. Their conduction band bottoms are primarily comprised of $2 p$ orbitals of $1 \mathrm{C}$ and $9 \mathrm{O}$ atoms and $3 \mathrm{p}$ orbitals of $10 \mathrm{~S}$ and $11 \mathrm{~S}$ atoms, $2 \mathrm{p}$ orbitals of 26O, 27O and 31P atoms and 3p orbitals of $29 \mathrm{~S}$ and $30 \mathrm{~S}$ atoms, and $2 \mathrm{p}$ orbitals of $8 \mathrm{C}, 11 \mathrm{~N}$ and $14 \mathrm{O}$ atoms and $3 \mathrm{p}$ orbital of $13 \mathrm{~S}$ atom, respectively. According to the band theory, the valence band top is the highest occupied molecular orbital (HOMO), and the conduction band bottom is the lowest unoccupied molecular orbital (LUMO), and they have the highest chemical activity and are separately apt to lose and gain electrons. Therefore, it can be concluded that the oxidation reaction centers of SEX, ADDTP and IPETC are separately $10 \mathrm{~S}$ and 11S, 29S and 30S, and $13 \mathrm{~S}$ atoms. Accordingly, the reduction reactions can occur on 1C, 9O, 10S and 11S atoms for SEX, 26O, 27O, 29S, 30S and 31P atoms for ADDTP, and 8C, 11N, $13 \mathrm{~S}$ and $14 \mathrm{O}$ atoms for IPETC, respectively. 

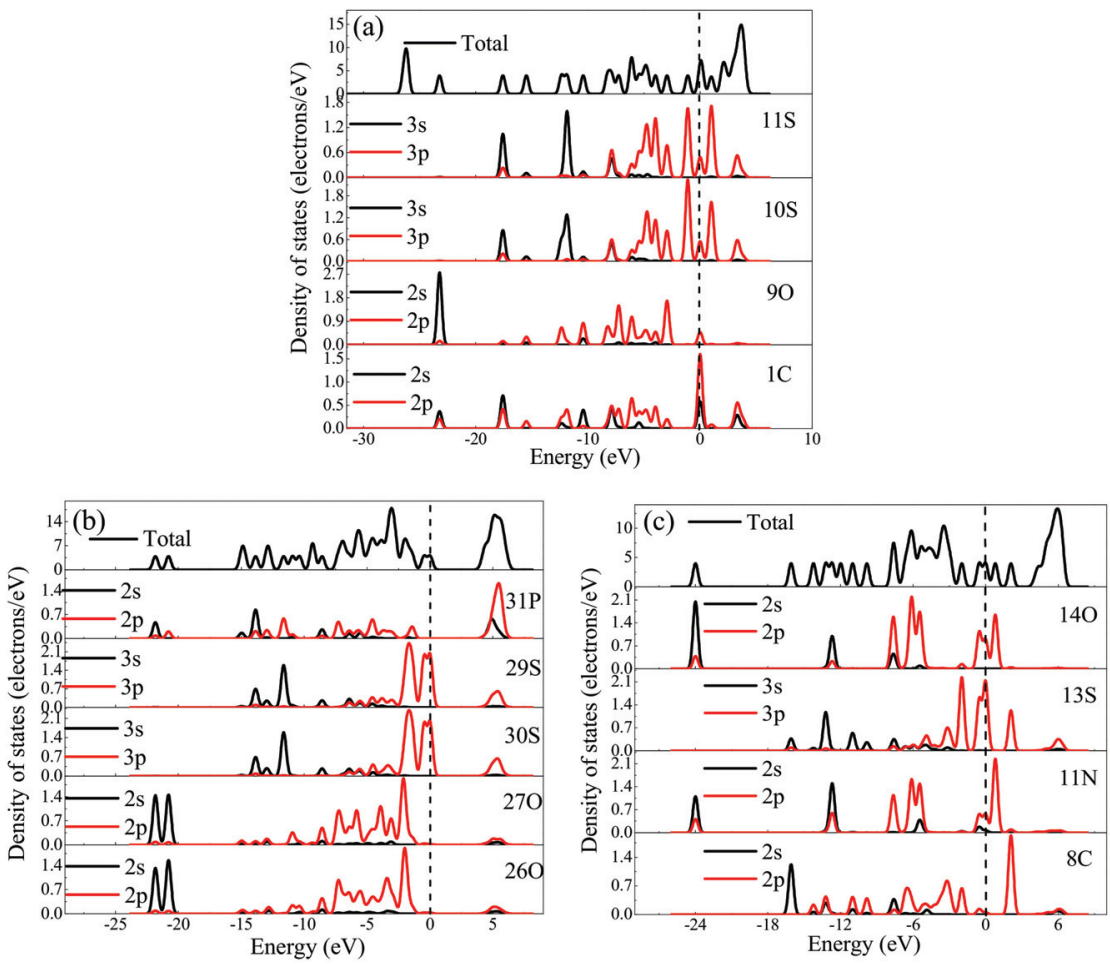

Figure 7. Densities of states of collectors ((a) IPETC; (b) ADDTP; (c) SEX).

Frontier Orbital Analysis

The electronic cloud pictures of frontier molecular orbitals of three optimized SEX, ADDTP and IPETC models are given in Figure 8a-f. From these subgraphs, the HOMOs of SEX, ADDTP and IPETC are mainly composed of electron orbitals of $10 \mathrm{~S}$ and 11S, 29S and 30S, and $13 \mathrm{~S}$ atoms, respectively. The LUMOs are primarily constituted by electron orbitals of 1C, 9O, 10S and 11S atoms for SEX, 26O, 27O, 29S, 30S and 31P atoms for ADDTP, and $8 \mathrm{C}, 11 \mathrm{~N}, 13 \mathrm{~S}$ and $14 \mathrm{O}$ atoms for IPETC, respectively. The above results are consistent with the results of density of states analysis in Section Density of States Analysis. Furthermore, the atoms of $-\mathrm{S}-\mathrm{C}=\mathrm{N}-\mathrm{C}$ - and $-\mathrm{N}-\mathrm{C}=\mathrm{O}-\mathrm{C}$ - groups in IPETC and $-\mathrm{O}-\mathrm{C}(=\mathrm{S})-\mathrm{S}-$ group in SEX are all almost in the same plane based on the dihedral angle values in Table 7. Moreover, it can be known from the result of density of states analysis in Section Density of States Analysis that the LUMO orbitals of IPETC and SEX all constitute the $p$ orbital of each atom in these functional groups. Therefore, it can be inferred that the LUMO orbitals of IPETC and SEX both are conjugated big $\pi$-bonds formed by electron orbitals of these functional groups. 


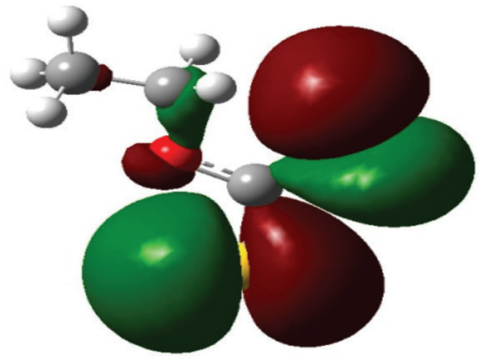

(a)

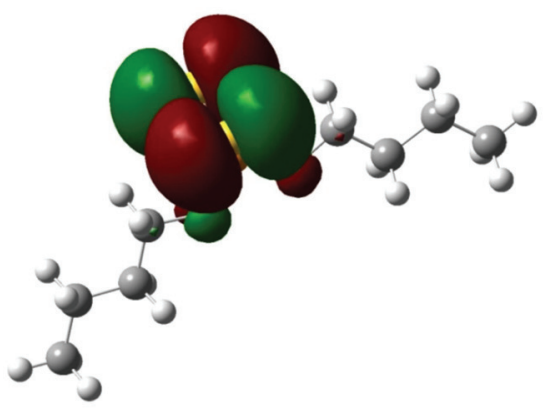

(c)

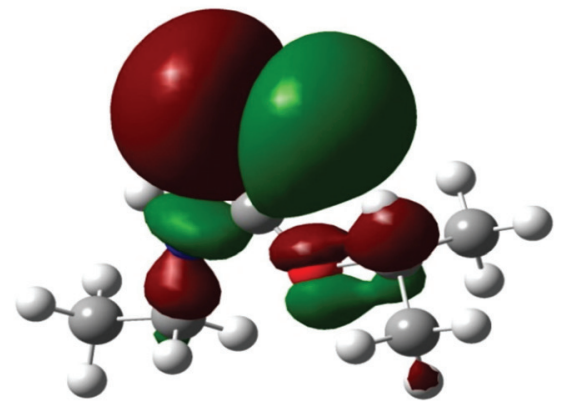

(e)

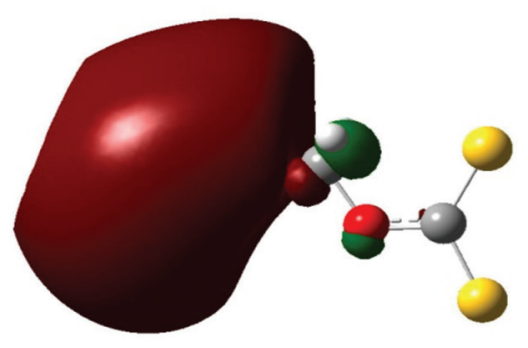

(b)

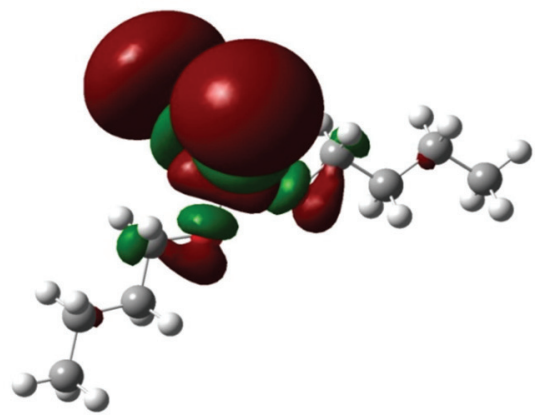

(d)

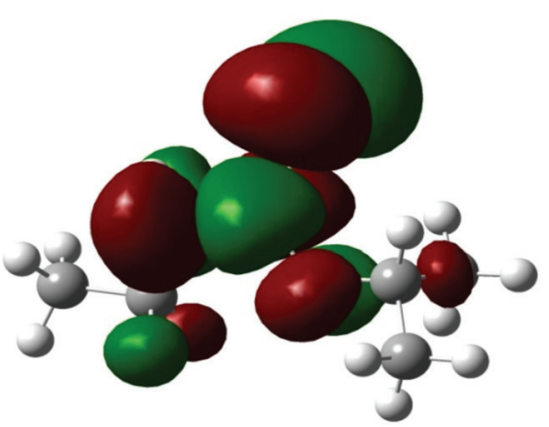

(f)

Figure 8. Electron cloud pictures of frontier molecular orbitals of optimized collector models ((a) HOMO of SEX; (b) LUMO of SEX; (c) HOMO of ADDTP; (d) LUMO of ADDTP; (e) HOMO of IPETC; (f) LUMO of IPETC).

The frontier orbital energies of three collectors and energy differences between collectors and minerals $(\Delta \mathrm{E})$ are shown in Table 9. According to frontier molecular orbital theory, a smaller absolute value of energy difference between the HOMO of one reactant and the LUMO of another one means that they are prone to react with each other. $\Delta \mathrm{E}_{1}$ are all evidently smaller than $\Delta \mathrm{E}_{2}$, suggesting that the chemical reaction between collectors and minerals is led by the electron transfer from collectors to minerals. Thus, the normal covalent bond predominates in the interaction. $\Delta \mathrm{E}_{1}$ between each collector and elemental sulfur is smaller than that between each collector and chalcopyrite/sphalerite/pyrite/anglesite/albite, indicating that the normal covalent bond between 
each collector and elemental sulfur is stronger than that between each collector and five other minerals. In comparison with SEX and ADDTP, both $\triangle \mathrm{E}_{1}$ between IPETC and elemental sulfur and $\Delta \mathrm{E}_{1}$ elemental sulfur $/ \Delta \mathrm{E}_{1}$ five other minerals of IPETC are the minimum. Thus, IPETC displays the optimal collecting power and selectivity for elemental sulfur among the three collectors.

Table 9. Frontier orbital energies of collectors and energy differences between collectors and minerals.

\begin{tabular}{clllcccccc}
\hline Collector & Orbital Energy (eV) & $\Delta \mathrm{E}^{\mathbf{a}}$ & Elemental Sulfur & Chalcopyrite & Pyrite & Sphalerite & Anglesite & Albite \\
\hline \multirow{2}{*}{ SEX } & HOMO & -4.57 & $\Delta \mathrm{E}_{1}$ & 0.39 & 0.64 & 0.78 & 1.54 & 1.69 & 1.77 \\
& LUMO & -3.07 & $\Delta \mathrm{E}_{2}$ & 2.55 & 2.60 & 2.21 & 2.38 & 2.44 & 2.67 \\
\hline \multirow{2}{*}{ ADDTP } & HOMO & -5.56 & $\Delta \mathrm{E}_{1}$ & 0.32 & 0.51 & 0.53 & 0.73 & 0.95 & 1.23 \\
& LUMO & -4.67 & $\Delta \mathrm{E}_{2}$ & 2.42 & 1.00 & 1.37 & 2.04 & 2.31 & 2.45 \\
\hline \multirow{2}{*}{ IPETC } & HOMO & -5.18 & $\Delta \mathrm{E}_{1}$ & 0.15 & 0.76 & 1.04 & 1.43 & 1.51 \\
& LUMO & -3.76 & $\Delta \mathrm{E}_{2}$ & 1.91 & 1.86 & 1.77 & 1.91 & 1.97 & 2.12 \\
\hline
\end{tabular}

${ }^{\mathrm{a}} \Delta \mathrm{E}_{1}=\mid \mathrm{E}(\mathrm{HOMO}$, collector $)-\mathrm{E}(\mathrm{LUMO}$, mineral $) \mid$ and $\Delta \mathrm{E}_{2}=\mid \mathrm{E}(\mathrm{HOMO}$, mineral $)-\mathrm{E}(\mathrm{LUMO}$, collector $) \mid$.

\subsection{Mechanism of IPETC Adsorption on Elemental Sulfur Surface}

\subsubsection{Adsorption Configuration and Adsorption Energy}

After many adsorption position tests, six possible configurations of IPETC adsorption on perfect elemental sulfur (110) plane are indicated in Figure 9a-f, and the adsorption energies are shown in Table 10. The adsorption energies of six configurations are all negative, and therefore these adsorption reactions can happen spontaneously. Nevertheless, the adsorption energy is the lowest for the configuration of simultaneous adsorption of carbonyl $\mathrm{S}$ together with $\mathrm{O}$, suggesting that this configuration is the most stable.

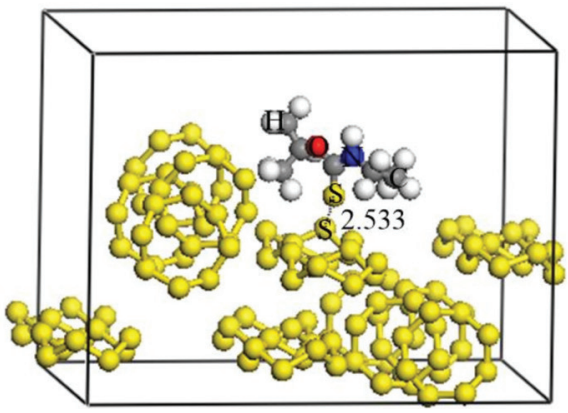

(a)

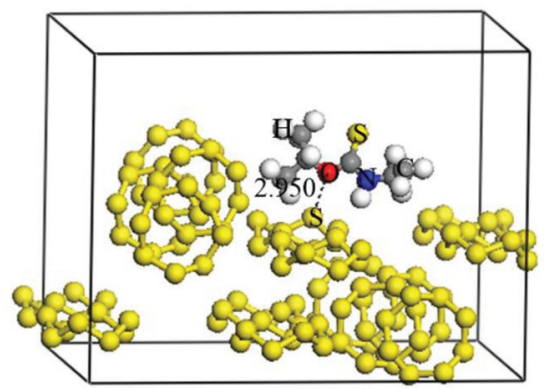

(c)

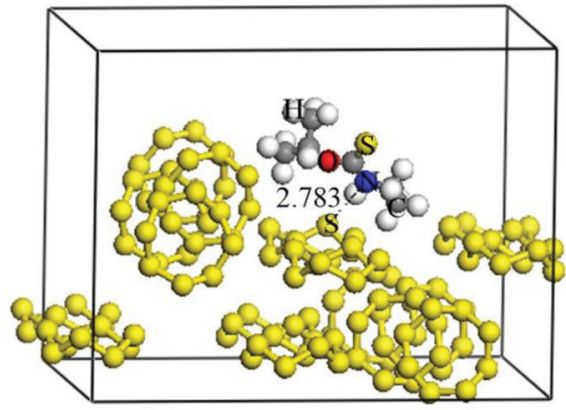

(b)

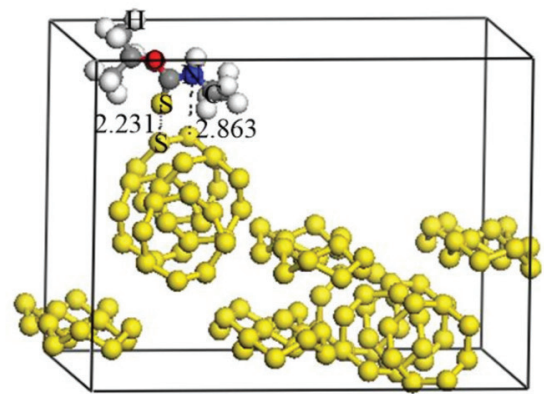

(d)

Figure 9. Cont. 


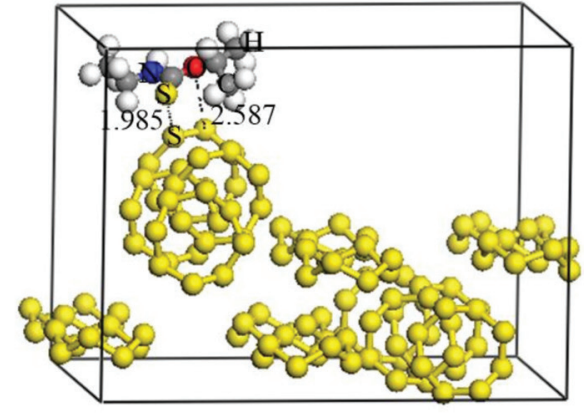

(e)

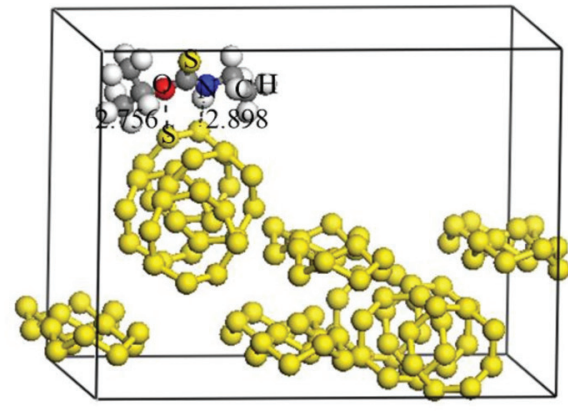

(f)

Figure 9. Adsorption configurations of IPETC on perfect elemental sulfur (100) crystal plane ((a) adsorption of carbonyl S atom; (b) adsorption of $\mathrm{N}$ atom; (c) adsorption of $\mathrm{O}$ atom; (d) adsorption of carbonyl $\mathrm{S}$ together with $\mathrm{N}$ atoms; (e) adsorption of carbonyl $\mathrm{S}$ together with $\mathrm{O}$ atoms; (f) adsorption of $\mathrm{N}$ together with $\mathrm{O}$ atoms).

Table 10. Adsorption energy of each adsorption configuration of IPETC on elemental sulfur (110) crystal plane.

\begin{tabular}{cc}
\hline Adsorption Configuration & Adsorption Energy (kJ/mol) \\
\hline Adsorption of carbonyl S & -19.79 \\
Adsorption of N & -10.23 \\
Adsorption of O & -6.16 \\
Simultaneous adsorption of carbonyl S together with N & -21.82 \\
Simultaneous adsorption of carbonyl S together with O & -26.98 \\
Simultaneous adsorption of N and O & -16.53 \\
\hline
\end{tabular}

The adsorption energies of six configurations of IPETC adsorption on the perfect crystal planes of chalcopyrite (112), sphalerite (110), pyrite (100), anglesite (001) and albite (001) are displayed in Table 11. Obviously, the most stable adsorption configuration of IPETC on the five crystal planes is also the simultaneous adsorption of carbonyl $S$ together with $\mathrm{O}$. Nevertheless, the adsorption energies for the first four minerals are negative and obey the sequence of chalcopyrite $<$ pyrite $<$ sphalerite $<$ anglesite, which are all larger than that for elemental sulfur in Table 9. Thus, it is easier for IPETC adsorption on elemental sulfur surface to occur. The adsorption energies for albite are all positive, and therefore IPETC adsorption on albite surface is difficult, which supported the results of pure mineral flotation and adsorption experiments in Section 3.2 that both the albite recovery and its adsorption amount on albite surface are very low.

Table 11. Adsorption energy of each adsorption configuration of IPETC on each crystal plane.

\begin{tabular}{|c|c|c|c|c|c|}
\hline \multirow[b]{2}{*}{ Adsorption Configuration } & \multicolumn{5}{|c|}{ Adsorption Energy (kJ/mol) } \\
\hline & $\begin{array}{l}\text { Chalcopyrite } \\
\text { (112) Plane }\end{array}$ & $\begin{array}{c}\text { Pyrite } \\
\text { (100) Plane }\end{array}$ & $\begin{array}{l}\text { Sphalerite (110) } \\
\text { Plane }\end{array}$ & $\begin{array}{l}\text { Anglesite } \\
\text { (001) Plane }\end{array}$ & $\begin{array}{c}\text { Albite (001) } \\
\text { Plane }\end{array}$ \\
\hline Adsorption of carbonyl S & -12.53 & -11.12 & -10.02 & -3.53 & 1.54 \\
\hline Adsorption of $\mathrm{N}$ & -6.88 & -3.78 & -2.12 & -1.38 & 4.10 \\
\hline Adsorption of $\mathrm{O}$ & -9.12 & -8.00 & -7.79 & -3.19 & 2.16 \\
\hline Simultaneous adsorption of carbonyl S together with $\mathrm{N}$ & -8.01 & -4.56 & -3.45 & -2.41 & 2.33 \\
\hline Simultaneous adsorption of carbonyl S together with $\mathrm{O}$ & -16.89 & -14.69 & -12.21 & -4.67 & 1.23 \\
\hline Simultaneous adsorption of $\mathrm{N}$ and $\mathrm{O}$ & -5.13 & -6.69 & -5.63 & -0.43 & 3.49 \\
\hline
\end{tabular}

The steadiest adsorption configurations of IPETC on perfect planes of chalcopyrite, pyrite, sphalerite and anglesite are presented in Figure $10 \mathrm{a}-\mathrm{d}$, and the Mulliken populations of corresponding adsorption bonds are shown in Table 12. For each configuration, the 
population of carbonyl $\mathrm{S}$ adsorption bond is much bigger than that of $\mathrm{O}$ adsorption bond. Thus, the interaction between carbonyl $\mathrm{S}$ and bonding atom in mineral surface is stronger.

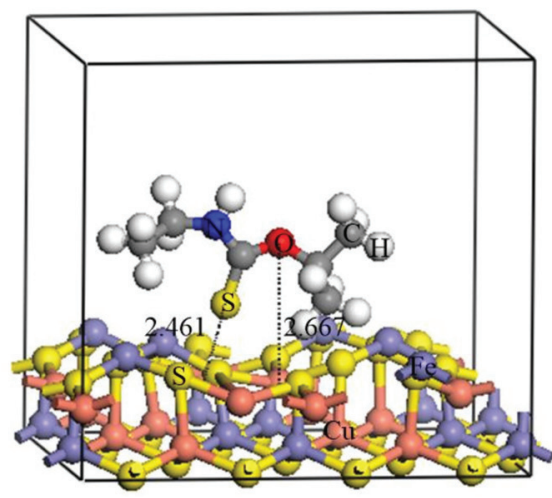

(a)

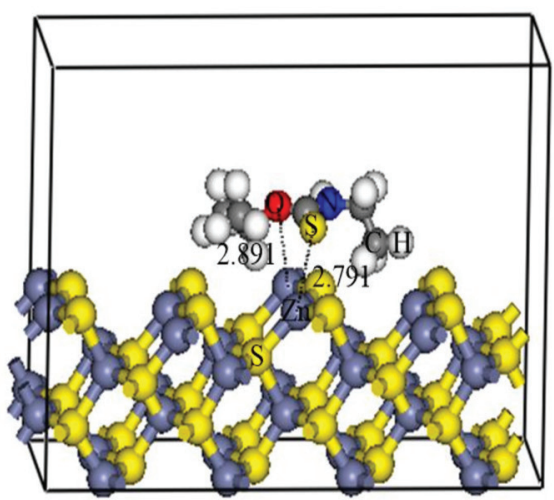

(c)

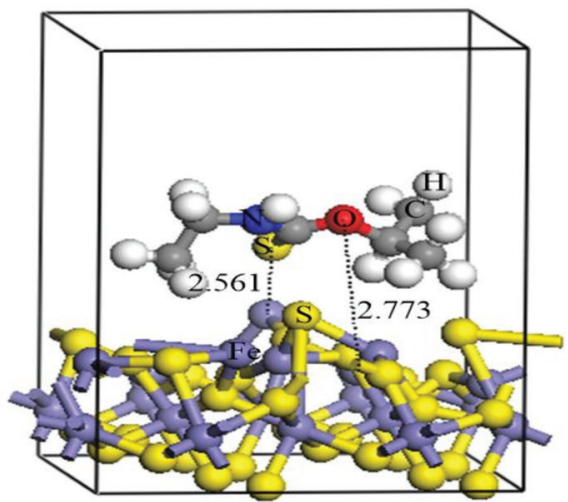

(b)

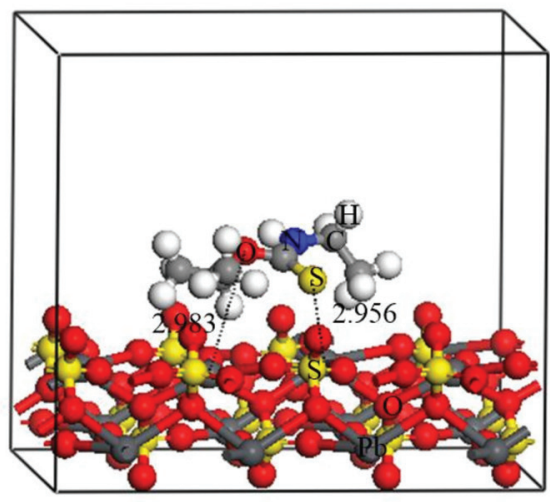

(d)

Figure 10. The steadiest adsorption configurations of IPETC on perfect crystal planes of chalcopyrite (112) (a), pyrite (100) (b), sphalerite (110) (c) and anglesite (001) (d).

Table 12. Mulliken population of adsorption bonds of each steadiest adsorption configuration of IPETC on each crystal plane.

\begin{tabular}{cccc}
\hline Crystal Plane & Adsorption Bond & Bond Length (̊̊) & Mulliken Population \\
\hline \multirow{2}{*}{ Elemental sulfur (110) } & S-S & 1.985 & 0.42 \\
& O-S & 2.587 & 0.15 \\
\hline \multirow{2}{*}{ Chalcopyrite (112) } & $\mathrm{S}-\mathrm{Cu}$ & 2.461 & 0.35 \\
& $\mathrm{O}-\mathrm{Cu}$ & 2.667 & 0.12 \\
\hline \multirow{2}{*}{ Pyrite (100) } & $\mathrm{S}-\mathrm{Fe}$ & 2.561 & 0.33 \\
& $\mathrm{O}-\mathrm{Fe}$ & 2.773 & 0.08 \\
\hline \multirow{2}{*}{ Sphalerite (110) } & $\mathrm{S}-\mathrm{Zn}$ & 2.791 & 0.23 \\
& $\mathrm{O}-\mathrm{Zn}$ & 2.891 & 0.11 \\
\hline \multirow{2}{*}{ Anglesite (001) } & $\mathrm{S}-\mathrm{Pb}$ & 2.956 & 0.19 \\
& $\mathrm{O}-\mathrm{Pb}$ & 2.983 & 0.12 \\
\hline
\end{tabular}




\subsubsection{Mulliken Population and Density of States Analyses}

The Mulliken populations and densities of states of bonding atoms before and after IPETC adsorption on perfect elemental sulfur (100) plane are presented in Table 13 and Figure 11, respectively. The $3 p$ orbital of carbonyl S atom of IPETC donates some electrons to the $3 p$ orbital of $\mathrm{S}$ atom on elemental sulfur surface to form a normal covalent bond, while the $2 p$ orbital of $\mathrm{O}$ atom of IPETC accepts the electrons from the $3 p$ orbital of $S$ atom in elemental sulfur surface to form a backdonation covalent bond.

Table 13. Mulliken charge populations of bonding atoms before and after adsorption.

\begin{tabular}{cccccc}
\hline \multirow{2}{*}{ Bonding Atom } & \multirow{2}{*}{ Adsorption State } & \multicolumn{3}{c}{ Electron Charge (e) } & \multirow{2}{*}{ Charge Population } \\
\cline { 3 - 5 } & & $\mathbf{s}$ & $\mathbf{p}$ & $\mathbf{d}$ & \\
\hline \multirow{2}{*}{$\mathrm{O}_{(\mathrm{O}-\mathrm{S})}$} & Before adsorption & 1.77 & 4.66 & 0.00 & -0.44 \\
& After adsorption & 1.77 & 4.71 & 0.00 & -0.46 \\
\hline \multirow{2}{*}{$\mathrm{S}_{(\mathrm{O}-\mathrm{S})}$} & Before adsorption & 1.89 & 4.19 & 0.00 & -0.01 \\
& After adsorption & 1.89 & 4.12 & 0.00 & -0.07 \\
\hline \multirow{2}{*}{ Carbonyl S } & Before adsorption & 1.82 & 4.41 & 0.00 & -0.23 \\
& After adsorption & 1.82 & 4.10 & 0.00 & 0.05 \\
\hline \multirow{2}{*}{$\mathrm{S}_{(\mathrm{S}-\mathrm{S})}$} & Before adsorption & 1.89 & 4.10 & 0.00 & 0.01 \\
& After adsorption & 1.89 & 4.12 & 0.00 & -0.01 \\
\hline
\end{tabular}

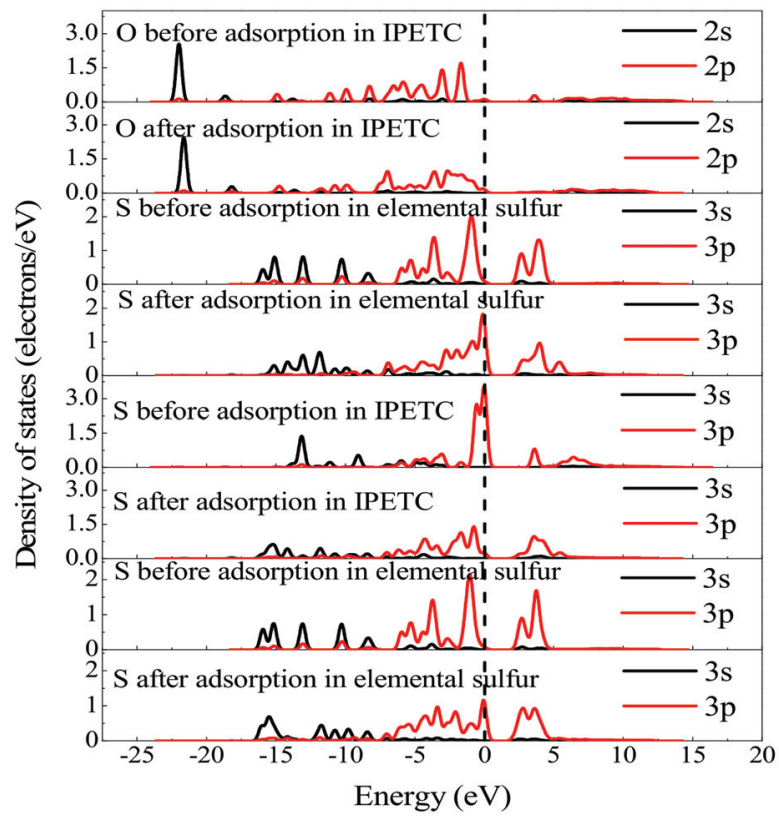

Figure 11. Densities of states of bonding atoms before and after IPETC adsorption on elemental sulfur (100) plane.

The $2 p$ state of $\mathrm{O}$ atom of IPETC slightly shifts to the higher energy direction, which means that it gets some electrons in the reaction. However, there is no evident variation in the $3 p$ state of bonding $S$ atom on elemental sulfur surface, indicating that the interaction between $\mathrm{O}$ and $\mathrm{S}$ atoms is weak. The $3 p$ state of carbonyl $\mathrm{S}$ atom of IPETC moves towards the lower energy direction, which indicates that when the $S$ atom of IPETC reacts with an $S$ atom on elemental sulfur surface, it loses some electrons and its oxidation is strengthened. 
At the same time, the localization of $3 p$ state of bonding $S$ atom on elemental sulfur surface declines and evident hybridization happens on the $3 p$ orbital of carbonyl $S$ atom and $3 p$ orbital of $\mathrm{S}$ atom from $-5 \mathrm{eV}$ to $0 \mathrm{eV}$. Thus, the interaction between carbonyl $\mathrm{S}$ atom in IPETC and $S$ atom in elemental sulfur surface is strong.

Based on the above results, it can be concluded that when IPETC interacts with elemental sulfur surface, carbonyl S of IPETC offers some electrons to the $S$ atom on mineral surface to form a normal covalent bond, while $\mathrm{O}$ of IPETC accepts some electrons from the $S$ atom to generate a backdonation covalent bond. The backdonation covalent bond is relatively weak, and thus a normal covalent bond plays a leading role.

\subsubsection{FTIR Spectrum Analysis}

The infrared spectra of IPETC, elemental sulfur and IPETC-adsorbed elemental sulfur are presented in Figure 12. After interaction with IPETC, the infrared spectrum of elemental sulfur changed significantly, suggesting that IPETC chemisorbed on elemental sulfur surface. Two new strong absorption peaks occurred at $2318.44 \mathrm{~cm}^{-1}$ and $503.42 \mathrm{~cm}^{-1}$, which are separately attributed to $\mathrm{C}=\mathrm{S}-\mathrm{S}$ and $\mathrm{C}-\mathrm{O}-\mathrm{S}$ coupled vibrations. The possible reason for this may be that when IPETC reacted with elemental sulfur, the $\mathrm{S}$ and $\mathrm{O}$ atoms of $\mathrm{C}=\mathrm{S}$ and $\mathrm{C}-\mathrm{O}$ bonds separately lost and obtained some electrons. As a result of this, a normal covalent bond and a backdonation covalent bond were formed between $\mathrm{C}=\mathrm{S}$ and $\mathrm{C}-\mathrm{O}$ bonds in IPETC and S atoms in elemental sulfur surface, resulting in the generation of two new coupled vibration peaks.

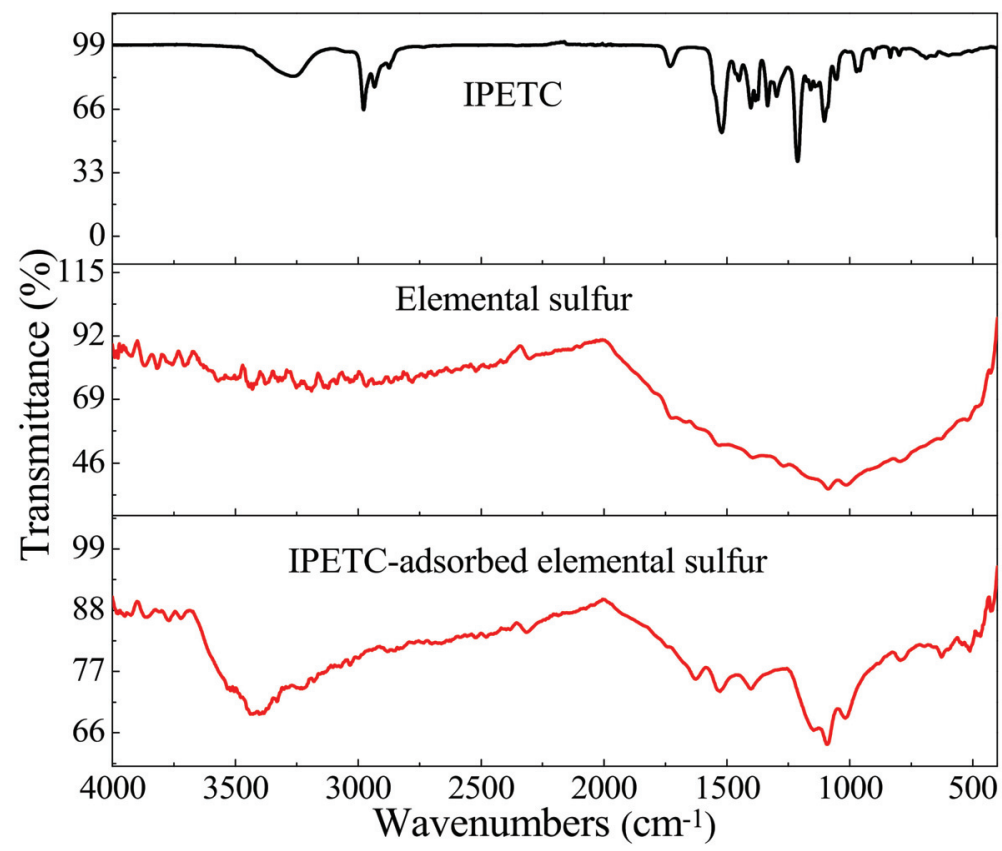

Figure 12. FTIR spectra of IPETC, elemental sulfur and IPETC-adsorbed elemental sulfur.

\section{Conclusions}

In this research, O-Isopropyl-N-Ethyl thionocarbamate (IPETC) collector was used to selectively recover elemental sulfur from a high-sulfur residue. The raw ore flotation test showed that in comparison with sodium ethyl xanthate (SEX) and ammonium dibutyl dithiophosphate (ADDTP) collectors, IPETC exhibited a superior collecting ability and selectivity to the elemental sulfur. Pure mineral flotation and adsorption experiments 
further proved that the collecting power and selectivity of IPETC to elemental sulfur are the optimum among the three collectors.

The bond length of $\mathrm{C}=\mathrm{S} / \mathrm{P}=\mathrm{S}$ covalent bond, Mulliken population and frontier orbital energy difference between collectors and minerals manifested that the selectivity of three collectors to elemental sulfur is in the order of IPETC $>$ ADDTP $>$ SEX. The density of states and frontier orbital analyses showed that the HOMO of each collector is mainly constituted by electron orbitals of carbonyl S atom, the LUMOs of IPETC and SEX are comprised of conjugated big $\pi$-bond formed by electron orbitals of the coplanar functional groups, and the LUMO of ADDTP is composed of the electron orbitals of $\mathrm{O}, \mathrm{S}$ and $\mathrm{P}$ atoms.

The adsorption configuration analysis indicated that the steadiest adsorption configuration of IPETC on the surfaces of elemental sulfur, chalcopyrite, sphalerite, pyrite, anglesite and albite is the simultaneous adsorption of carbonyl $\mathrm{S}$ together with $\mathrm{O}$, and IPETC adsorption on elemental sulfur surface is the most stable. The Mulliken population and density of state analyses of bonding atoms indicated that when IPETC reacts with the elemental sulfur surface, the $3 p$ orbital of carbonyl $S$ atom of IPETC donates electrons to the $3 p$ orbital of $S$ atom in elemental sulfur surface to form normal covalent bond while the $2 p$ orbital of $\mathrm{O}$ atom of IPETC obtains the electrons from the $3 p$ orbital of $\mathrm{S}$ atom in elemental sulfur surface to generate a backdonation covalent bond, and the stronger normal covalent bond plays a dominant role. The FTIR spectrum analysis supported the generation of a normal covalent bond and a backdonation covalent bond during IPETC adsorption on elemental sulfur surface.

Author Contributions: Conceptualization, Z.D. and B.X.; methodology, G.L. and B.Z.; software, F.Z.; validation, T.J.; formal analysis, F.W.; investigation, G.L.; resources, G.L.; data curation, Z.D.; writingoriginal draft preparation, G.L. and Z.D.; writing-review and editing, Z.D. and B.X.; supervision, B.X. and T.J.; funding acquisition, G.L. All authors have read and agreed to the published version of the manuscript.

Funding: This research was funded by National Key Research and Development Program of China (Nos. 2018YFC1902005 and 2018YFC1902006).

Institutional Review Board Statement: Not applicable.

Informed Consent Statement: Not applicable.

Data Availability Statement: Data available in a publicly accessible repository.

Conflicts of Interest: The authors declare no conflict of interest.

\section{References}

1. Abbasi, A.; Nasef, M.M.; Yahya, W.Z.N. Sulfur based polymers by inverse vulcanization: A novel path to foster green chemistry. Green Mater. 2020, 8, 172-180. [CrossRef]

2. Dong, Z.L.; Jiang, T.; Xu, B.; Yang, Y.B.; Li, Q. Recovery of gold from pregnant thiosulfate solutions by the resin adsorption technique. Metals 2017, 7, 555. [CrossRef]

3. Dong, Z.L.; Jiang, T.; Xu, B.; Yang, Y.B.; Li, Q. An eco-friendly and efficient process of low potential thiosulfate leaching-resin adsorption recovery for extracting gold from a roasted gold concentrate. J. Clean. Prod. 2019, 229, 387-398. [CrossRef]

4. Dong, Z.L.; Jiang, T.; Xu, B.; Yang, J.K.; Chen, Y.Z.; Yang, Y.B.; Li, Q. Comprehensive recoveries of selenium, copper, gold, silver and lead from a copper anode slime with a clean and economical hydrometallurgical process. Chem. Eng. J. 2020, $393,124762$. [CrossRef]

5. Xu, B.; Kong, W.H.; Li, Q.; Yang, Y.B.; Jiang, T. A review of thiosulfate leaching of gold: Focus on thiosulfate consumption and gold recovery from pregnant solution. Metals 2017, 7, 222. [CrossRef]

6. Xu, B.; Li, K.; Dong, Z.L.; Yang, Y.B.; Li, Q.; Liu, X.L.; Jiang, T. Eco-friendly and economical gold extraction by nickel catalyzed ammoniacal thiosulfate leaching-resin adsorption recovery. J. Clean. Prod. 2019, 233, 1475-1485. [CrossRef]

7. Xu, B.; Chen, Y.Z.; Dong, Z.L.; Jiang, T.; Zhang, B.S.; Liu, G.Q.; Yang, J.K.; Li, Q.; Yang, Y.B. Eco-friendly and efficient extraction of valuable elements from copper anode mud using an integrated pyro-hydrometallurgical process. Resour. Conserv. Recycl. 2021, 164, 105195. [CrossRef]

8. Gu, Y.; Zhang, T.A.; Liu, Y.; Mu, W.Z.; Zhang, W.G.; Dou, Z.H.; Jiang, X.L. Pressure acid leaching of zinc sulfide concentrate. Trans. Nonferr. Met. Soc. China 2010, 20, s136-s140. [CrossRef] 
9. Padilla, R.; Vega, D.; Ruiz, M.C. Pressure leaching of sulfidized chalcopyrite in sulfuric acid-oxygen media. Hydrometallurgy 2010, 86, 80-88. [CrossRef]

10. Jorjani, E.; Ghahreman, A. Challenges with elemental sulfur removal during the leaching of copper and zinc sulfides, and from the residues; a review. Hydrometallurgy 2017, 171, 333-343. [CrossRef]

11. Forward, F.A.; Veltman, H. Direct leaching zinc-sulfide concentrates by Sherritt Gordon. JOM 1959, 11, 836-840. [CrossRef]

12. Corriou, J.P.; Gély, R.; Viers, P. Thermodynamic and kinetic study of the pressure leaching of zinc sulfide in aqueous sulfuric acid. Hydrometallurgy 1988, 21, 85-102. [CrossRef]

13. Lampinen, M.; Laari, A.; Turunen, I. Kinetic model for direct leaching of zinc sulfide concentrates at high slurry and solute concentration. Hydrometallurgy 2015, 153, 160-169. [CrossRef]

14. Mu, W.Z.; Zhang, T.A.; Liu, Y.; Gu, Y.; Dou, Z.H.; Lv, G.Z.; Bao, L.; Zhang, W.G. E-pH diagram of ZnS-H2O system during high pressure leaching of zinc sulfide. Hydrometallurgy 2010, 20, 2012-2019. [CrossRef]

15. Liu, G.Q.; Jiang, K.X.; Zhang, B.S.; Dong, Z.L.; Zhang, F.; Wang, F.; Jiang, T.; Xu, B. Selective flotation of elemental sulfur from pressure acid leaching residue of zinc sulfide. Minerals 2021, 11, 89. [CrossRef]

16. Qin, S.C.; Jiang, K.X.; Wang, H.B.; Zhang, B.S.; Wang, Y.F.; Zhang, X.D. Research on behavior of iron in the zinc sulfide pressure leaching process. Minerals 2020, 10, 224. [CrossRef]

17. Rao, S.; Wang, D.X.; Liu, Z.Q.; Zhang, K.F.; Cao, H.Y.; Tao, J.Z. Selective extraction of zinc, gallium, and germanium from zinc refinery residue using two stage acid and alkaline leaching. Hydrometallurgy 2019, 183, 38-44. [CrossRef]

18. Wang, Z.Y.; Cai, X.L.; Zhang, Z.B.; Zhang, L.B.; Wang, S.X.; Peng, J.H. Separation and enrichment of elemental sulfur and mercury from hydrometallurgical zinc residue using sodium sulfide. Trans. Nonferr. Met. Soc. China 2015, 25, 640-646. [CrossRef]

19. Halfyard, J.E.; Hawboldt, K. Separation of elemental sulfur from hydrometallurgical residue: A review. Hydrometallurgy 2011, 109, 80-89. [CrossRef]

20. Li, H.L.; Yao, X.L.; Wang, M.X.; Wu, S.K.; Ma, W.W.; Wei, W.W.; Li, L.Q. Recovery of elemental sulfur from zinc concentrate direct leaching residue using atmospheric distillation: A pilot-scale experimental study. J. Air Waste Manag. 2014, 64, 95-103. [CrossRef]

21. Li, H.L.; Wu, X.Y.; Wang, M.X.; Wang, J.; Wu, S.K.; Yao, X.L.; Li, L.Q. Separation of elemental sulfur from zinc concentrate direct leaching residue by vacuum distillation. Sep. Purif. Technol. 2014, 138, 41-46. [CrossRef]

22. Chen, J.H.; Lan, L.H.; Chen, Y. Computational simulation of adsorption and thermodynamic study of xanthate, dithiophosphate and dithiocarbamate on galena and pyrite surfaces. Miner. Eng. 2013, 46-47, 136-143. [CrossRef]

23. Huang, Z.Q.; Zhong, H.; Wang, S.; Xia, L.Y.; Zou, W.B.; Liu, G.Y. Investigations on reverse cationic flotation of iron ore by using a Gemini surfactant: Ethane-1,2-bis (dimethyl-dodecyl-ammonium bromide). Chem. Eng. J. 2014, 257, 218-228. [CrossRef]

24. Ma, X.; Xia, L.Y.; Wang, S.; Zhong, H.; Jia, H. Structural modification of xanthate collectors to enhance the flotation selectivity of chalcopyrite. Ind. Eng. Chem. Res. 2017, 56, 6307-6316. [CrossRef]

25. Wang, Z.; Xu, L.H.; Wang, J.M.; Wang, L.; Xiao, J.H. A comparison study of adsorption of benzohydroxamic acid and amyl xanthate on smithsonite with dodecylamine as co-collector. Appl. Surf. Sci. 2017, 426, 1141-1147. [CrossRef]

26. Liu, F.P.; Wang, J.L.; Peng, C.; Liu, Z.H.; Wilson, B.P.; Lundström, M. Recovery and separation of silver and mercury from hazardous zinc refinery residues produced by zinc oxygen pressure leaching. Hydrometallurgy 2019, 185, 38-45. [CrossRef]

27. Fan, Y.Y.; Liu, Y.; Niu, L.P.; Jing, T.L.; Zhang, T.A. Separation and purification of elemental sulfur from sphalerite concentrate direct leaching residue by liquid paraffin. Hydrometallurgy 2019, 186, 162-169. [CrossRef]

28. Xing, P.; Ma, B.Z.; Wang, C.Y.; Wang, L.; Chen, Y.Q. A simple and effective process for recycling zinc-rich paint residue. Waste Manag. 2018, 76, 234-241. [CrossRef]

29. Qiu, T.S.; He, Y.Q.; Qiu, X.H.; Yang, X.L. Density functional theory and experimental studies of $\mathrm{Cu}^{2+}$ activation on a cyanideleached sphalerite surface. J. Ind. Eng. Chem. 2017, 45, 307-315. [CrossRef]

30. Rashchi, F.; Dashti, A.; Arabpour-Yazdi, M.; Abdizadeh, H. Anglesite flotation: A study for lead recovery from zinc leach residue. Miner. Eng. 2005, 18, 205-212. [CrossRef]

31. Dong, Z.L.; Jiang, T.; Xu, B.; Li, Q.; Zhong, H.; Yang, Y.B. Selective flotation of galena using a novel collector S-benzyl-Nethoxycarbonyl thiocarbamate: An experimental and theoretical investigation. J. Mol. Liq. 2021, 330, 115643. [CrossRef]

32. Xu, B.; Wu, J.T.; Dong, Z.L.; Jiang, T.; Li, Q.; Yang, Y.B. Flotation performance, structure-activity relationship and adsorption mechanism of a newly-synthesized collector for copper sulfide minerals in Gacun polymetallic ore. Appl. Surf. Sci. 2021, 551, 149420. [CrossRef]

33. Le, M.N.; Lee, M.S. Hydrometallurgical treatment of elemental sulfur in spent catalysts by aqueous and nonaqueous solutions at low temperature. Miner. Process. Extr. Metall. Rev. 2020, 41, 217-226. [CrossRef]

34. Jia, Y.; Huang, K.H.; Wang, S.; Cao, Z.F.; Zhong, H. The selective flotation behavior and adsorption mechanism of thiohexanamide to chalcopyrite. Miner. Eng. 2019, 137, 187-199. [CrossRef] 



\title{
Hydrochloric Acid Leaching Behaviors of Copper and Antimony in Speiss Obtained from Top Submerged Lance Furnace
}

\author{
Sujin Chae ${ }^{1}$, Kyoungkeun Yoo ${ }^{1, *}$, Carlito Baltazar Tabelin ${ }^{2}$ and Richard Diaz Alorro ${ }^{3}$ \\ 1 Department of Energy \& Resources Engineering, Korea Maritime and Ocean University (KMOU), 727, \\ Taejong-ro, Yeongdo-gu, Busan 49112, Korea; sujin.chae.082@gmail.com \\ 2 School of Minerals and Energy Resources Engineering, University of New South Wales, \\ Sydney 2052, NSW, Australia; c.tabelin@unsw.edu.au \\ 3 Western Australian School of Mines: Minerals, Energy and Chemical Engineering, \\ Faculty of Science and Engineering, Curtin University, Kalgoorlie 6430, WA, Australia; \\ richard.alorro@curtin.edu.au \\ * Correspondence: kyoo@kmou.ac.kr
}

Received: 28 September 2020; Accepted: 16 October 2020; Published: 20 October 2020

\begin{abstract}
Copper $(\mathrm{Cu})$ has been recovered from speiss generated from top submerged lance furnace process, but it was reported that the leaching efficiency of $\mathrm{Cu}$ in sulfuric acid solution decreased with increasing antimony $(\mathrm{Sb})$ content in the speiss. Scanning electron microscopy (SEM)-energy-dispersive $\mathrm{X}$-ray spectroscopy (EDS) results indicate that $\mathrm{Sb}$ exists as $\mathrm{CuSb}$ alloy, which would retard the leaching of $\mathrm{Cu}$. Therefore, hydrochloric acid leaching with aeration was performed to investigate the leaching behaviors of copper and antimony. The leaching efficiency of $\mathrm{Cu}$ increased with increasing agitation speed, temperature, $\mathrm{HCl}$ concentration, and the introduction ratio of $\mathrm{O}_{2}$, but also with decreasing pulp density. The leaching efficiency of $\mathrm{Cu}$ increased to more than $99 \%$ within $60 \mathrm{~min}$ in $1 \mathrm{~mol} / \mathrm{L} \mathrm{HCl}$ solution at $600 \mathrm{rpm}$ and $90{ }^{\circ} \mathrm{C}$ with $10 \mathrm{~g} / \mathrm{L}$ pulp density and $1000 \mathrm{cc} / \mathrm{min} \mathrm{O}_{2}$. The leaching efficiency of $\mathrm{Sb}$ increased and then decreased in all $1 \mathrm{~mol} / \mathrm{L} \mathrm{HCl}$ leaching tests, and precipitate was observed in the leach solution, which was determined to be $\mathrm{SbOCl}$ or $\mathrm{Sb}_{2} \mathrm{O}_{3}$ by XRD analyses. However, in $2 \mathrm{~mol} / \mathrm{L}-5 \mathrm{~mol} / \mathrm{L} \mathrm{HCl}$ solutions, the leaching efficiency of $\mathrm{Sb}$ increased to more than $95 \%$ (about $900 \mathrm{mg} / \mathrm{L}$ ) and remained, so more than $2 \mathrm{~mol} / \mathrm{L} \mathrm{HCl}$ could stabilize Sb ion in the $\mathrm{HCl}$ solution.
\end{abstract}

Keywords: copper; antimony; hydrochloric acid leaching; speiss

\section{Introduction}

Top submerged lance (TSL) technology has been used to recover valuable metals from the by-product of zinc smelting or industrial waste [1-3]. The valuable metals are concentrated in speiss, and impurities such as Fe are discarded as slag [4]. Although the composition of the speiss generated in the TSL process varies depending on input materials, generally, in South Korea, the speiss contains $\mathrm{Cu}, \mathrm{Sb}$, and precious metals as the main components. The recovery process of valuable metals from the speiss is summarized as shown Figure 1. From the speiss, $\mathrm{Cu}$ component is leached with sulfuric acid, and so the precious metals are concentrated in leach residue. Other impurities, such as Sb and $\mathrm{Pb}$, are discarded pyrometallurgically, and $\mathrm{Ag}$ and $\mathrm{Au}$ components are recovered by electrorefining processes in turn. 


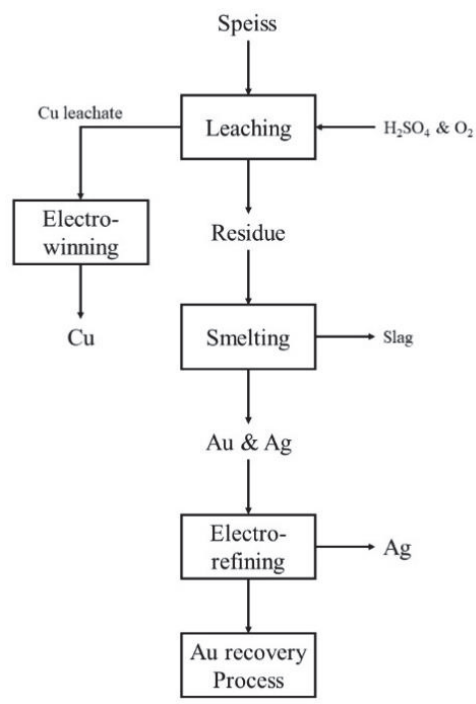

Figure 1. Schematic diagram of metal recovery process from speiss of top submerged lance process.

The high leaching efficiency of $\mathrm{Cu}$ from the speiss was required during the sulfuric acid leaching process because $\mathrm{Cu}$ in the residue reduces the purity of precious metal during the $\mathrm{Au}$ and Ag recovery process. Recently, as various secondary resources have been added to the TSL process, it was observed that the amount of antimony ( $\mathrm{Sb}$ ) increased and the leaching efficiency of Cu decreased. These facts, as a result, reduced the recovery efficiency of $\mathrm{Au}$ and $\mathrm{Ag}$ from subsequent processes. Therefore, although the leaching process of the speiss containing $\mathrm{Cu}$ and $\mathrm{Sb}$ should be improved, the leaching behaviors of materials containing $\mathrm{Cu}$ and $\mathrm{Sb}$ have been rarely reported.

The standard reduction potential of $\mathrm{Cu}$ is found to be $0.34 \mathrm{~V}[5,6]$, which indicates that $\mathrm{Cu}$ metal cannot be oxidized and dissolved by sulfuric acid. Additional oxidants such as $\mathrm{Fe}^{3+}[7,8], \mathrm{O}_{2}[9], \mathrm{Cl}_{2}[10]$ and $\mathrm{H}_{2} \mathrm{O}_{2}$ [11] or leaching media such as $\mathrm{HNO}_{3}[12,13], \mathrm{HCl}$ [14-17], and $\mathrm{NH}_{3}[18,19]$ have been used to leach $\mathrm{Cu}$ metals. The leaching of $\mathrm{Sb}$ in sulfuric acid solution has rarely been investigated, and the solubility of $\mathrm{Sb}_{2} \mathrm{O}_{3}$ or $\mathrm{Sb}_{2} \mathrm{O}_{5}$, which could be generated from the oxidation of $\mathrm{Sb}$, was found to be low [20]. The leaching of $\mathrm{Sb}$ has been investigated in sulfides using alkaline solution with $\mathrm{Na}_{2} \mathrm{~S}$ [21,22] and $\mathrm{HCl}$ with ozone [23], and from Pb dross [24] or fly ash [25] using hydrochloric acid. However, there have been few reports regarding $\mathrm{Sb}$ leaching, and the effect of $\mathrm{Sb}$ on the $\mathrm{Cu}$ leaching has not been reported.

Therefore, in the present study, the leach residue of the speiss was examined with SEM-EDS to understand the effect of $\mathrm{Sb}$ on the sulfuric acid leaching of the speiss, and then hydrochloric acid leaching tests with oxygen were performed to enhance the $\mathrm{Cu}$ leaching efficiency from the speiss. The effects of leaching factors such as temperature, agitation speed, $\mathrm{HCl}$ concentration, pulp density, and the flow rate of $\mathrm{O}_{2}$ on the leaching behaviors of $\mathrm{Cu}$ and $\mathrm{Sb}$ were investigated in hydrochloric acid solution.

\section{Materials and Methods}

The speiss samples used in this study were obtained from a zinc smelter in Korea, and the $\mathrm{D}_{50}$ and $\mathrm{D}_{90}$ of the speiss samples were $307.4 \mu \mathrm{m}$ and $795.5 \mu \mathrm{m}$, respectively. The speiss contained $77.16 \%$ $\mathrm{Cu}, 8.82 \% \mathrm{Sb}$, and $5.15 \% \mathrm{~Pb}$ as main components. Sulfuric acid $\left(\mathrm{H}_{2} \mathrm{SO}_{4}, 95 \%\right.$, Junsei Co., Ltd.: Tokyo, Japan) and hydrochloric acid ( $\mathrm{HCl}, 35 \%$, Junsei Co., Ltd.: Tokyo, Japan) were used as leaching media, and purities of $\mathrm{O}_{2}$, and $\mathrm{N}_{2}$ were $99.99 \%$ and $99.5 \%$, respectively. 
Leaching tests of the speiss were performed in a $500 \mathrm{~mL}$ five-necked Pyrex glass reactor using a heating mantle to maintain temperature. The reactor was fitted with an agitator and a reflux condenser, which was used to prevent solution loss at high temperatures. In a typical run, $200 \mathrm{~mL}$ of acid solution ( $2 \mathrm{~mol} / \mathrm{L} \mathrm{H}_{2} \mathrm{SO}_{4}$ or $0.1-5 \mathrm{~mol} / \mathrm{L} \mathrm{HCl}$ ) was poured into the reactor and, after the temperature of solution reached the thermal equilibrium $\left(30-90^{\circ} \mathrm{C}\right)$ at $200-800 \mathrm{rpm}$ agitation speed, $2 \mathrm{~g}$ of the speiss sample was added to the reactor in the experiments except the pulp density test. During the tests, gases such as $\mathrm{O}_{2}$, air, and $\mathrm{N}_{2}$ were introduced at $200 \mathrm{cc} / \mathrm{min}-1000 \mathrm{cc} / \mathrm{min}$, and $3 \mathrm{~cm}^{3}$ of the solution was withdrawn periodically at desired time intervals $(5-360 \mathrm{~min})$ with a syringe. The samples were filtered with a $0.22 \mu \mathrm{m}$ membrane filter and then the filtrate was diluted with $2 \% \mathrm{HNO}_{3}$ solution for $\mathrm{Cu}$ analysis and $3 \mathrm{~mol} / \mathrm{L} \mathrm{HCl}$ solution for $\mathrm{Sb}$ measurement, respectively.

The concentration of $\mathrm{Cu}$ and $\mathrm{Sb}$ in the solutions was measured with an inductively coupled plasma-atomic emission spectrometry (ICP-OES, Optima-8300, Perkin Elmer Inc.: Waltham, MA, USA). The precipitate generated during the leaching test was filtered and then dried at $105^{\circ} \mathrm{C}$. The precipitate was analyzed with an X-ray diffractometer (XRD, Smartlab, Rigaku Co.: Tokyo, Japan). The leaching residue obtained from the sulfuric acid leaching test was polished and then analyzed with a Scanning Electron Microscope (SEM, MIRA-3, Tescan Co.: Brno, Czech).

\section{Results and Discussion}

After sulfuric acid leaching of the speiss had been performed in $2 \mathrm{~mol} / \mathrm{L}$ sulfuric acid solution at $400 \mathrm{rpm}$ and $90^{\circ} \mathrm{C}$ with $1 \%$ pulp density and $1000 \mathrm{cc} /$ min introduction of $\mathrm{O}_{2}$, the leaching residue was obtained and then examined with SEM-EDS. Figure 2 shows the SEM image of the leaching residue, and the center and outer parts of the particle shows different shapes. A net shape was observed in the entire cross section of the particle, and the net shape was found to be a CuSb intermetallic alloy, based on the result of SEM-EDS analysis. In the center of the particle, the net shape is full of dark parts, which were found to be $\mathrm{Cu}$, while only the net shape was observed, without $\mathrm{Cu}$, in the outer part of the particle. These results indicate that $\mathrm{Cu}$ was leached from the outer of particle, but $\mathrm{Cu}$ remained inside the CuSb alloy net shape in the center of particle because $\mathrm{CuSb}$ would prevent leaching of $\mathrm{Cu}$. It has been reported that the leaching efficiency of $\mathrm{Sb}$ is lower or slower than $\mathrm{Cu}$ [26], and that the solubility of $\mathrm{Sb}$ is low in sulfuric acid [20]. Therefore, $\mathrm{Sb}$ should be dissolved to enhance the leaching efficiency of $\mathrm{Cu}$, so hydrochloric acid leaching tests were performed because chloride ion could make complex ions with metal, thus enhancing the solubility of the metal [27].

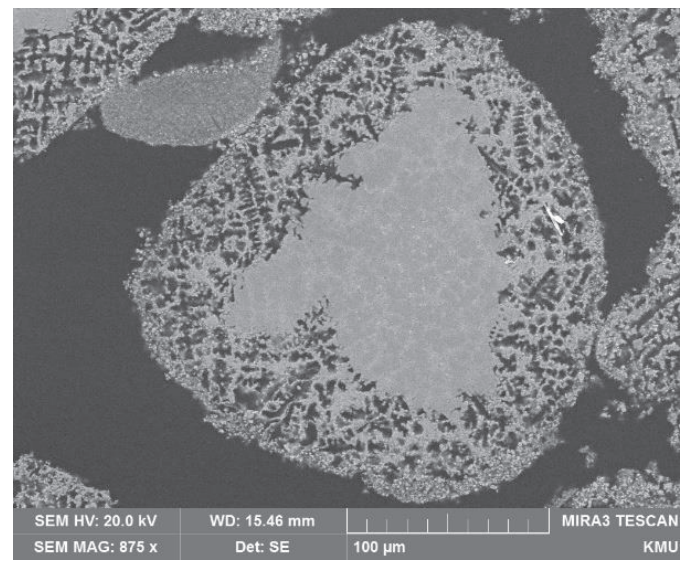

Figure 2. SEM image of sulfuric acid leaching residue of the speiss. 
Leaching tests of the speiss at agitation speeds in the range of 200-800 rpm were performed to investigate the effect of the liquid film boundary diffusion surrounding the particles on the leaching efficiency of $\mathrm{Cu}$ and $\mathrm{Sb}$ in $1 \mathrm{~mol} / \mathrm{L} \mathrm{HCl}$ at $90{ }^{\circ} \mathrm{C}$ with $1 \%$ pulp density and $1000 \mathrm{cc} / \mathrm{min} \mathrm{O}_{2}$. As shown in Figure $3 \mathrm{a}$, the leaching efficiency of $\mathrm{Cu}$ increased rapidly, and then gradually. The efficiency increased when the agitation speed was increased from $200 \mathrm{rpm}$ to $600 \mathrm{rpm}$, while the efficiencies show similar leaching behaviors at $600 \mathrm{rpm}$ and $800 \mathrm{rpm}$, so working agitation speed was fixed at $600 \mathrm{rpm}$ to ensure effective particle suspension in the solution in all the subsequent leaching tests. Figure $3 \mathrm{~b}$ shows the leaching behaviors of $\mathrm{Sb}$, where the leaching efficiency of $\mathrm{Sb}$ increased to more than $99 \%$ and then decreased with time. The efficiency at $200 \mathrm{rpm}$ decreased more slowly than those between $400 \mathrm{rpm}$ and $800 \mathrm{rpm}$, and, at $360 \mathrm{~min}$, lower leaching efficiency of Sb was observed at higher agitation speeds. When the concentration of Sb began to decrease, precipitate was observed in the solution. Figure 4 shows the XRD pattern of the precipitate, which was determined to be antimony oxychloride ( $\mathrm{SbOCl}$ ). These results indicate that $\mathrm{Cu}$ was leached from the speiss by $\mathrm{HCl}$ leaching, while $\mathrm{Sb}$ dissolved and was then precipitated as SbOCl.
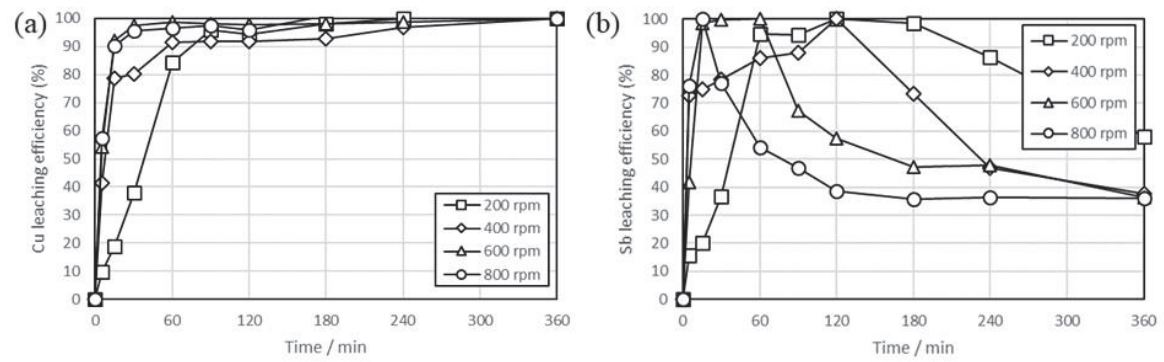

Figure 3. Leaching efficiencies of (a) $\mathrm{Cu}$ and (b) Sb with time in the function of agitation speed.

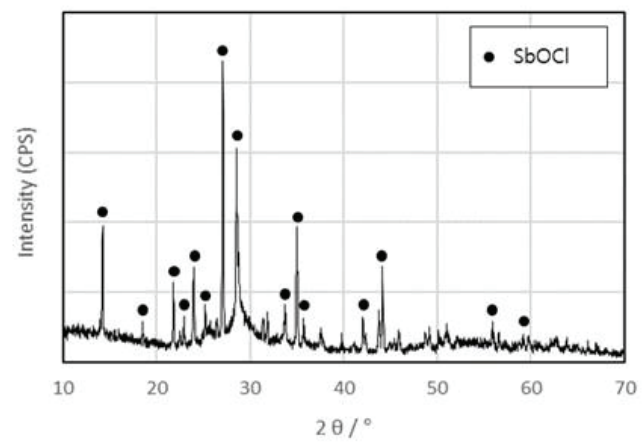

Figure 4. XRD pattern of leaching residue obtained from $\mathrm{HCl}$ leaching test in Figure 3.

In the TSL process, the metal product was generated as elemental metal or intermetallic alloy, as shown in Figure 1. The leaching of $\mathrm{Cu}$ metal can be summarized using the following equation [28]:

$$
\mathrm{Cu}^{2+}+\mathrm{Cu}=2 \mathrm{Cu}^{+}
$$

where cupric ion $\left(\mathrm{Cu}^{2+}\right)$ could oxidize $\mathrm{Cu}$ metal in hydrochloric acid or ammonia solution $[18,19,28]$ into cuprous ion $\left(\mathrm{Cu}^{+}\right)$. This $\mathrm{Cu}^{+}$ion is unstable, an so is easily oxidized into $\mathrm{Cu}^{2+}$ as follows [6]:

$$
2 \mathrm{Cu}^{+}+2 \mathrm{H}^{+}+1 / 2 \mathrm{O}_{2}=2 \mathrm{Cu}^{2+}+\mathrm{H}_{2} \mathrm{O}
$$


The regenerated $\mathrm{Cu}^{2+}$ could be reused as an oxidant for $\mathrm{Cu}$ metal leaching. Therefore, it is important to introduce oxygen into the leaching solution for $\mathrm{Cu}$ metal leaching. The leaching tests of the speiss were performed to investigate the effect of gas introduction on the leaching efficiency of $\mathrm{Cu}$ and $\mathrm{Sb}$ in $1 \mathrm{~mol} / \mathrm{L} \mathrm{HCl}$ at $90{ }^{\circ} \mathrm{C}$ and $600 \mathrm{rpm}$ with $1 \%$ pulp density. The $\mathrm{O}_{2}$ introduction rate was adjusted from $200 \mathrm{cc} / \mathrm{min}$ to $1000 \mathrm{cc} / \mathrm{min}$, and $1000 \mathrm{cc} / \mathrm{min}$ air and $\mathrm{N}_{2}$ were also introduced into the solution for comparison. As shown in Figure 5a, the leaching efficiency of $\mathrm{Cu}$ increased to more than $99 \%$ within $60 \mathrm{~min}$ in the cases of $\mathrm{O}_{2}$ introduction, whereas the efficiency with air introduction increased rapidly and then gradually to $99 \%$ within $360 \mathrm{~min}$. When $\mathrm{N}_{2}$ was introduced, the efficiency increased gradually to $18 \%$ within $360 \mathrm{~min}$. These results indicate that the anoxic condition prevents leaching of $\mathrm{Cu}$, because the regeneration of $\mathrm{Cu}^{2+}$, as shown in Equation (2), is suppressed, although $18 \%$ of $\mathrm{Cu}$ dissolved under the $\mathrm{N}_{2}$ introduction, which is due to partly oxidized surface of $\mathrm{Cu}$ [9]. Therefore, $\mathrm{O}_{2}$ should be introduced into the leach solution for $\mathrm{Cu}$ metal leaching, but the leaching efficiency of $\mathrm{Cu}$ increased regardless of the $\mathrm{O}_{2}$ introduction rate. Figure $5 \mathrm{~b}$ shows that the leaching efficiency of $\mathrm{Sb}$ increased and then decreased with time except with the introduction of $\mathrm{N}_{2}$, where the leaching efficiency of $\mathrm{Sb}$ was very low. An introduction rate of $1000 \mathrm{cc} / \mathrm{min}$ of $\mathrm{O}_{2}$ could retard the decrease in $\mathrm{Sb}$ concentration, so the gas introduction rate was fixed at $1000 \mathrm{cc} / \mathrm{min}_{2}$ in all subsequent leaching tests.
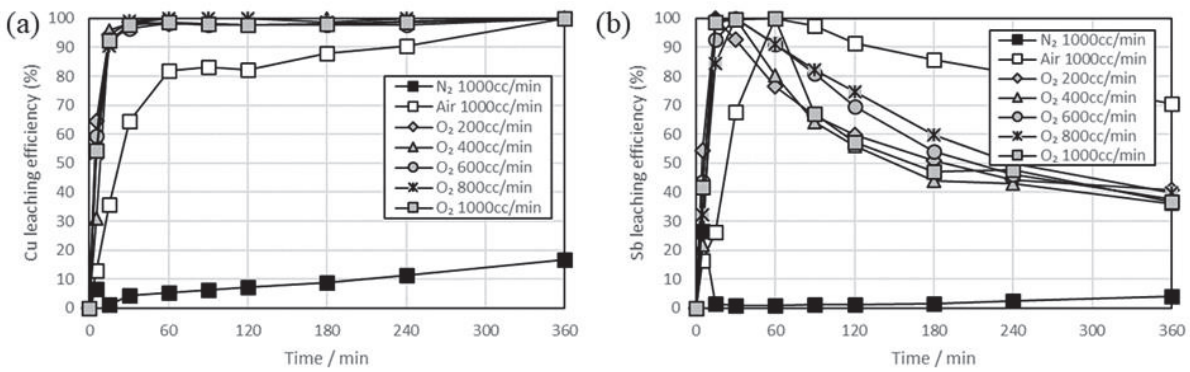

Figure 5. Leaching efficiencies of (a) $\mathrm{Cu}$ and (b) $\mathrm{Sb}$ with time in the function of gas introduction rate.

The effects of $\mathrm{HCl}$ concentration on the leaching efficiency of $\mathrm{Cu}$ and $\mathrm{Sb}$ were investigated under the following leaching conditions: $600 \mathrm{rpm}$ at $90{ }^{\circ} \mathrm{C}$ with $1 \%$ pulp density and $1000 \mathrm{cc} / \mathrm{min} \mathrm{O}_{2}$. In the case of $\mathrm{Cu}$ leaching, as shown in Figure 6a, higher leaching efficiency of $\mathrm{Cu}$ was observed at higher $\mathrm{HCl}$ concentrations at $15 \mathrm{~min}$, and then similar leaching behaviors of $\mathrm{Cu}$ were observed except for the test in $0.1 \mathrm{~mol} / \mathrm{L} \mathrm{HCl}$. In Figure $6 \mathrm{~b}$, low leaching efficiency of $\mathrm{Sb}$ was observed in $0.1 \mathrm{~mol} / \mathrm{L} \mathrm{HCl}$ solution over the entire leaching time, and the efficiency increased and then decreased with time in the $1 \mathrm{~mol} / \mathrm{L}$ $\mathrm{HCl}$ solution. When $\mathrm{HCl}$ concentration was increased to more than $2 \mathrm{~mol} / \mathrm{L}$, the leaching efficiency of $\mathrm{Sb}$ increased to more than $95 \%$ and then remained there. The concentration of $\mathrm{Sb}$ was measured to be about $900 \mathrm{mg} / \mathrm{L}$. These results indicate that more than $2 \mathrm{~mol} / \mathrm{L} \mathrm{HCl}$ could stabilize Sb ions in the solution with the $\mathrm{Sb}$ concentration range, and this fact has rarely been reported in conventional studies.

The leaching tests of the speiss were performed to investigate the effect of temperature on the leaching efficiency of $\mathrm{Cu}$ and $\mathrm{Sb}$ in $1 \mathrm{~mol} / \mathrm{L} \mathrm{HCl}$ at $30-90^{\circ} \mathrm{C}$ and $600 \mathrm{rpm}$ with $1 \%$ pulp density and $1000 \mathrm{cc} / \mathrm{min} \mathrm{O}_{2}$. Figure 7a shows that the leaching efficiency of $\mathrm{Cu}$ increased more rapidly at higher temperature, and that the efficiency increased to more than $99 \%$ within $120 \mathrm{~min}$ at $50-90{ }^{\circ} \mathrm{C}$ and within $360 \mathrm{~min}$ at $30^{\circ} \mathrm{C}$. In the case of Sb leaching as shown in Figure $7 \mathrm{~b}$, the leaching efficiency of $\mathrm{Sb}$ increased more rapidly at higher temperature during the early leaching time, except the test at $30^{\circ} \mathrm{C}$, and the efficiency decreased gradually. Although the leaching efficiency of $\mathrm{Sb}$ at $30^{\circ} \mathrm{C}$ increased to $53 \%$ at $60 \mathrm{~min}$, that of $\mathrm{Cu}$ increased as shown in Figure 7a. Since the precipitate of $\mathrm{Sb}$ was observed in the solution during the leaching test at $30^{\circ} \mathrm{C}, \mathrm{Cu}$ continued to dissolve while $\mathrm{Sb}$ dissolved and then precipitated. 

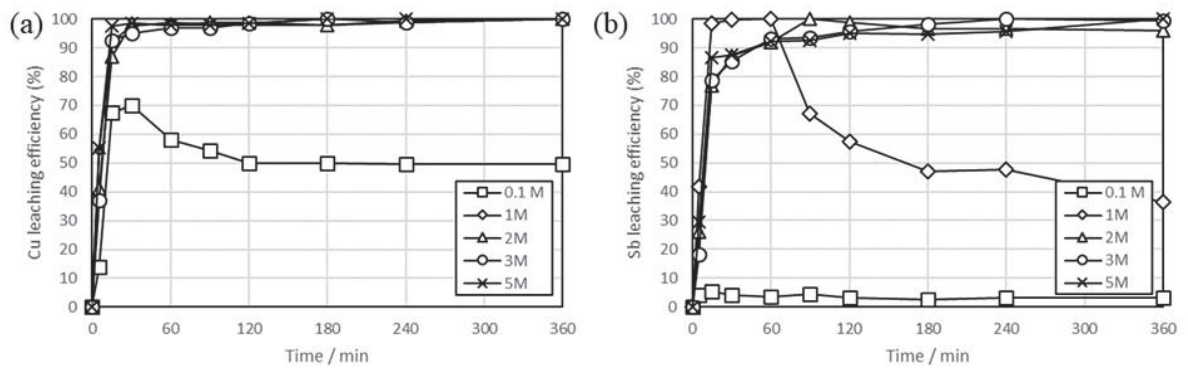

Figure 6. Leaching efficiencies of (a) $\mathrm{Cu}$ and (b) $\mathrm{Sb}$ with time in the function of $\mathrm{HCl}$ concentration.
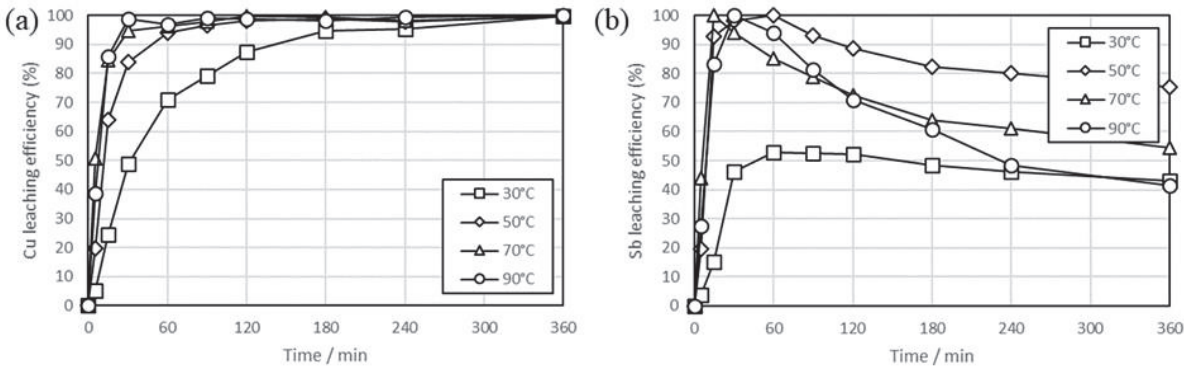

Figure 7. Leaching efficiencies of (a) $\mathrm{Cu}$ and (b) Sb with time as a function of temperature.

The effects of pulp density on the leaching efficiency of $\mathrm{Cu}$ and $\mathrm{Sb}$ were investigated in $1 \mathrm{~mol} / \mathrm{L}$ $\mathrm{HCl}$ solution at $90{ }^{\circ} \mathrm{C}$ and $600 \mathrm{rpm}$ with $1000 \mathrm{cc} / \mathrm{min} \mathrm{O}_{2}$. As shown in Figure 8a, the leaching efficiency of $\mathrm{Cu}$ decreased when increasing pulp density from $10 \mathrm{~g} / \mathrm{L}$ to $50 \mathrm{~g} / \mathrm{L}$. In the case of Sb leaching, except the pulp density of $10 \mathrm{~g} / \mathrm{L}$, Figure $8 \mathrm{~b}$ shows that the concentration of $\mathrm{Sb}$ increased and then decreased rapidly to about $10 \%$, and that the concentration of $\mathrm{Sb}$ in the leaching test with $10 \mathrm{~g} / \mathrm{L}$ increased and then decrease gradually to $40 \%$. The precipitates formed in the leaching test with $20 \mathrm{~g} / \mathrm{L}$ to $50 \mathrm{~g} / \mathrm{L}$ were collected and analyzed with XRD. As shown in Figure 9, $\mathrm{CuCl}_{2} \cdot 3 \mathrm{Cu}(\mathrm{OH})_{2}$ was observed in the precipitate formed in the test with $50 \mathrm{~g} / \mathrm{L}$, and, in the test with $20 \mathrm{~g} / \mathrm{L}$ or $30 \mathrm{~g} / \mathrm{L}$, the precipitate is determined to be $\mathrm{Sb}_{2} \mathrm{O}_{3}$. The pHs of the leaching solution increased to 3.8 and 4.2 in the leaching tests with $20 \mathrm{~g} / \mathrm{L}$ and $50 \mathrm{~g} / \mathrm{L}$, respectively. Therefore, the $\mathrm{Cu}$ precipitate in the test with $50 \mathrm{~g} / \mathrm{L}$ resulted from the higher $\mathrm{pH}$ and pulp density.
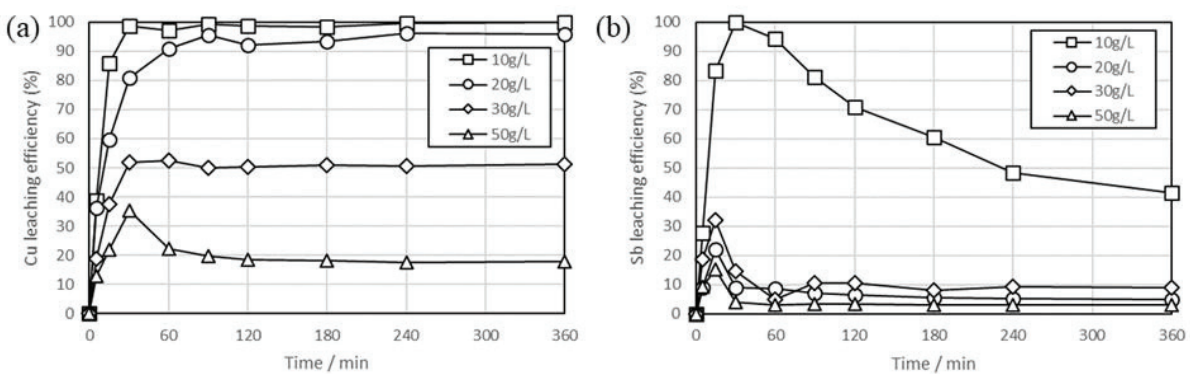

Figure 8. Leaching efficiencies of (a) $\mathrm{Cu}$ and (b) Sb with time in the function of pulp density. 


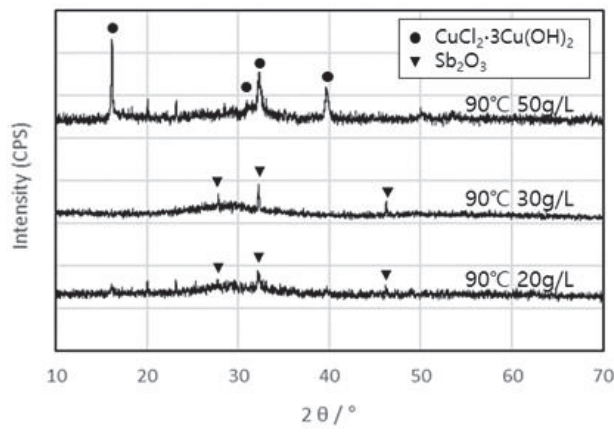

Figure 9. XRD pattern of leaching residue obtained from $\mathrm{HCl}$ leaching test in Figure 8.

\section{Conclusions}

SEM-EDS analysis of the leaching residue obtained from $\mathrm{H}_{2} \mathrm{SO}_{4}$ leaching of speiss and $\mathrm{HCl}$ leaching of speiss was performed to enhance the leaching efficiency of $\mathrm{Cu}$ and to investigate the leaching behavior of $\mathrm{Sb}$ in $\mathrm{HCl}$ solution.

The SEM-EDS results showed that $\mathrm{CuSb}$ alloy remained in the leaching residue even after $\mathrm{Cu}$ was leached by $\mathrm{H}_{2} \mathrm{SO}_{4}$ leaching, which indicates that the leaching rate of $\mathrm{CuSb}$ is slower than $\mathrm{Cu}$, and that $\mathrm{CuSb}$ could retard the leaching of $\mathrm{Cu}$. Therefore, $\mathrm{HCl}$ was used as a leaching agent to leach the speiss. The leaching efficiency of $\mathrm{Cu}$ increased with increasing agitation speed, temperature, $\mathrm{HCl}$ concentration, gas introduction rate but with decreasing pulp density. More than $99 \%$ of $\mathrm{Cu}$ was dissolved for $60 \mathrm{~min}$ in $1 \mathrm{~mol} / \mathrm{L} \mathrm{HCl}$ solution at $600 \mathrm{rpm}$ and $90^{\circ} \mathrm{C}$ with $10 \mathrm{~g} / \mathrm{L}$ pulp density and $1000 \mathrm{cc} / \mathrm{min} \mathrm{O}_{2}$. The leaching efficiency of Sb increased, and then was precipitated in all $1 \mathrm{~mol} / \mathrm{L} \mathrm{HCl}$ leaching tests, and the precipitate was determined to be $\mathrm{SbOCl}$. However, since more than $95 \%$ of $\mathrm{Sb}$ (about $900 \mathrm{mg} / \mathrm{L}$ ) was dissolved and remained in $2 \mathrm{~mol} / \mathrm{L}-5 \mathrm{~mol} / \mathrm{L} \mathrm{HCl}$ solutions, this result indicates that $2 \mathrm{~mol} / \mathrm{L}$ or more concentrated $\mathrm{HCl}$ could stabilize $\mathrm{Sb}$ ion in the $\mathrm{HCl}$ solution after $60 \mathrm{~min}$.

Author Contributions: Methodology, S.C. and K.Y.; writing-original draft preparation, S.C., C.B.T. and K.Y.; project administration and funding acquisition, K.Y.; data curation, S.C. and K.Y.; writing-review and editing, providing ideas, R.D.A. and K.Y. All authors have read and agreed to the published version of the manuscript.

Funding: This work was supported by the Technology Innovation Program (or Industrial Strategic Technology Development Program-Development of Material Component Technology) (20011176, Development of advanced technology in Hydrometallurgy for high added value of resources recovery) funded By the Ministry of Trade, Industry \& Energy (MOTIE, Korea).

Conflicts of Interest: The authors declare no conflict of interest.

\section{References}

1. Hoang, J.; Reuter, M.A.; Matusewicz, R.; Hughes, S.; Piret, N. Top submerged lance direct zinc smelting. Miner. Eng. 2009, 22, 742-751. [CrossRef]

2. Kim, B.S.; Jeong, S.B.; Lee, J.C.; Shin, D.; Moon, N.I. Behaviors of lead and zinc in top submerged lance (TSL) plant at Sukpo zinc refinery. Mater. Trans. 2012, 53, 985-990. [CrossRef]

3. Sohn, H.S. Current Status of Zinc Smelting and Recycling. J. Korean Inst. Resour. Recycl. 2019, $28,30-41$. [CrossRef]

4. Yoo, J.K.; Lee, M.; Kim, G.H.; Yoo, K. The Gravity Separation of Speiss and Limestone Granules Using Vibrating Zirconia Ball Bed. J. Korean Inst. Resour. Recycl. 2020, 29, 36-42. [CrossRef]

5. Brett, C.M.A.; Brett, A.M.O. Electrochemistry; Oxford University Press Inc.: New York, NY, USA, 1993; pp. 416-419.

6. Yoo, K.; Park, Y.; Choi, S.; Park, I. Improvement of Copper Metal Leaching in Sulfuric Acid Solution by Simultaneous Use of Oxygen and Cupric Ions. Metals 2020, 10, 721. [CrossRef] 
7. Lee, S.; Yoo, K.; Jha, M.K.; Lee, J. Separation of Sn from waste Pb-free Sn-Ag-Cu solder in hydrochloric acid solution with ferric chloride. Hydrometallurgy 2015, 157, 184-187. [CrossRef]

8. Xing, W.; Lee, S.; Lee, M. Solvent extraction of $\mathrm{Li}(\mathrm{I})$ from weak $\mathrm{HCl}$ solution with the mixture of neutral extractants containing $\mathrm{FeCl}_{3}$. J. Korean Inst. Resour. Recycl. 2018, 27, 53-58. [CrossRef]

9. Park, I.; Yoo, K.; Alorro, R.D.; Kim, M.; Kim, S. Leaching of copper from cuprous oxide in aerated sulfuric acid. Mater. Trans. 2017, 58, 1500-1504. [CrossRef]

10. Kim, E.Y.; Kim, M.S.; Lee, J.C.; Yoo, K.; Jeong, J. Leaching behavior of copper using electro-generated chlorine in hydrochloric acid solution. Hydrometallurgy 2010, 100, 95-102. [CrossRef]

11. Kim, S.; Lee, J.C.; Lee, K.S.; Yoo, K.; Alorro, R.D. Separation of tin, silver and copper from waste Pb-free solder using hydrochloric acid leaching with hydrogen peroxide. Mater. Trans. 2014, 55, 1885-1889. [CrossRef]

12. Yoo, K.; Lee, J.C.; Lee, K.S.; Kim, B.S.; Kim, M.S.; Kim, S.K.; Pandey, B.D. Recovery of Sn, Ag and Cu from waste $\mathrm{Pb}$-free solder using nitric acid leaching. Mater. Trans. 2012, 53, 2175-2180. [CrossRef]

13. Yoo, K.; Lee, K.; Jha, M.K.; Lee, J.; Cho, K. Preparation of nano-sized tin oxide powder from waste Pb-free solder by direct nitric acid leaching. J. Nanosci. Nanotechnol. 2016, 16, 11238-11241. [CrossRef]

14. Moon, G.; Yoo, K. Separation of $\mathrm{Cu}, \mathrm{Sn}, \mathrm{Pb}$ from photovoltaic ribbon by hydrochloric acid leaching with stannic ion followed by solvent extraction. Hydrometallurgy 2017, 171, 123-127. [CrossRef]

15. Chen, W.S.; Chen, Y.J.; Yueh, K.C. Separation of Valuable Metal from Waste Photovoltaic Ribbon through Extraction and Precipitation. J. Korean Inst. Resour. Recycl. 2020, 29, 69-77. [CrossRef]

16. Kang, Y.H.; Hyun, S.K. Study on the Preparation of Copper Sulfate by Copper Powder using Cation Membrane Electrowinning Prepared from Waste Cupric Chloride Solution. J. Korean Inst. Resour. Recycl. 2019, 28, 62-72. [CrossRef]

17. Kim, S.K.; Lee, J.C.; Yoo, K. Leaching of tin from waste Pb-free solder in hydrochloric acid solution with stannic chloride. Hydrometallurgy 2016, 165, 143-147. [CrossRef]

18. Jeon, S.; Yoo, K.; Alorro, R.D. Separation of $\mathrm{Sn}, \mathrm{Bi}, \mathrm{Cu}$ from $\mathrm{Pb}$-free solder paste by ammonia leaching followed by hydrochloric acid leaching. Hydrometallurgy 2017, 169, 26-30. [CrossRef]

19. Lim, Y.; Kwon, O.; Lee, J.; Yoo, K. The ammonia leaching of alloy produced from waste printed circuit boards smelting process. Geosyst. Eng. 2013, 16, 216-224. [CrossRef]

20. Karlsson, T.Y. Studies on the Recovery of Secondary Antimony Compounds from Waste. Ph.D. Thesis, Chalmers University of Technology, Göteborg, Sweden, 2017; pp. 5-7.

21. Awe, S.A.; Sundkvist, J.E.; Bolin, N.J.; Sandström, Å. Process flowsheet development for recovering antimony from Sb-bearing copper concentrates. Miner. Eng. 2013, 49, 45-53. [CrossRef]

22. Awe, S.A.; Sandström, A. Selective leaching of arsenic and antimony from a tetrahedrite rich complex sulphide concentrate using alkaline sulphide solution. Miner. Eng. 2010, 23, 1227-1236. [CrossRef]

23. Guo, X.Y.; Xin, Y.T.; Wang, H.; Tian, Q. Leaching kinetics of antimony-bearing complex sulfides ore in hydrochloric acid solution with ozone. Trans. Nonferrous Met. Soc. China 2017, 27, 2073-2081. [CrossRef]

24. Choi, S.; Yoo, K.; Alorro, R.D. Hydrochloric acid leaching behavior of metals from non-magnetic fraction of Pb dross. Geosyst. Eng. 2019, 22, 347-354. [CrossRef]

25. Elomaa, H.; Seisko, S.; Lehtola, J.; Lundström, M. A study on selective leaching of heavy metals vs. iron from fly ash. J. Mater. Cycles Waste Manag. 2019, 21, 1004-1013. [CrossRef]

26. Bae, E.; Yoo, K. Leaching behavior of valuable metals from by-product generated during purification of zinc electrolyte. Geosyst. Eng. 2016, 19, 312-316. [CrossRef]

27. Oh, J.; Yoo, K.; Bae, M.; Kim, S.; Alorro, R.D. The adsorption behaviors of gold ions in simulated leachate using magnetite. J. Korean Soc. Miner. Energy Resour. Eng. 2019, 56, 79-85. [CrossRef]

28. Lee, S.; Yoo, K.; Lee, J. Preparation of $\mathrm{Cu}_{2} \mathrm{O}$ Powder in $\mathrm{NaOH}$ solution Using $\mathrm{CuCl}$ Obtained from Spent Printed Circuit Boards Etchant. J. Korean Soc. Miner. Energy Resour. Eng. 2018, 55, 194-199. [CrossRef]

Publisher's Note: MDPI stays neutral with regard to jurisdictional claims in published maps and institutional affiliations.

(C) 2020 by the authors. Licensee MDPI, Basel, Switzerland. This article is an open access article distributed under the terms and conditions of the Creative Commons Attribution (CC BY) license (http://creativecommons.org/licenses/by/4.0/). 


\title{
Copper Recovery and Reduction of Environmental Loading from Mine Tailings by High-Pressure Leaching and SX-EW Process
}

\author{
Labone L. Godirilwe ${ }^{1}$, Kazutoshi Haga ${ }^{1, *}$, Batnasan Altansukh ${ }^{1}$, Yasushi Takasaki ${ }^{1}$, Daizo Ishiyama ${ }^{1}$, \\ Vanja Trifunovic ${ }^{2}$, Ljiljana Avramovic ${ }^{2}$, Radojka Jonovic ${ }^{2}$, Zoran Stevanovic ${ }^{2}$ and Atsushi Shibayama ${ }^{1, *}$ \\ 1 Department of Earth Resource Engineering and Environmental Science, Akita University, \\ Akita 010-0865, Japan; llgodirilwe@gmail.com (L.L.G.); altansukh@gipc.akita-u.ac.jp (B.A.); \\ yas-tksk@gipc.akita-u.ac.jp (Y.T.); ishiyama@gipc.akita-u.ac.jp (D.I.) \\ 2 Mining and Metallurgy Institute Bor, 19210 Bor, Serbia; vanja.trifunovic@irmbor.co.rs (V.T.); \\ ljiljana.avramovic@irmbor.co.rs (L.A.); rafinacija@irmbor.co.rs (R.J.); zoran.stevanovic@irmbor.co.rs (Z.S.) \\ * Correspondence: khaga@gipc.akita-u.ac.jp (K.H.); sibayama@gipc.akita-u.ac.jp (A.S.)
}

Citation: Godirilwe, L.L.; Haga, K.;

Altansukh, B.; Takasaki, Y.;

Ishiyama, D.; Trifunovic, V.;

Avramovic, L.; Jonovic, R.;

Stevanovic, Z.; Shibayama, A. Copper

Recovery and Reduction of

Environmental Loading from Mine

Tailings by High-Pressure Leaching and SX-EW Process. Metals 2021, 11,

1335. https://doi.org/10.3390/

met11091335

Academic Editors: Anna H. Kaksone and Chris Aldrich

Received: 16 July 2021

Accepted: 21 August 2021

Published: 24 August 2021

Publisher's Note: MDPI stays neutral with regard to jurisdictional claims in published maps and institutional affiliations.

Copyright: (c) 2021 by the authors. Licensee MDPI, Basel, Switzerland. This article is an open access article distributed under the terms and conditions of the Creative Commons Attribution (CC BY) license (https:// creativecommons.org/licenses/by/ $4.0 /)$.
Abstract: The flotation tailings obtained from Bor Copper Mine contain pyrite $\left(\mathrm{FeS}_{2}\right)$ and chalcopyrite $\left(\mathrm{CuFeS}_{2}\right)$, these sulfide minerals are known to promote acid mine drainage (AMD) which poses a serious threat to the environment and human health. This study focuses on the treatment of mine tailings to convert the AMD supporting minerals to more stable forms, while simultaneously valorizing the mine tailings. A combination of hydrometallurgical processes of high-pressure oxidative leaching (HPOL), solvent extraction (SX), and electrowinning (EW) were utilized to recover copper from mine tailings which contain about $0.3 \% \mathrm{Cu}$ content. The HPOL process yielded a high copper leaching rate of $94.4 \%$ when water was used as a leaching medium. The copper leaching kinetics were promoted by the generation of sulfuric acid due to pyrite oxidation. It was also confirmed that a low iron concentration $(1.4 \mathrm{~g} / \mathrm{L})$ and a high copper concentration $(44.8 \mathrm{~g} / \mathrm{L})$ obtained in the stripped solution resulted in an improved copper electrodeposition current efficiency during copper electrowinning. Moreover, pyrite, which is primarily in the mine tailings, was converted into hematite after HPOL. A stability evaluation of the solid residue confirmed almost no elution of metal ions, confirming the reduced environmental loading of mine tailings through re-processing.

Keywords: tailings valorization; high-pressure leaching; copper recovery; acid mine drainage; metal elution

\section{Introduction}

Mine tailings are waste material generated from the flotation process and there are billions of tons of already existing tailings all over the world. Moreover, several billion tons of additional mine tailings will inevitably be produced, as lower-grade and complex ores are being mined to sustain the world's growing demand for mineral resources [1,2]. Schlesinger et al. [3] (p.68) estimated that flotation tailings account for $98 \%$ of the ore fed in to concentrators, which are stored in large tailings dams near their mines. Unfortunately, the storage of mine tailings is associated with severe environmental challenges. If not managed properly, the failure of mine tailings storage facilities can result in catastrophic ramifications and environmental pollution, such as the well-known Brumadinho and Mariana tailings dam disasters in Brazil. The most serious environmental impact resulting from mine tailings is the generation of acid mine drainage (AMD). Mine tailings that contain metal sulfides, such as pyrite $\left(\mathrm{FeS}_{2}\right)$, are a major source of AMD [4-6]. Pyrite is a gangue mineral that is commonly found in mine tailings, when exposed to an environment with oxygen and water, oxidation of pyrite is promoted via reaction 1 , which results in low $\mathrm{pH}$ conditions of less than 3 [5,7-9]. 


$$
2 \mathrm{FeS}_{2}+7.5 \mathrm{O}_{2}+\mathrm{H}_{2} \mathrm{O} \rightarrow \mathrm{Fe}_{2}\left(\mathrm{SO}_{4}\right)_{3}+\mathrm{H}_{2} \mathrm{SO}_{4}
$$

The low $\mathrm{pH}$ conditions are detrimental because they increase the dissolution and mobility of toxic and heavy metals/metalloids such as $\mathrm{Cd}, \mathrm{Co}, \mathrm{Cr}, \mathrm{Cu}, \mathrm{Fe}, \mathrm{Mn}, \mathrm{Ni}, \mathrm{Pb}, \mathrm{Zn}$, As, and Se $[6,10]$. When these toxic metals accumulate in the environment, they become a major source of contamination to water sources and potentially endanger ecosystems and human health $[5,6,8,11]$. The flotation tailings from Bor Copper Mine contain pyrite and chalcopyrite, therefore, management of these mine tailings is extremely important, as well as developing effective long-term strategies to reduce the environmental footprint of the mining industry.

The reprocessing of mine tailings is now being globally explored as an approach to be sustainable in both active and inactive mining operations. As new technologies emerge, valuable metals can efficiently be extracted from mine tailings with reduced environmental impacts. Most old copper mine tailings have a comparable copper grade to that of low-grade ores $(0.2-0.3 \%)$ and considering their vast amount, they present a potential source of secondary raw material for copper production $[6,7,12-15]$. Several technologies have been used for the treatment of mine tailings to extract valuable metals, these mostly include bioleaching [12,15-17], flotation [10,14,18], hydrometallurgical methods $[4,6,7,19]$, or a combination of these treatment methods $[13,20]$. Hydrometallurgical methods are commonly considered for the treatment of low-grade sulfide material because of comprehensive metal recovery and shorter retention times. Antonijevi'c et al. [7] investigated the leaching of flotation tailings from Bor Copper Mine using sulfuric acid and iron (III) sulfate as an oxidant and obtained a copper recovery of $80 \%$ after $2 \mathrm{~h}$, highlighting that the flotation tailings should be valorized rather than used for land reclamation. Chen et al. [6] demonstrated that low-grade copper sulfide tailings with pyrite proportions of $31.50 \%$, can be recycled for environmentally friendly disposal through leaching and fractional precipitation methodology, from which a copper recovery of $98.45 \%$ could be achieved. Selective extraction of copper from tailings was successively investigated by Turan et al. [21] using a mixture of ammonia salts as leaching reactants and managed to obtain a copper recovery of $91.47 \%$ with no iron tenors to the leachate after $6 \mathrm{~h}$ of leaching at $30^{\circ} \mathrm{C}$.

This study evaluates the high-pressure oxidative leaching (HPOL) method as an effective way to recover copper and reduce the environmental loading from the mine tailings obtained from Bor Copper Mine, Serbia. The advantages of pressure leaching include fast kinetics, enhanced metal selectivity, and the generation of stable residues [22]. Han et al. [23] have already presented in full detail about high-pressure leaching of the concentrate obtained after the flotation of the mine tailings. This study considers highpressure leaching directly on the mine tailings as well as environmental evaluation of the leach residue stability. Particular interest was given to the high-temperature oxidation treatment of the mine tailings to convert the reactive and harmful minerals such as pyrite, to more stable forms such as hematite $\left(\mathrm{Fe}_{2} \mathrm{O}_{3}\right)$. Chalcopyrite $\left(\mathrm{CuFeS}_{2}\right)$ has also been listed as one of the sulfide minerals important in AMD formation [5]. Therefore, alongside the conversion of pyrite to hematite, the dissolution of residual chalcopyrite from flotation tailings will also aid in the prevention of AMD. To evaluate the effectiveness of this method in reducing the environmental loading caused by flotation tailings, metal elution tests were performed on the solid residue obtained after HPOL and on the flotation tailings. In addition to Han et al.'s [23] study, this research further investigates the electrowinning process for final copper recovery, in order to demonstrate the feasibility of a complete hydrometallurgical process when utilizing the discarded mine tailings. The electrowinning process was carried out to examine the effect of iron and copper concentration of the stripped solution on current efficiency for copper electrodeposition. 


\section{Materials and Methods}

\subsection{Experimental Sample}

The mine tailings sample used in this study was obtained from Bor Mine in Serbia. The sample was obtained $14 \mathrm{~m}$ below the ground surface of the tailings dam. The average particle size of the mine tailings sample was $27 \mu \mathrm{m}\left(\mathrm{D}_{50}\right)$. Table 1 shows the chemical compositions of the two samples utilized in this study; the mine tailings and the concentrate obtained after the flotation of the mine tailings. X-ray diffraction (XRD) analysis (Figure 1) showed that the main mineral compositions of the mine tailings and concentrate of the mine tailings were quartz $\left(\mathrm{SiO}_{2}\right)$, pyrite $\left(\mathrm{FeS}_{2}\right)$, and kaolinite $\left(\mathrm{Al}_{2} \mathrm{Si}_{2} \mathrm{O}_{5}\left(\mathrm{OH}_{4}\right)\right.$. The main copper mineral in the mine tailings was identified as chalcopyrite $\left(\mathrm{CuFeS}_{2}\right)$ using scanning electron microscope-energy dispersion spectroscopy (SEM-EDS) (Figure 2). The copper concentrate used in this study was prepared by flotation under determined optimal conditions: pH 10, pulp density 25\%, PAX collector dosage $100 \mathrm{~g}$ / t-ore, NaHS sulfidizer dosage $1000 \mathrm{~g}$ / $\mathrm{t}$-ore, MIBC frother dosage $200 \mathrm{~g} / \mathrm{t}$, flotation time $5 \mathrm{~min}$ [24]. The obtained copper concentrate and the original mine tailings were both used as feed samples in the subsequent leaching experiments.

Table 1. Chemical compositions of the mine tailings and concentrate.

\begin{tabular}{cccccc}
\hline & \multicolumn{5}{c}{ Grade (mass\%) } \\
\hline Elements & $\mathbf{C u}$ & Fe & Al & S & SiO $_{2}$ \\
\hline Mine tailings & 0.24 & 3.51 & 3.45 & 4.88 & 61.7 \\
Concentrate from mine tailings & 0.65 & 33.20 & 2.63 & 32.72 & 23.41 \\
\hline
\end{tabular}

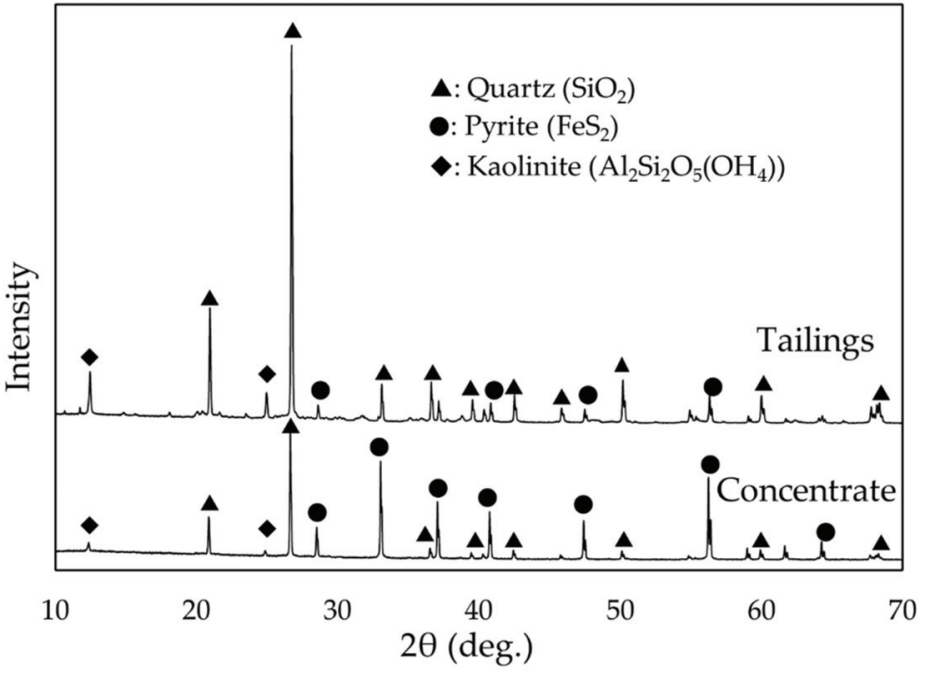

Figure 1. XRD patterns of mine tailings from Bor Copper Mine and concentrate of mine tailings. 


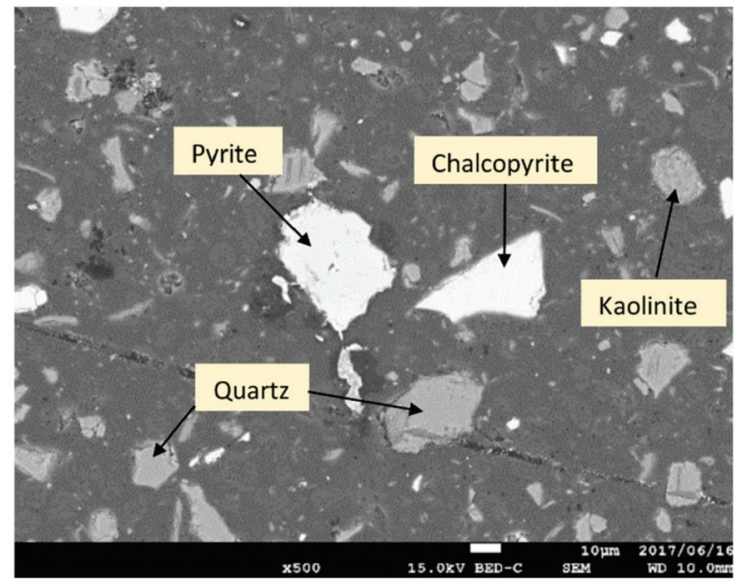

Figure 2. SEM image of the mine tailings from Bor Copper Mine.

\subsection{Experimental Procedure}

\subsubsection{High-Pressure Leaching}

An autoclave of a $200 \mathrm{~mL}$ Teflon beaker was used as a leaching reactor in the highpressure oxidative leaching experiment (Figure 3) for the mine tailings and concentrate from mine tailings. A sample weight of $10 \mathrm{~g}$ was mixed with $0-1.0 \mathrm{M}$ sulfuric acid $\left(\mathrm{H}_{2} \mathrm{SO}_{4}\right)$ solution, where $0 \mathrm{M}$ was distilled water, to obtain a pulp density of $100 \mathrm{~g} / \mathrm{L}$. The slurry was then placed inside the autoclave and heated. After the temperature reached $180{ }^{\circ} \mathrm{C}$, oxygen gas was injected at $2 \mathrm{MPa}$ into the slurry to provide an oxidative environment. The leaching duration was set to $1 \mathrm{~h}$. After the HPOL experiment, the sample was cooled and filtered to obtain a pregnant leach solution (PLS) and a solid residue, which were taken for chemical and mineralogical analysis using ICP-OES and XRD, respectively.

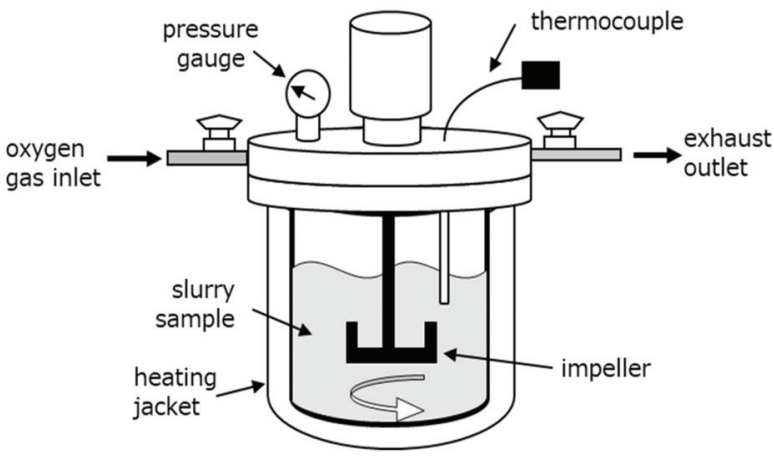

Figure 3. Illustrative setup of an autoclave reactor used for high-pressure oxidative acid leaching.

\subsubsection{Elution Test}

Elution properties of the mine tailings and the solid residue obtained after HPOL were evaluated. A sample weight of $0.4 \mathrm{~g}$ was placed in a sample tube (capacity: $5 \mathrm{~mL}$ ) together with $4 \mathrm{~mL}$ of different $\mathrm{pH}$ solutions ( $\mathrm{pH} 2$ (adjusted with $\mathrm{H}_{2} \mathrm{SO}_{4}$ ), $\mathrm{pH} 4$ (distilled water), and $\mathrm{pH} 7$ (adjusted with $\left.\mathrm{Ca}(\mathrm{OH})_{2}\right)$ ). The solutions were shaken for $6 \mathrm{~h}$ at $200 \mathrm{rpm}$, using a shaker (MMS-4020, EYELA). Afterward, the slurry was subjected to solid-liquid separation by centrifugation. Quantitative analysis of each metal in the solution was carried 
out using ICP-OES (SPS5500, SII nanotechnology). The elution rate was calculated as per Equation (2).

$$
\text { Elution rate }(\%)=\frac{C_{S} * V_{S}}{C_{R} * m_{R}} * 100
$$

where $C_{S}$ is the concentration of metal in the solution obtained from the elution test $(\mathrm{mg} / \mathrm{L})$, and $C_{R}$ is the concentration of metal in the sample (leach residue/mine tailings), $(\mathrm{mg} / \mathrm{kg}$ ). $V_{S}$ is the volume of solution $(\mathrm{L})$ and $m_{R}$ is the dry mass of the sample used $(\mathrm{kg})$.

\subsubsection{Solvent Extraction Test}

Extraction of copper from the PLS obtained after HPOL of the concentrate from mine tailings was previously carried out by Han et al. [23] using LIX-84I (2-hydroxy-5nonylace-tophenone oxime) extractant. Kerosene was used to dilute the extractant at a phase ratio of 1 . A $10 \mathrm{~mL}$ of the PLS and $2 \mathrm{~mL}$ of diluted extractant (organic/aqueous phase ratio $=0.2$ ) were placed in a plastic tube and the $\mathrm{pH}$ was adjusted to the desired value using a $1.0 \mathrm{M} \mathrm{NaOH}$ solution. The solution was mixed using an agitator at $600 \mathrm{rpm}$ and the extraction time was set to $15 \mathrm{~min}$. Afterward, the solution was centrifuged for $5 \mathrm{~min}$ at $4000 \mathrm{rpm}$ to ensure a rapid phase separation. To determine the metal extraction efficiency, the raffinate was analyzed using ICP-OES. The $\mathrm{Cu}$-loaded organic obtained from the optimal copper extraction conditions was subjected to stripping experiments where different sulfuric acid concentrations $(0.5,1.0$, and $1.5 \mathrm{M})$ were mixed with the $\mathrm{Cu}$-loaded organic (organic/aqueous phase ratio $=5$ ) at $600 \mathrm{rpm}$ and $15 \mathrm{~min}$ contacting time. The stripped solution was analyzed by ICP-OES for the determination of the stripping efficiency and copper concentration [23].

\subsubsection{Electrowinning Test}

Electrowinning of copper was carried out with a simulated solution prepared in consideration of the copper and ferric ion concentrations of the stripped solution from the solvent extraction stage ( $44.8 \mathrm{~g} / \mathrm{L} \mathrm{Cu}$ and $1.4 \mathrm{~g} / \mathrm{L} \mathrm{Fe})$ using distilled water, copper sulfate (II) pentahydrate $\left(\mathrm{CuSO}_{4} \cdot 5 \mathrm{H}_{2} \mathrm{O}\right)$ and iron (III) sulfate n-hydrate $\left(\mathrm{Fe}_{2}\left(\mathrm{SO}_{4}\right)_{3} \cdot \mathrm{nH}_{2} \mathrm{O}\right)$, where $\mathrm{n}$ was analyzed to be 6.33. The electrolyte also contained $170 \mathrm{~g} / \mathrm{L}$ of free $\mathrm{H}_{2} \mathrm{SO}_{4}$, and no additives were used. The electrolyte temperature was maintained at $40{ }^{\circ} \mathrm{C}$ with a bath heater and the volume of the electrolyte was $0.5 \mathrm{~L}$. The anode and cathode were made from a platinum plate of $1 \mathrm{~cm}^{2}$ surface area and mounted on epoxy resin with a conducting wire. The anode and cathode were positioned in a fixed mount facing each other, the distance between the electrodes was $3 \mathrm{~cm}$ and the mount was placed in the preheated electrolyte cell. A regulated DC power supply (Takasago, Ltd. GP025-5) was used, the operating current density was set at $250 \mathrm{~A} / \mathrm{m}^{2}$, and the electrolysis time was $4 \mathrm{~h}$. To further study the effects of metal concentration in the electrolyte, the copper and iron concentrations were varied between $25-45 \mathrm{~g} / \mathrm{L}$ and $0-1.5 \mathrm{~g} / \mathrm{L}$, respectively. The cathode was weighed before and after the electrolysis test to determine the weight of copper plated. The current efficiency was calculated as per Equation (3). The theoretical mass of the copper deposited was calculated using Equation (4):

$$
\begin{gathered}
\text { Current Efficiency, (C.E) }=\frac{\text { mass of } C \text { u deposited (actual) }}{\text { mass of } C \text { u deposited (theoretical) }} * 100 \\
\text { Cu deposited }(g)=\frac{m m * j * A * t}{n F}
\end{gathered}
$$

where $m m$ is the molar mass of copper, $j$ is the current density, $A$ is the electrode surface area, $t$ is the electrolysis time, $n$ is the number of electrons and $F$ is faradays constant. 


\section{Results and Discussion}

\subsection{High-Pressure Leaching}

\subsubsection{Leaching of Mine Tailing}

The effect of sulfuric acid concentration on direct pressure leaching of mine tailings was investigated using distilled water and $0.2-1.0 \mathrm{M} \mathrm{H}_{2} \mathrm{SO}_{4}$. Other leaching conditions were kept the same as in Han et.al [23] at a fixed pulp density of $100 \mathrm{~g} / \mathrm{L}$, total pressure of $2 \mathrm{MPa}$, leaching temperature of $180^{\circ} \mathrm{C}$, and leaching time of $1 \mathrm{~h}$. As shown in Figure 4, the highest achieved leaching rate of $\mathrm{Cu}$ was $98.72 \%$ when distilled water was used as a leaching medium, while the lowest achieved leaching rate of Fe was $16.31 \%$ at the same leaching conditions. The $\mathrm{Cu}$ and $\mathrm{Fe}$ concentrations in the leachate were $0.23 \mathrm{~g} / \mathrm{L}$ and $0.28 \mathrm{~g} / \mathrm{L}$, respectively. The high leaching rate of $\mathrm{Cu}$ can be attributed to the oxidation of pyrite which is one of the main minerals in the mine tailings. The pyrite was oxidized as per reaction 1 under a total pressure of $2 \mathrm{MPa}$ and leaching temperature of $180^{\circ} \mathrm{C}$, thus generating sulfuric acid $[7,9,25]$. This was verified by a decline in the $\mathrm{pH}$ value from 3.12 before leaching to 0.8 after leaching. The sulfuric acid generated by pyrite oxidation promoted the leaching of chalcopyrite via reaction 5. Han et al. [23] confirmed that the presence of pyrite $\left(\mathrm{FeS}_{2}\right)$ in the feed has an efficient effect on copper dissolution. Antonijevic et al. [7] also found that with the increasing concentration of $\mathrm{H}^{+}$ions in the leach solution, the dissolution of copper increased. Figure 5 shows the Eh-pH diagram, where the point indicates the $\mathrm{pH}$ and $\mathrm{Eh}(\mathrm{pH}: 0.8$, Eh: $676 \mathrm{mV}$ ) of the solution obtained after leaching. The stability of $\mathrm{Cu}^{2+}$ in solution is favored by the leaching conditions of a high temperature and high pressure thus enabling a high leaching rate. XRD measurement of the solid residue (Figure 6) showed the presence of hematite $\left(\mathrm{Fe}_{2} \mathrm{O}_{3}\right)$ and the absence of pyrite which was initially in the mine tailings. This indicates that the majority of ferric sulfate is hydrolyzed at a high temperature and total pressure to form hematite as shown by reaction 6 . The precipitation of $\mathrm{Fe}$ as hematite resulted in a high metal selectivity of dissolved copper over iron when only water was used as a leaching medium.

$$
\begin{gathered}
2 \mathrm{CuFeS}_{2}+\mathrm{H}_{2} \mathrm{SO}_{4}+8.5 \mathrm{O}_{2} \rightarrow 2 \mathrm{CuSO}_{4}+\mathrm{Fe}_{2}\left(\mathrm{SO}_{4}\right)_{3}+\mathrm{H}_{2} \mathrm{O} \\
\mathrm{Fe}_{2}\left(\mathrm{SO}_{4}\right)_{3}+3 \mathrm{H}_{2} \mathrm{O} \rightarrow \mathrm{Fe}_{2} \mathrm{O}_{3}+3 \mathrm{H}_{2} \mathrm{SO}_{4}
\end{gathered}
$$

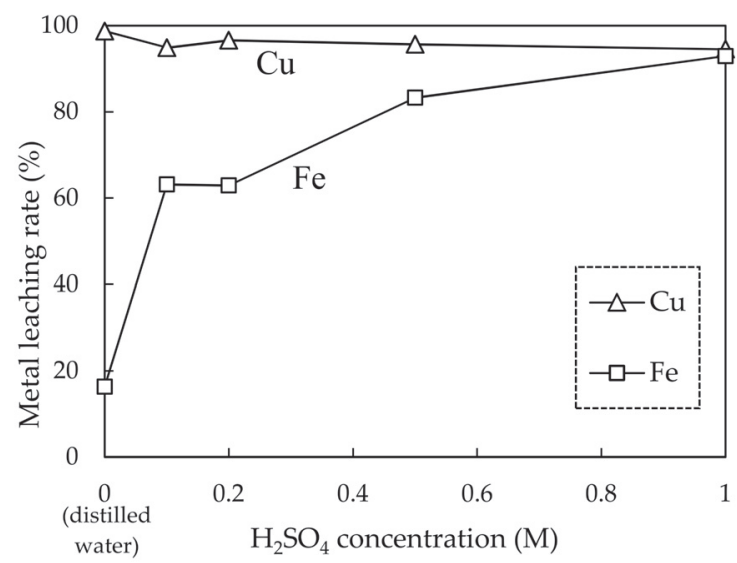

Figure 4. Effect of sulfuric acid concentration on the leaching rate of copper and iron. (Conditions: $100 \mathrm{~g} / \mathrm{L}, 1 \mathrm{~h}, 700 \mathrm{rpm}, 180^{\circ} \mathrm{C}, 2.0 \mathrm{MPa}$ total pressure). 


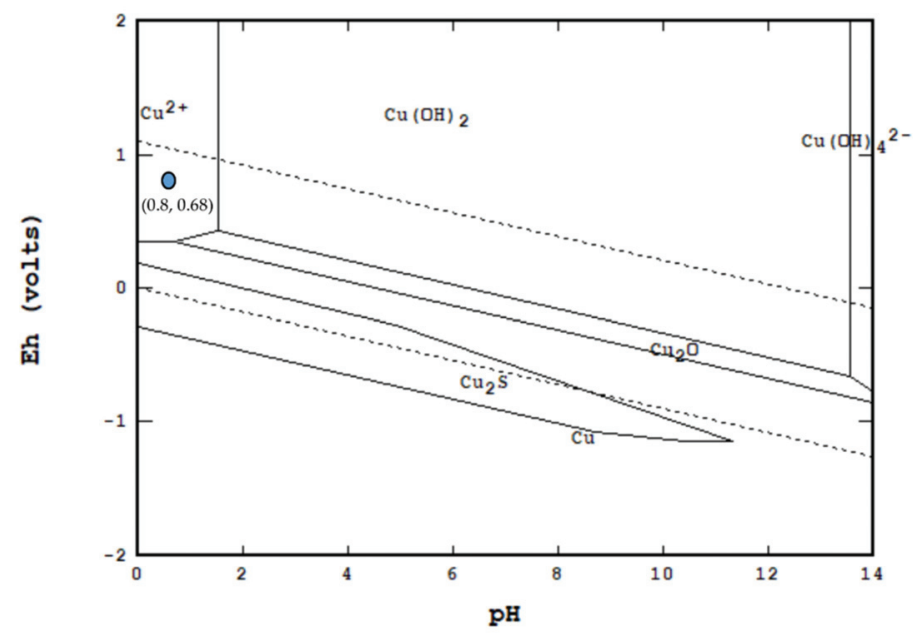

Figure 5. Eh-ph diagram for $\mathrm{Cu}-\mathrm{S}-$ water system calculated by STABCAL (Condition: $180{ }^{\circ} \mathrm{C}$, $2 \mathrm{MPa})$.

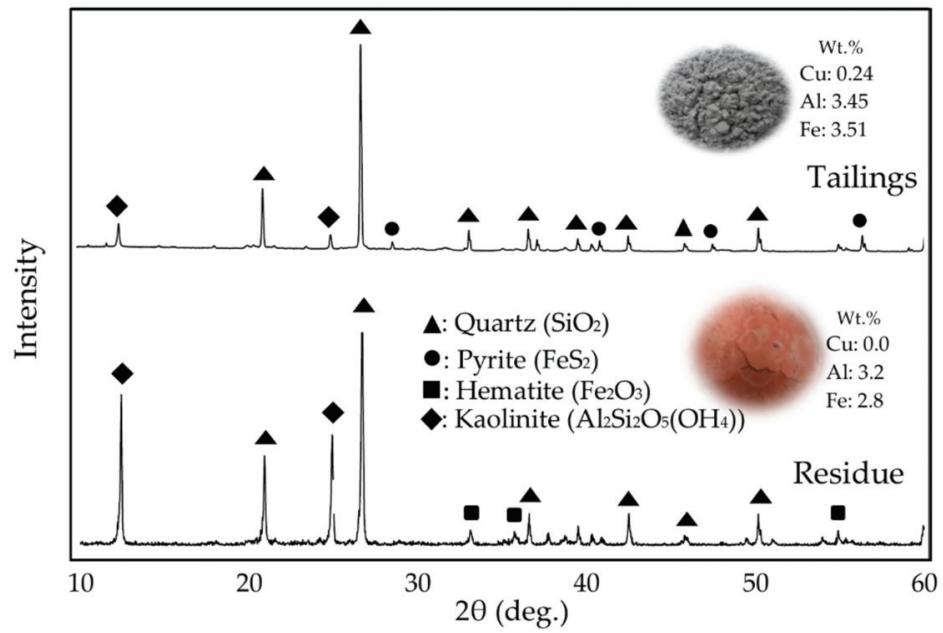

Figure 6. XRD patterns of the residue obtained after leaching of mine tailings with distilled water and the mine tailings.

\subsubsection{Elution Test of Leaching Residue Obtained from High-Pressure Leaching}

The elution test results are displayed in Figure 7a,b, showing copper and iron concentrations in the solution, respectively. The national effluent standards of copper and iron in Serbia could not be identified, therefore Japan was used for comparison of the results obtained from the elution test. Based on the wastewater discharge standards specified by the Ministry of the Environment in Japan the upper limit for $\mathrm{Cu}$ and $\mathrm{Fe}$ in the wastewater discharge is $3 \mathrm{mg} / \mathrm{L}$ and $10 \mathrm{mg} / \mathrm{L}$, respectively [26]. The concentration of copper in the solution of mine tailings exceeded this criterion at all the investigated $\mathrm{pH}$ values (Figure 7a), while the iron concentration in solution exceeded this criterion at a low $\mathrm{pH}$ value of 2 (Figure $7 \mathrm{~b}$ ). The elution rate of copper and iron from the mine tailings was calculated to be $4.58 \%$ and $0.46 \%$ respectively. On the other hand, the solid residue obtained from leaching the mine tailings could meet the regulatory metal criterion with 
a very low metal concentration below the detection limit $(<0.1 \mathrm{ppm})$ of ICP-EOS. Under various $\mathrm{pH}$ conditions, Fe did not elude, mainly because hematite is thermodynamically stable and therefore, less soluble. Furthermore, the elution rate of copper in the solid residue remained undetectable because $98.72 \%$ of copper has been recovered in the PLS. It can thus be confirmed that the elution rate of the mine tailings can be reduced by the HPL process, generating a benign solid residue of a reduced environmental loading.

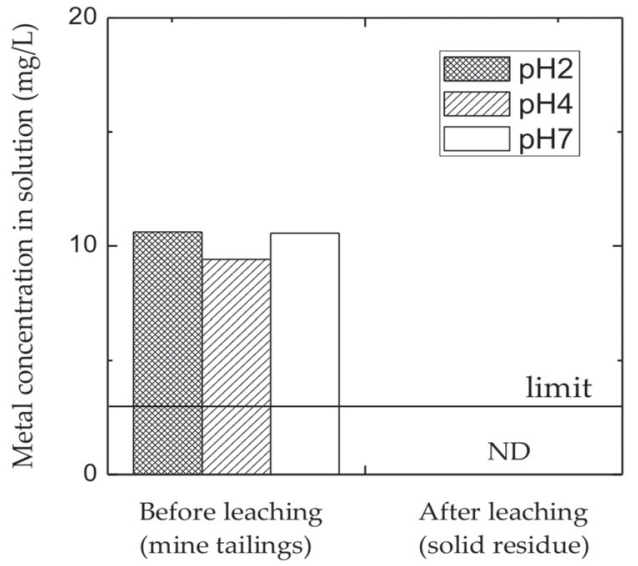

(a)

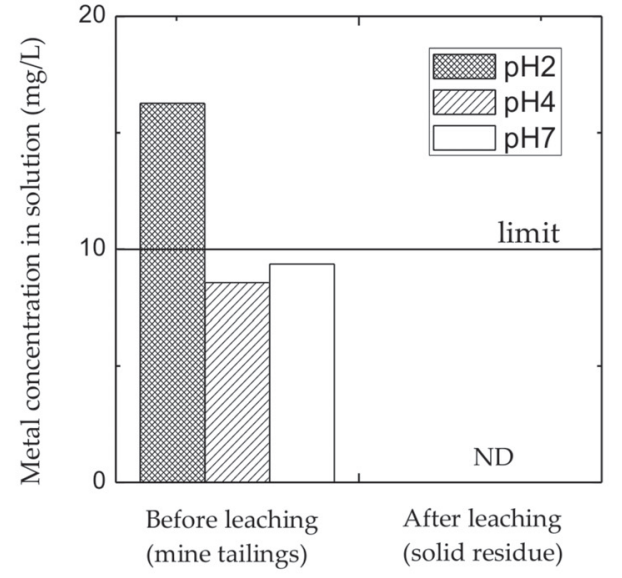

(b)

Figure 7. Metal concentration in the solution obtained from the elution test of mine tailings (before leaching) and solid residue (after leaching): (a) copper; (b) iron. ND = not detected.

\subsubsection{Leaching of Concentrate from Mine Tailings}

The grade of copper in mine tailings was upgraded from $0.24 \%$ to $0.65 \%$ through flotation. The concentrate was subjected to high-pressure leaching under the optimal conditions obtained from leaching the mine tailings (leaching medium distilled water, leaching time $1 \mathrm{~h}$ and total pressure $2 \mathrm{MPa}$ controlled by $\mathrm{O}_{2}$ gas, temperature $180^{\circ} \mathrm{C}$ ) [23]. To concentrate copper by solvent extraction and obtain a solution suitable for electrowinning, a higher copper concentration in the PLS than that obtained from high-pressure leaching of mine tailings $(0.23 \mathrm{~g} / \mathrm{L})$ is necessary. For this reason, the pulp density was adjusted to $400 \mathrm{~g} / \mathrm{L}$. Muravyov and Fomchenko [20], Antonijevic et al. [7], and Muravyov et al., [4] found that the pulp density has no significant effect on the leaching of metals from flotation tailings after obtaining similar values of dissolution degree with various pulp densities. Han et al. [23] achieved a high copper leaching rate of $94.4 \%$, showing no significant change when compared to the leaching rate of $\mathrm{Cu}$ from mine tailings $(98.72 \%)$ at a lower pulp density of $100 \mathrm{~g} / \mathrm{L}$. However, increasing the pulp density to $400 \mathrm{~g} / \mathrm{L}$ increased the leaching rate of iron up to $65.9 \%$. This is attributed to the increase in the added amount of pyrite, which resulted in an increase in free acid concentration in the solution and thus an increase in iron solubility [23]. The obtained PLS consisted of $2.9 \mathrm{~g} / \mathrm{L}$ of $\mathrm{Cu}$ and $102.9 \mathrm{~g} / \mathrm{L}$ of Fe with a $\mathrm{pH}$ of 0.23 . For further recovery of copper from the PLS, solvent extraction was carried out.

\subsection{Solvent Extraction of the Pregnant Leach Solution from $\mathrm{HPOL}$}

Han et al. [23] reported on the results of the extraction of copper from the PLS under the optimal HPOL conditions and extraction conditions stipulated in Section 2.2.3. Figure 8 was drawn based on the results obtained from Han et al. [23], which show that the extraction of copper increased from 10.1 to $93.7 \%$ as the $\mathrm{pH}$ was increased. However, the iron extraction rate remained below $11.3 \%$ yielding a good separation efficiency of $82.4 \%$ between copper 
and iron. The $\mathrm{pH}$ of 2.0 was established as an optimal $\mathrm{pH}$ for the selective extraction of copper from the PLS.

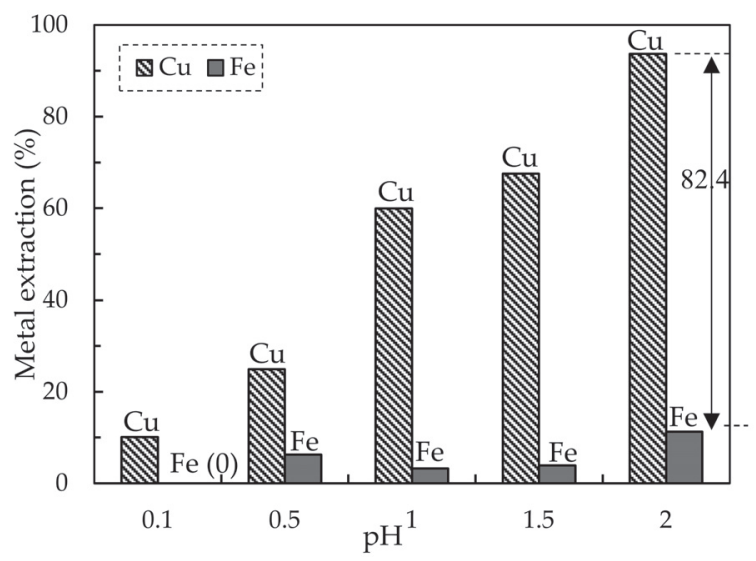

Figure 8. The extraction behavior of metals as a function of $\mathrm{pH}$ (Conditions: LIX-84I/Kerosene mixing ratio 1 , organic/aqueous phase ratio 0.2 , agitating speed $600 \mathrm{rpm}$, and contact time $15 \mathrm{~min}$ ).

Han et al. [23] also examined the stripping efficiency of copper from the $\mathrm{Cu}$-loaded organic phase using three different $\mathrm{H}_{2} \mathrm{SO}_{4}$ concentrations of $0.5,1.0$, and $1.5 \mathrm{M}$. The highest copper stripping efficiency of $97.4 \%$ was obtained at an $\mathrm{H}_{2} \mathrm{SO}_{4}$ concentration of $1.5 \mathrm{M}$ and was selected as the most suitable $\mathrm{H}_{2} \mathrm{SO}_{4}$ concentration for stripping copper from the $\mathrm{Cu}$-loaded organic phase. Figure 9 was prepared considering the data from Han et al. [23] of the metal concentrations in stripped solution as a function of $\mathrm{H}_{2} \mathrm{SO}_{4}$ concentration. As the $\mathrm{H}_{2} \mathrm{SO}_{4}$ concentration was increased, the copper concentration in the stripped solution increased while the iron concentration decreased. The optimal stripped solution contained approximately $44.8 \mathrm{~g} / \mathrm{L}$ copper and $1.4 \mathrm{~g} / \mathrm{L}$ iron [23]. This is comparable to the industrial electrolyte from the solvent extraction stage which typically contains $45 \mathrm{~g} / \mathrm{L} \mathrm{Cu}$ and less than $2.0 \mathrm{~g} / \mathrm{L}$ of Fe concentration [3] (p. 356).

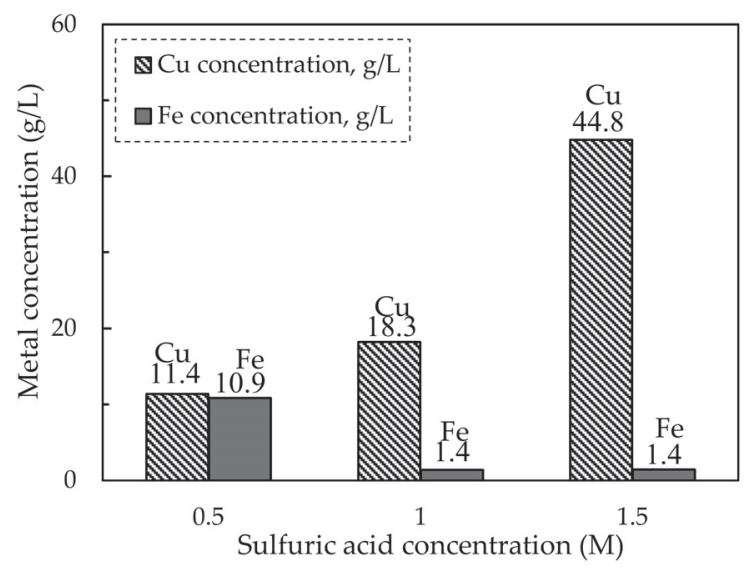

Figure 9. The metal concentration in stripped solution as a function of sulfuric acid concentration. (Conditions: organic/aqueous phase ratio 5, agitation speed $600 \mathrm{rpm}$, and contact time $15 \mathrm{~min}$ ). 


\subsection{Electrowinning of the Simulated Stripped Solution}

Current efficiency is an important parameter in electrowinning as it indicates the effectiveness of the electrowinning process. Ferric ion concentration is known to have negative interactions that significantly affect the current efficiency of copper electrodeposition during electrowinning. Therefore, to evaluate the efficiency of carrying out the electrowinning process on the obtained stripped copper solution, it is relevant to examine the current efficiency of the electrowinning process due to the inevitable Fe contamination during leaching. Figure 10 shows the influence of ferric ion concentration on the current efficiency of copper electrodeposition. As expected, a strong inverse relationship is observed, as the ferric ion concentration increases, the current efficiency of copper electrodeposition decreases. This is due to the presence of iron in the copper electrolyte which undergoes reduction from $\mathrm{Fe}^{3+}$ to $\mathrm{Fe}^{2+}$ at the cathode and re-oxidation to $\mathrm{Fe}^{3+}$ from $\mathrm{Fe}^{2+}$ at the anode. The cycle proceeds and consumes power that could be used for the deposition of copper. Considering the obtained Fe concentration of $1.4 \mathrm{~g} / \mathrm{L}$ in the stripped solution, the expected current efficiency is approximately $95 \%$, which is in the upper limit of the industrial range of $85-95 \%$ [3] (p. 358). Current efficiency loss was determined to be $2.8 \%$ per g/L of ferric ions, which agrees with Khouraibchia and Moats [27] 's empirical model of current efficiency (Equation (7)) and Schlesinger et al., [3] (p. 361)'s findings that current efficiency drops by approximately $2.5 \%$ for each addition of $1 \mathrm{~g} / \mathrm{L}$ of ferric ions.

$$
\begin{aligned}
\text { Current efficiency } & \text { (Khouraibchia and Moats's empirical model }) \\
& =88.19-4.19 *\left[\mathrm{Fe}^{3+}\right](\mathrm{g} / \mathrm{L})+0.52 *\left[\mathrm{Cu}^{2+}\right](\mathrm{g} / \mathrm{L}) \\
& +1.81 * 10^{-3} * \mathrm{j}\left(\mathrm{A} / \mathrm{m}^{2}\right)-6.83 * 10^{-3} *\left[\mathrm{Cu}^{2+}\right]^{2}(\mathrm{~g} / \mathrm{L}) \\
& +0.028 *\left[\mathrm{Fe}^{3+}\right](\mathrm{g} / \mathrm{L}) *\left[\mathrm{Cu}^{2+}\right](\mathrm{g} / \mathrm{L})+4.015 * 10^{-3} \\
& *\left[\mathrm{Fe}^{3+}\right](\mathrm{g} / \mathrm{L}) * \mathrm{j}\left(\mathrm{A} / \mathrm{m}^{2}\right)
\end{aligned}
$$

where $\mathrm{j}$ is the current density.

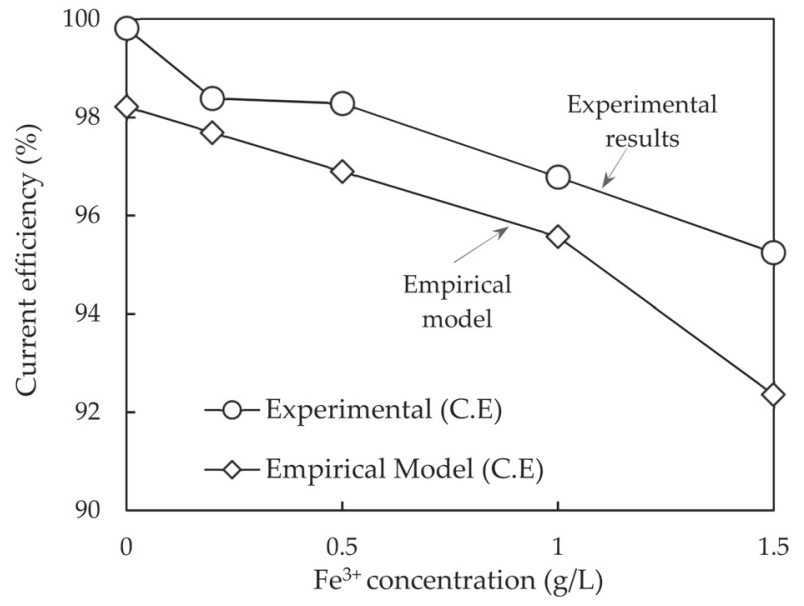

Figure 10. Effect of $\mathrm{Fe}^{3+}$ on current efficiency (C.E) of copper deposition. (Conditions: current density $250 \mathrm{~A} / \mathrm{m}^{2}$, temperature $40^{\circ} \mathrm{C}$, electrolysis time $4 \mathrm{~h}, \mathrm{Cu}^{2+}$ concentration $45 \mathrm{~g} / \mathrm{L}$ ).

Alongside the targeting of a low Fe concentration in the stripped solution, enriching copper concentration was also an important factor during the extraction process. To demonstrate the importance of obtaining a high $\mathrm{Cu}^{2+}$ concentration in the stripped solution, the effect of three copper concentrations $(25,35$, and $45 \mathrm{~g} / \mathrm{L})$ on current efficiency during electrowinning was investigated. The $\mathrm{Fe}^{3+}$ concentration in the electrolyte was varied from 
0 to $1.5 \mathrm{~g} / \mathrm{L}$ for each copper concentration investigated. Figure 11 displays the results obtained, showing that current efficiency losses are higher on dilute copper solutions than on concentrated copper solutions. From the gradients of the three plots, current efficiency loss per $\mathrm{g} / \mathrm{L}$ of $\mathrm{Fe}^{3+}$ was determined and is shown in Table 2. A solution of $45 \mathrm{~g} / \mathrm{L}$ copper concentration had the lowest current efficiency loss. This could be explained by the way that a high $\mathrm{Cu}^{2+}$ concentration in the electrolyte constantly provides sufficient copper ions to the cathode surface, thus improving deposition rate as well as the copper current efficiency [28]. Das and Krishna [29] also wrote that increasing the bath $\mathrm{Cu}^{2+}$ concentration increases the electrolyte viscosity, which impedes the distribution of $\mathrm{Fe}^{3+}$ over the cathode surface. Therefore, in this investigation, obtaining a high copper concentration of $44.8 \mathrm{~g} / \mathrm{L}$ significantly contributed to achieving a good current efficiency of about $95 \%$.

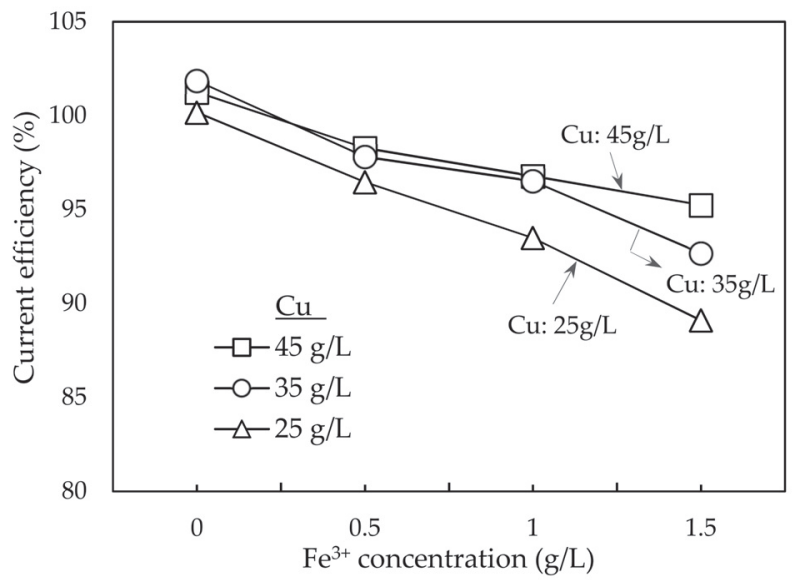

Figure 11. Effect of $\mathrm{Fe}^{3+}$ and $\mathrm{Cu}^{2+}$ concentration on $\mathrm{Cu}$ current efficiency. (Conditions: current density $250 \mathrm{~A} / \mathrm{m}^{2}$, temperature $40^{\circ} \mathrm{C}$, electrolysis time $4 \mathrm{~h}$ ).

Table 2. The effect of copper concentration on current efficiency loss per $\mathrm{g} / \mathrm{L}$ of Fe after the electrowinning experiments.

\begin{tabular}{cc}
\hline $\mathrm{Cu}^{2+}$ Concentration $(\mathrm{g} / \mathrm{L})$ & Current Efficiency \\
\hline 25 & 3.62 \\
35 & 2.88 \\
45 & 1.95 \\
\hline
\end{tabular}

In hydrometallurgical processes like these, where pyrite is vital to the leaching stage, an Fe contamination in the stripped solution is inevitable. Therefore, obtaining a high copper concentration in the stripped solution is important as it is less susceptible to current efficiency losses during electrowinning. Since the electrowinning experiments were conducted using synthetic solutions, the expected current efficiency on the real solution obtained from solvent extraction may be slightly lower than that obtained when utilizing a synthetic solution. This is due to the complexity of the stripped solution composition because of several other impurities that may cause side reactions. However, current efficiency loss due to ferric ions reduction has been found to have a significant effect on current efficiency compared to other impurities which showed no effect [30]. Therefore, the results obtained from the electrowinning of a simulated solution can be highly comparable to those obtained from electrowinning the real stripped solution under optimized conditions. 


\section{Conclusions}

This study demonstrated that leaching mine tailings could alleviate the possible environmental effects they can pose if left untreated, while simultaneously valorizing them. As an AMD preventative technique, the removal of pyrite from mine tailings through oxidative high-pressure leaching was successively achieved, resulting in the formation of hematite in the solid residue. The obtained residue from leaching the mine tailings, and the original sample of the mine tailings, were subjected to standardized elution tests. The eluded metal concentrations for the solid residue could meet the Ministry of the Environment of Japan's set limits for copper and iron in the wastewater discharge, while the original mine tailings exceeded the set limits, thus confirming the reduced environmental loading of the proposed copper recovery process.

A viable copper recovery process for re-treatment of mine tailings was developed by employing hydrometallurgical methods of high-pressure leaching, solvent extraction, and electrowinning. During high-pressure leaching, the generation of sulfuric acid due to pyrite oxidation promoted copper leaching kinetics when water was used as a leaching medium, thus yielding a high copper leaching rate of $94.4 \%$. Under the optimized solvent extraction conditions, over $93.7 \%$ of copper was extracted from the PLS while most of the iron was left in the organic phase. A high copper stripping efficiency of $97.4 \%$ was obtained resulting in an enriched solution containing $44.8 \mathrm{~g} / \mathrm{L} \mathrm{Cu}$ and $1.4 \mathrm{~g} / \mathrm{L} \mathrm{Fe}$. Due to a minimized iron carryover from the stripped solution, electrowinning power consumption by iron was greatly reduced and current efficiency for copper electrodeposition was over $95 \%$.

Author Contributions: Conceptualization, K.H., Y.T., V.T., L.A., Z.S. and A.S.; data curation, L.L.G. and B.A.; formal analysis, L.L.G., K.H., Y.T., D.I., V.T. and A.S.; investigation, L.L.G., K.H., Y.T., V.T. and L.A.; methodology, L.L.G., K.H., Y.T., V.T., L.A., R.J., Z.S. and A.S.; project administration, R.J., Z.S. and A.S.; resources, V.T., L.A., R.J. and Z.S.; supervision, Z.S. and A.S.; validation, D.I.; visualization, K.H.; writing—original draft, L.L.G.; writing—review \& editing, L.L.G., K.H., B.A., Y.T., D.I., V.T., L.A., R.J., Z.S. and A.S. All authors have read and agreed to the published version of the manuscript.

Funding: This research was supported by the Leading Program "New Frontier Leader Program for Rare Metals and Resources", the Science and Technology Research Partnership for Sustainable Development (SATREPS), Japan Science and Technology Agency (JST)/Japan International Cooperation Agency (JICA). And the experiments were supported by Akita University Support for Fostering Research Project. The authors greatly acknowledge their financial support.

Institutional Review Board Statement: Not applicable.

Informed Consent Statement: Not applicable.

Data Availability Statement: The data presented in this study are available on request from the corresponding authors.

Conflicts of Interest: The authors declare no conflict of interest. The funders had no role in the design of the study; in the collection, analyses, or interpretation of data; in the writing of the manuscript, or in the decision to publish the results.

\section{References}

1. Vriens, B.; Plante, B.; Seigneur, N.; Jamieson, H. Mine Waste Rock: Insights for Sustainable Hydrogeochemical Management. Minerals 2020, 10, 728. [CrossRef]

2. Tayebi-Khorami, M.; Edraki, M.; Corder, G.; Golev, A. Re-Thinking Mining Waste Through an Integrative Approach Led by Circular Economy Aspirations. Minerals 2019, 9, 286. [CrossRef]

3. Schlesinger, M.E.; King, M.J.; Sole, K.C.; Davenport, W.G. Extractive Metallurgy of Copper, 5th ed.; Elsevier: London, UK, 2011; pp. $68,356,358$ and 361.

4. Muravyov, M.I; Bulaev, A.G.; Kondrat'eva, T.F. Complex treatment of mining and metallurgical wastes for recovery of base metals. Miner. Eng. 2014, 64, 63-66. [CrossRef]

5. Park, I.; Tabelin, C.B.; Jeon, S.; Li, X.; Seno, K.; Ito, M.; Hiroyoshi, N. A review of recent strategies for acid mine drainage prevention and mine tailings recycling. Chemosphere 2019, 219, 588-606. [CrossRef] [PubMed] 
6. Chen, T.; Lei, C.; Yana, B.; Xiao, X. Metal recovery from the copper sulfide tailing with leaching and fractional precipitation technology. Hydrometallurgy 2014, 147, 178-182. [CrossRef]

7. Antonijevi'c, M.M.; Dimitrijevi'c, M.D.; Stevanovi'c, Z.O.; Serbula, S.M.; Bogdanovic, G.D. Investigation of the possibility of copper recovery from the flotation tailings by acid leaching. J. Hazard. Mater. 2008, 158, 23-34. [CrossRef]

8. Huang, Z.; Jiang, L.; Wu, P.; Dang, Z.; Zhu, N.; Liu, Z.; Luo, H. Leaching characteristics of heavy metals in tailings and their simultaneous immobilization with triethylenetetramine functioned montmorillonite (TETA-Mt) against simulated acid rain Environ. Pollut. 2020, 266, 115236. [CrossRef]

9. Li, X.; Gao, M.; Hiroyoshi, N.; Tabelin, C.B.; Taketsugu, T.; Ito, M. Suppression of pyrite oxidation by ferric-catecholate complexes: An electrochemical study. Miner. Eng. 2019, 138, 226-237. [CrossRef]

10. Alam, R.; Shang, J.Q. Effect of operating parameters on desulphurization of mine tailings by froth flotation. J. Environ. Manag. 2012, 97, 122-130. [CrossRef]

11. Guo, Y.; Huang, P.; Zhang, W.; Yuan, X.; Fan, F.; Wang, H.; Liu, J.; Wang, Z. Leaching of heavy metals from Dexing copper mine tailings pond. Trans. Nonferrous Met. Soc. China 2013, 23, 3068-3075. [CrossRef]

12. Ahmadi, A.; Khezri, M.; Abdollahzadeh, A.A.; Askari, M. Bioleaching of copper, nickel and cobalt from the low grade sulfidic tailing of Golgohar Iron Mine, Iran. Hydrometallurgy 2015, 154, 1-8. [CrossRef]

13. Figueiredo, J.; Vila, M.C.; Matos, K.; Martins, D.; Futuro, A.; Dinis, M.; Góis, J.; Leite, A.; Fiúz, A. Tailings reprocessing from Cabeço do Pião dam in Central Portugal: A kinetic approach of experimental data. J. Sustain. Min. 2018, 17, 139-144. [CrossRef]

14. Lü, C.; Wang, Y.; Qian, P.; Liu, Y.; Fu, G.; Ding, J.; Ye, S.; Chen, Y. Separation of chalcopyrite and pyrite from a copper tailing by ammonium humate. Chin. J. Chem. Eng. 2018, 26, 1814-1821. [CrossRef]

15. Mäkinen, J.; Salo, M.; Khoshkhoo, M.; Sundkvist, J.; Kinnunena, P. Bioleaching of cobalt from sulfide mining tailings; a mini-pilot study. Hydrometallurgy 2020, 196, 105418. [CrossRef]

16. Falagán, C.; Grail, B.M.; Johnson, D.B. New approaches for extracting and recovering metals from mine tailings. Miner. Eng. 2017, 106, 71-78. [CrossRef]

17. Kondrat'eva, T.F.; Pivovarova, T.A.; Bulaev, A.G.; Melamud, V.S.; Muravyov, M.I.; Usoltsev, A.V.; Vasil'ev, E.A. Percolation bioleaching of copper and zinc and gold recovery from flotation tailings of the sulfide complex ores of the Ural region, Russia. Hydrometallurgy 2012, 111, 82-86. [CrossRef]

18. Lutandula, M.S.; Maloba, B. Recovery of cobalt and copper through reprocessing of tailings from flotation of oxidized ores. J. Environ. Chem. Eng. 2013, 1, 1085-1090. [CrossRef]

19. Urosevic, D.M.; Dimitrijevic, M.D.; Jankovic, Z.D.; Antic, D.V. Recovery of Copper from Copper Slag and Copper Slag Flotation Tailings by Oxidative Leaching. Physicochem. Probl. Miner. Process. 2015, 51, 73-82. [CrossRef]

20. Muravyov, M.I.; Fomchenko, N.V. Biohydrometallurgical treatment of old flotation tailings of sulfide ores containing nonnonferrous metals and gold. Miner. Eng. 2018, 122, 267-276. [CrossRef]

21. Turan, M.D.; Orhan, R.; Turan, M.; Nizamoğlu, H. Use of Ammonia Salts in Selective Copper Extraction from Tailings. Min. Metall. Explor. 2020, 37, 1349-1356. [CrossRef]

22. Stopić, R.S.; Friedrich, B.G. Pressure hydrometallurgy: A new chance to non-polluting processes. Mil. Tech. Cour. 2011, 59, 29-44. [CrossRef]

23. Han, B.; Altansukh, B.; Haga, K.; Stevanović, Z.; Jonović, R.; Avramović, L.; Urosević, D.; Takasaki, Y.; Masuda, N.; Ishiyama, D.; et al. Development of copper recovery process from flotation tailings by a combined method of high-pressure leaching-solvent extraction. J. Hazard. Mater. 2018, 352, 192-203. [CrossRef]

24. Han, B.; Altansukh, B.; Haga, K.; Stevanovi 'c, Z.; Radojka, J.; Markovic, R.; Avramovic, L.; Obradovic, L.; Takasaki, Y.; Masuda, N.; et al. Copper upgrading and recovery process from mine tailing of Bor region, Serbia using flotation. Soc. Mater. Eng. Resour. Jpn. 2014, 20, 225-229. [CrossRef]

25. McDonald, R.G.; Muir, D.M. Pressure oxidation leaching of chalcopyrite. Part, I. Comparison of high and low temperature reaction kinetics and products. Hydrometallurgy 2007, 86, 191-205. [CrossRef]

26. Ministry of the Environment, Government of Japan. Uniform National Effluent Standards (Last Update: 21 October 2015). Available online: https://www.env.go.jp/en/water/wq/nes.html (accessed on 30 March 2021).

27. Khouraibchia, Y.; Moats, M. Evaluation of copper electrowinning parameters on current efficiency and energy consumption using surface response methodology. In Proceedings of the 217th ECS Meeting, Vancouver, BC, Canada, 25-30 April 2010.

28. Owais, A. Effect of electrolyte characteristics on electrowinning of copper powder. J. Appl. Electrochem. 2009, 39, 1587-1595. [CrossRef]

29. Das, S.C.; Gopala Krishna, P. Effect of Fe (III) during copper electrowinning at higher current density. Int. J. Miner. Process. 1996, 46, 91-105. [CrossRef]

30. Moats, M. How to evaluate current efficiency in copper electrowinning. In Separation Technologies for Minerals, Coal, and Earth Resources; Young, C.A., Luttrell, G.H., Eds.; Society for Mining, Metallurgy, and Exploration, Inc. (SME): Englewood, CO, USA, 2012; pp. 333-339. 



\title{
The Effects of Coexisting Copper, Iron, Cobalt, Nickel, and Zinc Ions on Gold Recovery by Enhanced Cementation via Galvanic Interactions between Zero-Valent Aluminum and Activated Carbon in Ammonium Thiosulfate Systems
}

\author{
Sanghee Jeon ${ }^{1, *}$, Sharrydon Bright ${ }^{2}$, Ilhwan Park ${ }^{1}$, Carlito Baltazar Tabelin ${ }^{3}$, Mayumi Ito ${ }^{1}$ \\ and Naoki Hiroyoshi ${ }^{1, *}$ \\ 1 Division of Sustainable Resource Engineering, Faculty of Engineering, Hokkaido University, \\ Sapporo 060-8628, Japan; i-park@eng.hokudai.ac.jp (I.P.); itomayu@eng.hokudai.ac.jp (M.I.) \\ 2 Department of Mining, Chemical and Metallurgical Engineering, Faculty of Engineering, \\ University of Zimbabwe, Harare 00263, Zimbabwe; sharrydonbright@frontier.hokudai.ac.jp \\ 3 School of Minerals and Energy Resource Engineering, The University of New South Wales, \\ Sydney, NSW 2052, Australia; c.tabelin@unsw.edu.au \\ * Correspondence: shjun1121@eng.hokudai.ac.jp (S.J.); hiroyoshi@eng.hokudai.ac.jp (N.H.); \\ Tel.: +81-11-706-6918 (S.J.)
}

Citation: Jeon, S.; Bright, S.; Park, I.; Tabelin, C.B.; Ito, M.; Hiroyoshi, N The Effects of Coexisting Copper, Iron, Cobalt, Nickel, and Zinc Ions on Gold Recovery by Enhanced

Cementation via Galvanic

Interactions between Zero-Valent Aluminum and Activated Carbon in Ammonium Thiosulfate Systems. Metals 2021, 11, 1352. https:// doi.org/10.3390/met11091352

Academic Editor: Felix A. Lopez

Received: 30 July 2021

Accepted: 25 August 2021

Published: 27 August 2021

Publisher's Note: MDPI stays neutral with regard to jurisdictional claims in published maps and institutional affiliations.

Copyright: (C) 2021 by the authors Licensee MDPI, Basel, Switzerland. This article is an open access article distributed under the terms and conditions of the Creative Commons Attribution (CC BY) license (https:// creativecommons.org/licenses/by/ $4.0 /)$.

\begin{abstract}
The use of galvanic interactions between zero-valent aluminum (ZVAl) and activated carbon $(\mathrm{AC})$ to recover gold $(\mathrm{Au})$ ions is a promising technique to overcome the challenges due to the poor recovery in ammonium thiosulfate systems, but the applicability to practical Au ore processing remains elusive so far. The present study describes (1) the recovery of Au ions from low Au concentrations, which are typical concentrations used in Au ore processing; and (2) an investigation into the effects of various coexisting base metal ions that can be present in pregnant ore-leached solutions. The results showed that high Au recovery (i.e., over $85 \%$ ) was obtained even at low Au concentrations under the following conditions: 1:1 of $0.15 \mathrm{~g}$ of $\mathrm{ZVAl}$ and $\mathrm{AC}$ with $10 \mathrm{~mL}$ of ammonium thiosulfate solution containing $5 \mathrm{mg} / \mathrm{L}$ of Au ions at $25^{\circ} \mathrm{C}$ for $1 \mathrm{~h} \mathrm{in}$ an anoxic atmosphere. Selected coexisting metal ions (i.e., copper, iron, cobalt, nickel, and zinc) were studied to establish their effects on Au recovery, and the results showed that the Au recovery was enhanced (about $90 \%$ ) when copper ions coexist in the solution with minimal effects from other competing base metal ions.
\end{abstract}

Keywords: ammonium thiosulfate; gold; cementation; galvanic interaction; zero-valent aluminum; activated carbon

\section{Introduction}

Changing international regulations, consumer perceptions, and investor expectations in recent years have pushed for more sustainable and eco-friendly mineral processing and metal extraction technologies [1,2]. In gold (Au) hydrometallurgy, cyanide-based technologies such as carbon-in-pulp (CIP) and carbon-in-leach (CIL) remain widely used in both medium- and large-scale Au mining operations [3]. Unfortunately, cyanide is a very toxic compound that poses serious environmental and health hazards when improperly handled and disposed of, so its use is strictly controlled and prohibited in many countries [1,4].

Among the many alternative methods for Au extraction, copper $(\mathrm{Cu})$-catalyzed ammonium thiosulfate leaching is one of the most promising because it uses lixiviants that are non-toxic and less corrosive (Equation (1)) [4,5].

$$
\mathrm{Au}+5 \mathrm{~S}_{2} \mathrm{O}_{3}{ }^{2-}+\mathrm{Cu}\left(\mathrm{NH}_{3}\right)_{4}{ }^{2+} \rightarrow \mathrm{Au}\left(\mathrm{S}_{2} \mathrm{O}_{3}\right)_{2}{ }^{3-}+4 \mathrm{NH}_{3}+\mathrm{Cu}\left(\mathrm{S}_{2} \mathrm{O}_{3}\right)_{3}{ }^{5-}
$$


Furthermore, this approach is effective for the treatment of secondary resources such as e-wastes that contain various types of materials such as plastics, resins, and ferrous, base, and precious metal alloys. Ha et al. [6], for example, reported that over $98 \%$ of Au was leached from waste mobile phones. Similarly, Jeon et al. [7] successfully leached 99\% of Au from the printed circuit boards (PCBs) of waste mobile phones under the following conditions: $1 \mathrm{M}$ of thiosulfate, $1 \mathrm{M}$ of ammonia/ammonium, and $10 \mathrm{mM}$ of $\mathrm{Cu}$ ions for $24 \mathrm{~h}$ at $25^{\circ} \mathrm{C}$. Another potential application of $\mathrm{Cu}$-catalyzed ammonium thiosulfate leaching is in the treatment of carbonaceous-type and pyritic Au ores that are unsuitable for cyanidebased methods with the absence of preg-robbing. As a result, remarkable leaching studies for Au ores also have been reported as follows: Molleman and Dreisinger [8] extracted about $84 \%$ of $\mathrm{Au}$ from pyritic Au concentrate after $24 \mathrm{~h}$ using this method, while Ficeriova et al. [9] dissolved 99\% of Au within 45 min with complex sulfide concentrates. Despite these promising results, applications of $\mathrm{Cu}$-catalyzed ammonium thiosulfate leaching in industrial-scale plants remain limited to date because an acceptable method for Au ion recovery from pregnant leach liquors/solutions remains elusive $[4,7]$.

Conventional CIP and CIL technologies employ activated carbon (AC) to recover Au ions from pregnant leach solutions, an approach that is simple and highly efficient $[1,10]$. Although activated carbon is very efficient when used with cyanide, it is ineffective when thiosulfate is employed because of the low adsorption affinity of the larger, more negative $\mathrm{Au}$ thiosulfate complex adsorption to the AC [1]. According to Navarro et al. [11], Au recovery by $\mathrm{AC}$ adsorption from an ammonium thiosulfate medium was only about $50 \%$ after $8 \mathrm{~h}$. Cementation (reductive precipitation), an electrochemical process whereby Au ions are reduced to metallic Au by reductants, is also a well-established recovery technique for cyanide-based technologies. Metal reductants or cementation agents such as zerovalent base metals (e.g., copper $(\mathrm{Cu})$, zinc $(\mathrm{Zn})$, aluminum $(\mathrm{Al})$, and iron $(\mathrm{Fe})$ ) are often used. In ammonium thiosulfate, however, cementation of $\mathrm{Au}$ ions is difficult because of various unwanted side reactions [7,12-15]: (1) reduction of $\mathrm{Cu}$ ions employed as a catalyst; (2) dissolution of the cementation agents, which leads to high reagent consumption; and (3) formation of oxide/sulfide layers on cementation agents that inhibit Au recovery. Furthermore, abundant sulfur and $\mathrm{Cu}$ ions present in the solution restrict the application of solvent extraction and electrowinning for Au ion recovery [1,15].

In our previous study, a novel recovery technique that uses synergistic interactions between zero-valent aluminum ( $\mathrm{ZVAl}$ ) and $\mathrm{AC}$ for enhanced Au recovery in the ammonium thiosulfate system was developed [15]. The results showed that ZVAl or AC alone could not recover $\mathrm{Au}$ ions, consistent with the results of many previous studies. When mixed, however, over $99 \%$ of $\mathrm{Au}$ ions could be recovered through the following mechanisms: (i) ZVAl acts as an electron donor while AC as an electron mediator to an Au thiosulfate complex; and (ii) making a galvanic cell, which finally leads to enhanced Au recovery [15] Although the previous study established a high recovery of Au ions from ammonium thiosulfate solutions, this was obtained in a model solution, which contains only a high concentration of Au ions. This means that the applicability of this technique to real Au ore processing and/or e-waste recycling with a low Au ion concentration and coexisting metal ions remains untested.

The present study aims to assess the applicability of this simple and highly efficient novel recovery technique (ZVAl-AC recovery technique) to real Au ore processing. The objectives of this paper are specifically as follows: (a) to recover Au from the solution with less than $10 \mathrm{mg} / \mathrm{L} \mathrm{Au}$, and (b) to investigate the effects of various coexisting metal ions on Au recovery. The previous study on Au ion recovery by the ZVAl-AC technique obtained high Au recovery (i.e., 99\%) from the solutions but contained a $100 \mathrm{mg} / \mathrm{L}$ concentration of $\mathrm{Au}$ ions, which is much higher than the typical Au concentration in ores. There are surely mines containing high Au concentrations such as $150 \mathrm{~g} / \mathrm{t}$ in Australia [16], $94 \mathrm{~g} / \mathrm{t}$ in Korea [17], and $60 \mathrm{~g} / \mathrm{t}$ in China [18], but those mines with high Au contents have been actively explored; hence, currently operating/investigating mines mainly deal with refractory or complex ores with relatively low Au concentrations such as $6 \mathrm{~g} / \mathrm{t}$ in Laos [19], 
$6.2 \mathrm{~g} / \mathrm{t}$ in China [20], $6.2 \mathrm{~g} / \mathrm{t}$ in Iran [21], or $11.2 \mathrm{~g} / \mathrm{t}$ in Ghana [22]. Furthermore, Au ore contains minerals such as pyrite, arsenopyrite, chalcopyrite, and/or malachite in which various elements (e.g., $\mathrm{Cu}, \mathrm{Fe}, \mathrm{Co}, \mathrm{Ni}$, and $\mathrm{Zn}$ ) are incorporated [23-28]. Once these elements are dissolved in the solution, they can affect Au recovery by competing and/or co-depositing with Au during the recovery process. Thus, identification of Au recovery mechanisms in solutions with low Au concentrations and coexisting metal ions will be essential in the industrial-scale application of ammonium thiosulfate leaching.

The first objective was achieved by batch-type experiments in ammonium thiosulfate solution containing only $\mathrm{Au}$ ions (i.e., Au-thiosulfate solution) at low concentrations (i.e., 5 and $10 \mathrm{mg} / \mathrm{L}$ ), while for the second objective, different concentrations of coexisting metal ions (i.e., $\mathrm{Cu}, \mathrm{Fe}, \mathrm{Co}, \mathrm{Ni}$, or $\mathrm{Zn}$ ions) were added to the Au-thiosulfate solutions with and without $\mathrm{Cu}$ ions. The residues were also observed using a scanning electron microscope with energy dispersive $\mathrm{X}$-ray spectroscopy. This study provides a bridge for the application of this simple, highly efficient recovery technique, which has remained in model testing for $\mathrm{Au}$ ore processing, and will be helpful for researchers interested in the recovery of Au ions as well as in the behavior of base metal ions in thiosulfate systems.

\section{Materials and Methods}

\subsection{Recovery of Au Ions from Solutions with a Low Au Concentration}

The stock ammonium thiosulfate solution containing Au ions (i.e., Au-thiosulfate solution) was prepared by dissolving 5 or $10 \mathrm{mg} / \mathrm{L}$ of Au powder $(99.999 \%$, Wako Pure Chemical Industries, Ltd., Osaka, Japan) in an ammonium thiosulfate solution containing $1 \mathrm{M}$ of $\mathrm{Na}_{2} \mathrm{~S}_{2} \mathrm{O}_{3}, 0.5 \mathrm{M}$ of $\mathrm{NH}_{3}, 0.25 \mathrm{M}$ of $\left(\mathrm{NH}_{4}\right)_{2} \mathrm{SO}_{4}$, and $10 \mathrm{mM}$ of $\mathrm{CuSO}_{4}$ (pH between 9.5 and 10) using a $300 \mathrm{~mL}$ Erlenmeyer flask shaken in a thermostat water bath shaker at $25{ }^{\circ} \mathrm{C}$ for $24 \mathrm{~h}$ with constant shaking at $120 \mathrm{~min}^{-1}$. The concentration of $\mathrm{Au}$ ions in the stock solution was measured by inductively coupled plasma atomic emission spectroscopy (ICP-AES, ICPE-9820, Shimadzu Corporation, Tokyo, Japan) (margin of error $= \pm 2 \%$ ). Subsequently, $0.15 \mathrm{~g}$ of ZVAl (99.99\%, Wako Pure Chemical Industries, Ltd., Osaka, Japan) and/or $0.15 \mathrm{~g}$ of AC (99.99\%, Wako Pure Chemical Industries, Ltd., Osaka, Japan) was mixed with $10 \mathrm{~mL}$ of Au-thiosulfate solution in $50 \mathrm{~mL}$ Erlenmeyer flasks at $25^{\circ} \mathrm{C}$ (shaking at $120 \mathrm{~min}^{-1}$ ) under nitrogen purging conditions to remove the dissolved oxygen in the solution. After $1 \mathrm{~h}$, the filtrate and residue were separated by filtration using $0.2 \mu \mathrm{m}$ syringe-driven membrane filters (LMS Co., Ltd., Tokyo, Japan). The residues were washed thoroughly with deionized water $\left(18 \mathrm{M} \Omega \cdot \mathrm{cm}\right.$, Mill-Q ${ }^{\circledR}$ Integral Water Purification System, Merck Millipore, Billerica, MA, USA), dried in a vacuum oven at $40{ }^{\circ} \mathrm{C}$, and analyzed by a scanning electron microscope with energy-dispersive X-ray spectroscopy (SEM-EDX, Superscan SSX-550, Shimadzu Corporation, Tokyo, Japan). Meanwhile, the concentrations of $\mathrm{Au}$ ions remaining in the filtrates were analyzed by ICP-AES. For validity, accuracy, and replicability of results, experiments were conducted in triplicates.

\subsection{Recovery of Au Ions from Solutions Containing Coexisting Metal Ions}

In order to investigate the effects of coexisting metal ions on Au recovery using the ZVAl-AC technique, Au-thiosulfate solutions together with base metal ions $(\mathrm{Cu}, \mathrm{Fe}, \mathrm{Co}, \mathrm{Ni}$, and $\mathrm{Zn}$ ions) of concentration varying from 0 to $50 \mathrm{mM}$ with and without $\mathrm{Cu}$ ions were prepared. The reagents used as sources of competing ions were analytical-grade powders of $\mathrm{CuSO}_{4} \cdot 5 \mathrm{H}_{2} \mathrm{O}, \mathrm{NiSO}_{4} \cdot 6 \mathrm{H}_{2} \mathrm{O}, \mathrm{FeSO}_{4} \cdot 7 \mathrm{H}_{2} \mathrm{O}, \mathrm{ZnSO}_{4} \cdot 7 \mathrm{H}_{2} \mathrm{O}$, and $\mathrm{CoSO}_{4} \cdot 7 \mathrm{H}_{2} \mathrm{O}$ (Wako Pure Chemical Industries Ltd., Osaka, Japan). Subsequently, $10 \mathrm{~mL}$ of Au-thiosulfate solution containing each base metal ion was purged with ultra-pure $\mathrm{N}_{2}$ to remove any dissolved oxygen, and then mixed with $0.15 \mathrm{~g}$ of $\mathrm{ZVAl}$ and $\mathrm{AC}$ at $25^{\circ} \mathrm{C}$ for $1 \mathrm{~h}$, shaking at $120 \mathrm{~min}^{-1}$. After the predetermined mixing time, the suspension was filtered and the residues were washed thoroughly with deionized water, dried in a vacuum oven at $40^{\circ} \mathrm{C}$, and analyzed by SEM-EDX. Meanwhile, the filtrates were analyzed by ICP-AES. For validity, accuracy, and replicability of results, experiments were conducted in triplicates. 


\section{Results}

\subsection{Recovery of Au Ions from Solutions Containing a Low Au Concentration}

Figure 1 shows the recovery of $\mathrm{Au}$ ions from the ammonium thiosulfate solution containing Au concentrations of 5, 10, and $100 \mathrm{mg} / \mathrm{L}$ by ZVAl and AC. Au recovery was calculated according to the following equation:

$$
\text { Au recovery }(\%)=\frac{[A u](i)-[A u](\mathrm{f})}{[A u](i)} \times 100 \%
$$

where $[A u](\mathrm{i})$ and $[A u](\mathrm{f})$ are the initial and final Au concentrations, respectively.

(a)

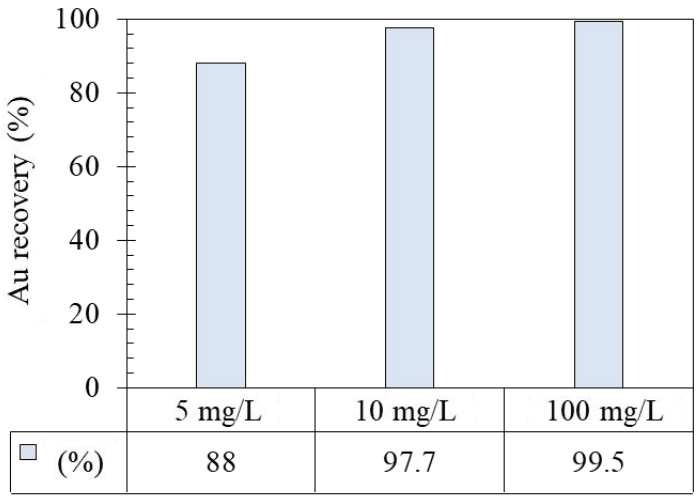

(b)

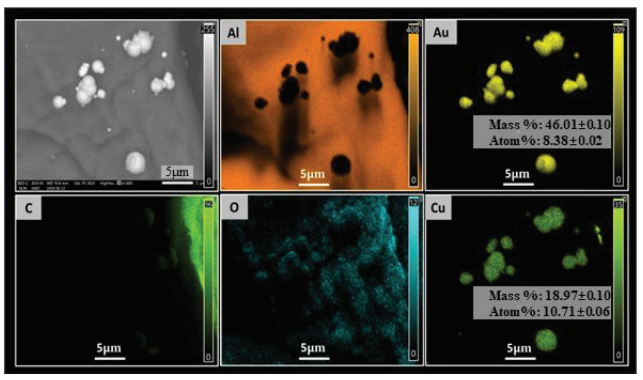

Figure 1. (a) Recovery of Au ions from ammonium thiosulfate solutions with varying initial concentrations from 5 to $100 \mathrm{mg} / \mathrm{L}$, and (b) SEM photomicrographs with corresponding elemental maps of the recovery residue at $10 \mathrm{~mL} / \mathrm{L}$ of $\mathrm{Au}$ initial concentration.

The results showed that over $99 \%$ of $\mathrm{Au}$ was recovered when the initial concentration was $100 \mathrm{mg} / \mathrm{L}$, while about $90 \%$ of Au was recovered when the initial concentration was $5 \mathrm{mg} / \mathrm{L}$. The results indicate that recovery slightly decreases as the initial concentration decreases, similar to the results reported by Wang et al. [29] and Nguyen et al. [30] for the cementation of $\mathrm{Au}$ ions, but still showed a high recovery of $90 \%$. Figure $1 \mathrm{~b}$ shows the SEM photomicrographs with corresponding elemental maps of the residue at $10 \mathrm{~mL} / \mathrm{L}$ of $\mathrm{Au}$ initial concentration, and the results showed that $\mathrm{Au}$ and $\mathrm{Cu}$ were detected on the surface of ZVAl.

\subsection{Recovery of Au Ions from Solutions Containing Coexisting Metal Ions}

\subsubsection{Recovery of $\mathrm{Au}$ Ions with Varying $\mathrm{Cu}$ Concentrations in the Solution}

This section focuses on the effects of $\mathrm{Cu}$ ions on Au recovery for the following reasons: 
- $\mathrm{Cu}$ ions are an essential catalyst in ammonium thiosulfate systems, increasing Au dissolution in ammonium thiosulfate systems 20- to 25-fold (Equation (1)) [1,4];

- $\mathrm{Cu}$ ions could be introduced via the dissolution of $\mathrm{Cu}$ minerals such as chalcopyrite and malachite [23-28] found in Au ores.

Figure 2 presents how $\mathrm{Cu}$ ions affect Au recovery when using ZVAl and AC. The results show that the initial increase in $\mathrm{Cu}$ ion concentration by $10 \mathrm{mM}$ enhanced $\mathrm{Au}$ recovery. This could be attributed to the formation of galvanic cells as a consequence of $\mathrm{Cu}$ cementation. Galvanic interactions enhance electron transfer from $\mathrm{ZVAl}$ to the $\mathrm{Au}$ thiosulfate complex, increasing Au recovery [15]. In the second region from 10 to $40 \mathrm{mM}$ $\mathrm{Cu}, \mathrm{Au}$ recovery was high and consistent at about $90 \%$. In this region, all the Au that can be recovered was already cemented on the $\mathrm{ZVAl}$; hence, increasing $\mathrm{Cu}$ ions did not affect $\mathrm{Au}$ recovery. In the final region above $40 \mathrm{mM} \mathrm{Cu}$, excess $\mathrm{Cu}$ ions began to reduce Au recovery while $\mathrm{Cu}$ precipitation still increased. As shown in Figure 3, the decrease in Au recovery could be attributed to the competition between the reduction of $\mathrm{Cu}$ species (Equations (3) and (4)) and Au species (Equation (5)) [4,7,12].

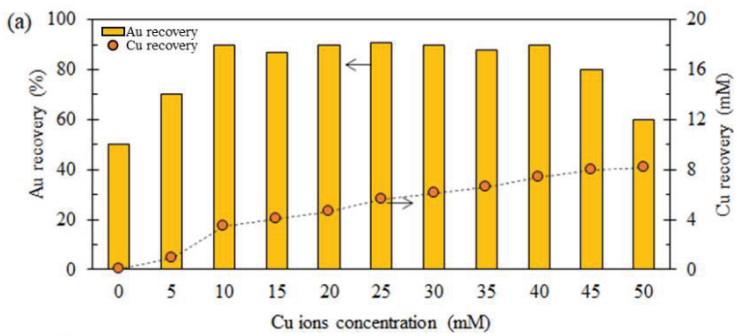

(b)

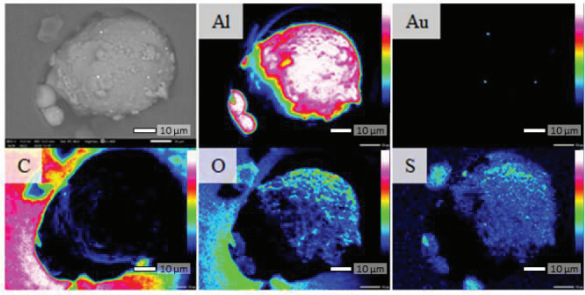

(c)
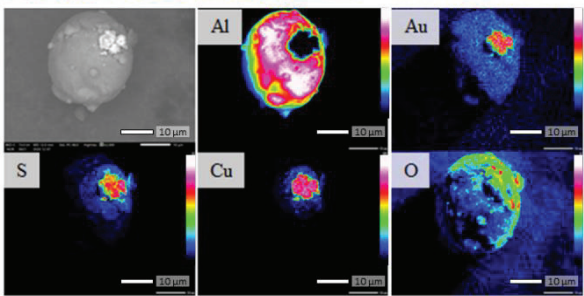

(d)

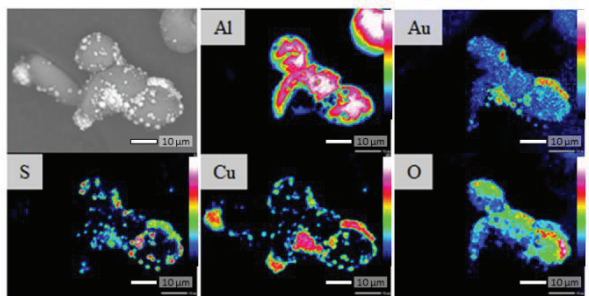

Figure 2. (a) Recovery of gold ions from ammonium thiosulfate solution with varying additions of $\mathrm{Cu}$ ions with concentrations from 0 to $50 \mathrm{mM}$, and SEM photomicrographs with corresponding elemental maps of the residues at (b) $0 \mathrm{mM}$, (c) $10 \mathrm{mM}$, and (d) $50 \mathrm{mM}$ of $\mathrm{Cu}$ ion additions. 


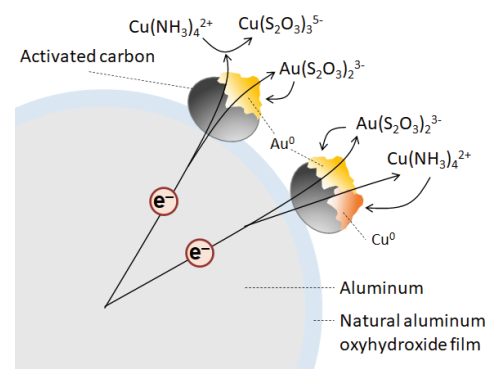

Figure 3. Schematic diagram of the competitive electron transfer from ZVAl to the $\mathrm{Cu}$ complex and the Au-thiosulfate complex.

SEM-EDX results showed that in the absence of $\mathrm{Cu}$ ions (residue at $0 \mathrm{mM} \mathrm{Cu}$ ), $\mathrm{Au}$ was recovered as small point-like depositions on the surface of ZVAl (Figure 2b), while the area of $\mathrm{Au}$ deposition increased when $\mathrm{Cu}$ concentration increased by 10 and $50 \mathrm{mM}$ (Figure 2b,c), and showed that deposited Au occurs together with deposited $\mathrm{Cu}$.

$$
\begin{gathered}
\mathrm{Cu}\left(\mathrm{NH}_{3}\right)_{4}{ }^{2+}+3 \mathrm{~S}_{2} \mathrm{O}_{3}{ }^{2-}+\mathrm{e}^{-} \rightarrow \mathrm{Cu}\left(\mathrm{S}_{2} \mathrm{O}_{3}\right)_{3}{ }^{5-}+4 \mathrm{NH}_{3} \\
\mathrm{Cu}\left(\mathrm{NH}_{3}\right)_{4}{ }^{2+}+2 \mathrm{e}^{-} \rightarrow \mathrm{Cu}+4 \mathrm{NH}_{3} \\
\mathrm{Au}\left(\mathrm{S}_{2} \mathrm{O}_{3}\right)_{2}{ }^{3-}+\mathrm{e}^{-} \rightarrow \mathrm{Au}^{0}+2 \mathrm{~S}_{2} \mathrm{O}_{3}{ }^{2-}
\end{gathered}
$$

3.2.2. Recovery of $\mathrm{Au}$ Ions with Varying $\mathrm{Fe}, \mathrm{Co}, \mathrm{Ni}$, and $\mathrm{Zn}$ Concentrations in the Solution

In this part of the study, various metal ions including $\mathrm{Fe}, \mathrm{Co}, \mathrm{Ni}$, and $\mathrm{Zn}$ ions that could coexist in pregnant Au ore solutions were selected and their effects on Au recovery were elucidated.

The effects of Fe ions on Au recovery are shown in Figure 4. Figure 4a,b shows the recovery of $\mathrm{Au}$ ions with varying addition concentrations of Fe ions in the absence and presence of $\mathrm{Cu}$ ions in the solution, respectively. In both cases, the results showed that the effects of Fe ions on Au recovery were negligible. This could be explained by the very low solubility of Fe ions under basic conditions [31]; hence, Fe precipitates are readily formed in the solution, which neither favors nor hinders Au recovery. The precipitate in the solution was analyzed by SEM-EDX and showed that Fe precipitates were formed in the solution as shown in Figure 4c. When $10 \mathrm{mM}$ of $\mathrm{Cu}$ ions were added to the solution, Au recovery was enhanced and consistently showed about $85-90 \%$ Au recovery (Figure $4 \mathrm{~b}$ ), which indicates that $\mathrm{Au}$ can be successfully recovered regardless of the presence of Fe ions.

Figure $5 \mathrm{a}, \mathrm{b}$ shows the results of Au recovery with varying Co ion additions without and with $\mathrm{Cu}$ ions, respectively. In the absence of $\mathrm{Cu}$ ions (Figure 5a), Au recovery increased to $60 \%$ with the addition of $1 \mathrm{mM}$ of Co ions, then decreased as the addition of Co ions increased due to the competitive reduction of $\mathrm{Co}$ ions and $\mathrm{Au}$ ions. In the presence of $\mathrm{Cu}$ ions in the solution, however, Au recovery was about $90 \%$, indicating that the negative effects of $\mathrm{Co}$ ions on $\mathrm{Au}$ recovery were hindered in the presence of $\mathrm{Cu}$ ions and high $\mathrm{Au}$ recovery could be obtained (Figure $5 \mathrm{~b}$ ). Figure $5 \mathrm{c}$ presents the residue analysis by SEM-EDX. The results show that $\mathrm{Co}, \mathrm{Au}$, and $\mathrm{Cu}$ were recovered on the surface of $\mathrm{ZVAl}$ and deposition areas of Au were very close to that of $\mathrm{Cu}$.

Figure $6 \mathrm{a}, \mathrm{b}$ shows the effects of $\mathrm{Ni}$ ions on Au recovery with varying concentrations without and with $\mathrm{Cu}$ ions, respectively. The results showed that in the absence of $\mathrm{Cu}$ ions, Au recovery increased to $83 \%$ with the addition of $10 \mathrm{mM}$ of $\mathrm{Ni}$ ions, then recovery decreased as the addition of $\mathrm{Ni}$ ions increased by the competitive reduction. In the presence of $\mathrm{Cu}$ ions, however, Au recovery was constantly high at all ranges of $\mathrm{Ni}$ ion additions [32]. Figure 6c presents the SEM-EDX analysis of the residue, showing that $\mathrm{Ni}, \mathrm{Cu}$, and Au were co-cemented on ZVAl particles. 
(a)
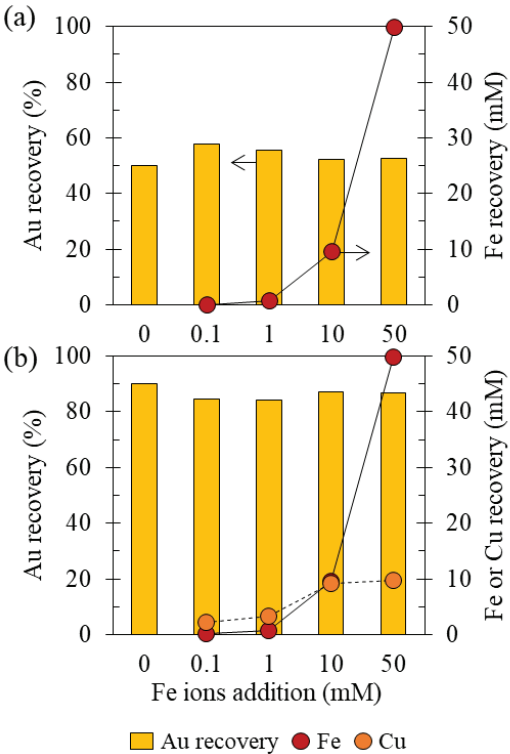

(c)
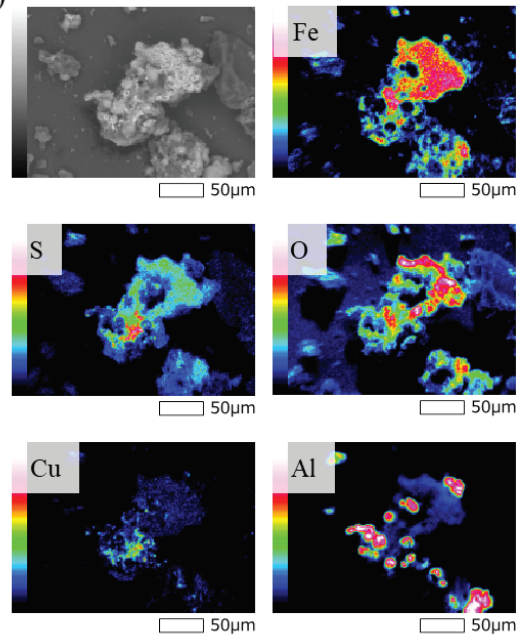

Figure 4. Recovery of gold ions from an ammonium thiosulfate solution with varying addition of $\mathrm{Fe}$ ion concentrations from 0 to $50 \mathrm{mM}$ (a) without and (b) with $10 \mathrm{mM}$ of $\mathrm{Cu}$ ions in the solution, and (c) SEM photomicrographs with corresponding elemental maps of the precipitates in the solution.

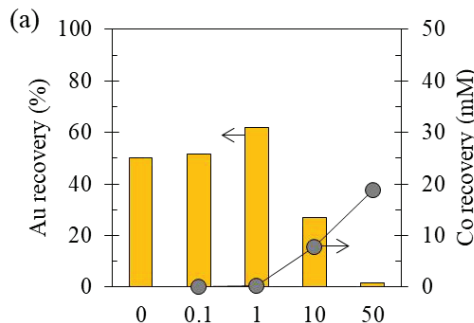

(c)
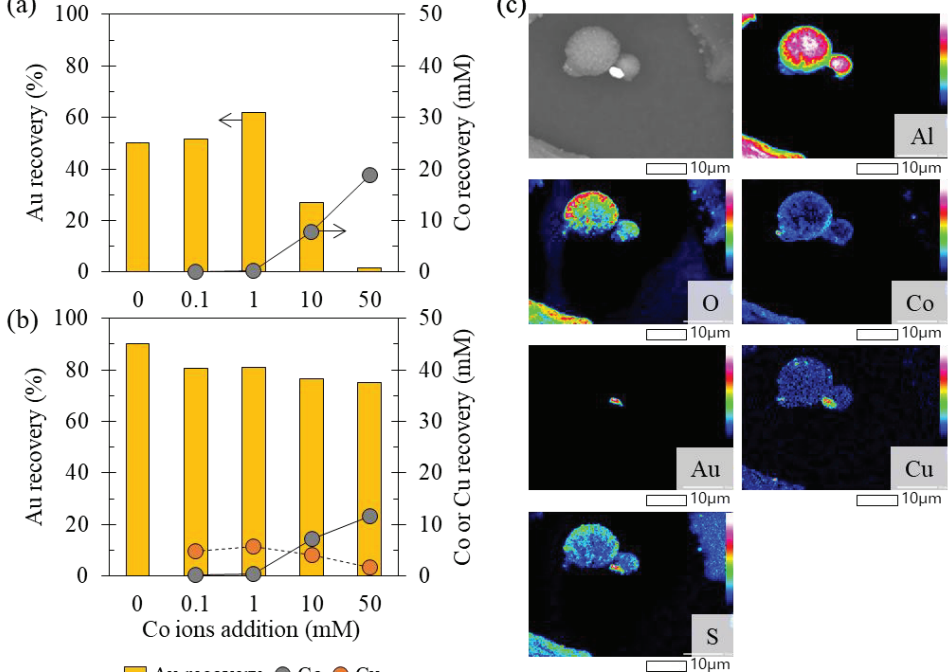

Figure 5. Recovery of gold ions from ammonium thiosulfate solutions with varying additions of Co ion concentrations from 0 to $50 \mathrm{mM}$ (a) without and (b) with $10 \mathrm{mM}$ of $\mathrm{Cu}$ ions in the solution, and (c) SEM photomicrographs with corresponding elemental maps of residue. 

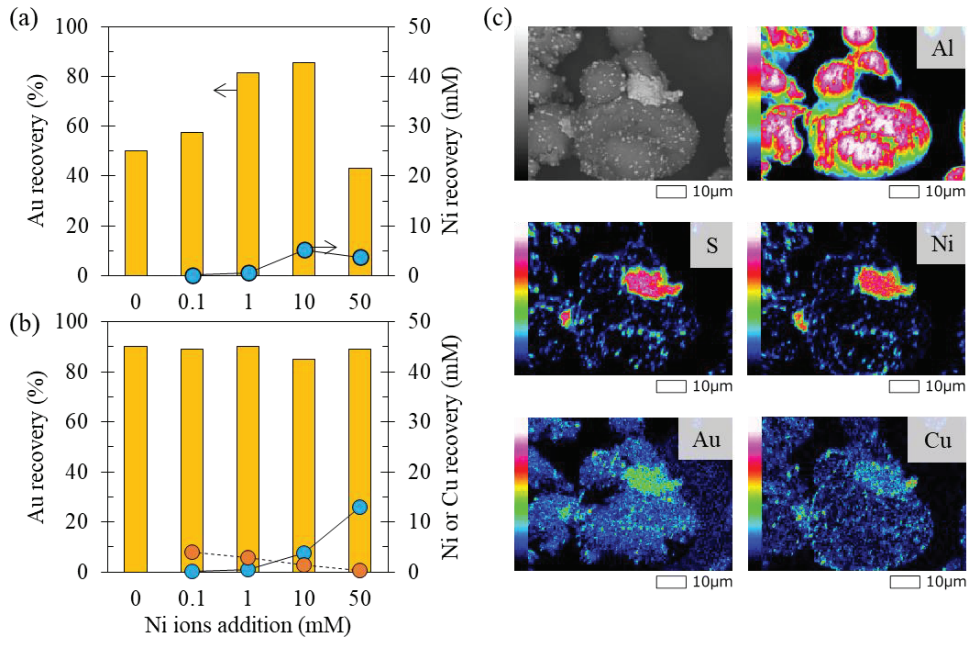

$\square \mathrm{Au}$ recovery $\bigcirc \mathrm{Ni} \bigcirc \mathrm{Cu}$

Figure 6. Recovery of gold ions from ammonium thiosulfate solution with varying additions of $\mathrm{Ni}$ ion concentrations from 0 to $50 \mathrm{mM}$ (a) without and (b) with $10 \mathrm{mM}$ of $\mathrm{Cu}$ ions in the solution, and (c) SEM photomicrographs with corresponding elemental maps of the residue.

Figure 7a,b shows the recovery of Au ions with varying additions of $\mathrm{Zn}$ ions in the solution from 0.1 to $50 \mathrm{mM}$ without and with $\mathrm{Cu}$ ions in the solution, respectively. Without $\mathrm{Cu}$ ions, $\mathrm{Au}$ recovery increased with the increase in $\mathrm{Zn}$ ion addition, while Au recovery remained at an almost constant value of $90 \%$ with $\mathrm{Cu}$ ions, regardless of the addition of $\mathrm{Zn}$. The SEM photomicrograph with corresponding elemental maps shows that both $\mathrm{Zn}$ and $\mathrm{Cu}$ were recovered on the surface of $\mathrm{ZVAl}$ with $\mathrm{Au}$.

(a)
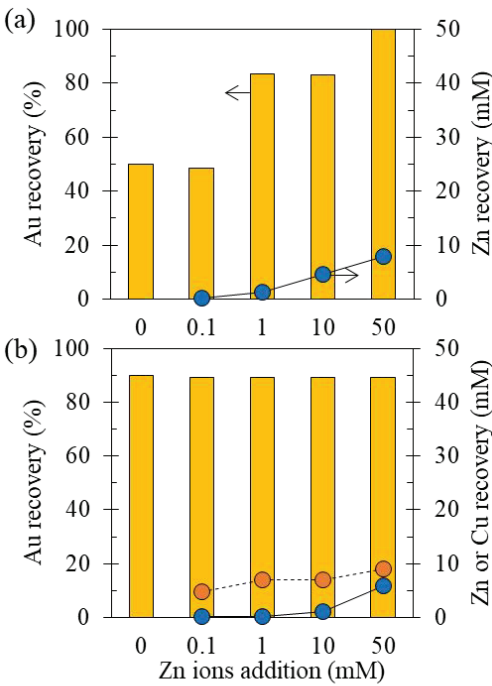

$\square$ Au recovery $\bigcirc \mathrm{Zn} \bigcirc \mathrm{Cu}$ (c)
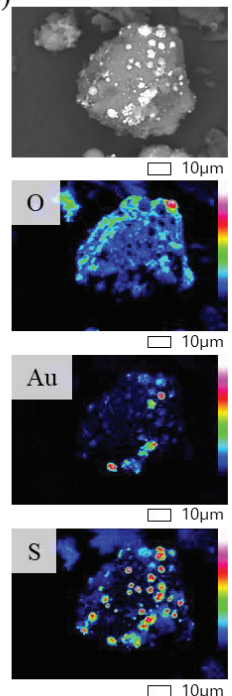
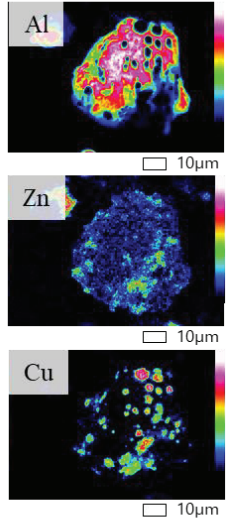

$\square 10 \mu \mathrm{m}$

Figure 7. Recovery of gold ions from an ammonium thiosulfate solution with varying additions of $\mathrm{Zn}$ ion concentrations from 0 to $50 \mathrm{mM}$ (a) without and (b) with $10 \mathrm{mM}$ of $\mathrm{Cu}$ ions in the solution, and (c) SEM photomicrographs with corresponding elemental maps of residue. 
The observed results can be summarized by the following four effects with Figure 8:

- $\quad$ Effect 1: Fe ions precipitated from solution phase, and they did not affect Au recovery.

- $\quad$ Effect 2: Zn ions and low concentrations of Co and Ni ions enhanced Au recovery.

- $\quad$ Effect 3: Higher concentrations of Co and Ni ions suppressed Au recovery.

- Effect 4: In the presence of $\mathrm{Cu}$ ions, the effects of other coexisting metal ions were hindered, i.e., Au recovery was almost constant (the orange section illustrated in Figure 8), regardless of the presence of other coexisting metal ions.

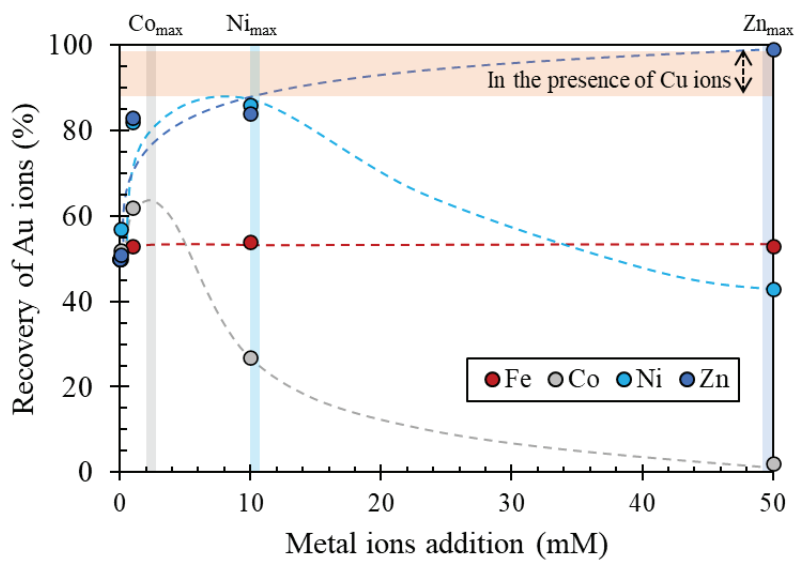

Figure 8. The competitive cementation tendency between Au ions and other base metal ions reacted on the surface of $\mathrm{AC}$ attached to $\mathrm{ZVAl}$ in the absence of $\mathrm{Cu}$ ions.

For Effect 1, Fe ions had low solubility and precipitated in the current system and had no effect on Au recovery. Effect 2 (enhanced Au recovery with some of the metal ions) may have occurred due to the formation of new reaction sites for Au deposition: the coexisting metal ions were reduced on the AC (electron mediator) attached to ZVAl, and the deposit elemental metals acted as secondary electron mediators or new cathode sites for Au deposition. Effect 3 (suppressive effect of the coexisting metal ions on Au recovery) can be interpreted by assuming the competition of cementation reactions (reduction of metal ions) between $\mathrm{Au}$ and coexisting metal ions: a limited amount of electron flow from the donor (ZVAl) was shared with both the Au and coexisting metal ions, causing a decrease in the amount of Au deposition. At a certain concentration of metal ions, the enhanced effect (Effect 2) shifted to suppressive effect (Effect 3) and Au recovery reached its maximum at that point. The concentrations of coexisting metal ions promoting maximum $\mathrm{Au}$ recovery are shown as $\mathrm{Me}_{\max }$ in Figure 8. The $\mathrm{Me}_{\max }$ concentration was lowest for $\mathrm{Co}$, followed by $\mathrm{Ni}$, then highest for $\mathrm{Zn}$. This order may correspond to the order of the standard redox potential of these metal ions, as shown in Table 1: the standard redox potential for $\mathrm{Co}\left(\mathrm{NH}_{3}\right)_{6}{ }^{3+} / \mathrm{Co}$ is higher than that of the others, suggesting that reductive deposition of $\mathrm{Co}$ occurs at lower concentrations. This could be the reason why the enhanced Au cementation occurred at low concentrations of $\mathrm{Co}$. For the $\mathrm{Ni}$ and $\mathrm{Zn}$, the standard redox potentials are lower than $\mathrm{Co}$, and higher concentrations are needed to form the new cathode site for $\mathrm{Au}$ deposition; hence, higher concentrations of $\mathrm{Ni}$ and $\mathrm{Zn}$ were needed for the enhanced $\mathrm{Au}$ recovery. 
Table 1. Standard redox potentials of $\mathrm{Au}, \mathrm{Cu}, \mathrm{Co}, \mathrm{Ni}$, and $\mathrm{Zn}$ in ammonium thiosulfate systems [33-37].

\begin{tabular}{cc}
\hline Metals & $\mathbf{E}^{0} / \mathbf{V}$ \\
\hline $\mathrm{Au}\left(\mathrm{S}_{2} \mathrm{O}_{3}\right)_{2}{ }^{3-} / \mathrm{Au}$ & 0.27 \\
$\mathrm{Cu}\left(\mathrm{NH}_{3}\right)_{4}{ }^{2+} / \mathrm{Cu}\left(\mathrm{S}_{2} \mathrm{O}_{3}\right)_{2}{ }^{3-}$ & 0.22 \\
$\mathrm{Co}\left(\mathrm{NH}_{3}\right)_{6}{ }^{3+} / \mathrm{Co}\left(\mathrm{NH}_{3}\right)^{2+}(x$ is mainly 5 under the current conditions $)$ & 0.21 \\
$\mathrm{Co}\left(\mathrm{NH}_{3}\right)_{6}{ }^{3+} / \mathrm{Co}$ & 0.1 \\
$\mathrm{Cu}\left(\mathrm{NH}_{3}\right)_{4}{ }^{2+} / \mathrm{Cu}$ & -0.05 \\
$\mathrm{Cu}\left(\mathrm{NH}_{3}\right)_{4}{ }^{2+} / \mathrm{Cu}_{2} \mathrm{~S}$ & -0.2 \\
$\mathrm{Ni}_{\left(\mathrm{NH}_{3}\right)_{6}{ }^{2+} / \mathrm{Ni}}$ & -0.49 \\
$\mathrm{Zn}\left(\mathrm{NH}_{3}\right)_{4}{ }^{2+} / \mathrm{Zn}$ & -1.04 \\
\hline
\end{tabular}

From an engineering viewpoint, Effect 4 is probably the most noteworthy result here. In the presence of $\mathrm{Cu}$ ions, the effects of other coexisting metal ions were hindered, and high Au recovery was achieved (i.e., 85-95\%). As show in Table 1, with the exception of Co ions, standard redox potentials of $\mathrm{Cu}$ ions are higher than other metal ions [37,38]. When a high concentrations of $\mathrm{Cu}$ ions coexists, $\mathrm{Cu}$ ions would preferentially be reduced and deposited on AC/ZVAl surfaces [39]. $\mathrm{Cu}$ is an electro-conductor, and its conductivity is much higher than that of other metals (Table 2), and it acts as a high-efficiency secondary electron mediator or cathode site, enhancing electron transfer from ZVAl to Au ions (Figure 9). For that, the effects of other coexisting metal ions (especially the suppressive effect of the ions) on $\mathrm{Au}$ recovery would be minimized in the presence of $\mathrm{Cu}$ ions, and this is schematically illustrated in Figure 9.

Table 2. Conductivity of $\mathrm{Cu}, \mathrm{Zn}, \mathrm{Co}$, and Ni [40,41].

\begin{tabular}{cc}
\hline Metals & Conductivity $\left(\mathbf{S} / \mathbf{m} \times \mathbf{1 0}^{\mathbf{7}}\right.$ at $\left.\mathbf{2 5}{ }^{\circ} \mathbf{C}\right)$ \\
\hline $\mathrm{Cu}$ & 5.98 \\
$\mathrm{Zn}$ & 1.7 \\
$\mathrm{Co}$ & 1.6 \\
$\mathrm{Ni}$ & 1.4 \\
\hline
\end{tabular}

(a)

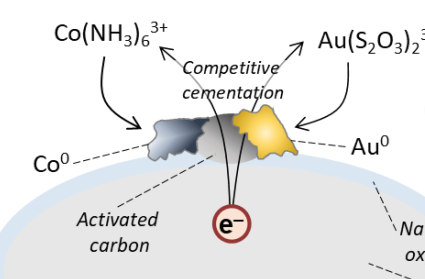

(b)

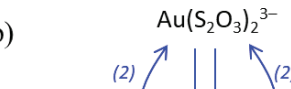

$\mathrm{Au}\left(\mathrm{S}_{2} \mathrm{O}_{3}\right)_{2}{ }^{3-}$
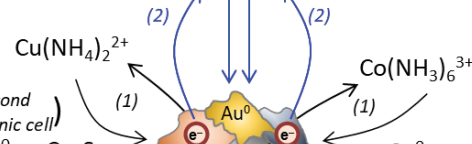

$\mathrm{CO}^{\mathrm{O}}$

( $\left.\begin{array}{c}\text { Second } \\ \text { galvanic cell }\end{array}\right)$

Activated

carbon

Figure 9. Schematic diagram of the competitive electron transfer from ZVAl to Cu-ammine, Coammine, and Au-thiosulfate complex (a) without and (b) with $\mathrm{Cu}$ ions in the system.

\subsubsection{Recovery of Au Ions from Solutions Containing Various Coexisting Metal Ions}

Figure 10 shows the results of the experiment using the solution containing $10 \mathrm{mM}$ of all base metal ions together with $\mathrm{Au}$ ions, like a model solution of pregnant leached solution. The results showed that over $90 \%$ of $\mathrm{Au}$ was recovered together with $\mathrm{Co}, \mathrm{Cu}, \mathrm{Zn}$, and $\mathrm{Ni}$, except for Fe ions, and SEM-EDX analysis of the solid product showed that $\mathrm{Au}$ and other base metals were deposited on the same sites. This result confirms that high $\mathrm{Au}$ recovery is achieved even when other base metal ions coexist in the presence of $\mathrm{Cu}$ ions. 
(a)

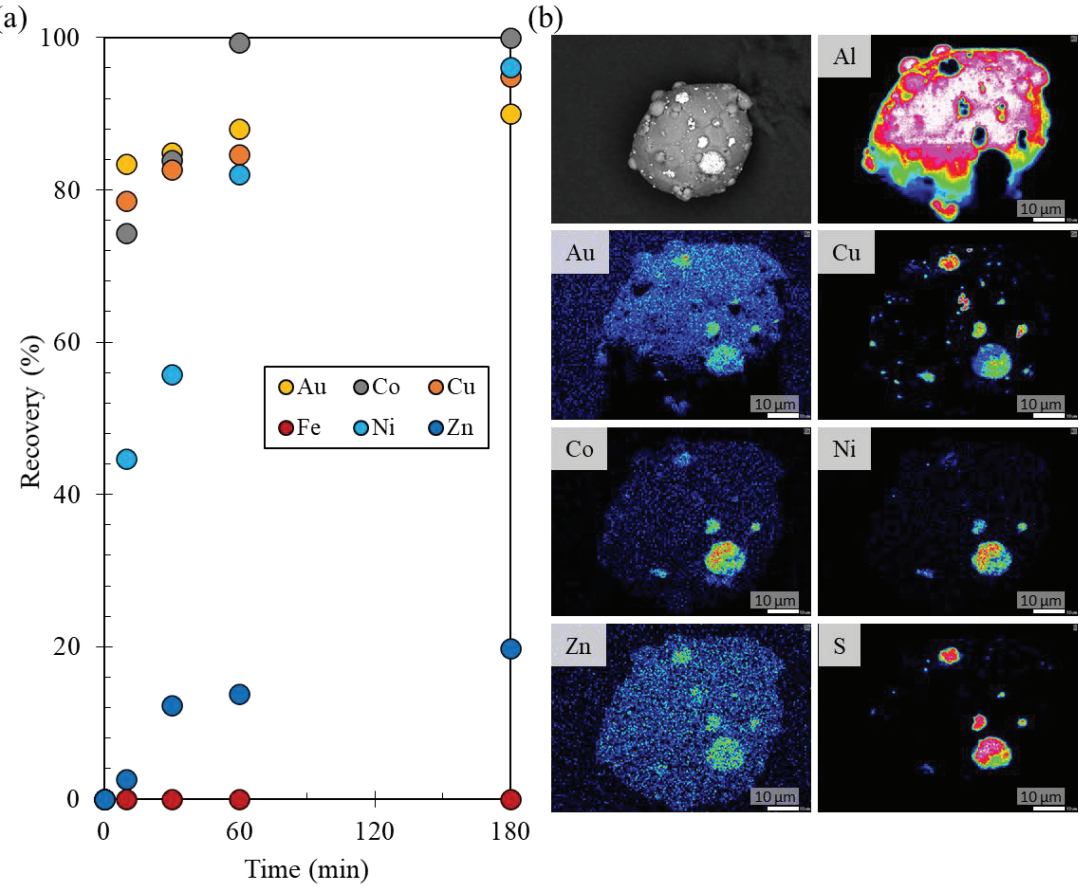

Time (min) (b)

Figure 10. (a) Metal ion recovery from the ammonium thiosulfate solution containing all metal ions (i.e., $\mathrm{Au}, \mathrm{Co}, \mathrm{Cu}, \mathrm{Fe}, \mathrm{Ni}$, and $\mathrm{Zn}$ ions) over time, and (b) SEM photomicrographs and corresponding elemental maps of the residue.

The components/concentrations of the elements are different depending on the type as well as the location of the ores. Based on previous studies, typical $\mathrm{Cu}, \mathrm{Co}, \mathrm{Ni}$, and $\mathrm{Zn}$ concentrations in the ore are: $\mathrm{Cu}$ at about 250 to $5000 \mathrm{ppm}[38,42]$, Co at about 12 to $50 \mathrm{ppm}$ [39,40], $\mathrm{Ni}$ at about $0.002 \%$ to $0.03 \%$ [43,44], and $\mathrm{Zn}$ at about $0.002 \%$ to $1.7 \%[5,43-45]$ (explanation of Fe content was excluded since it does not affect the current leaching/recovery system). In the absence of $\mathrm{Cu}$ ions in the solution, the results showed that $\mathrm{Au}$ recovery decreased from $0.03 \mathrm{Co} / \mathrm{Al}$ mass ratio and $0.04 \mathrm{Ni} / \mathrm{Al}$ mass ratio (in the case of $\mathrm{Zn}$ ion addition, $\mathrm{Au}$ recovery continuously increased to over $0.22 \mathrm{Zn} / \mathrm{Al}$ mass ratio) while high and constant $\mathrm{Au}$ recovery was obtained in the presence of $\mathrm{Cu}$ ions in the solution regardless of the $\mathrm{Me} / \mathrm{Al}$ mass ratio under the current conditions. In the ammonium thiosulfate system, $\mathrm{Cu}$ ions are essentially employed as a catalyst for enhancing the $\mathrm{Au}$ extraction rate by 25 -fold, and successful Au recovery was obtained from a solution containing various base metal ions. Note that a much higher concentration of the elements can be present in the ore and affect the recovery system, even in the presence of proper $\mathrm{Cu}$ ions. In this case, an increase in $\mathrm{ZVAl}$ mass ratio could be expected to increase Au recovery. Thus, this novel recovery technique using galvanic interactions between $\mathrm{ZVAl}$ and $\mathrm{AC}$ can be employed in the treatment of Au ore containing various elements.

\section{Conclusions}

The present study describes the applicability of a simple and high-efficiency recovery technique by enhanced cementation of galvanic interaction between $\mathrm{ZVAl}$ and $\mathrm{AC}$ for $\mathrm{Au}$ ore processing, which includes:

- Recovery of Au ions from the solution with low Au concentrations of about less than $10 \mathrm{mg} / \mathrm{L}$; 
- Investigation of the effects of various coexisting metal ions that could be present in ore for Au recovery.

The recovery results showed that recovery efficiency slightly decreases as the initial concentration decreases, but still showed over $85 \%$ recovery. Selected coexisting $\mathrm{Cu}, \mathrm{Fe}$, $\mathrm{Co}, \mathrm{Ni}$, and $\mathrm{Zn}$ ions were studied to establish their effects on Au recovery, and the results showed that the Au recovery improved (>85-90\%) when $\mathrm{Cu}$ ions were present in the solution with minimal effects of other competing base metal ions. The recovery of $\mathrm{Au}$ ions from the solution containing $\mathrm{Cu}, \mathrm{Fe}, \mathrm{Co}, \mathrm{Ni}$, and $\mathrm{Zn}$ ions was also carried out and the results showed that even if various metal ions coexisted together with $\mathrm{Au}$ ions in the solution, over $90 \%$ of Au could be recovered. In the ammonium thiosulfate system, $\mathrm{Cu}$ ions are employed as an essential catalyst; thus, the results showed a high possibility of applicability to Au ore mining processes.

Author Contributions: Conceptualization, S.J., I.P., M.I. and N.H.; methodology, S.J. and N.H.; investigation, S.J. and S.B.; writing-original draft preparation, S.J. and S.B.; writing-review and editing, S.J., I.P., C.B.T., M.I. and N.H.; project administration, S.J., I.P., M.I. and N.H.; funding acquisition, S.J. All authors have read and agreed to the published version of the manuscript.

Funding: This study was financially supported by Japan Oil, Gas and Metals National Corporation (JOGMEC).

Data Availability Statement: Data available on request due to restrictions, as the research is ongoing.

Conflicts of Interest: The authors declare no conflict of interest.

\section{References}

1. Aylmore, M.; Muir, D. Thiosulfate leaching of gold-A review. Miner. Eng. 2001, 14, 135-174. [CrossRef]

2. Tabelin, C.B.; Park, I.; Phengsaart, T.; Jeon, S.; Villacorte-Tabelin, M.; Alonzo, D.; Yoo, K.; Ito, M.; Hiroyoshi, N. Copper and critical metals production from porphyry ores and e-wastes: A review of resource availability, processing/recycling challenges, socio-environmental aspects, and sustainability issues. Resour. Conserv. Recycl. 2021, 170, 105610. [CrossRef]

3. Opiso, E.M.; Aseneiro, J.P.J.; Banda, M.H.T.; Tabelin, C.B. Solid-phase partitioning of mercury in artisanal gold mine tailings from selected key areas in Mindanao, Philippines, and its implications for mercury detoxification. Waste Manag. Res. 2018, 36, 269-276. [CrossRef] [PubMed]

4. Jeon, S.; Tabelin, C.B.; Takahashi, H.; Park, I.; Ito, M.; Hiroyoshi, N. Interference of coexisting copper and aluminum on the ammonium thiosulfate leaching of gold from printed circuit boards of waste mobile phones. Waste Manag. 2018, 81, 148-156. [CrossRef] [PubMed]

5. Aazami, M.; Lapidus, G.; Azadeh, A. The effect of solution parameters on the thiosulfate leaching of Zarshouran refractory gold ore. Int. J. Miner. Process. 2014, 131, 43-50. [CrossRef]

6. Ha, V.H.; Lee, J.-C.; Huynh, T.H.; Jeong, J.; Pandey, B. Optimizing the thiosulfate leaching of gold from printed circuit boards of discarded mobile phone. Hydrometallurgy 2014, 149, 118-126. [CrossRef]

7. Jeon, S.; Tabelin, C.B.; Park, I.; Nagata, Y.; Ito, M.; Hiroyoshi, N. Ammonium thiosulfate extraction of gold from printed circuit boards (PCBs) of end-of-life mobile phones and its recovery from pregnant leach solution by cementation. Hydrometallurgy 2020, 191, 105214. [CrossRef]

8. Molleman, E.; Dreisinger, D. The treatment of copper-gold ores by ammonium thiosulfate leaching. Hydrometallurgy 2002, 66, 1-21. [CrossRef]

9. Ficeriová, J.; Baláz, P.; Villachica, C.L. Thiosulfate leaching of silver, gold and bismuth from a complex sulfide concentrates. Hydrometallurgy 2005, 77, 35-39. [CrossRef]

10. Fleming, C.A.; Mezei, A.; Bourricaudy, E.; Canizares, M.; Ashbury, M. Factors influencing the rate of gold cyanide leaching and adsorption on activated carbon, and their impact on the design of CIL and CIP circuits. Miner. Eng. 2011, 24, 484-494. [CrossRef]

11. Navarro, P.; Vargas, C.; Alonso, M.; Alguacil, F. The adsorption of gold on activated carbon from thiosulfate-ammoniacal solutions. Gold Bull. 2006, 39, 93-97. [CrossRef]

12. Arima, H.; Fujita, T.; Yen, W.-T. Gold Cementation from Ammonium Thiosulfate Solution by Zinc, Copper and Aluminium Powders. Mater. Trans. 2002, 43, 485-493. [CrossRef]

13. Hiskey, J.B.; Lee, J. Kinetics of gold cementation on copper in ammoniacal thiosulfate solutions. Hydrometallurgy 2003, 69, 45-56. [CrossRef]

14. Dong, Z.; Jiang, T.; Xu, B.; Yang, Y.; Li, Q. Recovery of Gold from Pregnant Thiosulfate Solutions by the Resin Adsorption Technique. Metals 2017, 7, 555. [CrossRef] 
15. Jeon, S.; Tabelin, C.B.; Takahashi, H.; Park, I.; Ito, M.; Hiroyoshi, N. Enhanced cementation of gold via galvanic interactions using activated carbon and zero-valent aluminum: A novel approach to recover gold ions from ammonium thiosulfate medium. Hydrometallurgy 2020, 191, 105165. [CrossRef]

16. Vaughan, J.P. The process mineralogy of gold: The classification of ore types. JOM 2004, 56, 46-48. [CrossRef]

17. Cho, K.; Kim, H.; Myung, E.; Purev, O.; Choi, N.; Park, C. Recovery of Gold from the Refractory Gold Concentrate Using Microwave Assisted Leaching. Metal 2020, 10, 571. [CrossRef]

18. Qin, H.; Guo, X.; Tian, Q.; Yu, D.; Zhang, L. Recovery of gold from sulfide refractory gold ore: Oxidation roasting pretreatment and gold extraction. Miner. Eng. 2021, 164, 106822. [CrossRef]

19. Islam, K.; Vilaysouk, X.; Murakami, S. Integrating remote sensing and life cycle assessment to quantify the environmental impacts of copper-silver-gold mining: A case study from Laos. Resour. Conserv. Recycl. 2020, 154, 104630. [CrossRef]

20. Yang, Y.; Gao, W.; Xu, B.; Li, Q.; Jiang, T. Study on oxygen pressure thiosulfate leaching of gold without the catalysis of copper and ammonia. Hydrometallurgy 2019, 187, 71-80. [CrossRef]

21. Gorji, M.; Hosseini, M.R.; Ahmadi, A. Comparison and optimization of the bio-cyanidation potentials of B. megaterium and P. aeruginosa for extracting gold from an oxidized copper-gold ore in the presence of residual glycine. Hydrometallurgy 2020, 191, 105218. [CrossRef]

22. Agorhom, E.A.; Owusu, C. The Effects of Pulp Rheology on Gravity Gold Recovery in Free Milling Gold Ore of the Tarkwaian Systems of Ghana. Miner. Process. Extr. Met. Rev. 2020, 1-6. [CrossRef]

23. Tabelin, C.B.; Silwamba, M.; Paglinawan, F.C.; Mondejar, A.J.S.; Duc, H.G.; Resabal, V.J.; Opiso, E.M.; Igarashi, T.; Tomiyama, S.; Ito, M.; et al. Solid-phase partitioning and release-retention mechanisms of copper, lead, zinc and arsenic in soils impacted by artisanal and small-scale gold mining (ASGM) activities. Chemosphere 2020, 260, 127574. [CrossRef]

24. Park, I.; Hong, S.; Jeon, S.; Ito, M.; Hiroyoshi, N. A Review of Recent Advances in Depression Techniques for Flotation Separation of Cu-Mo Sulfides in Porphyry Copper Deposits. Metal 2020, 10, 1269. [CrossRef]

25. Park, I.; Higuchi, K.; Tabelin, C.B.; Jeon, S.; Ito, M.; Hiroyoshi, N. Suppression of arsenopyrite oxidation by microencapsulation using ferric-catecholate complexes and phosphate. Chemosphere 2021, 269, 129413. [CrossRef] [PubMed]

26. Sahoo, P.; Venkatesh, A. Constraints of mineralogical characterization of gold ore: Implication for genesis, controls and evolution of gold from Kundarkocha gold deposit, eastern India. J. Asian Earth Sci. 2015, 97, 136-149. [CrossRef]

27. Wu, J.; Ahn, J.; Lee, J. Gold deportment and leaching study from a pressure oxidation residue of chalcopyrite concentrate. Hydrometallurgy 2021, 201, 105583. [CrossRef]

28. Adams, M.; Lawrence, R.; Bratty, M. Biogenic sulphide for cyanide recycle and copper recovery in gold-copper ore processing. Miner. Eng. 2008, 21, 509-517. [CrossRef]

29. Wang, Z.; Chen, D.; Chen, L. Application of fluoride to enhance aluminum cementation of gold from acidic thiocyanate solution. Hydrometallurgy 2007, 89, 196-206. [CrossRef]

30. Nguyen, H.; Tran, T.; Wong, P. A kinetic study of the cementation of gold from cyanide solutions onto copper. Hydrometallurgy 1997, 46, 55-69. [CrossRef]

31. Silwamba, M.; Ito, M.; Hiroyoshi, N.; Tabelin, C.B.; Fukushima, T.; Park, I.; Jeon, S.; Igarashi, T.; Sato, T.; Nyambe, I.; et al. Detoxification of lead-bearing zinc plant leach residues from Kabwe, Zambia by coupled extraction-cementation method. $J$. Environ. Chem. Eng. 2020, 8, 104197. [CrossRef]

32. Arima, H.; Fujita, T.; Yen, W.-T. Using Nickel as a Catalyst in Ammonium Thiosulfate Leaching for Gold Extraction. Mater. Trans. 2004, 45, 516-526. [CrossRef]

33. Liu, X.; Jiang, T.; Xu, B.; Zhang, Y.; Li, Q.; Yang, Y.; He, Y. Thiosulphate leaching of gold in Cu-NH3-S2O32-- - H2O system: An updated thermodynamic analysis using predominance area and species distribution diagrams. Miner. Eng. 2020, $151,106336$. [CrossRef]

34. Liu, X.; Xu, B.; Yang, Y.; Li, Q.; Jiang, T.; He, Y. Thermodynamic analysis of ammoniacal thiosulfate leaching of gold catalyzed by $\mathrm{Co}(\mathrm{III}) / \mathrm{Co}(\mathrm{II})$ using Eh-pH and speciation diagrams. Hydrometallurgy 2018, 178, 240-249. [CrossRef]

35. Xu, B.; Li, K.; Li, Q.; Yang, Y.; Liu, X.; Jiang, T. Kinetic studies of gold leaching from a gold concentrate calcine by thiosulfate with cobalt-ammonia catalysis and gold recovery by resin adsorption from its pregnant solution. Sep. Purif. Technol. 2019, $213,368-377$. [CrossRef]

36. BC Campus, Appendix: Standard Reduction Potentials by Value. Available online: https://opentextbc.ca/introductorychemistry/ back-matter/appendix-standard-reduction-potentials-by-value-2/ (accessed on 1 April 2021).

37. Senanayake, G.; Senaputra, A.; Nicol, M.J. Effect of thiosulfate, sulfide, copper(II), cobalt(II)/(III) and iron oxides on the ammoniacal carbonate leaching of nickel and ferronickel in the caron process. Hydrometallurgy 2010, 105, 60-68. [CrossRef]

38. Djokic, S.S. Electroless Depositiore on of Metals and Alloys, Modern Aspects of Electrochemistry; Brian, E.C., Conway, E., Ralph, E.W., White, E., Eds.; Springer: Berlin/Heidelberg, Germany, 2002; pp. 51-133.

39. Senanayake, G.; Zhang, X.M. Gold leaching by copper (II) in ammoniacal thiosulfate solutions in the presence of additives. Part II: Effects of residual $\mathrm{Cu}(\mathrm{II}), \mathrm{pH}$ and redox potentials on reactivity of colloidal gold. Hydrometallurgy 2012, 115-116, 21-29. [CrossRef]

40. Compare Metals. Available online: https://metals.comparenature.com/en/copper-vs-cobalt/comparison-6-30-0 (accessed on 15 April 2021).

41. New Medical Device Shielding Requirements and Die Casting (IEC 60601-0-2: 2014 -4th Edition). Available online: https: / / www.abdiecasting.com/new-medical-device-shielding-requirements-and-die-casting/ (accessed on 26 May 2021). 
42. Örgül, S.; Atalay, Ü. Reaction chemistry of gold leaching in thiourea solution for a Turkish gold ore. Hydrometallurgy 2002, 67, 71-77. [CrossRef]

43. Soltani, F.; Darabi, H.; Badri, R.; Zamankhan, P. Improved recovery of a low-grade refractory gold ore using flotation-preoxidationcyanidation methods. Int. J. Min. Sci. Technol. 2014, 24, 537-542.

44. Melashvili, M.; Fleming, C.; Dymov, I.; Matthews, D.; Dreisinger, D. Dissolution of gold during pyrite oxidation reaction. Miner. Eng. 2016, 87, 2-9. [CrossRef]

45. Murthy, D.S.R.; Kumar, V.; Rao, K.V. Extraction of gold from an Indian low-grade refractor gold ore through physical beneficiation and thiourea leaching. Hydrometallurgy 2003, 68, 125-130. [CrossRef] 


\title{
Development of Hydrometallurgical Process for Recovery of Rare Earth Metals (Nd, Pr, and Dy) from Nd-Fe-B Magnets
}

\author{
Pankaj Kumar Choubey ${ }^{1}$, Nityanand Singh ${ }^{1}$, Rekha Panda ${ }^{1}$, Rajesh Kumar Jyothi ${ }^{2}$, Kyoungkeun Yoo ${ }^{3}$, \\ Ilhwan Park ${ }^{4, *}$ and Manis Kumar Jha ${ }^{1, *}$
}

Citation: Choubey, P.K.; Singh, N.; Panda, R.; Jyothi, R.K.; Yoo, K.; Park, I.; Jha, M.K. Development of Hydrometallurgical Process for Recovery of Rare Earth Metals (Nd, Pr, and Dy) from Nd-Fe-B Magnets. Metals 2021, 11, 1987. https:// doi.org/10.3390/met11121987

Academic Editor: Alberto

Moreira Jorge Junior

Received: 2 November 2021

Accepted: 6 December 2021

Published: 9 December 2021

Publisher's Note: MDPI stays neutral with regard to jurisdictional claims in published maps and institutional affiliations.

Copyright: (c) 2021 by the authors. Licensee MDPI, Basel, Switzerland. This article is an open access article distributed under the terms and conditions of the Creative Commons Attribution (CC BY) license (https:// creativecommons.org/licenses/by/ $4.0 /)$.
1 Metal Extraction and Recycling Division, CSIR-National Metallurgical Laboratory, Jamshedpur 831007, India; impankaj.choubey@gmail.com (P.K.C.); nityanandsinghjsr@gmail.com (N.S.); rekhapanda1608@gmail.com (R.P.)

2 Mineral Resources Research Division, Korea Institute of Geoscience and Mineral Resources, Daejeon 34132, Korea; rkumarphd@kigam.re.kr

3 Department of Energy and Resources Engineering, Korea Maritime and Ocean University (KMOU), Busan 49112, Korea; kyoo@kmou.ac.kr

4 Division of Sustainable Resources Engineering, Faculty of Engineering, Hokkaido University, Sapporo 060-8606, Japan

* Correspondence: i-park@eng.hokudai.ac.jp (I.P.); mkjha@nmlindia.org (M.K.J.)

Abstract: Non-availability of rich primary resources of rare earth metals (REMs) and the generation of huge amounts of discarded magnets containing REMs, compelled the researchers to explore the possibilities for the recovery of REMs from discarded magnets. Therefore, the present paper reports the recovery of REMs (Nd, Pr, and Dy) from discarded Nd-Fe-B magnets. The process consists of demagnetization, pre-treatment, and hydrometallurgical processing to recover REMs as salt. Leaching studies indicate that $95.5 \% \mathrm{Nd}, 99.9 \% \mathrm{Pr}$, and $99.9 \%$ Dy were found to be dissolved at the optimized experimental condition i.e., acid concentration $2 \mathrm{M} \mathrm{H}_{2} \mathrm{SO}_{4}$, temperature $75^{\circ} \mathrm{C}$, pulp density $100 \mathrm{~g} / \mathrm{L}$, and mixing time $60 \mathrm{~min}$. Solvent extraction technique was tried for the selective extraction/separation of REMs and Fe. The result indicates that $99.1 \%(24.42 \mathrm{~g} / \mathrm{L})$ of Nd along with $90 \%(1.08 \mathrm{~g} / \mathrm{L})$ of Pr and total Fe were co-extracted using 35\% Cyanex 272 at organic to aqueous $(\mathrm{O} / \mathrm{A})$ ratio 1/1, eq. $\mathrm{pH} 3.5$ in $10 \mathrm{~min}$ of mixing time. It requires multistage separation and therefore, not feasible in view of economics. Thus, direct precipitation of REMs salt and iron oxide as pigment was studied using two stages of precipitation at different $\mathrm{pH}$. The obtained precipitate of REMs and Fe hydroxides were dried separately to remove the moisture and further treated at elevated temperature to get pure REMs oxide and red oxide.

Keywords: REMs; secondary resources; recycling; pretreatment; hydrometallurgy; Nd-Fe-B magnet

\section{Introduction}

Due to rapid industrialization and technological advancement, old electronic devices are replaced with new ones, resulting in the generation of massive amounts of discarded electronic scraps such as personal computers, mobile phones, televisions, etc. [1]. It has been reported that 53.5 million tons $(\mathrm{Mt})$ of e-waste were generated in 2019 and it has been expected that 74.7 Mt of e-waste will be generated by 2030 [2]. The discarded e-waste contains a variety of metals such as base metals $(\mathrm{Cu}, \mathrm{Ni}, \mathrm{Sn}, \mathrm{Pb}$, etc.), rare earth metals $(\mathrm{Nd}$, $\mathrm{Pr}$, Dy, etc.) including hazardous metals that may cause a serious environmental threat if disposed into the landfilling without treatment, as well as the loss of valuables. Therefore, it is needed to develop a sustainable process for the extraction of metals from e-waste, which may also minimize the dependency on primary natural resources.

Various studies have been made to recover rare earth metals (REMs) using pyro/hydro-metallurgy and hybrid processes. Onal et al. [3] reported the nitration of Nd-Fe-B magnet at $200{ }^{\circ} \mathrm{C}$ to convert the refractory magnet into soluble species of REMs. Further, 
calcined magnets were leached in water at room temperature to dissolve more than $95 \%$ REMs while maintaining a pulp density of $60 \mathrm{~g} / \mathrm{L}$. In addition, a magnet was roasted at $800{ }^{\circ} \mathrm{C}$ to transform the refractory magnet into soluble species of REMs. The roasted product was pressure leached in $0.6 \mathrm{M}$ hydrochloric acid at $180{ }^{\circ} \mathrm{C}$ to leach $99 \%$ REMs [4]. The mechano-chemical studies have also been made with the addition of ferric sulfate to convert the refractory magnet into their sulfate salt to make the subsequent leaching step easier. The pre-treated product was further leached in water at elevated temperature and subsequently, REMs were precipitated with oxalic acid at $\mathrm{pH} 1.9$ [5].

In addition, oxidative roasting followed by organic acid leaching has been used to recover the REMs from $\mathrm{Nd}-\mathrm{Fe}-\mathrm{B}$ magnet. The refractory $\mathrm{Nd}-\mathrm{Fe}-\mathrm{B}$ magnet was oxidized into the acid susceptible species by heating at $900{ }^{\circ} \mathrm{C}$ for $480 \mathrm{~min}$. The oxidized product was dissolved in a mixture of malic and citric acids at $90{ }^{\circ} \mathrm{C}$ to leach more than $90 \%$ REMs [6]. Kumari et al. [1] reported the sulfuric acid leaching and precipitation process for recovery of $\mathrm{Nd}$, almost $\sim 99.99 \%$ REMs (Nd, Dy and Pr) were leached in $1 \mathrm{M}$ sulfuric acid at room temperature. Further, $\mathrm{Nd}$ was precipitated with $\sim 98 \%$ purity by using ammonia to get $\mathrm{Nd}$ salt at $\mathrm{pH}$ 1.65; however, minor co-precipitation of Dy and Pr also occurred. In a subsequent study, electrochemical leaching was conducted in a mixture of $0.1 \mathrm{M} \mathrm{H}_{2} \mathrm{SO}_{4}$ and $0.05 \mathrm{M}$ $\mathrm{H}_{2} \mathrm{C}_{2} \mathrm{O}_{4}$ at the current density of $20 \mathrm{~A} / \mathrm{dm}^{2}$ to enhance the leaching efficiency of REMs [7]. The obtained leach liquor was subjected to separation and purification studies to extract the REMs. Pavon et al. [8] extracted 99.9\% Nd from the leach liquor of $\mathrm{Nd}-\mathrm{Fe}-\mathrm{B}$ magnet at eq. $\mathrm{pH} 0.8$ to 1.5 with $0.3 \mathrm{M}$ Cyanex 572. Further, $58.62 \% \mathrm{Nd}, 98.46 \% \mathrm{Dy}$, and $85.59 \% \operatorname{Pr}$ were extracted at $\mathrm{pH} 2$ with $1 \mathrm{M}$ D2EHPA and stripped with $2 \mathrm{M}$ nitric acid [9].

Besides the solvent extraction, precipitation studies have also been investigated for the extraction of REMs from leach liquor of Nd-Fe-B magnet. Lee et al. [10] used sodium hydroxide to precipitate $\mathrm{Nd}$ as $\mathrm{Nd}(\mathrm{OH})_{3}$ at $\mathrm{pH}$ 0.6. Rabatho et al. [11] leached $98 \%$ of $\mathrm{Nd}$ and $81 \%$ of Dy in $1 \mathrm{M} \mathrm{HNO}_{3}$ at $25^{\circ} \mathrm{C}$ in presence of $0.3 \mathrm{M} \mathrm{H}_{2} \mathrm{O}_{2}$, but Fe remained in the residue. Further, $81.8 \%$ Dy and $91.5 \% \mathrm{Nd}$ were recovered by precipitation using oxalic acid $\left(\mathrm{H}_{2} \mathrm{C}_{2} \mathrm{O}_{4}\right)$ in a range of $\mathrm{pH} 8$ at room temperature [11]. A lot of research on this topic is reported, but due to various factors it is still not applied for commercial exploitation in industries. Another aspect of this research is recycling, which will play an important role in the circular economy as well as in the conservation of natural resources. The important findings in the developed process are closed-loop, which means all the materials will be recycled in the production flow with no waste, i.e., zero waste generation.

Keeping in view of the above, the present paper reports the novel process for selective recovery of REMs oxides $(\mathrm{Nd}, \mathrm{Pr}$, and $\mathrm{Dy})$ from discarded magnets of the hard disk considering the cost of the process. The magnets were separated by being dismantled, demagnetized by heat treatment, crushed to reduce the particle size, leached to dissolve the REMs, and selective extraction of REMs using solvent extraction/precipitation to produce REMs oxides. Compared to previous studies, the developed process reports less energy for demagnetization of discarded $\mathrm{Nd}-\mathrm{Fe}-\mathrm{B}$ magnets as well as a smaller number of stages to get REMs like rare earth oxides.

\section{Materials and Methods}

\subsection{Pre-Treatment of Nd-Fe-B Magnets}

At first, a discarded hard disk of CPUs was dismantled to separate the Nd-Fe-B magnets for recovery of rare earth metals including iron. Further, Nd-Fe-B magnets were demagnetized by heating at $300{ }^{\circ} \mathrm{C}$ for $3 \mathrm{~h}$. The demagnetized material was crushed into small sizes $(2 \times 2 \mathrm{~mm})$ using the mortar pestle to make the particle surface area higher, which will enable effective leaching. The process flow-sheet for the pre-treatment of Nd-Fe$\mathrm{B}$ magnet is presented as Figure 1. The composition of $\mathrm{Nd}-\mathrm{Fe}-\mathrm{B}$ magnet was determined by the chemical analysis method and presented in Table 1. 


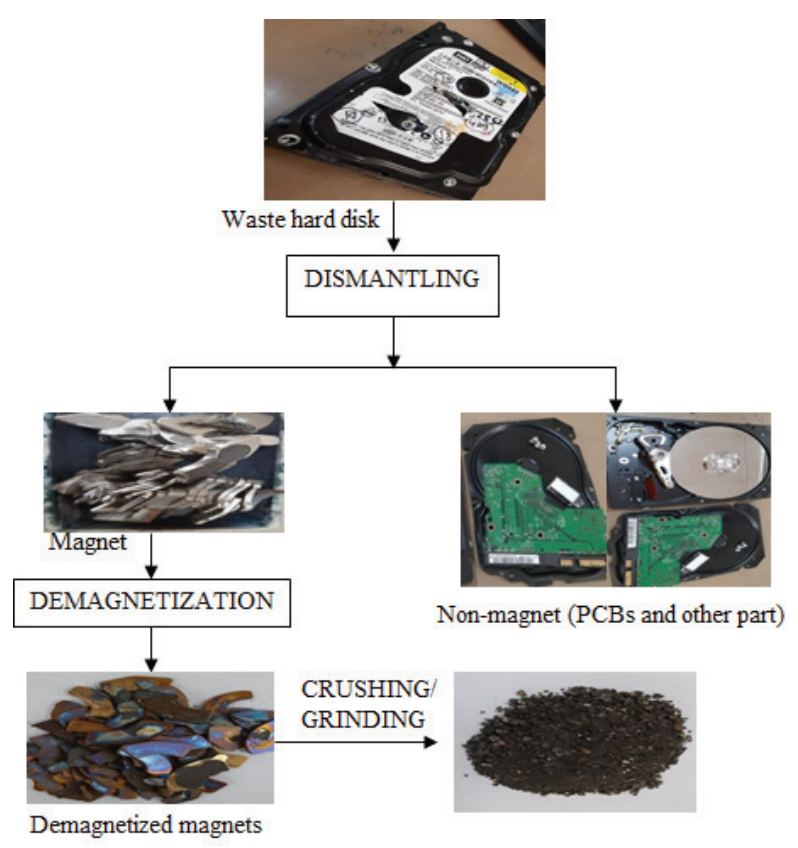

Figure 1. Pre-treatment of magnets prior to leaching of REMs.

Table 1. Composition of metals present in Nd-Fe-B magnet.

\begin{tabular}{cccc}
\hline REMs & Contents (wt \%) & Non-REMs & Contents (wt \%) \\
\hline $\mathrm{Nd}$ & 29.5 & $\mathrm{Fe}$ & 59.5 \\
$\mathrm{Dy}$ & 2.5 & $\mathrm{Ni}$ & 4.1 \\
$\mathrm{Pr}$ & 1.3 & $\mathrm{Co}$ & 3.1 \\
\hline
\end{tabular}

\subsection{Leaching Procedure}

Dissolution experiments were carried out in a leaching reactor of capacity: $100 \mathrm{~mL}$ (Borosil, Mumbai, India) equipped with a condenser facility to avoid the loss of liquid through evaporation due to heating. Leaching studies were carried out using a hot plate fitted with a temperature controller and sensor. To optimize the process parameters for the effective dissolution of REMs, the concentration of sulfuric acid leachant and temperature were varied between 0.5 to $2.5 \mathrm{M}$ and 25 to $90^{\circ} \mathrm{C}$, respectively. To study the dissolution behavior of REMs along with other metals, the samples of slurry/leach liquor were collected at regular intervals of time during the leaching experiment. The leach liquor was separated from the leached residue using filtration method. The metals present in the leached residue and leach liquor were checked to see the material balance. Satisfactory material balance was obtained for each set of leaching experiments by calculating the weight of the sample before leaching, which is equal to the amount of metals concentration in solution plus the weight of leached residue. Further, the leach liquor was processed for REMs extraction using the solvent extraction technique.

\subsection{Solvent Extraction Procedure}

Solvent extraction studies were carried out in a conical flask using a magnetic stirrer (Borosil, Mumbai, India) at room temperature. The equal volume of leach liquor and extractant Cyanex 272 (Figure 2) $(50 \mathrm{~mL} / 50 \mathrm{~mL})$ were put in the conical flask for proper mixing. Ammonium hydroxide was used to maintain the eq. $\mathrm{pH}$ in the range of 1 to 
3.5. When the solution attained the equilibrium, the metal-loaded organic extractant and raffinate were separated using a separating funnel. The metals-loaded organic extractant was stripped using dil. sulfuric acid. The concentration of metal ions in the loaded extractant and raffinate were analyzed by using ICP-OES (VISTA-PMX, CCD Simultaneous, Make: Australia). The material balance was checked by calculating the metal ions present in the strip solution obtained from loaded extractant, raffinate, and the head sample.<smiles>[3H]P(=O)(CC(C)CC(C)(C)C)CC(C)(C)C</smiles>

Figure 2. Structure of Cyanex 272 [bis (2,2,4 trimethylpentyl) phosphinic acid].

\subsection{Precipitation Procedure}

Precipitation experiments were conducted in a beaker (capacity: $100 \mathrm{~mL}$ ) under the constant stirring speed (300 rpm) at standard temperature using ammonium hydroxide as a precipitant. The solution $\mathrm{pH}$ was varied in the range of 1.0 to 2.5 by the addition of ammonium hydroxide $(25.96 \mathrm{M})$ for the precipitation of REMs. During the precipitation reaction, samples were collected at regular intervals of time to observe the precipitation behavior of metals at various $\mathrm{pH}$ and time.

\subsection{Characterization and Analysis of Samples}

Non-ferrous metals were analyzed using Atomic Absorption Spectrophotometer, AAS, Analyst 200 (Perkin Elmer, Waltham, MA, USA), and REMs were analyzed using Inductively Coupled Plasma-Optical Emission Spectrophotometer, ICP-OES, VISTA-PMX, CCD Simultaneous (Australia). X-ray diffraction (XRD, Bruker AXS D8 instrument) (Bruker, Wisconsin, WI, USA) and scanning electron microscope energy dispersive $\mathrm{X}$-ray spectroscopy (SEM-EDS, JXA-8230 Electron Probe Micro Analyzer, JEOL) (JEOL, Tokyo, Japan) were carried to analyze the phases as well as morphological appearances of the beneficiated magnet. XRD pattern shows that Nd-Fe-B magnet mainly contains the peak of $\mathrm{Nd}_{2} \mathrm{Fe}_{14} \mathrm{~B}$ (Figure 3) and was also confirmed by EDS analysis (Figure 4). The Eh- $\mathrm{pH}$ of the solution was analyzed (Eh: 0.55 to $1.05 \mathrm{~V}$ ) using Eutech pH 700 (Thermo Fisher Scientific, 7 Gul Circle, level 2M, Keppel Logistic Building, Singapore). Analytical grade (AR) ammonium hydroxide, sulfuric acid, hydrochloric acid supplied by Rankem, India, were used for experimental purposes.

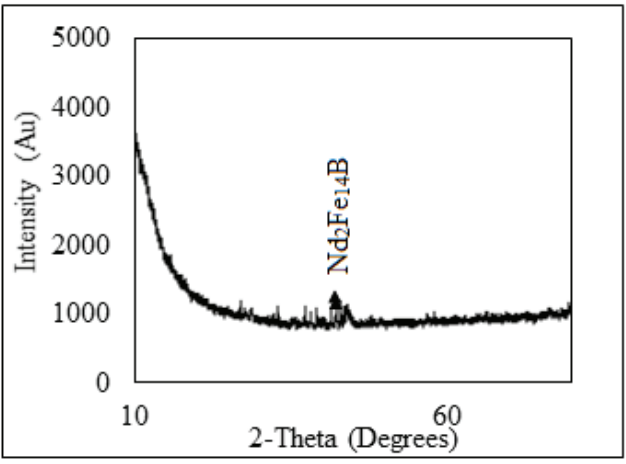

Figure 3. XRD pattern of crushed magnet. 


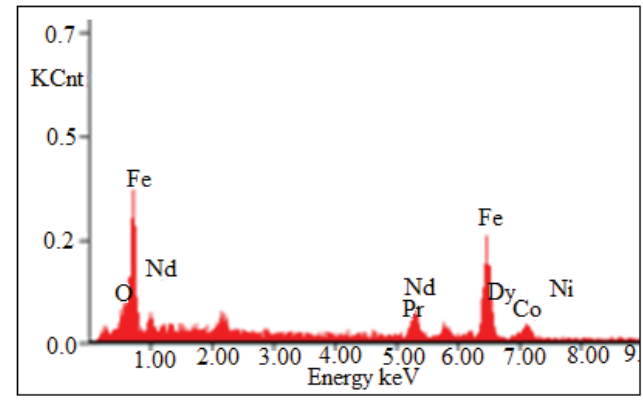

Figure 4. EDS pattern of demagnetized crushed Nd-Fe-B magnet.

\section{Results and Discussion}

In order to recover the REMs from discarded Nd-Fe-B magnets, leaching, solvent extraction, and precipitation experiments were carried out. At first, $\mathrm{Nd}-\mathrm{Fe}-\mathrm{B}$ magnets were demagnetized by heat treatment. The demagnetized material was crushed to get fine powder for making it suitable for the effective leaching of REMs. The leaching studies were conducted varying different experimental parameters to get suitable conditions for metals dissolution. Further, from the leach liquor, solvent extraction studies were made to extract the REMs, particularly, Nd from the leach liquor. The loaded organic was stripped to get $\mathrm{Nd}$ enriched solution. Finally, the precipitation studies were carried out to recover the $\mathrm{Nd}$ as precipitate with other elements as minor/trace. The obtained results are discussed below.

\subsection{Leaching Study}

For the effective dissolution of metals from waste Nd-Fe-B magnets, the various experimental parameters, i.e., acid concentration, reaction time, temperature, pulp density, etc. were studied to leach the REMs effectively from the demagnetized and crushed powder of magnets.

\subsubsection{Effect of Acid Concentration}

Leaching experiments were performed using different acid concentrations of leachant varied from 0.5 to $2.5 \mathrm{M}$ at temp. $60{ }^{\circ} \mathrm{C}$ and mixing time $60 \mathrm{~min}$ maintaining pulp density $100 \mathrm{~g} / \mathrm{L}$. Results (Figure 5) show that the dissolution of REMs (Nd, Pr and Dy) was found to be increased with increasing acid concentration due to the increase in the acidic strength of the leachant. But, above the acid concentration of $2 \mathrm{M}$, the leaching efficiency of REMs remained the same. This indicates that $2 \mathrm{M} \mathrm{H}_{2} \mathrm{SO}_{4}$ has enough acidity to leach the REMs. Hence, $2 \mathrm{M} \mathrm{H}_{2} \mathrm{SO}_{4}$ was chosen as the optimum concentration of acid for the dissolution of REMs from spent Nd-Fe-B magnets. The chemical reaction involved during the leaching of REMs is presented in Equation (1):

$$
2 \mathrm{Nd}_{2} \mathrm{Fe}_{14} \mathrm{~B}+37 \mathrm{H}_{2} \mathrm{SO}_{4} \rightarrow 2 \mathrm{Nd}_{2}\left(\mathrm{SO}_{4}\right)_{3}+28 \mathrm{FeSO}_{4}+\mathrm{B}_{2}\left(\mathrm{SO}_{4}\right)_{3}+18.5 \mathrm{H}_{2}
$$

\subsubsection{Effect of Temperature}

To optimize the temperature for leaching of REMs, experiments were performed at various experimental temperatures varying in the range of 60 to $90{ }^{\circ} \mathrm{C}$ at a pulp density of $100 \mathrm{~g} / \mathrm{L}$. Figure 6 showed that leaching efficiency of Nd, Pr, and Dy enhanced with the increase in solution temperature due to the increase in the rate of reaction. A total of $\sim 95.5 \% \mathrm{Nd}$ was found to be leached at $75^{\circ} \mathrm{C}$ and a further increase in solution temperature above $75{ }^{\circ} \mathrm{C}$ had no significant enhancement on the dissolution of REMs. Therefore, $75{ }^{\circ} \mathrm{C}$ was chosen as the optimum temperature for leaching of REMs for further sets of leaching experiments. 


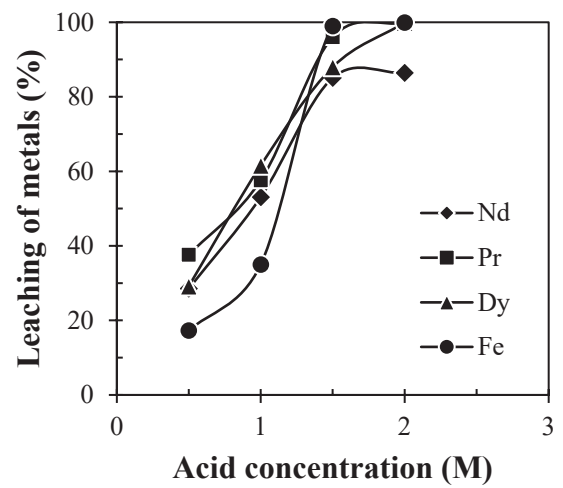

Figure 5. Effect of acid concentration on leaching of REMs from Nd-Fe-B magnets (Solid: Crushed magnet; Liquid: 0.5 to $2 \mathrm{M} \mathrm{H}_{2} \mathrm{SO}_{4}$; Pulp density: $100 \mathrm{~g} / \mathrm{L}$; Temp.: $60{ }^{\circ} \mathrm{C}$; Time: $60 \mathrm{~min}$ ).

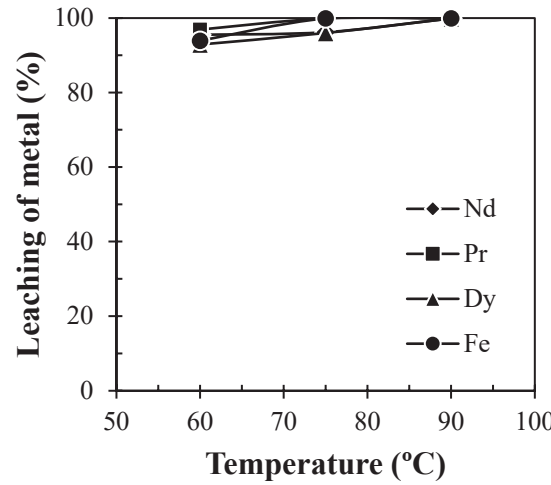

Figure 6. Effect of temperature on leaching of REMs from Nd-Fe-B magnets (Solid: Crushed magnet; Liquid: $2 \mathrm{M} \mathrm{H}_{2} \mathrm{SO}_{4}$; Pulp density: $100 \mathrm{~g} / \mathrm{L}$; Time: $60 \mathrm{~min}$ ).

\subsubsection{Effect of Pulp Density}

For the optimization of solid to liquid ratio, experiments were performed in a range of pulp density variations from 25 to $200 \mathrm{~g} / \mathrm{L}$ at $60{ }^{\circ} \mathrm{C}$ in $60 \mathrm{~min}$. It was found that leaching of REMs remains the same in the range of pulp density 25 to $100 \mathrm{~g} / \mathrm{L}$ (Figure 7), but leaching efficiency of REMs was found to be decreased at the pulp density above $100 \mathrm{~g} / \mathrm{L}$. This indicates that the number of moles of metallic constitutes ( $\mathrm{Nd}$, $\mathrm{Pr}$, and $\mathrm{Dy}$ ) of REMs became higher than that of leachant molecules, resulting in the decrease in the leaching efficiency of REMs above the pulp density of $100 \mathrm{~g} / \mathrm{L}$. Therefore, $100 \mathrm{~g} / \mathrm{L}$ pulp density was chosen as the optimum condition for the dissolution of REMs from the discarded magnet.

\subsection{Solvent Extraction of $\mathrm{Nd}$ and $\mathrm{Pr}$}

Selective extraction and stripping of REMs/Fe using solvent extraction technique were tried. Experiments were carried out to recover $\mathrm{Nd}$ from the obtained leach liquor containing $24.45 \mathrm{~g} / \mathrm{L} \mathrm{Nd}, 1.2 \mathrm{~g} / \mathrm{L} \mathrm{Pr}, 2.49 \mathrm{~g} / \mathrm{L} \mathrm{Dy}$, and $49.76 \mathrm{~g} / \mathrm{L}$ Fe using Cyanex 272. It was found that extraction of $\mathrm{Nd}$ increases with the increase in eq. $\mathrm{pH}$, while $\mathrm{Pr}$ and $\mathrm{Fe}$ also co-extracted (Figure 8). About $15.59 \mathrm{~g} / \mathrm{L}$ Nd were extracted using 35\% Cyanex 272 at eq. $\mathrm{pH} 0.75$ in $10 \mathrm{~min}$ mixing time, while complete extraction of $\mathrm{Nd}$ occurred at eq. $\mathrm{pH}$ 3. Further increase in eq. $\mathrm{pH}$ had no significant effect on the extraction of Nd. Further increase in eq. $\mathrm{pH}$ had no significant effect on the extraction of Nd. Hence, eq. $\mathrm{pH} 3$ was considered as optimum $\mathrm{pH}$ for the extraction of $\mathrm{Nd}$ from leach liquor. Further, extraction 
co-efficient (Kd) (Equation (2)) and separation factor $\left(\beta_{\mathrm{Nd} / \mathrm{Pr}}\right)$ (Equation (3)) of Nd were calculated and found to be 1.5 and 4.42 , respectively. The low value of separation factor and extraction co-efficient for $\mathrm{Nd}$ indicates that the separation can be possible using multistage extraction. The $\mathrm{pH}$ was adjusted during the solvent extraction experiment. The $\mathrm{pH}$ was not adjusted separately for aqueous feed, therefore, no precipitation occurred. As per the Eh-pH diagram, the REMs (Nd, Pr) were precipitated as their hydroxides at or above $\mathrm{pH}$ 1.5. However, at the same $\mathrm{pH}, \mathrm{REMs}$ form their complexes and had a tendency to be transferred into the organic phase during solvent extraction. The solvent extraction reaction is very fast in comparison to the slow precipitation reaction. Hence, no precipitation was observed during the solvent extraction of REMs under the studied conditions.

$$
\begin{gathered}
K d=\frac{\text { Conc. of } \mathrm{Nd} \text { in organic phase }}{\text { Conc. of } \mathrm{Nd} \text { in aqueous phase }} \\
\beta=\frac{\text { Extraction coefficient of metal } \mathrm{Nd}}{\text { Extraction coefficient of metal } \mathrm{Pr}}
\end{gathered}
$$

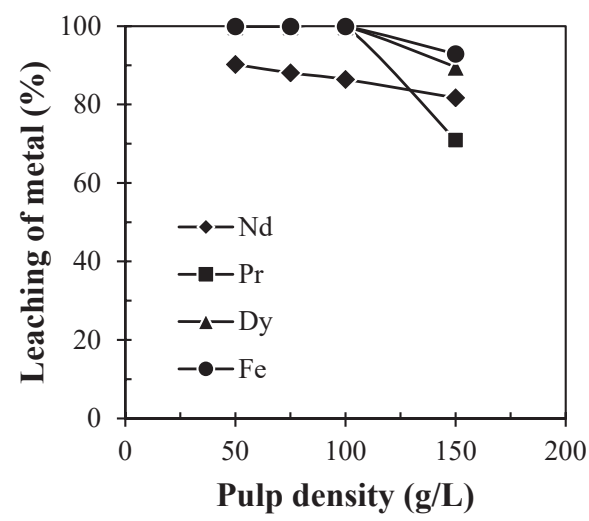

Figure 7. Effect of pulp density on leaching of REMs from Nd-Fe-B magnets (Solid: Crushed magnet; Acid concentration: $2 \mathrm{M} \mathrm{H}_{2} \mathrm{SO}_{4}$; Temp.: $60{ }^{\circ} \mathrm{C}$; Time: $60 \mathrm{~min}$ ).

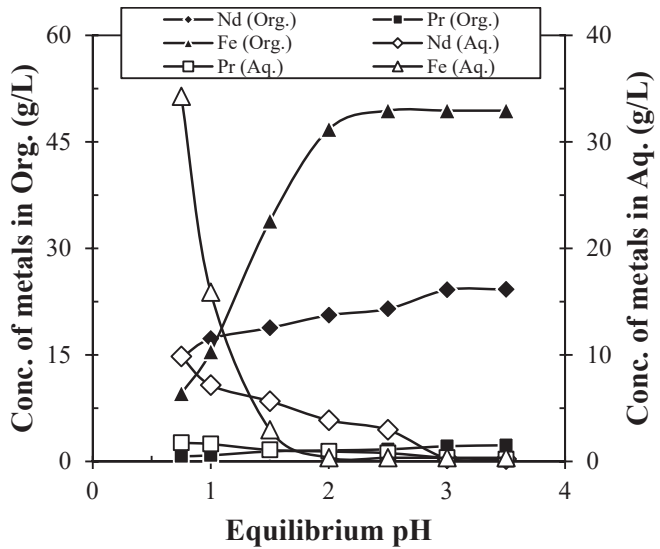

Figure 8. Extraction of $\mathrm{Nd}$ and Pr from leach liquor of spent Nd-Fe-B magnet (Extractant: $35 \%$ Cyanex 272; Solution: Leach liquor containing 24.45 g/L Nd, 1.2 g/L Pr, 2.49 g/L Dy, and 49.76 g/L Fe; Time: $10 \mathrm{~min}$; O/A ratio: 1/1). 
The multistage solvent extraction process for the separation of REMs and Fe will increase the production cost. Therefore, to make the process feasible and economical, direct precipitation studies were carried out.

\subsection{Recovery of REMs from Leach Liquor by Precipitation}

Further, the precipitation studies were carried out to recover REMs from the obtained leach liquor $24.45 \mathrm{~g} / \mathrm{L} \mathrm{Nd}, 1.2 \mathrm{~g} / \mathrm{L}$ Pr, $2.49 \mathrm{~g} / \mathrm{L}$ Dy and $49.76 \mathrm{~g} / \mathrm{L}$ Fe using the precipitation technique. The $\mathrm{pH}$ of the solution was varied in the range of 0.5 and 2.0 using ammonium hydroxide to precipitate selectively the REMs at room temperature, where REEs represents the rare earth elements (Equations (4) and (5)):

$$
\begin{gathered}
\operatorname{REE}_{2}\left(\mathrm{SO}_{4}\right)_{3}+6 \mathrm{NH}_{4} \mathrm{OH} \rightarrow 2 \mathrm{REE}(\mathrm{OH})_{3}+3\left(\mathrm{NH}_{4}\right)_{2} \mathrm{SO}_{4} \\
2 \mathrm{REE}(\mathrm{OH})_{3} \rightarrow \mathrm{REE}_{2} \mathrm{O}_{3}+3 \mathrm{H}_{2} \mathrm{O}
\end{gathered}
$$

The precipitation of $\mathrm{Nd}, \mathrm{Pr}$, and Dy (Figure 9) was found to be increased with the increase in $\mathrm{pH}$ from 0.5 to 2.0 due to the low solubility of REMs at eq. $\mathrm{pH} 2$. Eh-pH diagram drawn using the HSC chemistry version 6.0, which shows that $\mathrm{Nd}$ exists as $\mathrm{Nd}(\mathrm{OH})_{3}$ above pH 0.5 (Figure 10), while iron hydroxide formed at $\mathrm{pH}$ above 1.5 (Figure 11). Therefore, the $\mathrm{pH}$ of the solution was kept between 0.5 to 2 to avoid the co-precipitation of iron during the recovery of REMs hydroxides. The precipitated product was characterized by SEM-EDS (Figure 12), which shows that a strong peak of $\mathrm{Nd}$ appeared for the precipitated products. The composition of the precipitated product is shown in Table 2. It confirmed the formation of $\mathrm{Nd}$ product in the precipitated sample leaving iron in the solution.

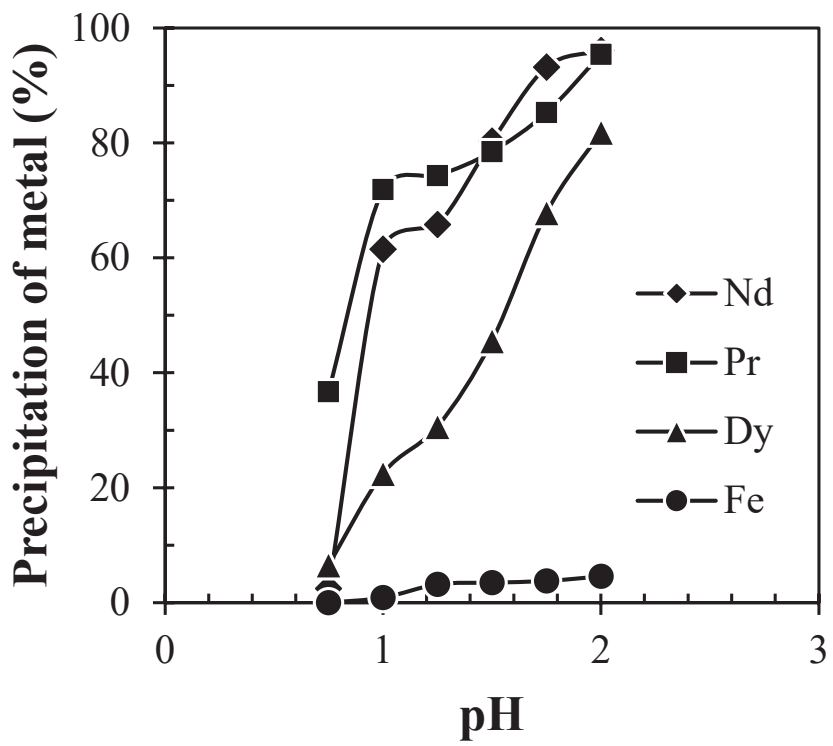

Figure 9. Effect of $\mathrm{pH}$ on precipitation of REMs from the liquor of Nd-Fe-B magnets (Solution: Leach liquor containing $24.45 \mathrm{~g} / \mathrm{L} \mathrm{Nd}, 1.2 \mathrm{~g} / \mathrm{L} \mathrm{Pr}, 2.49 \mathrm{~g} / \mathrm{L}$ Dy and $49.76 \mathrm{~g} / \mathrm{L}$ Fe; Precipitant: Dil. Ammonium hydroxide; Time: $15 \mathrm{~min}$ ). 


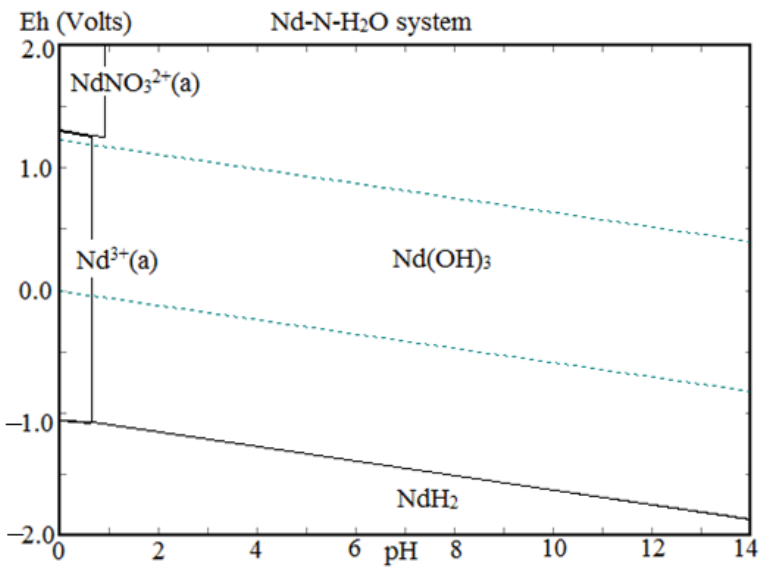

Figure 10. Eh-pH diagram of neodymium.

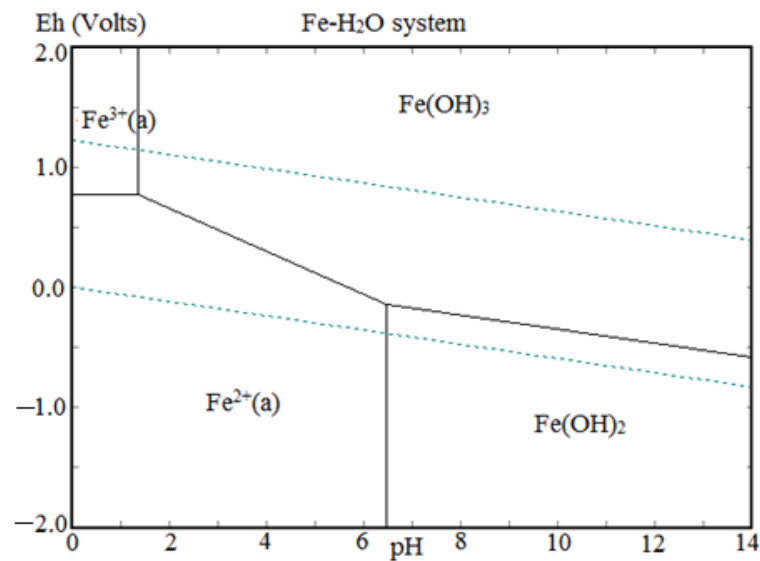

Figure 11. Eh-pH diagram of iron.
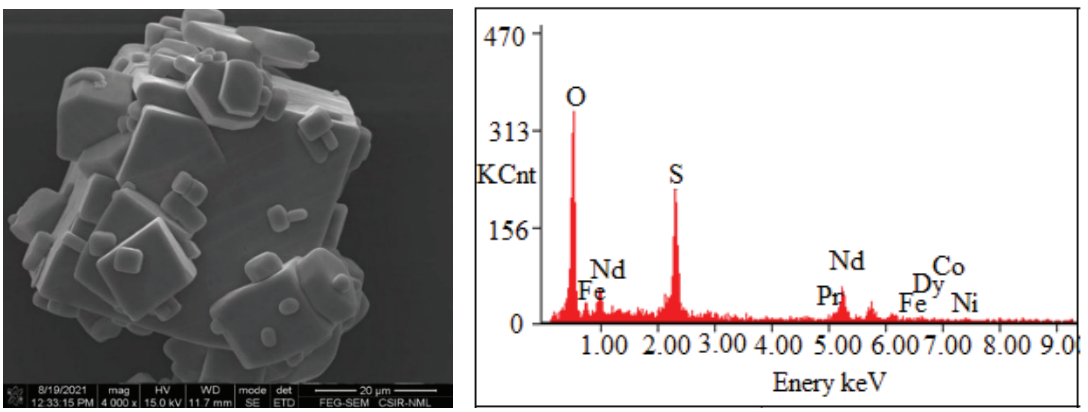

Figure 12. SEM-EDS of precipitated salts of REMs. 
Table 2. Composition (EDS) of precipitated salts of REMs.

\begin{tabular}{ccc}
\hline Element & Wt $\%$ & At $\%$ \\
\hline O K & 26.1 & 62.9 \\
S K & 16.8 & 20.2 \\
Pr L & 6.10 & 1.67 \\
Nd L & 41.6 & 11.1 \\
Fe K & 1.02 & 0.70 \\
Dy L & 5.03 & 1.20 \\
Co K & 0.91 & 0.65 \\
Ni K & 0.47 & 0.23 \\
\hline
\end{tabular}

After the separation of REMs, iron (49.7 g) was completely removed by maintaining the $\mathrm{pH}$ above 3 using ammonium hydroxide as a precipitant at $60{ }^{\circ} \mathrm{C}$ as shown in Equations (6) and (7). It has been assumed that iron was precipitated as $\mathrm{Fe}^{3+}$ due to the high stability of ferric ion. The complete process flow sheet has been developed for the dissolution/extraction of REMs from waste Nd-Fe-B magnets of hard disks as shown in Figure 13. Further, comparative data for extraction of REMs from discarded Nd-Fe-B magnets are summarized in Table 3, which reflects that high temperature is required for pre-treatment (demagnetization, roasting) of magnets prior to hydrometallurgical extraction of REMs. However, demagnetization temperature is comparatively low in the present study, which makes the process feasible from an energy point of view.

$$
\begin{gathered}
\mathrm{Fe}_{2}\left(\mathrm{SO}_{4}\right)_{3}+6 \mathrm{NH}_{4} \mathrm{OH} \rightarrow 2 \mathrm{Fe}(\mathrm{OH})_{3}+3\left(\mathrm{NH}_{4}\right)_{2} \mathrm{SO}_{4} \\
2 \mathrm{Fe}(\mathrm{OH})_{3} \rightarrow \mathrm{Fe}_{2} \mathrm{O}_{3}+3 \mathrm{H}_{2} \mathrm{O}
\end{gathered}
$$
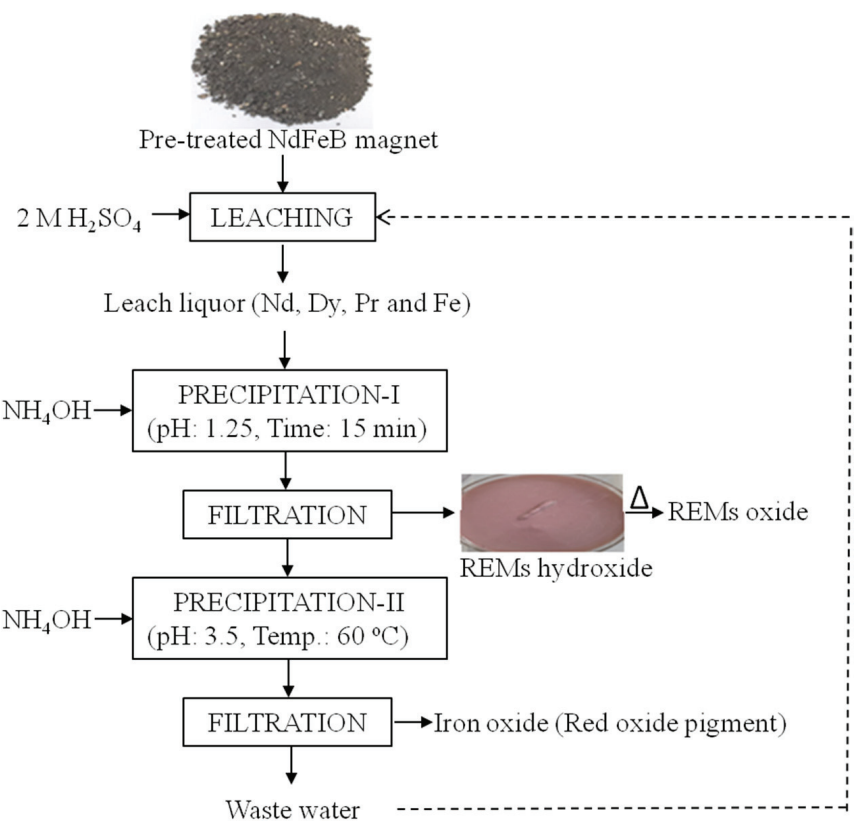

Figure 13. Developed process flow-sheet to recover REMs from spent Nd-Fe-B magnets. 
Table 3. Literature review on the extraction of rare earth elements from discarded Nd-Fe-B magnets.

\begin{tabular}{|c|c|c|c|}
\hline $\begin{array}{l}\text { Demagnetization and } \\
\text { Roasting Conditions }\end{array}$ & $\begin{array}{l}\text { Experimental Conditions } \\
\text { (Leaching and } \\
\text { Precipitation/Evaporation) }\end{array}$ & Salient Results & References \\
\hline $\begin{array}{l}\text { Demagnetization and roasting } \\
\text { not done }\end{array}$ & $\begin{array}{l}\text { Leachant: } 2 \mathrm{M} \mathrm{H}_{2} \mathrm{SO}_{4} \text {, Temp.: } \\
25^{\circ} \mathrm{C} \text {, Time: } 24 \mathrm{~h} \text {, } \\
\text { Evaporation: Temp.: } 110^{\circ} \mathrm{C}\end{array}$ & $\sim 95 \%$ REEs were extracted & Yingnakorn et al. [12] \\
\hline $\begin{array}{l}\text { Demagnetization: } 500^{\circ} \mathrm{C} \text {, } \\
\text { Time: } 60 \mathrm{~min}\end{array}$ & Not done & Demagnetized & Lee et al. [10] \\
\hline $\begin{array}{l}\text { Demagnetization: } 400{ }^{\circ} \mathrm{C} \text {, } \\
\text { Time: } 120 \mathrm{~min}\end{array}$ & Not done & Demagnetized & Feng et al. [13] \\
\hline $\begin{array}{l}\text { Demagnetization: } 350 \text {, Time: } \\
60 \text { min, Roasting: } 800^{\circ} \mathrm{C} \text {, } \\
\text { Time: } 120 \text { min }\end{array}$ & $\begin{array}{l}\text { Temp.: } 180{ }^{\circ} \mathrm{C} \text {, Time: } 120 \mathrm{~min} \text {; } \\
\text { Acid concentration: } 0.6 \mathrm{M} \\
\text { HCl, Pulp density: } 100 \mathrm{~g} / \mathrm{L} \\
\text { Precipitation: Temp.: } 50^{\circ} \mathrm{C} \text {, } \\
\text { Initial pH: } 2.2 \text {, Time: } 30 \mathrm{~min}\end{array}$ & $99 \%$ of REEs were extracted & Liu et al. [4] \\
\hline $\begin{array}{l}\text { Demagnetization: } 350{ }^{\circ} \mathrm{C} \text {, } \\
\text { Roasting: } 900{ }^{\circ} \mathrm{C}\end{array}$ & $\begin{array}{l}\text { Leachant: } 1 \text { M Citric/Maleic } \\
\text { Acid, Temp.: } 90{ }^{\circ} \mathrm{C} \text {, Pulp } \\
\text { density: } 50 \mathrm{~g} / \mathrm{L}\end{array}$ & $99 \%$ recovery of $\mathrm{Nd}$ occurred & Reisdorfer et al. [6] \\
\hline Roasting: $950^{\circ} \mathrm{C}$ & $\begin{array}{l}\text { Leachant: } 1.8 \mathrm{M} \mathrm{HCl}+3.5 \mathrm{M} \\
\text { NH4Cl, Pulp density: } 100 \mathrm{~g} / \\
\text { L, Temp.: } 100^{\circ} \mathrm{C} \text {, Time: } 5 \text { days } \\
\text { Precipitant: Oxalic acid }\end{array}$ & 90\% REMs were dissolved & Hoogerstraete et al. [14] \\
\hline Roasting: $950^{\circ} \mathrm{C}$ & $\begin{array}{l}\text { Leachant: } 5 \mathrm{M} \mathrm{HNO}_{3} \text {, Pulp } \\
\text { density: } 1000 \mathrm{~g} / \mathrm{L} \text {, Temp.: } 80 \\
{ }^{\circ} \mathrm{C} \text {, Time: } 72 \mathrm{~h} \\
\text { Precipitant: Ammonium } \\
\text { nitrate, Eq. pH: } 2 \text {, Time: } 60 \\
\text { min, Temp.: } 70^{\circ} \mathrm{C}\end{array}$ & $\begin{array}{l}\mathrm{Nd} \text { and } \mathrm{Dy} \text { recovered as } \mathrm{Nd}_{2} \mathrm{O}_{3} \\
\text { and } \mathrm{Dy}_{2} \mathrm{O}_{3} \text { with purity } 99.6 \% \\
\text { and } 99.8 \% \text {, respectively }\end{array}$ & Riano and Binnemans [15] \\
\hline Roasting: $750^{\circ} \mathrm{C}$ & $\begin{array}{l}\text { Leachant: Water, Pulp density: } \\
20 \text { g/L, Time: } 1 \text { h, Temp.: } 25^{\circ} \mathrm{C}\end{array}$ & 95-100\% REMs were extracted & Onal et al. [16] \\
\hline
\end{tabular}

\section{Conclusions}

Based on the laboratory scale studies to recover REMs from discarded Nd-Fe-B magnet of hard disks, the following conclusions have been made and are discussed below.

1. It was found that the magnetic strength of $\mathrm{Nd}-\mathrm{Fe}-\mathrm{B}$ hard disk magnet was lost by heat treatment at $300{ }^{\circ} \mathrm{C}$ in $2 \mathrm{~h}$.

2. The complete leaching of $\mathrm{Nd}, \mathrm{Pr}, \mathrm{Dy}$, and Fe occurred from the demagnetized magnet using $2 \mathrm{M} \mathrm{H}_{2} \mathrm{SO}_{4}$ at $75^{\circ} \mathrm{C}$ in $60 \mathrm{~min}$ and pulp density $100 \mathrm{~g} / \mathrm{L}$.

3. It was found that $99.1 \% \mathrm{Nd}, 94 \% \mathrm{Pr}$, and $99.9 \%$ Fe got extracted from leach liquor using $35 \%$ Cyanex 272 at O/A ratio 1/1 in 10 min. The selective extraction of REMs can only be achieved by using multistage solvent extraction. Thus, direct precipitation studies were carried out at different eq. $\mathrm{pH}$ for the selective extraction of REMs and Fe.

4. Further, $\sim 93.15 \% \mathrm{Nd}, \sim 85 \% \mathrm{Pr}$, and $\sim 68 \%$ Dy were precipitated from the leach liquor of discarded magnet at $\mathrm{pH} 1.75$ at room temperature in $15 \mathrm{~min}$. The precipitated hydroxide of REMs was converted to their oxides by heating at $120^{\circ} \mathrm{C}$ for $2 \mathrm{~h}$.

5. Finally, $96.5 \%$ Fe was precipitated as ferric ion through the air sparging between eq. $\mathrm{pH} 3.5$ to 4 at $60{ }^{\circ} \mathrm{C}$.

Author Contributions: Methodology, N.S. and P.K.C.; Validation, P.K.C. and R.P.; Writing-original draft preparation, N.S. and P.K.C.; Writing-review and editing, M.K.J., K.Y. and I.P.; Supervision, M.K.J. and R.K.J.; Project administration, M.K.J. and I.P.; Funding acquisition, I.P. All authors have read and agreed to the published version of the manuscript. 
Funding: This study was partially supported by the Japan Society for the Promotion of Science (JSPS) Grant-in-Aid for Early-Career Scientists (JP20K15214). The work has been supported by CSIR-NML under Urban Ore Recycling Centre (FTC-0014/MLP-3116) and various Indo-Korean long term collaboration programs.

Institutional Review Board Statement: Not applicable.

Informed Consent Statement: Not applicable.

Data Availability Statement: The data presented in this study are available on request from the corresponding author.

Acknowledgments: Authors are grateful to the Director CSIR-National Metallurgical Laboratory, Jamshedpur, India, for giving the permission to publish the paper and work done under CSIR-NML projects and international collaborations.

Conflicts of Interest: The authors declare no conflict of interest.

\section{References}

1. Kumari, A.; Jha, M.K.; Pathak, D.D. An innovative environmental process for the treatment of scrap Nd-Fe-B magnets. J. Environ. Manag. 2020, 273, 111063. [CrossRef] [PubMed]

2. Dhir, A.; Malodia, S.; Awan, U.; Sakashita, M.; Kaur, P. Extended valence theory perspective on consumers' e-waste recycling intentions in Japan. J. Clean. Prod. 2021, 312, 127443. [CrossRef]

3. Onal, M.A.R.; Aktan, E.; Borra, C.R.; Blanpain, B.; Gerven, T.V.; Guo, M. Recycling of NdFeB magnets using nitration, calcination and water leaching for REE recovery. Hydrometallurgy 2017, 167, 115-123. [CrossRef]

4. Liu, F.; Porvali, A.; Wang, J.; Wang, H.; Peng, C.; Wilson, B.P.; Lundstrom, M. Recovery and separation of rare earths and boron from spent Nd-Fe-B Magnets. Miner. Eng. 2020, 145, 106097. [CrossRef]

5. Loy, S.V.; Onal, M.A.R.; Binnemans, K.; Gerven, T.V. Recovery of valuable metals from NdFeB magnets by mechanochemically assisted ferric sulfate leaching. Hydrometallurgy 2020, 191, 105154.

6. Reisdorfer, G.; Bertuol, D.; Tanabe, E.H. Recovery of neodymium from the magnets of hard disk drives using organic acids. Miner. Eng. 2019, 143, 105938. [CrossRef]

7. Makarova, I.; Soboleva, E.; Osipenko, M.; Kurilo, I.; Laatikainen, M. Electrochemical leaching of rare-earth elements from spent NdFeB magnets. Hydrometallurgy 2020, 192, 105264. [CrossRef]

8. Pavon, S.; Fortunya, A.; Collb, M.T.; Sastrec, A.M. Neodymium recovery from NdFeB magnet wastes using Primene 81R.Cyanex 572 IL by solvent extraction. J. Environ. Manag. 2018, 222, 359-367. [CrossRef] [PubMed]

9. Niam, A.C.; Wang, Y.; Chen, S.; Chang, G.; You, S. Simultaneous recovery of rare earth elements from waste permanent magnet (WPMs) leach liquor by solvent extraction and hollow fiber supported liquid membrane. Chem. Eng. Process. 2020, $148,107831$. [CrossRef]

10. Lee, C.H.; Chen, Y.J.; Liao, C.H.; Popuri, R.S.; Tsai, S.L.; Hung, C.E. Selective leaching process for Neodymium recovery from scrap Nd-Fe-B magnet. Metall. Mater. Trans. A Phys. Metall. Mater. Sci. 2013, 44, 5825-5833. [CrossRef]

11. Rabatho, J.P.; Tongamp, W.; Takasaki, Y.; Haga, K.; Shibayama, A. Recovery of Nd and Dy from rare earth magnetic waste sludge by hydrometallurgical process. J. Mater. Cycles Waste Manag. 2013, 15, 171-178. [CrossRef]

12. Yingnakorn, T.; Laokhen, P.; Sriklang, L.; Patcharawit, T.; Khumkoa, S. Study on Recovery of Rare Earth Elements from NdFeB Magnet Scrap by Using Selective Leaching. Mater. Sci. Forum 2020, 1009, 149-154. [CrossRef]

13. Feng, L.Y.; Zhu, M.G.; Wei, L.; Dong, Z.; Feng, L.; Lang, C.; Wu, J.Y.; Yan, Q.; An, D. The Impact Induced Demagnetization Mechanism in NdFeB Permanent Magnets. Chin. Phys. Lett. 2013, 30, 097501.

14. Hoogerstraete, T.V.; Blanpain, B.; Gerven, T.V.; Binnemans, K. From NdFeB magnets towards the rare-earth oxides: A recycling process consuming only oxalic acid. RSC Adv. 2014, 4, 64099-64111. [CrossRef]

15. Riano, S.; Binnemans, K. Extraction and separation of neodymium and dysprosium from used NdFeB magnets: An application of ionic liquids in solvent extraction towards the recycling of magnets. Green Chem. 2015, 17, 2931-2942. [CrossRef]

16. Onal, M.A.R.; Borra, C.R.; Guo, M.; Blanpain, B.; Van Gerven, T. Recycling of NdFeB magnets using sulfation, selective roasting, and water leaching. J. Sustain. Metall. 2015, 1, 199-215. [CrossRef] 
MDPI

St. Alban-Anlage 66

4052 Basel

Switzerland

Tel. +41 616837734

Fax +41 613028918

www.mdpi.com

Metals Editorial Office

E-mail: metals@mdpi.com

www.mdpi.com/journal/metals

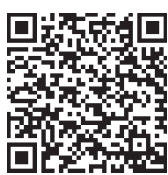





\section{MDPI}

St. Alban-Anlage 66

4052 Basel

Switzerland

Tel: +41 616837734

Fax: +41 613028918 